\title{
AVALIAÇÃO DO RISCO À SAÚDE DA POPULAÇÃO VIZINHA ÀS ÁREAS DE DISPOSIÇÃO FINAL DE RESÍDUOS SÓLIDOS URBANOS: O ATERRO SANITÁRIO COMO CENÁRIO DE EXPOSIÇÃO AMBIENTAL
}

Mônica de Abreu Azevedo

Tese apresentada à Escola de Engenharia de São Carlos, da Universidade de São Paulo, como parte dos requisitos para a obtenção do Título de Doutor em Engenharia Hidráulica e Saneamento.

ORIENTADOR: Prof. Dr. Valdir Schalch

São Carlos 
Ficha catalográfica preparada pela Seção de Tratamento da Informação do Serviço de Biblioteca - EESC/USP
A994a
Azevedo, Mônica de Abreu
Avaliação do risco à saúde da população vizinha às áreas de disposição final de resíduos sólidos urbanos : - aterro sanitário como cenário de exposição ambiental / Mônica de Abreu Azevedo. -- São Carlos, 2004.

Tese (Doutorado) -- Escola de Engenharia de São Carlos-Universidade de São Paulo, 2004.

Área : Hidráulica e Saneamento.

Orientador: Prof. Dr. Valdir Schalch.

1. Resíduos sólidos. 2. Disposição de resíduos.

3. Saúde pública. 4. Exposição ambiental. 5. Avaliação de risco. 6. Aterro sanitário. I. Título. 


\section{FOLHA DE JULGAMENTO}

\section{Candidata: Engenheira MÔNICA DE ABREU AZEVEDo}

Tese defendida e julgada em 16-01-2004 perante a Comissão Julgadora:

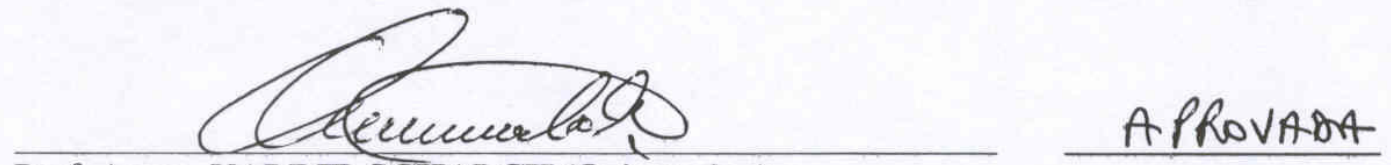

Prof. Assoc. VALDIR SCHALCH (Orientador)

(Escola de Engenharia de São Carlos/USP)

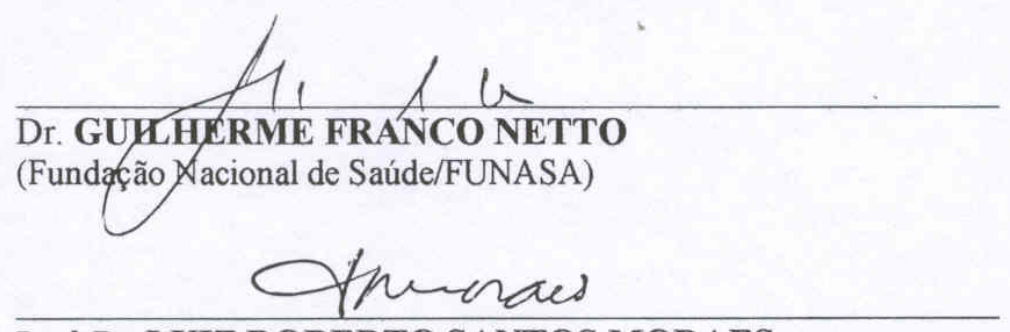

APNOUDA

Prof. Dr. LUIZ ROBERTO SANTOS MORAES

(Universidade Federal da Bahia/UFBA)

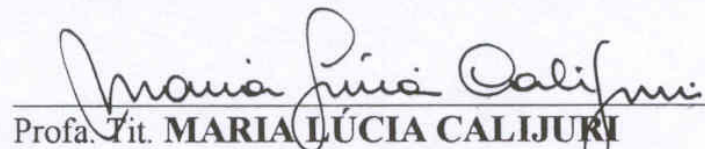

(Universidade Fed

APROVADA

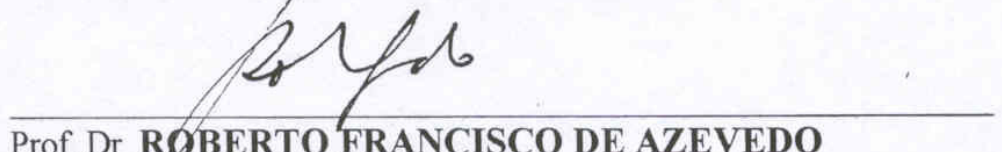

APROVADO

Prof. Dr. ROBERTO FRANCISCO DE AZEVEDO

(Universidade Federal de Viçosa/UFV)
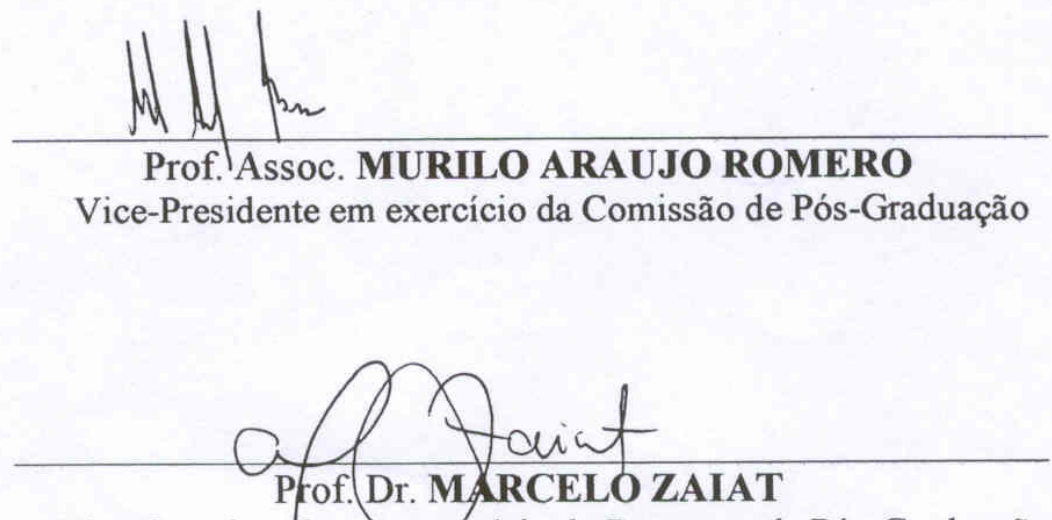

Vice-Coordenador emexercício do Programa de Pós-Graduação em Engenharia (Hidráulica e Saneamento) 
À minha filha Mariana, minha vida, meu estímulo, minha força para continuar sempre.

A meus pais Antônio e Anna Emilce, por tudo que significam para mim e por tudo que fizeram por mim. 


\section{AGRADECIMENTOS}

Ao meu orientador Professor Valdir Schalch, por ter me aceito como sua orientada e por ter acreditado na viabilidade de meu projeto de pesquisa. Agradeço também a oportunidade e o privilégio do convívio e toda a gentileza com que sempre me tratou.

À Escola de Engenharia de São Carlos, especialmente, aos Professores Fazal Hussain Chaudhry e Luiz Antonio Daniel, pelo apoio e incentivo recebidos durante meu doutorado; à Fernanda Maria Struzziatto e Flávia Gialorenço Canova por toda ajuda, empenho, dedicação, prestadas na contabilidade do meu projeto de pesquisa e por toda gentileza e atenção dedicadas; à Maria Auxiliadora C. Altieri Pin e Pavlovna Damião Rocha Bueno, por todo apoio recebido.

À Universidade Federal de Viçosa, pela licença de treinamento concedida e, especialmente, aos Professores Antônio Simões Silva e Carlos Antônio Oliveira Vieira, pelo apoio recebido; à Margarida Maria Rezende Lopes, funcionária da Pró-Reitoria de Pesquisa e Pós-graduação, por toda atenção, dedicação e gentileza com que sempre me tratou durante todo meu período de treinamento.

À CAPES pela bolsa de doutorado.

À FAPESP pelo financiamento concedido ao meu projeto de pesquisa, sem o qual teria sido impossível a realização do presente estudo. 
À Fundação Nacional de Saúde, FUNASA, por meio da Coordenadoria de Vigilância Ambiental, em especial ao Dr. Guilherme Franco Netto, pelo apoio financeiro recebido para meus deslocamentos para São Paulo e, particularmente, pelas orientações e aconselhamentos técnicos, que muito contribuíram para o desenvolvimento desta pesquisa.

Ao Departamento de Limpeza Urbana do município de São Paulo, LIMPURB, especialmente, aos engenheiros Plínio Valente, Marcelo Penha Martins e Zeev Moise, pelo apoio técnico e logístico obtidos para a execução da pesquisa de campo e pelos dados e informações fornecidos; aos motoristas Valdir e Everaldo, pelo apoio.

Ao engenheiro Silvio Luiz Elias de Andrade e aos senhores Guisolfo Jacinto da Silva e Juarez Assunção, da Empresa Heleno \& Fonseca Construtécnica, responsável pela obra do Aterro Sanitário Bandeirantes, por todo apoio recebido. Agradeço também a oportunidade e o privilégio do convívio.

À Seção de Enteroparasitose, da Divisão de Biologia Médica, do Instituto Adolfo Lutz de São Paulo, nas pessoas da Dra Domingas Maria Aparecida Vieira Torres, Celma Maria da Silva Quadros e Maria Trajano Soares, responsáveis pela a execução dos exames parasitológicos de fezes na população de estudo, cujo empenho, dedicação e eficiência, foram imprescindíveis para os resultados obtidos pela presente pesquisa.

Ao Núcleo de Geoprocessamento, NUGEO, da Universidade Federal de Viçosa, em especial ao pesquisador da EMBRAPA - Solos, Waldir de Carvalho Júnior, pelo trabalho de georeferenciamento dos dados levantados na pesquisa.

Ao Sr. Walter Décio Fernandes Andrade por todo apoio e ajuda recebidos. 
Meus agradecimentos especiais vão para as pessoas que contribuíram e me apoiaram viabilizando, cada uma de sua maneira, a realização deste trabalho de pesquisa:

Agradeço a minha irmã Eloísa, pelas orientações, apoio, colaboração, amizade, companheirismo, pelos seus conhecimentos repassados e por sua sensibilidade. Sem você, meu percurso teria sido mais difícil.

A minha amiga Elaine, por todas as noites dormidas com Mariana, para que eu pudesse viajar a São Carlos e cursar as disciplinas do doutorado; por toda presteza com que sempre me atendeu nos momentos que precisei. Agradeço o privilégio da sua amizade.

A minha equipe de pesquisa: Luciana Vieira Lima, Maria de Fátima Teixeira, Simone de Souza Ferreira e Edésio Elias Lopes, companheiros de trabalho, cuja dedicação, seriedade, profissionalismo e comprometimento com a pesquisa, tornaram este estudo possível. Obrigada pela amizade e confiança.

Ao Padre João Belisário do Comaru de Araújo, da Paróquia São José e, atualmente, na Paróquia Bom Jesus dos Passos em São Paulo, por todo apoio, carinho, atenção e amizade. Nossas conversas, seus aconselhamentos e apoio tornaram os momentos difíceis mais amenos, possibilitando o meu percurso. Meu muito obrigada.

Ao Professor Léo Heller,da Escola de Engenharia da UFMG, pelo incentivo e apoio recebidos para a realização desta pesquisa.

À minha filha Mariana por toda a sua compreensão nas minhas inúmeras e longas ausências para a execução desta pesquisa. Você é a razão de tudo.

À minha mãe por todo apoio e carinho dedicados a mim e a Mariana, sem os quais a realização deste trabalho teria sido mais difícil. 
De uma maneira muito especial, encerro meus agradecimentos, agradecendo a meu pai, que sempre me incentivou. Mesmo estando doente sempre queria saber como “andava meu doutorado". Infelizmente, encerro este trabalho há um mês de seu falecimento. A alegria da tarefa cumprida se esvai por não poder compartilhá-la com você. Obrigada, meu pai, por seu incentivo, amor e exemplo de vida que nos deixou. 
"Se quer seguir-me, narro-lhe; não uma aventura, mas experiência, a que me induziram, alternadamente, séries de raciocínios $e$ intuições. Tomou-me tempo, desânimos, esforços. Dela me prezo, sem vangloriar-me. Surpreendo-me, porém, um tanto à parte de todos, penetrando conhecimento que os outros ainda ignoram. O senhor, por exemplo, que sabe e estuda, suponho nem tenha idéia do que seja na verdade - um espelho? Demais, decerto, das noções de física, com que se familiarizou, as leis da óptica. Reporto-me ao transcendente. Tudo, aliás, é a ponta de um mistério. Inclusive os fatos. Ou a ausência deles. Duvida? Quando nada acontece, há um milagre que não estamos vendo". 
SUMÁRIO

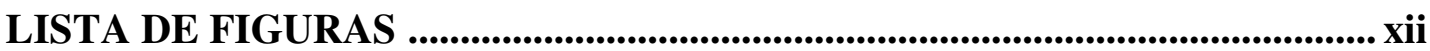

LISTA DE TABELAS ....................................................................................... $\mathrm{xV}$

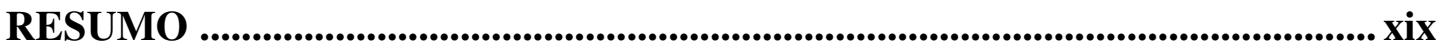

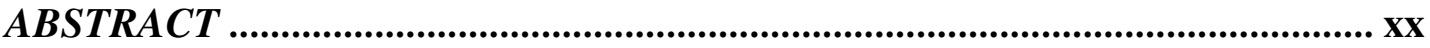

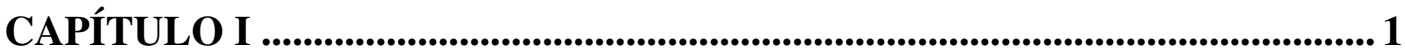

1. INTRODUÇÃ

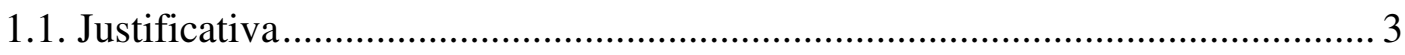

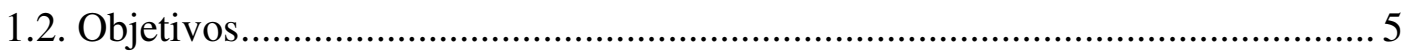

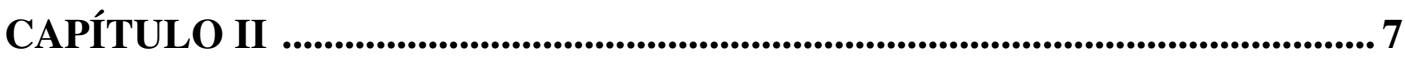

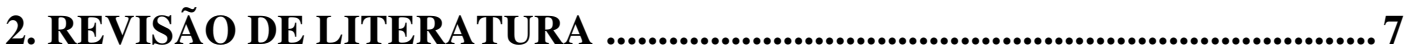

2.1. Aspectos Epidemiológicos Relacionados aos Resíduos Sólidos .................. 7

2.2. Aspectos Microbiológicos Relacionados à Disposição Ambiental dos Resíduos

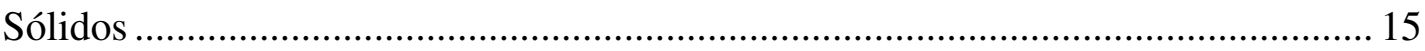

2.3. Aspectos Ambientais Relacionados aos Resíduos Sólidos ........................... 18

2.4. Relação: Resíduos Sólidos, Ambiente e Saúde Pública .................................26 
2.5. Classificação Ambiental para as Doenças Relacionadas à Água, às Excretas e aos

Resíduos Sólidos 36

2.6. Tipos de Estudos Epidemiológicos ………................................................... 42

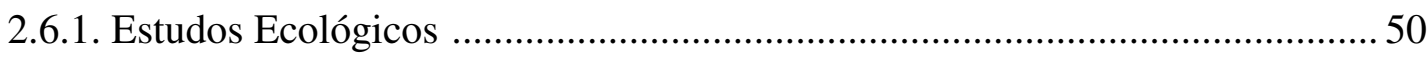

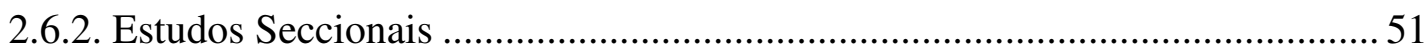

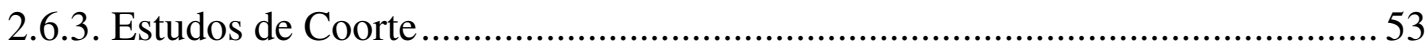

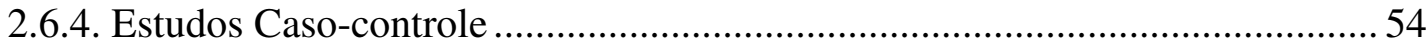

2.7. Estudos Epidemiológicos Relacionados ao Saneamento ................................ 55

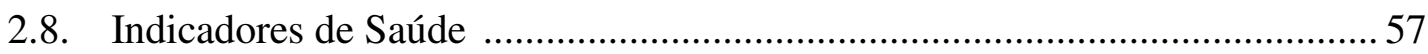

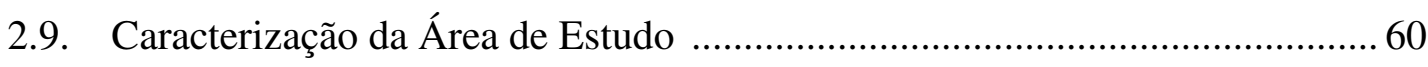

2.9.1. O Município de São Paulo e a Questão dos Resíduos Sólidos......................... 61

2.9.2. Aterro Sanitário Bandeirantes ................................................................... 71

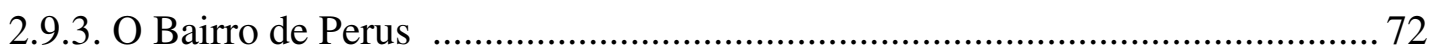

CAPÍTULO III

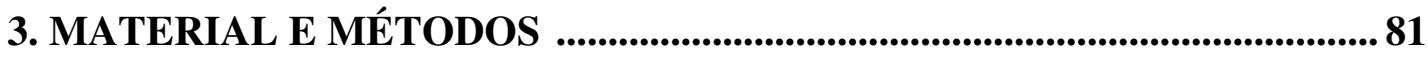

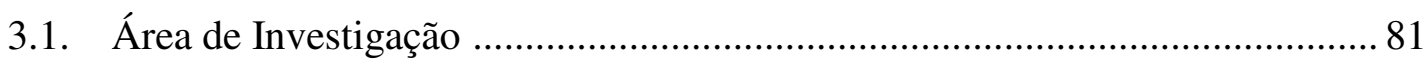

3.1.1. Critérios Utilizados para a Seleção da Área de Investigação ......................... 81

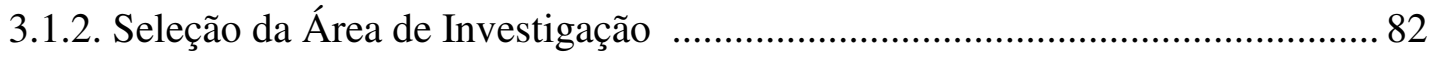

3.1.3. Características da Área de Investigação ..................................................... 87

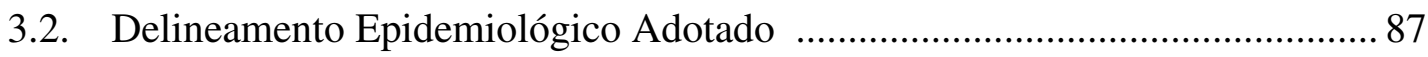

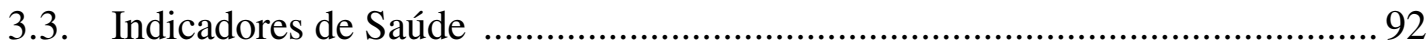

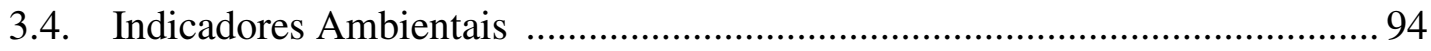

3.5. Dimensionamento da Amostra de Estudo ...................................................... 95

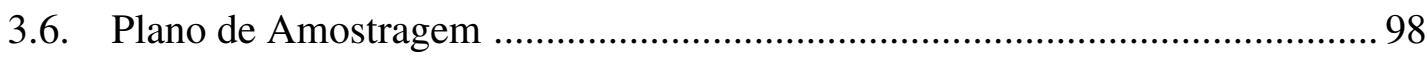

3.7. Protocolo de Pesquisa Adotado pelo Estudo ................................................ 103 
3.8. Coleta de dados .................................................................................... 105

3.9. Seleção e Treinamento da Equipe de Pesquisa .............................................. 109

3.10. Resumo do Levantamento de Dados Realizado ........................................... 110

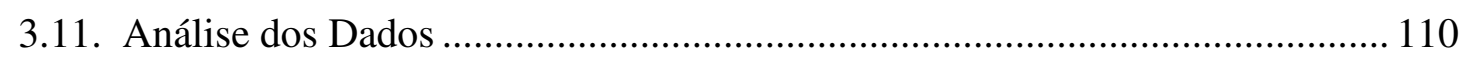

3.11.1 Banco de Dados e Recursos de Informática ............................................... 110

3.11.2 Definição da Base de Dados Geográficos .................................................. 111

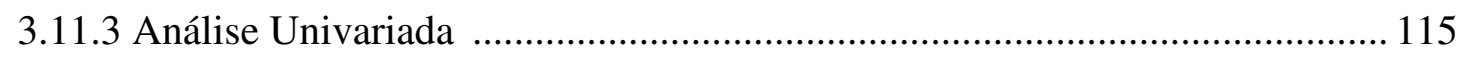

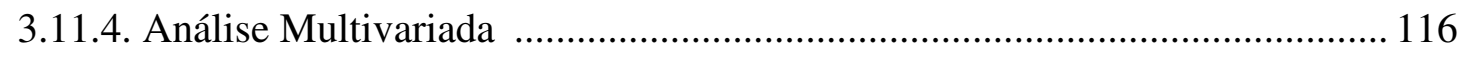

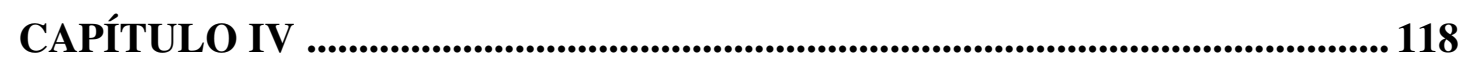

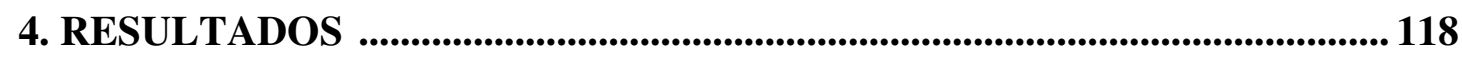

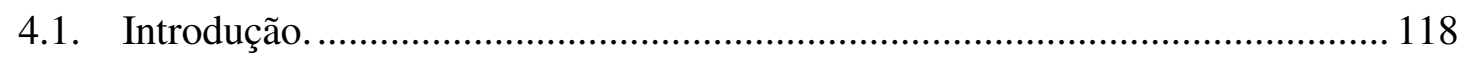

4.2. Caracterização da Amostra de Estudo ........................................................... 120

4.3. Indicadores Ambientais - Caracterização da Área de Estudo ........................ 137

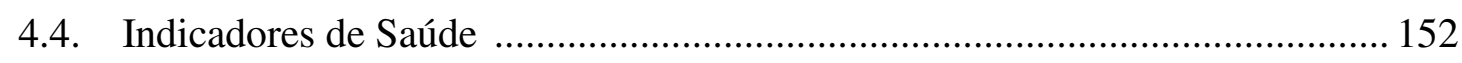

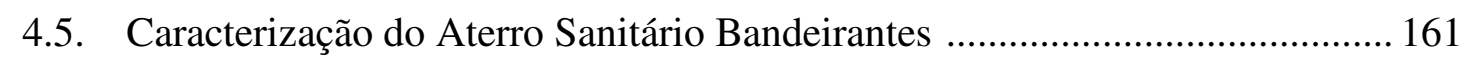

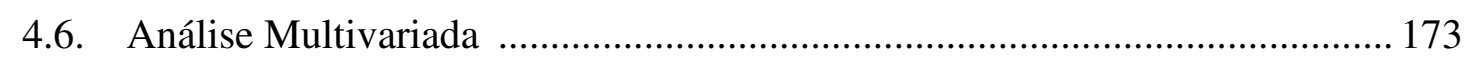

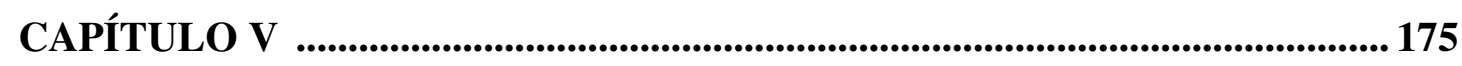

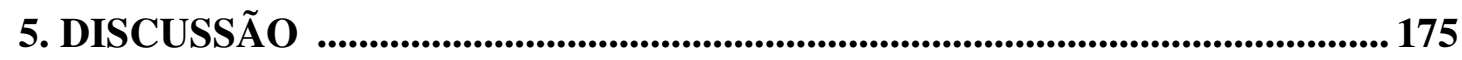

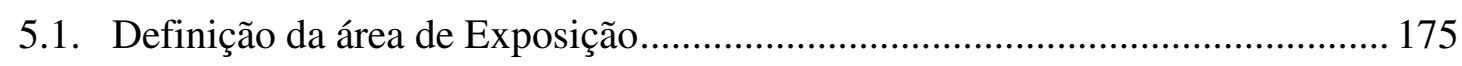

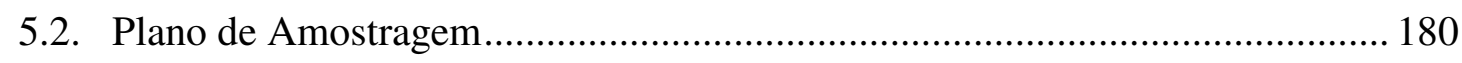

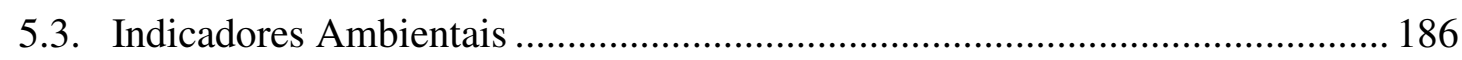

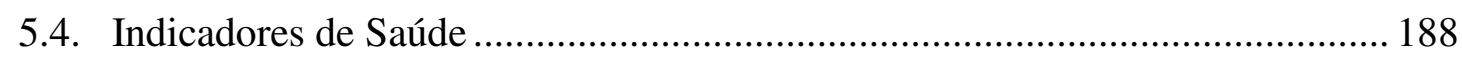

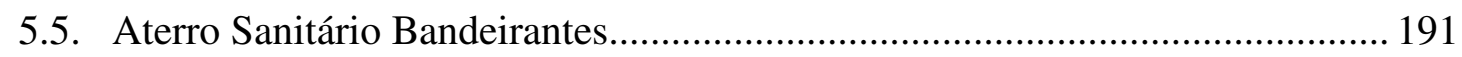


6. CONCLUSÃO

ANEXO A - Protocolo de Pesquisa 1..................................................................... 197

ANEXO B - $\quad$ Protocolo de Pesquisa 2 ........................................................................ 221

ANEXO C - Protocolo de Pesquisa 3 ............................................................. 235

ANEXO D - Carta de Encerramento da Pesquisa ..........................................254

REFERÊNCIAS BIBLIOGRÁFICAS ................................................................ 256

APÊNDICE 1 - Quadras do setor 187 pertencentes à faixa de exposição SPA e às vilas Jardim do Russo, Inácio Manacá e Operário

APÊNDICE 2 - Quadras do setor 187 pertencentes à faixa de exposição SPA e à vila Nova Perus

APÊNDICE 3 - Quadras do setor 187 pertencentes à faixa de exposição SPC e às vilas Caiúba, Osana, Hungareza, Fanton, Malvina, Flamengo e Jardim São Paulo

APÊNDICE 4 - Figuras referentes à monitorização do lençol freático realizado durante o mês de março de 2003 no Aterro Sanitário Bandeirantes 


\section{LISTA DE FIGURAS}

FIGURA 1 - Esquemas de vias de contato homem-lixo........................................26

FIGURA 2 - Composição dos resíduos sólidos produzidos no município de São Paulo 63

FIGURA 3 - Destinação dos resíduos sólidos gerados no município de São Paulo

FIGURA 4 - Mapa de localização das unidades de tratamento e destinação dos resíduos em São Paulo. 70

FIGURA 5 - Localização do Aterro Sanitário Bandeirantes em relação à cidade de São Paulo .75

FIGURA 6 - $\quad$ Localização do Aterro Sanitário Bandeirantes em relação ao bairro de Perus da cidade de São Paulo .76

FIGURA 7 - $\quad$ Arranjo geral do Aterro Sanitário Bandeirantes na cidade de São Paulo

FIGURA 8 - Distribuição mensal dos casos de diarréia na população infantil do bairro de Perus no ano de 2001 89 
FIGURA 9 - Distribuição da amostra em função dos números de entrevistas e exames parasitológicos realizados nas três áreas de exposição pesquisadas

FIGURA 10 - Número de crianças participantes no estudo por residência. 121

FIGURA 11 - Distribuição da população de estudo por sexo 122

FIGURA 12 - Renda média mensal das famílias que participaram do estudo 123

FIGURA 13 - Destino dados aos esgotos sanitários gerados nas residências 124

FIGURA 14 - Condições ambientais do peridomicílio das habitações do estudo.

FIGURA 15 - Grau de escolaridade dos pais 128

FIGURA 16 - Percentagem de crianças que têm hábito de brincar em locais em condições sanitárias inadequadas 130

FIGURA 17 - Distribuição geográfica da amostra de estudo 131

FIGURA 18 - Distribuição da frequiência do aparecimento de mosca 143

FIGURA 19 - Distribuição da freqüência do aparecimento de barata. 144

FIGURA 20 - Distribuição da frequiência do aparecimento de rato 145

FIGURA 21 - Distribuição da ocorrência de doenças respiratórias na população em geral 154

FIGURA 22 - Distribuição da ocorrência de dengue e câncer na população em geral 155

FIGURA 23 - Distribuição da ocorrência de diarréia na população de estudo ......158

FIGURA 24 - Distribuição da ocorrência de parasitose intestinal (Protozoários) na população de estudo. 159

FIGURA 25 - Distribuição da ocorrência de parasitose intestinal (Helmintos) na população de estudo. 160 
FIGURA 26 - Relato de problemas relacionados ao aterro sanitário na área de estudo 165

FIGURA 27 - Relato de problemas relacionados ao aterro sanitário na área de estudo (odor) 166

FIGURA 28- Relato de problemas relacionados ao aterro sanitário na área de estudo (poeira). 167

FIGURA 29 - Relato de problemas relacionados ao aterro sanitário na área de estudo (chorume) 168

FIGURA 30 - Relato de problemas relacionados ao aterro sanitário na área de estudo (presença de insetos) 169

FIGURA 31 - Relato de problemas relacionados ao aterro sanitário na área de estudo (presença de roedores) 170

FIGURA 32 - Destino dado aos esgotos sanitários na área de estudo 171

FIGURA 33 - Presença de esgoto a céu aberto na área de estudo. 172

FIGURA 34 - Quadras sorteadas para amostragem na área de estudo 183

FIGURA 35 - Quadras amostradas na área de estudo 184 


\section{LISTA DE TABELAS}

TABELA 1 - Indicadores bacteriológicos em lisímetros contendo resíduos sólidos 16

TABELA 2 - Indicadores bacteriológicos encontrados nos resíduos sólidos e chorume de um aterro sanitário com idade de 9 anos 17

TABELA 3 - Tempo de sobrevivência de microrganismos nos resíduos sólidos urbanos 18

TABELA 4 - Avaliação dos impactos ambientais ocasionados pela disposição dos resíduos sólidos .21

TABELA 5 - Microrganismos isolados em 1000 moscas agrupadas em 85 lotes, tomados em diversas partes da cidade de Santiago do Chile 30

TABELA 6 - Proporção de microrganismos de diferentes gênero isolados em 1000 moscas agrupadas em 85 lotes, tomados em diversas partes da cidade de Santiago do Chile 31

TABELA 7 - Proporção de Enterobcteriaceae em 1000 moscas agrupadas em 85 lotes, tomados em diversas partes da cidade de Santiago do Chile 31 
TABELA 8 - Proporção de microrganismos de vários gêneros da família

Enterobcteriaceae isolados em 1000 moscas agrupadas em 85 lotes, tomados em diversas partes da cidade de Santiago do Chile

TABELA 9 - Identificação dos artrópodes encontrados em dois locais de disposição final de resíduos sólidos ( Mokattan e Ezbel el Nakhl) da cidade do Cairo, Egito. 33

TABELA 10 - Classificação ambiental das infecções relacionadas à água . 37

TABELA 11 - Doenças relacionadas com as excretas 38

TABELA 12 - Classificação ambiental das enfermidades transmissíveis relacionadas aos resíduos sólidos 39

TABELA 13 - Classificação ambiental para as doenças relacionadas aos resíduos sólidos 43

TABELA 14 - Tipologia dos desenhos de investigação em epidemiologia. .50

TABELA 15 - Características dos desenhos de investigação em epidemilogia........56

TABELA 16 - Histórico da disposição dos resíduos sólidos urbanos no Aterro Sanitário Bandeirantes, SP .73

TABELA 17 - Distribuição da população urbana e rural por região administrativa do Distrito de Saúde de Perus .74

TABELA 18 - Distribuição da população por faixa etária e por regional administrativa no Distrito de Saúde de Perus .79

TABELA 19 - Amostragem de empregos por setor de atividade econômica no Distrito de Saúde Perus 80

TABELA 20 - Renda mensal por domicílio na regional de Perus .80

TABELA 21 - Classificação das sub-áreas de investigação. .83

TABELA 22 - Método de estudo epidemiológico empregado na pesquisa. 90 
TABELA 23 - Número de quadras e residências por faixa de exposição 100

TABELA 24 - Total de residências, pesos para fins de proporcionalidade, número de crianças e residências a serem amostradas por faixa de exposição considerada 101

TABELA 25 - Levantamento de dados realizado 112

TABELA 26 - Distribuição da população de estudo por área e faixa etária 119

TABELA 27 - Número médio de pessoas por residência e faixa etária, segundo as áreas de estudo

TABELA 28 - Caracterização das áreas de estudo segundo a freqüência das variáveis qualitativas que obtiveram o valor de $\mathrm{p}$ inferior ao limite de significância de $5 \%$ 132

TABELA 29 - Caracterização das áreas de estudo segundo a freqüência das variáveis qualitativas que obtiveram o valor de $\mathrm{p}$ superior ao limite de significância de $5 \%$ 138

TABELA 30 - Caracterização das áreas de estudo segundo a freqüência de observação de vetores 141

TABELA 31 - Frequiência de observação de vetores, segundo as estações do ano, nas áreas de estudo. 142

TABELA 32 - Caracterização das áreas de estudo em função de possíveis problemas correlatos ao aterro sanitário. 147

TABELA 33 - Resultados das análises de qualidade da água consumida pela população de estudo 148 
TABELA 34 - Caracterização das áreas de estudo segundo a frequiência das variáveis qualitativas empregadas como indicadores de saúde da população em geral 153

TABELA 35 - Caracterização das áreas de estudo segundo a freqüência das variáveis qualitativas empregadas como indicadores de saúde da população de estudo 156

TABELA 36 - Resultado do monitoramento da água subterrânea no Aterro Sanitário Bandeirantes 163

TABELA 37 - Resultado final do modelo de regressão logística 174

TABELA 38 - Valor da amostra obtido em função da metodologia de amostragem praticada. 185 


\section{RESUMO}

AZEVEDO, M. A. (2004). Avaliação do Risco à Saúde da População Vizinha às Áreas de Disposição Final de Resíduos Sólidos Urbanos: O Aterro Sanitário como Cenário de Exposição Ambiental. São Carlos, 2004. 263p. Tese (Doutorado) Escola de Engenharia de São Carlos, Universidade de São Paulo.

O presente estudo visou ao desenvolvimento de um estudo epidemiológico do tipo transversal para a avaliação do risco para a saúde da população residente próxima a uma área de disposição final de resíduos sólidos urbanos. O levantamento dos dados foi realizado no Bairro de Perus, na cidade de São Paulo, SP, vizinho ao Aterro Sanitário Bandeirantes. O Aterro Bandeirantes recebe diariamente cerca de 6.000 toneladas de resíduos sólidos do tipo Classe II e III. O aterro ocupa uma área total de $1.400 .000 \mathrm{~m}^{2}$, contendo aproximadamente 33 milhões de toneladas de resíduos dispostos. Os riscos para a saúde pública foram avaliados junto à população de estudo, 972 crianças na faixa etária de 1 a 5 anos incompletos, residente próxima ao Aterro Bandeirantes. A área de estudo foi dividida em faixas distantes de $500 \mathrm{~m}$ do limite do aterro, para a definição das condições de exposição. Os indicadores de saúde utilizados foram: as prevalências de enfermidades diarréicas e parasitárias e os índices antropométricos. Na área de estudo, foi realizado um levantamento da qualidade ambiental, com intuito de relacionar os impactos ambientais, ocasionados pela prática de disposição final considerada, aos indicadores de saúde empregados. Os resultados obtidos, pela realização deste estudo, permitiram concluir que há relações estatisticamente significativas entre as exposições pesquisadas e os indicadores de saúde empregados.

Palavras-chave: resíduos sólidos; disposição de resíduos; saúde pública; exposição ambiental; avaliação de risco; aterro sanitário. 


\begin{abstract}
AZEVEDO, M. A. (2004). Healh risk assessement to population who lives near a municipal solid waste disposal site: the landfill as the environmental exposure scenery. São Carlos, 2004. 263p. Tese (Doutorado) - Escola de Engenharia de São Carlos, Universidade de São Paulo.

This work had the objective to develop an epidemiological study, using a transversal design, to evaluate the health risk to people who lives near a municipal solid waste disposal site. The study was accomplished at Bairro de Perus, in the city of São Paulo S.P, Brazil, near to the Bandeirantes Landfill site. The Bandeirantes Landfill receives daily around 6,000 tons of class II and III solid waste types. The landfill occupies a total area of 1,400,000 $\mathrm{m}^{2}$, containing around 33 millions of tons of disposed waste. The public health risks were evaluated among 972 children, of one to five years old, who live near the Bandeirantes landfill. The studied area was divided in distant lines of 500 meters from the landfill limit to define the exposure conditions. The used health indicators were: diarrhoeal, intestinal parasite prevalence and nutritional status. In the studied area, an environmental quality survey was accomplished with the intentions of relating the environmental impacts occasioned by the solid waste disposal to the used health indicators. The obtained results made it clear to conclude that there are statistical associations between the researches environmental exposures and the used health indicators.
\end{abstract}

Keywords: solid waste; solid waste disposal; public health; environmental exposure; risk assessment; landfill. 


\section{CAPÍTULO I}

\section{INTRODUÇÃO}

Os resíduos sólidos urbanos, quando dispostos inadequadamente no meio ambiente, causam uma série de impactos ambientais, muito dos quais têm conseqüências diretas ou indiretas sobre a saúde pública.

O conhecimento sobre os impactos ambientais ocasionados pela disposição de resíduos sólidos no meio ambiente têm sido objeto de várias investigações científicas, contudo, pouca atenção tem sido dada às conseqüências ou aos efeitos destas alterações ambientais sobre a saúde pública.

A comunidade científica reconhece a importância dos resíduos sólidos na transmissão de doenças por constituírem um ambiente adequado à sobrevivência e proliferação de vetores biológicos e mecânicos (FORATTINI, 1969; OLIVEIRA, 1978; ROCHA \& LINDENBERGER, 1990). Contudo, a importância dos resíduos sólidos como causa direta de doenças não está conclusivamente comprovada (OLIVEIRA, 1978).

Assim sendo, o papel que os resíduos sólidos exercem na estrutura epidemiológica de uma comunidade vêm sendo, historicamente, relegado pelas 
políticas públicas e pouco considerado na adoção das práticas de gestão voltadas para a saúde pública e ambiental das municipalidades.

Por entender que os efeitos dos resíduos sólidos sobre a saúde de uma comunidade vão além da correlação com as doenças transmitidas por vetores, representando um potencial de risco bem maior que os especificados classicamente na literatura especializada, a presente pesquisa pretendeu estudar a correlação existente entre os impactos ambientais ocasionados pela disposição ambiental dos resíduos sólidos urbanos e seus efeitos sobre a saúde pública.

A hipótese básica testada por esta pesquisa foi:

A disposição ambiental dos resíduos sólidos urbanos ocasiona agravos à saúde humana, advindos não apenas da proliferação de vetores biológicos e mecânicos, como também da poluição e contaminação ambientais ocasionadas na área. A residência na proximidade destas áreas significa um fator de risco para a população. As diferentes técnicas de disposição ambiental de resíduos sólidos correspondem a fatores de risco distintos para a população exposta.

Este estudo teve o objetivo de testar e validar esta hipótese, bem como de procurar quantificar os riscos envolvidos. $\mathrm{O}$ aterro sanitário foi considerado como cenário de exposição ambiental a ser pesquisado, por constituir-se na técnica sanitariamente adequada de disposição de resíduos no solo e em uma meta a ser alcançada, para a disposição final dos resíduos sólidos urbanos, na maioria das 
municipalidades brasileiras, uma vez que apenas $13,7 \%$ dos municípios brasileiros adotam esta prática. Segundo os dados da PESQUISA NACIONAL DE SANEAMENTO BÁSICO (2000), 63,1\% dos municípios brasileiros depositam seus resíduos em lixões, restando muito, ainda, a ser feito no País para a melhoria dos sistemas de gestão de resíduos sólidos.

\subsection{Justificativa}

Apesar de amplamente reconhecida, no meio técnico e científico, a importância que os resíduos sólidos urbanos exercem na estrutura epidemiológica de uma comunidade, estando relacionados à incidência de várias doenças, poucos estudos têm sido realizados com o intuito de associar os efeitos do gerenciamento destes resíduos à saúde pública.

$\mathrm{Na}$ revisão da literatura realizada para o desenvolvimento desta pesquisa, verificou-se que os estudos estavam basicamente relacionados:

- à identificação e à quantificação de organismos indicadores e patogênicos nos resíduos submetidos a processos de tratamento e/ou disposição final em escala real ou em simulações de laboratório (KNOLL, 1961; GOLUEKE, 1977; 1986; MERCEDES et al., 1993; AZEVEDO, 1993; GERBA, 1996);

- à caracterização química e biológica dos resíduos sólidos ou do líquido percolado dos processos de tratamento e/ou disposição final em escala real ou em simulações de laboratório (SCHALCH, 1984; MERBACH JR, 1989; GOMES, 1989; SCHALCH, 1992); 
- à associação entre as condições de acondicionamento e coleta dos resíduos sólidos urbanos e indicadores bioestatísticos (HELLER, 1995; CATAPRETA, 1997; MORAES, 1998);

- à identificação e à associação de doenças ou agravos à saúde ocasionados pelo contato, exposição ou proximidade dos sistemas de tratamento e/ou disposição final de resíduos sólidos urbanos (WILLSON et al., 1980; STENTIFORD, 1991; GOLDBERG et al. 1995a, 1995b), e de resíduos sólidos perigosos (VIANNA \& POLAN, 1984; BUDNICK et al., 1984; PAIGEN et al., 1987; GRIFFITH et al., 1989; MALLIN, 1990; BERRY \& BOVE, 1997; GESCHWIND et al., 1992; KHARRAZI, et al., 1997; CROEN et al., 1997; AHUMADA, 1998).

Estudos epidemiológicos relacionados especificamente aos resíduos sólidos urbanos, realizados no País, são basicamente os estudos efetuados por HELLER (1995), CATAPRETA (1997) e MORAES (1998), havendo, portanto, a carência de estudos que abordem a questão dos resíduos sólidos e sua relação com a saúde pública. Neste sentido, HELLER (1997) afirma que apesar de existirem algumas referências que contribuem para iniciar a formulação de um modelo causal Lixo versus Doença, este ainda tem que ser construído e validado.

Dentro deste contexto e compreendendo a importância da geração de dados e informações que possam nortear a gestão pública dos resíduos sólidos, direcionandoa para a melhoria da saúde pública e ambiental das municipalidades brasileiras, é que a presente pesquisa visou ao desenvolvimento de um estudo epidemiológico, no qual foi estudada a relação entre a disposição ambiental dada aos resíduos sólidos urbanos, segundo a prática do aterro sanitário, e seus efeitos sobre a saúde pública. $\mathrm{O}$ 
intuito foi buscar avaliar o risco para a saúde pública da residência em áreas próximas aos locais utilizados para a disposição final de resíduos sólidos.

As questões que nortearam a elaboração e a execução do presente estudo foram:

- A exigüidade de dados quantitativos sobre a associação entre as distintas formas de disposição ambiental dos resíduos sólidos urbanos e a saúde pública.

- A falta de estudos epidemiológicos, realizados no País, que associem a exposição ambiental relacionada à poluição e à contaminação ambientais ocorrentes nas áreas utilizadas para a disposição final de resíduos, aos agravos à saúde.

- A desconsideração ou desconhecimento por parte das autoridades públicas dos impactos ambientais ocasionados pela disposição de resíduos sólidos e suas conseqüências para a saúde pública, não sendo, portanto, devidamente considerados dentro dos programas de saneamento com vistas à melhoria da saúde coletiva.

\subsection{Objetivos}

O presente estudo teve como objetivo geral a avaliação do risco para a saúde humana da disposição ambiental de resíduos sólidos, considerando como cenário de exposição ambiental o aterro sanitário; e graus de exposição diferentes, estabelecidos em função da distância entre o local de residência da população em estudo e o local utilizado no município para a disposição final dos resíduos gerados.

Constituíram objetivos específicos do presente estudo, os seguintes: 
- Verificar para a situação de exposição pesquisada (aterro sanitário), se existe um efeito dose-resposta entre a maior proximidade de residência do local de disposição final dos RSU e a prevalência de enfermidades diarréicas e parasitárias e os índices antropométricos, escolhidos, para efeito deste estudo, como os indicadores de saúde;

- Verificar a eficiência e o desempenho da solução de disposição final pesquisada na proteção à saúde pública;

- Determinar a distância a partir da qual a disposição ambiental de resíduos sólidos, realizada segundo a técnica do aterro sanitário, não representa um fator de risco para a saúde da população;

- Definir uma metodologia para o desenvolvimento de estudos epidemiológicos, que avaliem os riscos para a saúde pública da disposição ambiental dos resíduos sólidos urbanos, utilizando-se como indicadores de saúde a prevalência por enfermidades diarréicas e parasitárias e os índices antropométricos. 


\section{CAPÍTULO II}

\section{REVISÃO DE LITERATURA}

\subsection{Aspectos Epidemiológicos Relacionados aos Resíduos Sólidos}

Vários autores reconhecem a importância dos efeitos dos resíduos sólidos sobre a saúde pública e o meio ambiente. Contudo, a correlação destes fatores não tem sido objeto de estudos e pesquisas, que permitam a adoção de ações efetivas voltadas para a saúde ambiental das municipalidades brasileiras. Desta forma, o papel que os resíduos sólidos exercem na estrutura epidemiológica de uma comunidade e, conseqüentemente, na saúde pública tem sido relegado e desconsiderado pelas políticas públicas.

Do ponto de vista sanitário, a importância dos resíduos sólidos como causa direta de doenças não está conclusivamente comprovada (OLIVEIRA, 1978). FEDORAK \& ROGERS (1991) relatam que poucas são as informações referentes aos efeitos sobre a saúde pública relacionados aos resíduos sólidos municipais e que, na maioria da bibliografia disponível, pequena atenção tem sido dedicada à associação entre as formas de disposição final dos resíduos sólidos e a saúde pública. 
PARHEN (1987) cita que a literatura, concernente aos efeitos sobre a saúde decorrentes da exposição dos resíduos sólidos municipais, é escassa.

No entanto, como fator indireto, vários autores (FORATTINI, 1969; OLIVEIRA, 1978; ROCHA \& LINDENBERG, 1990) reconhecem a importância dos resíduos sólidos na transmissão de doenças, por constituírem no ambiente adequado à sobrevivência e à proliferação de vetores biológicos. Contudo, poucos são os estudos presentes na bibliografia especializada que associam o manejo, a coleta e a disposição inadequada dos resíduos sólidos a indicadores de saúde pública.

HELLER (1995), investigando diversos cenários de saneamento no município de Betim - MG, demonstrou que o acondicionamento e a disposição inadequados dos resíduos sólidos, nas áreas investigadas, estavam associados à morbidade de crianças por diarréia. O autor analisou quatro aspectos distintos relacionados ao manuseio dos resíduos sólidos domésticos: a forma de acondicionamento, a solução dada para a disposição, a frequiência semanal da coleta pública e a disposição das fezes das fraldas. Para todos os aspectos considerados, foi encontrado um risco relativo significativo. A um nível de significância de $5 \%$, foi observado um risco relativo ${ }^{1}$ estatisticamente significativo para:

- acondicionamento em embalagem inadequada $X$ acondicionamento em saco de lixo ou nenhum:

- disposição em lote vago ou córrego X

disposição na rua com elevada freqüência de coleta:

$1,61(1,11-2,34)$

\footnotetext{
${ }^{1}$ Risco Relativo (RR) ou Razão de Incidências é uma medida de associação que expressa uma comparação matemática entre o risco de adoecer em um grupo exposto a um fator qualquer e o risco correspondente em um grupo não exposto ao mesmo fator. O risco relativo indica quantas vezes é mais freqüente o dano nos expostos (que têm o fator de risco) do que nos não expostos.
} 
- não usar fraldas X disposição das fraldas em

vaso ou fossa:

- disposição inadequada das fezes das fraldas $X$

disposição das fezes das fraldas em vaso ou fossa

$1,50(1,04-2,19)$

Com relação ao acondicionamento dado aos resíduos sólidos domiciliares, o estudo, realizado por HELLER (1995), constata a importância tanto do lixo ser embalado em sacos apropriados, quanto de ser disposto imediatamente para a coleta. Quanto à disposição, os resultados obtidos constatam a inadequação sanitária da prática de lançamento dos resíduos sólidos em lotes vagos ou em córregos. O risco de diarréia em crianças associado a essas práticas é aproximadamente $61 \%$ maior $\left(\right.$ Risco Relativo $=1,61 ;$ IC $\left.95 \%^{2}: 1,11-2,34\right)$, quando comparado às crianças cujas famílias são beneficiadas pela coleta de resíduos.

CATAPRETA (1997) encontrou uma correlação estatística entre a qualidade dos serviços de coleta de resíduos sólidos domiciliares praticados em algumas vilas e favelas de Belo Horizonte - MG e indicadores de saúde avaliados (doenças diarréicas, parasitárias e dermatológicas). Os resultados obtidos demonstram que a população não atendida por coleta de resíduos sólidos domiciliares está exposta a um risco aproximadamente 1,4 vez maior, para as doenças investigadas, do que a população provida dos serviços de coleta.

MORAES (1997 e 1998) encontrou uma associação estatisticamente significativa entre o tipo de acondicionamento e coleta de resíduos sólidos e a prevalência de nematóides intestinais (Ascaris lumbricoides, Trichuris trichiura e

\footnotetext{
${ }^{2}$ IC - Intervalo de confiança, com probabilidade de significância de $95 \%$.
} 
ancilostomídeos) e a incidência de diarréia em crianças residentes em áreas periurbanas de Salvador - Ba. As prevalências de nematóides intestinais, avaliadas em crianças de 5 a 14 anos de idade, considerando como fatores de exposição domicílios que não dispõem de coleta de lixo, dispõem de coleta irregular e domicílios com coleta regular, foram, respectivamente, de: $65 \%, 43,3 \%$ e $41 \%$ para Ascaris lumbricoides; $86,8 \%, 73,1 \%$ e 66,3\% para Trichuris trichiura e, 23,4\%, 8,5\% e 9,8\% para ancilostomídeos, respectivamente. A incidência de diarréia em crianças menores de 5 anos de idade residentes em domicílios sem coleta de lixo, com coleta irregular e com coleta regular foi, respectivamente, 5,04;2,86 e 1,77 episódios/criança.ano.

Porém, não se tem relato na bibliografia especializada de estudos realizados no País considerando diversos cenários de disposição final dada aos resíduos sólidos urbanos e indicadores de saúde pública.

Após uma extensa revisão bibliográfica, foram encontrados apenas dois artigos que relatam os resultados de estudos epidemiológicos realizados considerando a incidência de doenças e os efeitos sobre a saúde na população residente próxima a áreas de aterros municipais de resíduos sólidos urbanos.

GOLDBERG et al. (1995 a) realizaram um estudo epidemiológico do tipo caso-controle para avaliar o risco de baixo peso ao nascer e de nascimentos prematuros entre crianças cujas mães moravam na proximidade do aterro de resíduos sólidos urbanos de Montreal, Quebec. A área vizinha ao aterro foi dividida em zonas de exposição e os autores encontraram, para a zona mais próxima do aterro, um risco elevado para o baixo peso ao nascer $(\mathrm{OR}=1,20 ; 95 \% \text { IC: } 1,04-1,39)^{3}$; um excesso

\footnotetext{
${ }^{3}$ OR - Odds-ratio é um indicador para a estimativa do risco relativo a partir dos valores levantados
} 
de risco, mas não estatisticamente significativo para um menor período de gestação $(\mathrm{OR}=1,09 ; 95 \%$ IC: 0,96 - 1,24) e uma associação não significativa para nascimentos prematuros. GOLDBERG et al. (1995 b), investigando a incidência de câncer entre pessoas que viviam próximas ao mesmo aterro de resíduos sólidos urbanos de Montreal, encontraram para os homens, residindo na zona de exposição mais próxima ao aterro, um alto risco para câncer de pulmão ( $R R=1,3 ; 95 \%$ IC: 1,0 - 1,5); câncer de fígado ( $R R=1,3 ; 95 \%$ IC: 0,9 - 1,8) e, câncer de traquéia, brônquio e pulmão (RR = 1,1; 95\% IC: 1,0 - 1,2). Entre as mulheres, as taxas de câncer de estômago $(\mathrm{RR}=1,2 ; 95 \%$ IC: 0,9 - 1,5) e câncer de útero foram elevados $(\mathrm{RR}=1,2$; 95\% IC: 1,0 - 1,5); mas, segundo os autores, a incidência de câncer de mama foi menor do que a esperada $(\mathrm{RR}=0,9 ; 95 \%$ IC: $0,9-1,0)$.

Contudo, vários estudos epidemiológicos, que avaliaram a relação entre várias doenças e agravos à saúde e a proximidade de residência de aterros sanitários, os quais eram utilizados para a disposição conjunta de resíduos sólidos urbanos e resíduos perigosos ou, somente, de resíduos perigosos, foram encontrados na bibliografia especializada (VIANNA \& POLAN, 1984; BUDNICK et al., 1984; PAIGEN et al., 1987; GRIFFITH et al., 1989; MALLIN, 1990; GESCHWING et al., 1992; BERRY \& BOVE, 1997; KHARRAZI et al., 1997; CROEN et al., 1997).

Os efeitos sobre a saúde das pessoas residentes próximas a aterros sanitários mais comumente reportados na bibliografia são o baixo peso ao nascer e o retardo de crescimento em crianças. O primeiro estudo detalhado a esse respeito, foi realizado em Love Canal, próximo às Cataratas do Niagara, Nova York (PAIGEN et al., 1987).

em estudos do tipo caso-controle. É uma medida do efeito do fator de exposição em estudo no desenvolvimento da doença ou agravo à saúde pesquisados, representando a razão entre as chances em 
Os pesquisadores encontraram uma estatura significativamente menor para as crianças que viveram, pelo menos $75 \%$ de seu tempo de vida, próximas ao Love Canal - um notório depósito a céu aberto de resíduos químicos tóxicos, quando comparada à estatura de crianças que viveram longe do Love Canal, sem contato com esse sítio de resíduos perigosos. Os resultados obtidos foram mantidos, mesmo após os ajustes estatísticos, considerando: o peso ao nascer, as condições socioeconômicas e a altura dos pais das crianças, avaliados pelo estudo.

VIANNA \& POLAN (1984) realizaram, anteriormente, um estudo no Love Canal, no qual ficou demonstrado que as crianças que viviam próximas ao local apresentavam um baixo peso ao nascer anormal. Os pesquisadores avaliaram a incidência do baixo peso ao nascer nas crianças no período de 1940 a 1978. Esses dois estudos concluem que as crianças do Love Canal foram postas em risco pela exposição às 20.000 toneladas de resíduos químicos dispostas em sua vizinhança. Esses resíduos permanecem enterrados no local e as famílias que residem ou se mudaram para o local, provavelmente, estão também sujeitas a riscos à saúde.

Outro estudo realizado com crianças residentes próximas a outro aterro sanitário confirma os resultados obtidos, expressos anteriormente. BERRY \& BOVE (1997) encontraram um baixo peso ao nascer para as crianças residentes próximas ao aterro sanitário de Lipari, Nova Jersey, durante o período de 1971 a 1975. Este período coincide com a maior disposição de material tóxico no local.

KHARRAZI et al. (1997) desenvolveram um estudo no aterro sanitário BKK, situado a $29 \mathrm{~km}$ a leste do centro de Los Angeles, na cidade de West Covina. No ano de 1963, iniciou-se a operação do aterro, com o recebimento dos resíduos sólidos 
urbanos produzidos nas áreas no entorno. De 1972 até 1984, o aterro passou a receber resíduos perigosos, Classe $\mathrm{I}$, os quais eram dispostos em uma área especialmente preparada para tal. Após este período, a expansão urbana atingiu as proximidades do aterro. Os moradores passaram a reclamar de vários problemas ambientais. Durante o período de 1975 a 1984, intensificou-se a disposição de resíduos perigosos no aterro. Ao todo, aproximadamente, 4 milhões de toneladas de resíduos perigosos foram dispostas na área. Quando, em 1989, encerrou-se a disposição de resíduos perigosos e o aterro de resíduos Classe I foi técnica e oficialmente fechado, este distava cerca de 150m das residências adjacentes. Nessas condições de exposição, os autores encontraram um baixo peso ao nascer entre as crianças nascidas durante o período de maior disposição de resíduos perigosos.

BUDNICK et al. (1984) investigando a taxa de mortalidade por câncer nos anos de 1950-1959, 1960-1969 e 1970-1979, e a incidência de nascimentos com defeitos congênitos, no período de 1973-1978, em um sítio contaminado por produtos carcinogênicos, denominado Drake Superfund, localizado no condado de Clinton, Pensilvânia (com uma população de 39.000 habitantes na época), encontram para a década de 1970 um aumento significativo do número de mortes por câncer de bexiga nos homens e um aumento do número de morte por câncer na população em geral, residente em três condados próximos. Contudo, uma relação estatisticamente significativa não foi encontrada pelos pesquisadores para a incidência de nascimentos com defeitos congênitos. Clinton foi um dos únicos dois condados nos Estados Unidos, no qual a $\beta$-nafitalina foi manufaturada durante 20 anos, antes da realização desse estudo.

Em 1989, um estudo realizado pela EPA (U.S. Evironmental Protection 
Agency), foram examinados 593 sítios de disposição de resíduos em 339 condados dos Estados Unidos. Este estudo revelou uma contaminação da água subterrânea, utilizada para abastecimento público em 49 locais pesquisados. O estudo demonstrou, também, um excesso no número de mortes por câncer de bexiga, pulmão, estômago e reto, para a população residente nos condados onde existiam locais de disposição de resíduos perigosos, quando comparados com os condados que não possuíam sítios de disposição de resíduos perigosos (GRIFFITH et al., 1989).

Um estudo realizado por MALLIN (1990) encontrou um aumento na incidência de câncer de bexiga em Illinois, Estados Unidos, onde um aterro sanitário contaminou a água de abastecimento público com tricloroetileno, tetracloroetileno e outros solventes clorados.

Um aumento na incidência de leucemia, em uma comunidade residente próxima a um local de disposição de resíduos sólidos industriais tóxicos, operado ilegalmente de 1977 a 1983, foi reportado em um estudo realizado por GREISER et al., (1991), em Rhine-Westfalia, Alemanha.

GESCHWING et al. (1992), investigando a má formação congênita e a residência próxima a locais de disposição de resíduos perigosos, no estado de Nova York, encontraram um aumento de $12 \%(\mathrm{OR}=1,12,95 \% \mathrm{IC}=1,06-1,18) \mathrm{em}$ nascimentos com defeitos congênitos, cujas mães das crianças residiam a uma distância de 1 milha (aproximadamente 1,6km) de 590 sítios pesquisados.

CROEN, et al. (1997) investigaram se a residência das mães próximas a locais de disposição de resíduos perigosos aumentava o risco de nascimentos de crianças com má formação congênita. Os autores encontraram, para as relações pesquisadas, riscos estatisticamente significativos para a má formação do tubo 
neurológico e defeitos no coração.

\subsection{Aspectos Microbiológicos Relacionados à Disposição Ambiental dos Resíduos Sólidos}

Segundo GERBA (1996), poucos foram os estudos realizados com o intuito de avaliar a ocorrência de microrganismos entéricos em aterros sanitários ou em lisímetros de laboratório. O autor cita alguns trabalhos que avaliaram a ocorrência de organismos indicadores e organismos patogênicos em células de aterros sanitários e em lisímetros de laboratório, apresentados nas Tabelas 1 e 2, ressaltando o fato que várias bactérias patogênicas, incluindo Salmonella, foram isoladas nos resíduos escavados das células do aterro sanitário estudado.

O mesmo autor comenta que apenas um estudo (HUBER et al., 1994) ${ }^{4}$ avaliou a ocorrência de vírus entéricos nos resíduos sólidos municipais, nesse caso dispostos em três aterros sanitários. As ocorrências dos vírus foram analisadas em fraldas descartáveis enterradas por um período entre 2 a 10 anos. Os autores estudaram a presença de enterovirus, poliovírus, vírus da hepatite A e rotavirus. Enterovirus não foram detectados em nenhuma amostra analisada. Três amostras foram positivas para o poliovírus, mas negativas para o rotavirus e vírus da hepatite A. Contudo, os autores concluíram que, embora o RNA do poliovírus estivesse presente em algumas das fraldas analisadas, o vírus não era viável pelo ensaio de cultura celular, após dois anos ou mais em aterro sanitário. Ovos de Cryptosporidium

\footnotetext{
${ }^{4}$ HUBER, M. S. et al. Study of persistence of enteric viruses in landifilled disposable diapers.
} Environmental Science Technology. 28: 1767 - 1772, 1994. 
foram encontrados em fraldas enterradas por dois anos a uma profundidade de 3,3m, embora os métodos de detecção usados no estudo não fossem capazes de determinar se os oocistos eram ainda infecciosos.

TABELA 1 - Indicadores bacteriológicos em lisímetros contendo resíduos sólidos

\begin{tabular}{l|c|c|c}
\hline \multirow{2}{*}{ Bactéria } & \multicolumn{3}{|c}{ Resíduo úmido (ufc/g) } \\
\cline { 2 - 4 } & Inicial & Após 2 anos & Após 10 anos \\
\hline Coliformes totais & $6,8 \times 10^{8}$ & $5,6 \times 10^{4}$ & $1,4 \times 10^{3}$ \\
\hline Coliformes fecais & $2,6 \times 10^{7}$ & $5,6 \times 10^{3}$ & $<0,2$ \\
\hline Streptococus fecais & $1,4 \times 10^{8}$ & $1,6 \times 10^{4}$ & $2,4 \times 10^{2}$ \\
\hline
\end{tabular}

Fonte: KINMAN et al., 1986 apud GERBA, 1996.

A ocorrência de microrganismos no chorume, em células experimentais de aterro sanitário e em lisímetros, foi estudada por alguns pesquisadores citados por GERBA (1996), podendo-se concluir que, tanto para os organismos indicadores quanto para os organismos patogênicos pesquisados, o tempo de sobrevivência é variável em função do tempo e das condições de operação do aterro, havendo uma diferença no tempo de sobrevivência dos organismos indicadores, quando simuladas distintas situações de disposição final. Para a disposição em "lixões" foi encontrado um tempo maior de sobrevivência dos organismos indicadores que nos aterros sanitários. A Tabela 3 apresenta o tempo de sobrevivência de alguns organismos nos resíduos sólidos urbanos.

FEDORAK \& ROGERS (1991) dizem que a disseminação de 
microrganismos por meio dos aterros de resíduos sólidos pode ocorrer pelo transporte por meio do chorume gerado, podendo contribuir para a contaminação de águas subterrâneas; pelo transporte aéreo, via aerossol, no qual as partículas em suspensão podem conter diversos microrganismos e, por meio de vetores, seja quando ingerem detritos, seja pelo carreamento na superfície de seu corpo.

TABELA 2 - Indicadores bacteriológicos encontrados nos resíduos sólidos e chorume de um aterro sanitário com idade de $9 \operatorname{anos}^{\mathrm{a}}$

\begin{tabular}{l|c|c|c|c}
\hline Tipo de amostra & $\begin{array}{c}\text { Profundidade } \\
\text { de coleta da } \\
\text { amostra (m) }\end{array}$ & Coliformes & Coliformes & Streptococus \\
fecais & fecais \\
\hline Solo de cobertura & 0,46 & $2,4 \times 10^{5}$ & $3,5 \times 10^{3}$ & $9,8 \times 10^{5}$ \\
\hline RSM $^{\text {b }}$ & 1,56 & $1,1 \times 10^{2}$ & $<2,0 \times 10^{1}$ & $2,0 \times 10^{4}$ \\
\hline RSM & 2,13 & $2,4 \times 10^{3}$ & $2,0 \times 10^{1}$ & $6,0 \times 10^{4}$ \\
\hline RSM & 2,60 & $1.6 \times 10^{5}$ & $2,3 \times 10^{2}$ & $6,3 \times 10^{5}$ \\
\hline RSM & 2,74 & $5,4 \times 10^{4}$ & $3,3 \times 10^{2}$ & - \\
\hline Chorume & 3,01 & $9,2 \times 10^{3}$ & $3,5 \times 10^{2}$ & $1,1 \times 10^{2}$ \\
\hline RSM & 3,20 & $3,5 \times 10^{4}$ & $4,9 \times 10^{2}$ & $3,5 \times 10^{4}$ \\
\hline Camada & 3,96 & $5,0 \times 10^{1}$ & $<2,0 \times 10^{1}$ & $<2,0 \times 10^{4}$ \\
de impermeabilização & 3,35 & $5,0 \times 10^{1}$ & $<2,0 \times 10^{1}$ & $2,0 \times 10^{4}$ \\
\hline Solo abaixo da & & & & \\
\hline impermeabilização & 3,96 & & & \\
\hline
\end{tabular}

\footnotetext{
${ }^{a}$ número mais provável (NMP); ufc/g ou ml

${ }^{\mathrm{b}} \mathrm{RSM}=$ resíduos sólidos municipais

Fonte: GERBA, 1996.
} 
TABELA 3 - Tempo de sobrevivência de microvetores nos resíduos sólidos urbanos

\begin{tabular}{l|c}
\hline \multicolumn{1}{c|}{ Organismo } & Tempo (dias) \\
\hline Salmonella typhi & $29-70$ \\
\hline Entamoeba histolytica & $8-12$ \\
\hline Ascaris lumbricoides & $2000-2500$ \\
\hline Leptospira interrogans & $15-43$ \\
\hline Poliovírus & $20-170$ \\
\hline Bacilo da tuberculose & $150-180$ \\
\hline Larvas de vermes & $25-40$ \\
\hline Fon & \\
\hline
\end{tabular}

Fonte: SUBERKROPP \& KLUG, 1974.

\subsection{Aspectos Ambientais Relacionados aos Resíduos Sólidos}

Os resíduos sólidos quando dispostos no meio ambiente, seja por meio da prática do aterro sanitário, seja inadequadamente nos "lixões/vazadouros", entram em decomposição devido ao elevado teor de matéria orgânica presente, principalmente nos resíduos gerados nos países em desenvolvimento.

A decomposição dos resíduos sólidos ocasiona uma série de impactos ambientais adversos, dos quais ressaltam-se:

- A atração de vetores biológicos e mecânicos, devido à disponibilidade de alimento, abrigo e proteção que estes organismos encontram no lixo.

- Contaminação e/ou alteração das características biológicas, físicas e químicas do solo e recursos hídricos superficiais e subterrâneos, que muitas vezes 
são utilizados como fontes de abastecimento de água potável. ACURIO et al. (1998) chamam atenção para os problemas de eutrofização advindos como aumento da contaminação de $\mathrm{N}$ e $\mathrm{P}$ nos corpos d'água superficiais, bem como para a contaminação química que estes recursos naturais estão sujeitos, uma vez que na maioria dos países da América Latina e Caribe os resíduos sólidos municipais são dispostos junto aos resíduos industriais perigosos. GIROULT \& BROWN (1996) afirmam que o problema mais sério está relacionado à infiltração do chorume e à possível contaminação dos aqüíferos subterrâneos situados abaixo dos "lixões" ou dos aterros sanitários, o que pode resultar na poluição química e biológica por vírus da água subterrânea. Os autores comentam que os riscos para a saúde pública advindos com a contaminação das águas subterrâneas são maiores do que para as águas superficiais, uma vez que a população vizinha às áreas de disposição final de resíduos sólidos pode utilizar água de poços subterrâneos sem tratamento e, mesmo quando a água proveniente destes poços é submetida a um tratamento, este pode não ser eficiente contra a poluição química advinda do chorume.

- Contaminação do ar ocasionada, principalmente, pela disposição a céu aberto dos resíduos sólidos, resultando na geração de odores desagradáveis, fumos, gases e partículas em suspensão, como produtos da queima provocada ou espontânea e do arraste pelo vento. ACURIO et al. (1998) afirmam que todos os países da América Latina e Caribe têm problemas de contaminação atmosférica pela queima não controlada de lixo.

- Impactos sobre a paisagem ocasionados pela disposição inadequada dos resíduos sólidos, o que afeta a saúde ambiental das municipalidades, diminuindo a qualidade de vida da população. 
Outro aspecto ambiental importante a ser considerado é a co-disposição dos resíduos sólidos municipais com os resíduos perigosos (industriais e/ou dos serviços de saúde), com graves implicações e efeitos sobre a saúde pública e o meio ambiente. Esta é uma situação verificada, segundo ACURIO et al. (1998), nos países da América Latina e Caribe.

A Tabela 4 resultado da revisão bibliográfica, realizada para subsidiar este trabalho, bem como das reflexões que levaram a elaboração da metodologia de pesquisa empregada pelo presente estudo, apresenta uma compilação dos impactos ambientais, decorrentes da disposição inadequada dos resíduos sólidos, relatados na bibliografia pesquisada. Os impactos foram avaliados qualitativamente, como positivos ou negativos, segundo os conceitos e definições propostas por BRILHANTE \& CALDAS (1999) e OREA (1994). Foi construída uma matriz (Tabela 4), na qual os impactos ambientais diretos foram avaliados em função do tipo de resíduo disposto (resíduo sólido urbano, resíduo perigoso e resíduo dos serviços de saúde); e de suas características físicas, químicas e biológicas. A avaliação dos impactos ambientais foi realizada considerando, como impacto, todos os efeitos sobre os fatores ambientais (meio físico - água superficial, água subterrânea, ar, solo e paisagem; meio biológico - macrofauna, microfauna, macroflora e microflora; meio antrópico), e os fatores socioeconômicos, relatados na bibliografia pesquisada (PEAVY et al., 1987; EPA, 1994; AZEVEDO, 1995; GIROULT \& BROWN, 1996; COAD, 1996; PALMISANO \& BARLAZ, 1996; DIAZ et al., 1996; CEPIS, 1997; JARAMILLO, 1997; ACURIO et al., 1998; BARROS, 1998). Na avaliação dos impactos ambientais, foi dada ênfase aos possíveis efeitos da alteração destes fatores sobre a saúde pública. 
TABELA 4 - Avaliação dos impactos ambientais ocasionados pela disposição ambiental inadequada dos resíduos sólidos

Legenda:

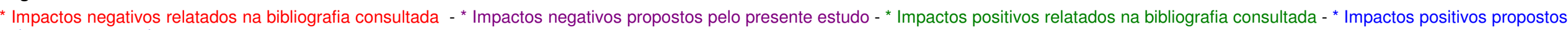
pelo presente estudo

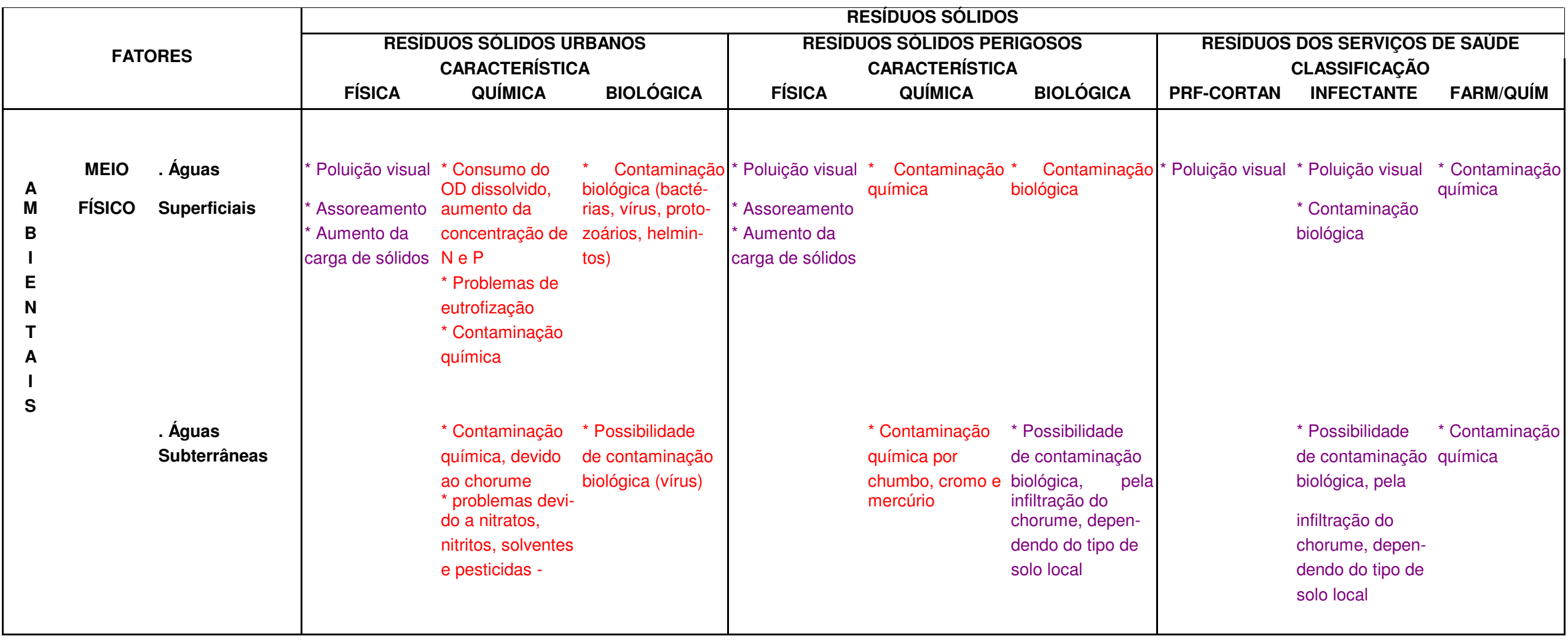




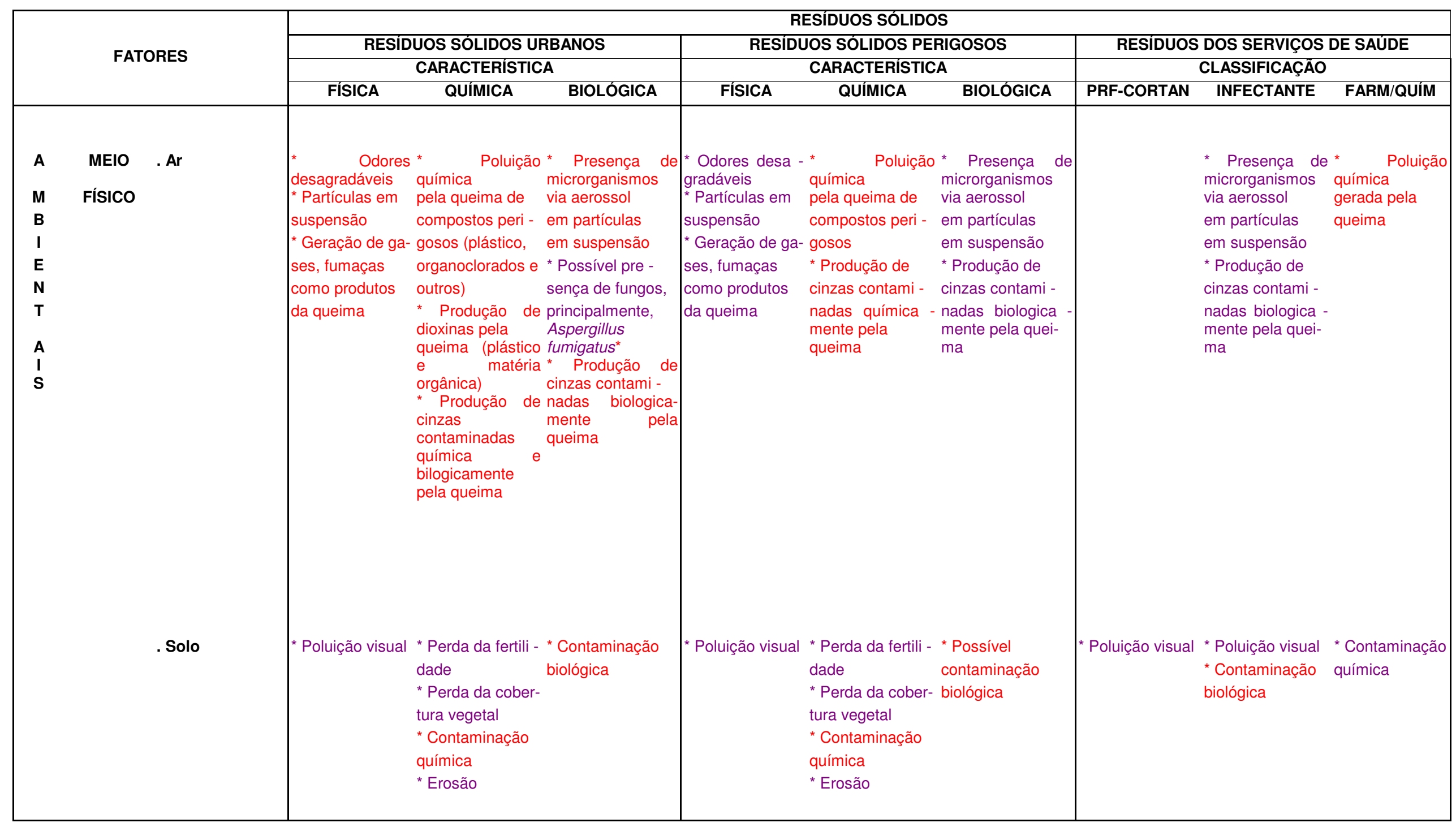




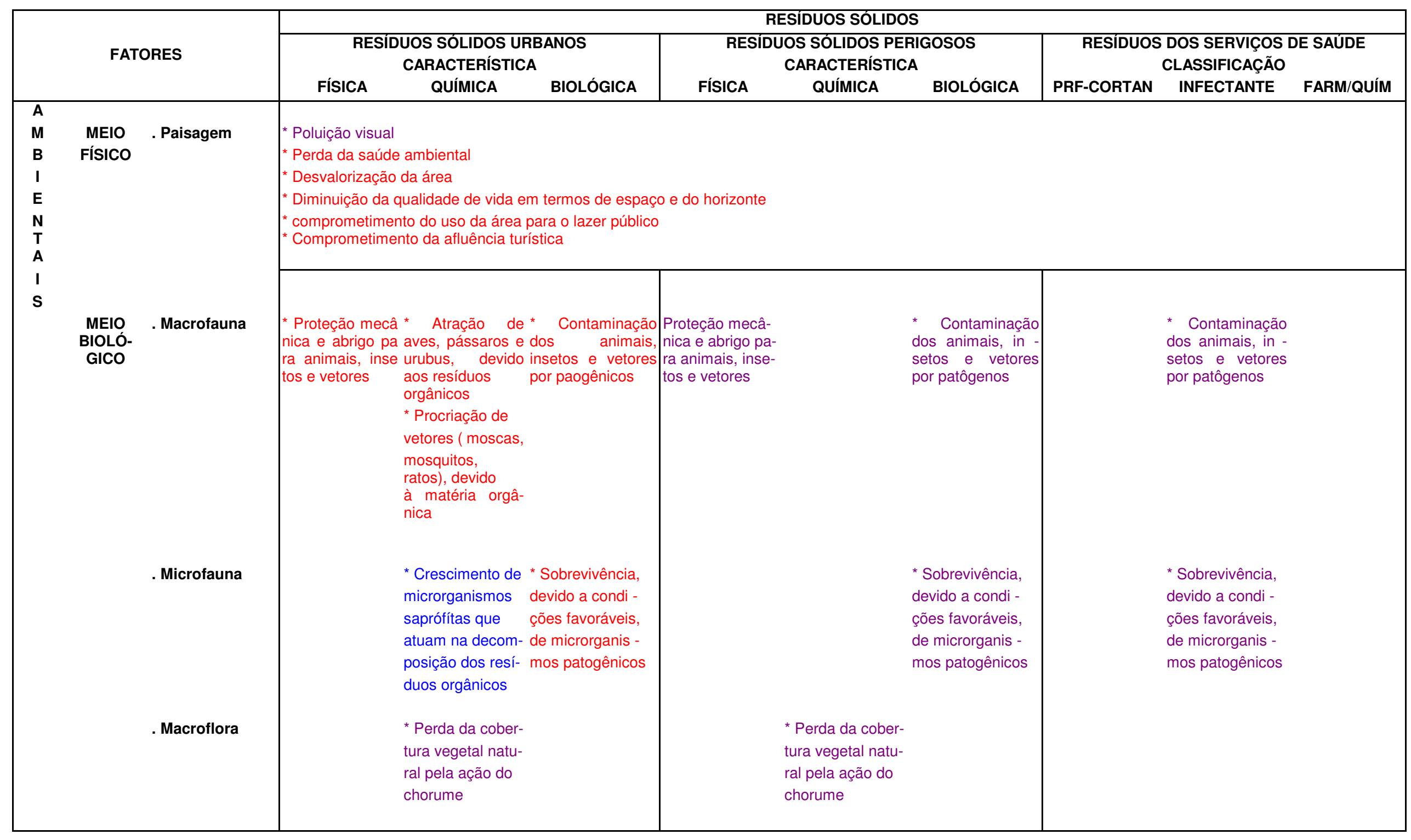




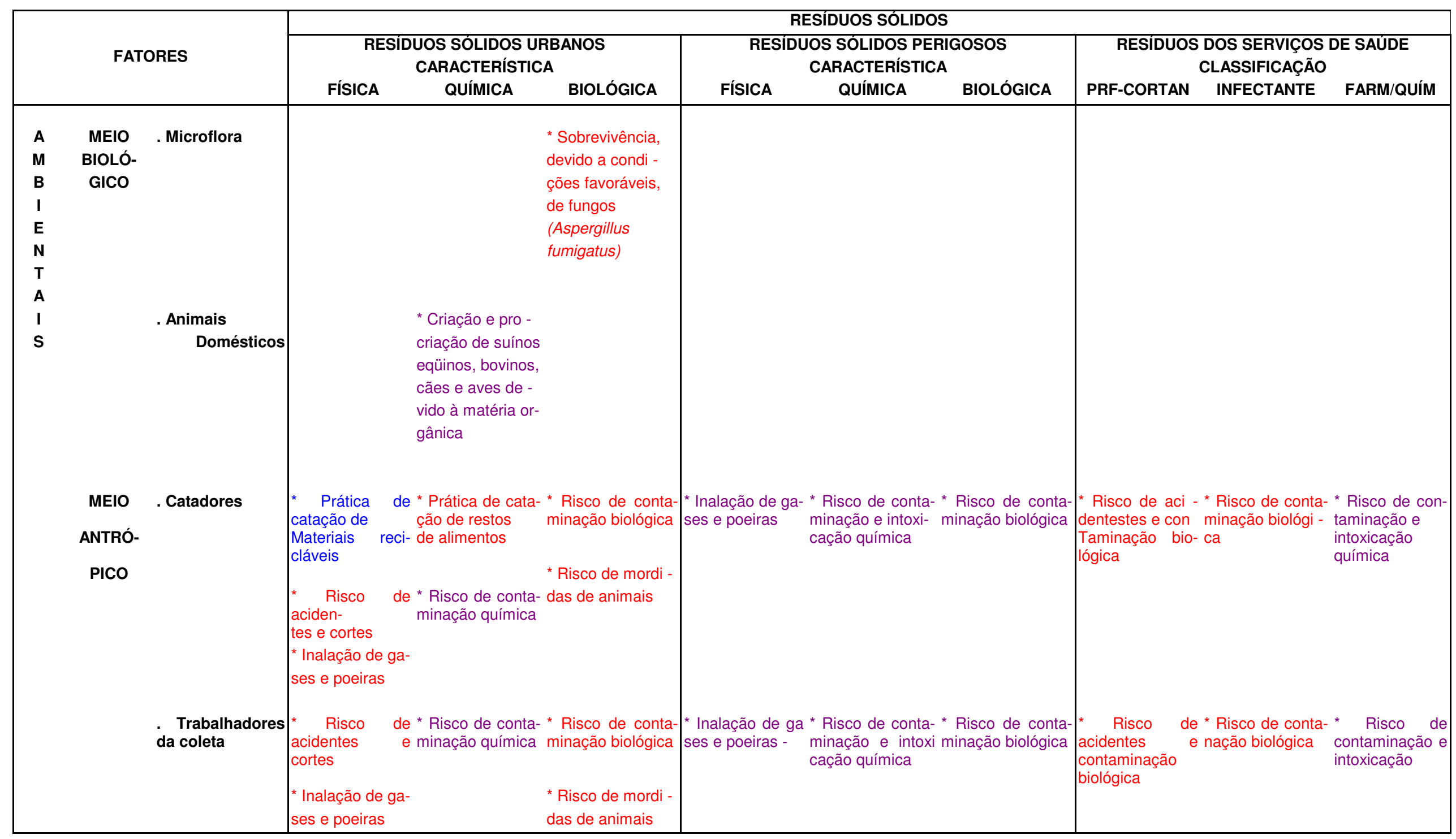




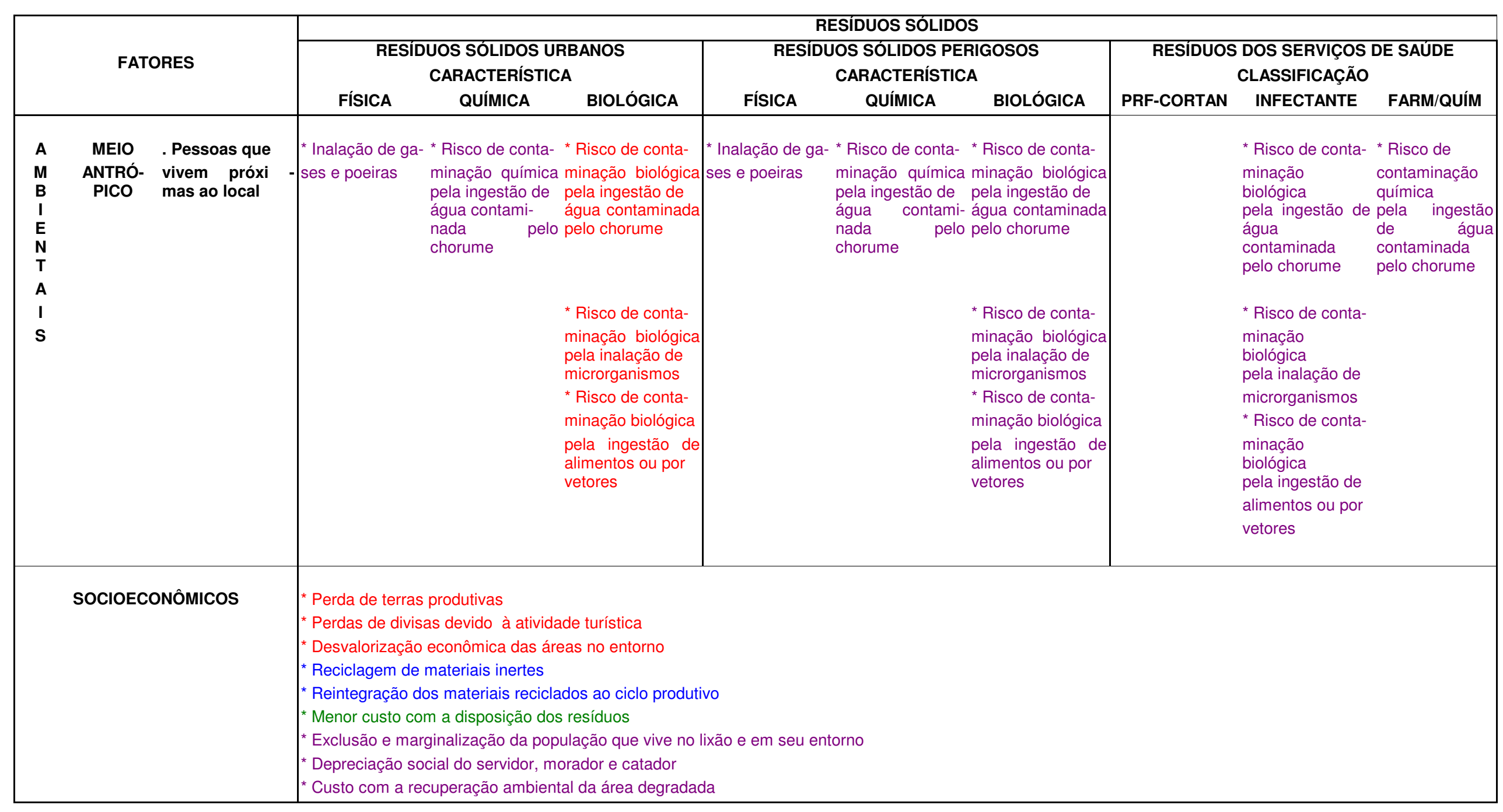




\subsection{Relação: Resíduos Sólidos, Ambiente e Saúde Pública}

Pelo exposto nos itens anteriores e pelos resultados obtidos dos estudos apresentados, torna-se evidente os riscos para a saúde pública decorrentes do contato direto ou indireto com os resíduos sólidos. NAJM apud HELLER (1997) propõe um esquema das vias de contato lixo-homem (Figura 1) que, sinteticamente, explica as trajetórias pelas quais pode ocorrer a transmissão de doenças oriundas da disposição inadequada dos resíduos sólidos urbanos.

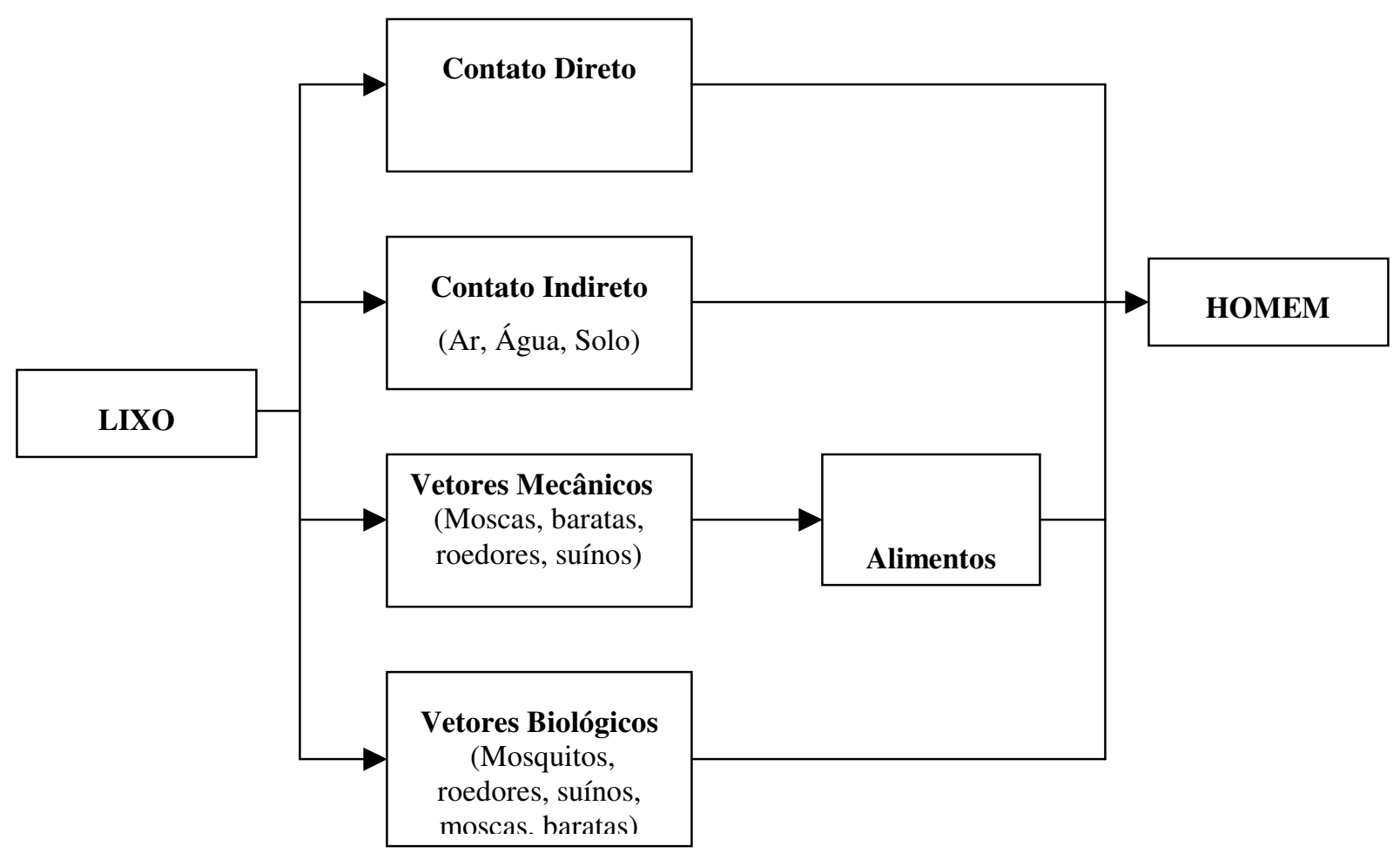

Fonte: NAJM apud HELLER (1997)

FIGURA 1 - Esquema de vias de contato homem-lixo 
Observa-se, pela análise da Figura 1, a diversidade das vias de transmissão das doenças ou agravos à saúde relacionados aos resíduos sólidos, tornando-se difícil sua caracterização e a definição do raio de exposição ao qual o ser humano pode estar exposto, principalmente, quando considerados os fatores de exposição ambiental indiretos e a ação dos vetores biológicos e mecânicos.

GIROULT \& BROWN (1996) consideram como grupos de risco, sujeitos aos impactos adversos sobre a saúde pública advindos com o gerenciamento inadequado dos resíduos sólidos, os seguintes grupos:

- a população de áreas não atendidas pelos serviços de coleta, especialmente crianças na idade pré-escolar;

- os trabalhadores dos serviços de limpeza urbana, principalmente os operadores e coletores de resíduos;

- as pessoas que trabalham com produtos infecciosos, tóxicos e carcinogênicos;

- as pessoas residentes próximas aos locais de disposição final de resíduos sólidos;

- a população abastecida com água poluída devido à disposição inadequada dos resíduos no solo.

Cabe acrescentar a esse grupo, os catadores de lixo, que têm contado direto com os resíduos. ACURIO et al. (1998) consideram também como grupo exposto, a população de forma geral, a qual está sujeita aos impactos ocasionados pela disposição dos resíduos sólidos no meio ambiente, por meio da contaminação de corpos d'água superficiais e subterrâneos. Os mesmos autores chamam atenção para o fato que, quando considerada a disposição ambiental de resíduos perigosos, toda a 
população urbana deve ser considerada como exposta.

Apesar de reconhecidos os riscos para a saúde pública da disposição inadequada dos resíduos sólidos e as vias de contaminação pela qual a população exposta está sujeita, não se tem comprovado na bibliografia especializada a causalidade da relação: disposição ambiental inadequada dos resíduos sólidos urbanos versus doença, mesmo quando considerada a transmissão por vetores biológicos.

DIAZ et al. (1996) afirmam que, embora seja certo que vetores (insetos e roedores) podem transmitir vários agentes patogênicos (disenteria amebiana e bacilar, febre tifóide, salmonelose, várias parasitoses, cólera, febre amarela, peste e outras), é freqüentemente difícil traçar os efeitos de tal transmissão a uma população específica.

Contudo, ao se analisar os aspectos sanitários e epidemiológicos da disposição inadequada dos resíduos sólidos, há de se considerar o caráter temporário e transitório de permanência de alguns vetores nos lixões. Este fato assume grande importância na transmissão de várias doenças. Dois estudos realizados, na cidade de Santiago do Chile, em 1953 (OPAZO, 1969), e na cidade do Cairo, Egito (DANIEL, et al., 1989), podem elucidar esse fato.

A primeira pesquisa constituiu-se em um estudo bacteriológico e da flora entérica transportada por moscas. Os autores estudaram a flora microbiana de mil moscas repartidas em 85 amostras, formadas cada uma por 5 a 20 exemplares capturados em um mesmo sítio. As Tabelas 5, 6, 7 e 8 apresentam, de forma resumida, os resultados obtidos.

Este estudo demonstrou que $84,7 \%$ das amostras estavam contaminadas com 
microrganismos da família Enterobacteriaceae. Destas, 12,5 \% eram espécies patogênicas específicas. Em 63 dos 85 lotes, ou seja, em $74 \%$, continham Enterobacteriaceae capaz de provocar intoxicações alimentares.

Este estudo comprovou que as moscas do tipo doméstico são portadoras de microrganismos patogênicos, especialmente da flora entérica. Este fato tem íntima relação com a morbidade e mortalidade por enfermidades diarréicas e infecções entéricas, principalmente em crianças menores de um ano de idade. Também são observadas as presenças de microrganismos chamados oportunistas em infecção hospitalares, como Proteus e Klebsiella, que podem estar relacionadas com a prevalência desses microrganismos em infecções hospitalares.

No estudo realizado na cidade do Cairo, Egito, foi pesquisada, em dois locais de disposição final de resíduos sólidos (lixões de Mokattam e Ezbel el Nakhl), a presença de artrópodes. Os pesquisadores identificaram 56 espécies de artrópodes vivendo tanto nos locais de disposição dos resíduos sólidos, quanto nas favelas vizinhas. Dentre as espécies identificadas, destacam-se, por sua importância epidemiológica, as seguintes, em ordem decrescente de prevalência (DANIEL, et. al., 1989):

- Pulga Xenopsylla cheopis em roedores (Rattus norvegicus), estando estes em contato próximo com a população local.

- Pulga Ctenocephalides felis felis, parasita não só de roedores como também do homem e de cachorro, podendo também viver livremente em áreas não habitadas pelo ser humano.

- Carrapato-Ripicephalus sanguineus.

- Moscas sinantrópicas - Musca domestica vicina, Musca sorbens e 
Piophila casei.

TABELA 5 - Microrganismos isolados em 1000 moscas agrupadas em 85 lotes, tomados em diversas partes da cidade de Santiago do Chile

\begin{tabular}{|c|c|}
\hline Microorganismo & $\mathrm{N}^{\circ}$ de cepas \\
\hline Enterobacteriaceae & 133 \\
\hline Eberthella typhosa & 1 \\
\hline Salmonella & 6 \\
\hline Shigella & 2 \\
\hline Paracolobactrum & 47 \\
\hline Proteus & 20 \\
\hline Escherichia & 28 \\
\hline Alcalescens & 1 \\
\hline Klebsiella & 15 \\
\hline Coliformes & 12 \\
\hline Serratias & 1 \\
\hline Pseudomonaceae & 4 \\
\hline Pseudomona & 4 \\
\hline Achromobacteriaceae & 13 \\
\hline Alcaligenes & 2 \\
\hline Achromobacter & 11 \\
\hline Micrococaceas & 11 \\
\hline \multicolumn{2}{|l|}{ Micrococus } \\
\hline Total & 161 \\
\hline
\end{tabular}

Fonte: OPAZO, 1969. 
TABELA 6 - Proporção de microrganismos de diferentes gênero isolados em 1000 moscas agrupadas em 85 lotes, tomados em diversas partes da cidade de Santiago do Chile

\begin{tabular}{l|c|c}
\hline \multicolumn{1}{c|}{ Microrganismos } & $\begin{array}{c}\text { Frequiência } \\
\text { (Amostras positivas) }\end{array}$ & Porcentagem \\
\hline E. typhosa & 1 & 1,2 \\
\hline Salmonella & 6 & 7,0 \\
\hline Shigella & 2 & 74,1 \\
\hline Outras Enterobcteriaceae & 63 & 15,3 \\
\hline Outros gêneros & 13 & 100,0 \\
\hline Total de amostra & 85 & \\
\hline
\end{tabular}

Fonte: OPAZO, 1969.

TABELA 7 - Proporção de Enterobcteriaceae em 1000 moscas agrupadas em 85 lotes, tomados em diversas partes da cidade de Santiago do Chile

\begin{tabular}{l|c|c}
\hline \multicolumn{1}{c|}{ Microrganismos } & Freqüência & Porcentagem \\
\hline Enterobcteriaceae & 72 & 84,7 \\
\hline Outras famílias & 13 & 15,3 \\
\hline Total & 85 & 100,0 \\
\hline
\end{tabular}

Fonte: OPAZO, 1969. 
TABELA 8 - Proporção de microrganismos de vários gêneros da família Enterobcteriaceae isolados em 1000 moscas agrupadas em 85 lotes, tomados em diversas partes da cidade de Santiago do Chile

\begin{tabular}{l|c|c}
\hline \multicolumn{1}{c|}{ Microrganismos } & $\begin{array}{c}\text { Frequiência } \\
\text { (Amostras positivas) }\end{array}$ & Porcentagem \\
\hline Eberthella & 1 & 1,4 \\
\hline Salmonella & 6 & 8,3 \\
\hline Shigella & 2 & 2,8 \\
\hline Outros microrganismos & 63 & 87,5 \\
\hline Total & 72 & 100,0 \\
\hline
\end{tabular}

Fonte: OPAZO, 1969.

A Tabela 9 apresenta o resultado da pesquisa de artrópodes, realizada por DANIEL et al. (1989), em dois locais de disposição final de resíduos sólidos, na cidade do Cairo, Egito.

Por outro lado, segundo estudos efetuados pela Organização Pan-americana de Saúde, as práticas higiênicas de acondicionamento e transporte dos resíduos sólidos em ambiente fechado e a destinação final realizada com controle sanitário, reduzem em $90 \%$ a existência de moscas e em $65 \%$ a população de roedores (SENGÉS, 1969). 
TABELA 9 - Identificação dos artrópodes encontrados em dois locais de disposição final de resíduos sólidos ( Mokattan e Ezbel el Nakhl) da cidade do Cairo, Egito.

\begin{tabular}{|c|c|c|c|c|c|c|c|c|c|c|c|c|c|}
\hline \multirow{2}{*}{$\begin{array}{r}\text { Localidade } \\
\text { Habitat }\end{array}$} & \multicolumn{4}{|c|}{ Mokattam } & \multicolumn{9}{|c|}{ Ezbel el Nakhl } \\
\hline & Lixão & \multicolumn{3}{|c|}{ Favelas vizinhas } & \multicolumn{2}{|c|}{ Lixão } & \multicolumn{3}{|c|}{ Favelas vizinhas } & \multicolumn{4}{|c|}{ Animais e locais de abrigo } \\
\hline $\begin{array}{l}\text { Artrópodes } \\
\text { identificados }\end{array}$ & $\begin{array}{c}\text { Resí- } \\
\text { duo } \\
\text { dispos- } \\
\text { to } \\
(1)\end{array}$ & $\begin{array}{c}\begin{array}{c}\text { Local } \\
\text { de } \\
\text { dormir }\end{array} \\
\text { (2) }\end{array}$ & $\begin{array}{c}\text { Quintal } \\
\text { (3) }\end{array}$ & $\begin{array}{l}\text { Local de } \\
\text { disposi- } \\
\text { ção das } \\
\text { fezes } \\
\text { (4) }\end{array}$ & $\begin{array}{c}\text { Resí- } \\
\text { duo } \\
\text { dispos- } \\
\text { to } \\
(5)\end{array}$ & $\begin{array}{l}\text { Cadáve- } \\
\text { res de } \\
\text { roedores } \\
\text { Rattus } \\
\text { norvegicus } \\
\text { (6) }\end{array}$ & $\begin{array}{c}\text { Cozinha } \\
\text { (7) }\end{array}$ & $\begin{array}{c}\text { Quintal } \\
\text { (8) }\end{array}$ & $\begin{array}{c}\text { Local de } \\
\text { armaze- } \\
\text { namento } \\
\text { de ali- } \\
\text { mentos } \\
(9)\end{array}$ & $\begin{array}{l}\text { Canil } \\
\text { (10) }\end{array}$ & $\begin{array}{c}\text { Roedor } \\
\text { (11) }\end{array}$ & $\begin{array}{c}\text { Pombo } \\
\\
\text { (12) }\end{array}$ & $\begin{array}{c}\text { Gali- } \\
\text { nheiro } \\
\text { (13) }\end{array}$ \\
\hline $\begin{array}{l}\text { ARANEIDEA } \\
\text { Eresidae } \\
\text { Steodyphus dufori }\end{array}$ & & & & & & & + & + & 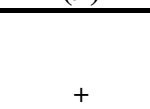 & & & & \\
\hline $\begin{array}{l}\text { ACARINA } \\
\text { Macrochelidae g. et sp. } \\
\text { Androlaeps casalis casalis } \\
\text { Uropodidae g.et sp. } \\
\text { Cheyletidae } \\
\text { Cheyletus eruditus } \\
\text { Ixodidae } \\
\text { Rhipicephalus sanguineus } \\
\text { Acaridae } \\
\text { Acotyledon Krameri } \\
\text { Caloglyphus berlesi } \\
\text { Suidasia pontifer } \\
\text { Rhizoglyphus sp. }\end{array}$ & & & $\begin{array}{l}+ \\
+ \\
+\end{array}$ & $\begin{array}{l}+ \\
+ \\
+\end{array}$ & & & & & & + & & $\begin{array}{l}+ \\
+ \\
+\end{array}$ & \\
\hline $\begin{array}{c}\text { BLANTARIA } \\
\text { Periplaneta americana }\end{array}$ & & & & & & & & & + & & & & \\
\hline $\begin{array}{l}\text { DERMAPTERA } \\
\text { Formiculae }\end{array}$ & & & & & & & & & & & & + & \\
\hline $\begin{array}{l}\text { PSOCOPTERA } \\
\text { Larvae, ident. }\end{array}$ & & & & & & & & & & & & + & \\
\hline \begin{tabular}{l}
\multicolumn{1}{c}{ HETEROPTERA } \\
\multicolumn{1}{c}{ Xylocoridae } \\
$\begin{array}{l}\text { Xylocoris } \\
\text { galactinus }\end{array}$ \\
$\begin{array}{l}\text { Xylocoris } \\
\text { confusus }\end{array}$
\end{tabular} & & & $\begin{array}{l}+ \\
+\end{array}$ & & & & & & & & & & \\
\hline
\end{tabular}


Tabela 9 - Continuação

\begin{tabular}{|c|c|c|c|c|c|c|c|c|c|c|c|c|c|}
\hline $\begin{array}{c}\text { Artrópodes } \\
\text { identificados }\end{array}$ & 1 & 2 & 3 & 4 & 5 & 6 & 7 & 8 & 9 & 10 & 11 & 12 & 13 \\
\hline $\begin{array}{l}\text { HYMENOPTERA } \\
\text { Formicidae } \\
\text { Formicinae ssp. } \\
\text { Myrmicinae } \\
\text { Tetramorium sp. } \\
\text { Cataglyphis ssp. }\end{array}$ & & + & $\begin{array}{l}+ \\
+\end{array}$ & & & & & & & & & & \\
\hline $\begin{array}{c}\text { COLEOPTERA } \\
\text { Histeridae } \\
\text { Carcinops pumilo } \\
\text { Cleridae } \\
\text { Necrobia rufipes } \\
\text { Dermestidae } \\
\text { Dermestes frischi } \\
\text { Attagenus ssp. } \\
\text { Dermetes } \text { sp. (Larvae) } \\
\text { Cucujidae } \\
\text { Laemophloeus sp. } \\
\text { Bostruchidae } \\
\text { Rhizopertha dominica } \\
\text { Bostrychidae } \text { g. et sp. } \\
\text { Anobiidae } \\
\text { Stagobium panicem } \\
\text { Ptinidae } \\
\text { Mezium affine } \\
\text { Tenebrionidae } \\
\text { Alphitobius diapenerinus } \\
\text { Blaps polychresta } \\
\text { Palorus subdepressus } \\
\text { Palorus subfilum } \\
\text { Tribolium castaneum } \\
\text { Scarabaeidae } \\
\text { Larvae indet. } \\
\text { Curculionidae } \\
\text { Calandra sp. } \\
\text { Colydiiae } \\
\text { Anommatus sp. }\end{array}$ & & & $\begin{array}{l}+ \\
+\end{array}$ & + & & & & $\begin{array}{l}+ \\
+\end{array}$ & & & & $\begin{array}{l}+ \\
+ \\
+ \\
+ \\
+ \\
+ \\
+\end{array}$ & + \\
\hline \begin{tabular}{l}
\multicolumn{1}{c}{ DIPTERA } \\
Drosophilidae \\
Drosophila repleta \\
Drosophila melangaster \\
$\quad$ Sphaeroceridae \\
Coproica hirtula \\
Coproica vagans
\end{tabular} & & $\begin{array}{l}+ \\
+ \\
+\end{array}$ & $\begin{array}{l}+ \\
+\end{array}$ & $\begin{array}{l}+ \\
+\end{array}$ & + & & & & $\begin{array}{l}+ \\
+\end{array}$ & & & & \\
\hline
\end{tabular}


Tabela 9 - Continuação

\begin{tabular}{|c|c|c|c|c|c|c|c|c|c|c|c|c|c|}
\hline $\begin{array}{c}\text { Artrópodes } \\
\text { identificados }\end{array}$ & 1 & 2 & 3 & 4 & 5 & 6 & 7 & 8 & 9 & 10 & 11 & 12 & 13 \\
\hline $\begin{array}{c}\text { Milichidae } \\
\text { Desmometopa trasalis } \\
\text { Cardidae } \\
\text { Meoneura sp } \\
\text { Piophilidae } \\
\text { Phiophila casei } \\
\text { Muscidae } \\
\text { Musca domestica } \\
\text { Musca sorbens } \\
\text { Hybotidae } \\
\text { Drapetis sp. } \\
\text { Phoridae } \\
\text { Dohrniphora cornuta } \\
\text { Megaselia giraudi } \\
\text { Sciaridae g. et sp. } \\
\text { Empididae g. et sp. }\end{array}$ & $\begin{array}{l}+ \\
+ \\
+ \\
+\end{array}$ & + & $\begin{array}{l}+ \\
+\end{array}$ & + & $\begin{array}{l}+ \\
+\end{array}$ & + & + & + & + & + & & & \\
\hline $\begin{array}{c}\text { SIPHONAPTERA } \\
\text { Pulicidae } \\
\text { Xenopsylla cheopis } \\
\text { Ctenocephalides felis felis }\end{array}$ & & + & + & & & & & & & + & $\begin{array}{l}+ \\
+\end{array}$ & & \\
\hline
\end{tabular}

Fonte: DANIEL et al., 1989. 


\subsection{Classificação Ambiental para as Doenças Relacionadas à Água, às Excretas e aos Resíduos Sólidos}

A engenharia de saúde pública tem como enfoque a realização de ações que modifiquem as condições ambientais de risco para a saúde. Para que essas ações possam ser bem sucedidas, revertendo na melhoria das condições de saúde das comunidades, é importante que as doenças sejam classificadas sobre uma ótica ambiental, por meio da qual as doenças infecciosas possam ser classificadas em categorias relacionadas aos aspectos ambientais e às estratégias adequadas de prevenção e de controle dos mecanismos de transmissão (AZEVEDO \& AZEVEDO, 2003).

No final da década de 1970, esforços foram empreendidos no sentido de se estudarem as doenças infecciosas, sob o enfoque das estratégias mais adequadas para seu controle (HELLER, 1995). Nessa visão, as doenças são classificadas tendo por base suas vias de transmissão e seu ciclo, distintamente da classificação biológica clássica, que agrupa as doenças segundo o agente etiológico: vírus, bactéria, protozoário ou helminto (FEACHEM et al., 1983).

White, Bradley e White apresentaram em 1972 a primeira classificação ambiental para as doenças infecciosas relacionadas à água (MARA \& FEACHEM, 1999). Posteriormente, essa classificação foi modificada por Feachem (FEACHEM, 1975). A Tabela 10 apresenta a classificação ambiental das infecções relacionadas à água, proposta por FEACHEM (1975). 
TABELA 10 - Classificação ambiental das infecções relacionadas à água

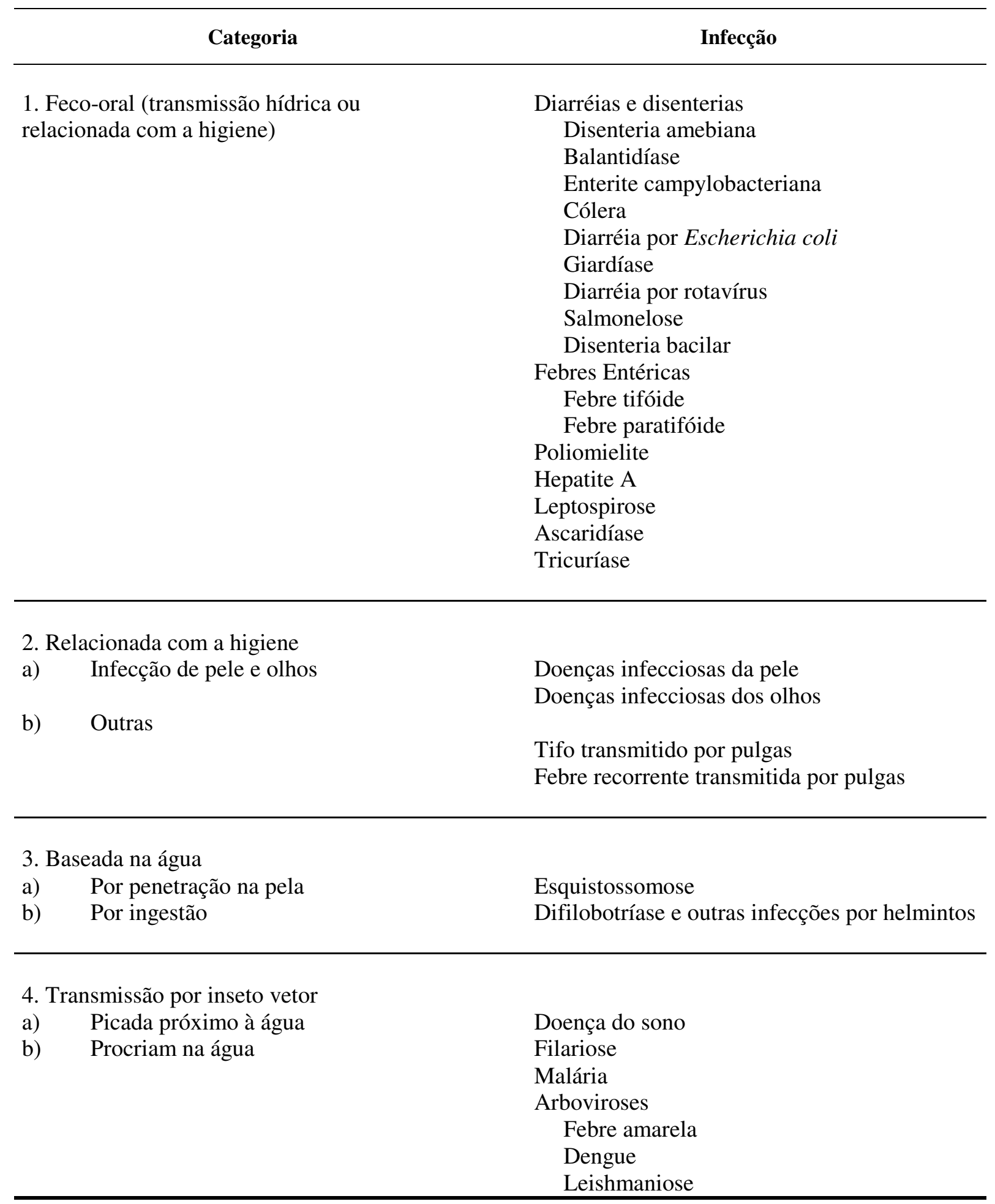

Fonte: CAIRNCROSS \& FEACHEM (1990).

Posteriormente, FEACHEM et al. (1983) desenvolveram uma classificação 
ambiental para as doenças relacionadas com as excretas, agrupando-as em cinco categorias (Tabela 11). Os autores utilizaram o mesmo raciocínio desenvolvido para a classificação ambiental das doenças relacionadas com a água, ou seja, as enfermidades foram classificadas em função dos mecanismos de transmissão.

\section{TABELA 11 - Doenças relacionadas com as excretas}

\begin{tabular}{ll}
\hline \multicolumn{1}{c}{ Categoria } & \multicolumn{1}{c}{ Infecção } \\
\hline 1. Doenças Feco-orais não bacteriana & Enterobíase \\
& Infecções Enteroviróticas \\
& Heminolepíase \\
& Amebíase, Giardíase \\
& Balantidíase \\
\hline 2. Doenças Feco-orais bacterianas & Febre tifóide e paratifóide, Salmoneloses \\
& Disenteria bacilar \\
& Cólera \\
& Diarréia por $E$. coli \\
& Enterite campylobacteriana \\
\hline 3. Helmintos no solo & Ascaridíase \\
& Tricuríase \\
\hline 4. Teníases & Ancilostomíase \\
\hline 5. Helmintos Hídricos & Teníases \\
\hline
\end{tabular}

Fonte: FEACHEM et al. (1983); CAIRNCROSS \& FEACHEM (1990).

Apesar da classificação ambiental das doenças infecciosas estar bem estabelecida para as doenças relacionadas à água e às excretas, muito ainda tem que ser feito em relação às doenças relacionadas aos resíduos sólidos.

MARA e ALABASTER (1995) apresentaram uma classificação ambiental 
para as enfermidades transmissíveis relacionadas aos resíduos sólidos. Os autores introduziram uma sexta categoria na classificação ambiental das doenças infecciosas - as doenças relacionadas aos vetores, controladas por práticas de higiene doméstica, coleta e disposição adequada dos resíduos sólidos. A Tabela 12 apresenta essa classificação.

TABELA 12 - Classificação ambiental das enfermidades transmissíveis relacionadas aos resíduos sólidos

\begin{tabular}{l|l|l}
\hline \multicolumn{1}{c|}{ Categoria } & \multicolumn{1}{|c}{ Doenças } & \multicolumn{1}{c}{ Controle } \\
\hline $\begin{array}{l}\text { 1. Doenças relacionadas com } \\
\text { insetos vetores }\end{array}$ & $\begin{array}{l}\text { Infecções excretadas transmi- } \\
\text { tidas por moscas ou baratas } \\
\text { Filariose } \\
\text { Tularemia }\end{array}$ & $\begin{array}{l}\text { Melhoria do acondicionamento } \\
\text { e da coleta do lixo } \\
\text { Controle de insetos }\end{array}$ \\
\hline $\begin{array}{l}\text { 2. Doenças relacionadas com } \\
\text { vetores roedores }\end{array}$ & $\begin{array}{l}\text { Peste } \\
\text { Leptospirose } \\
\text { Demais doenças relacionadas } \\
\text { com a moradia, a água e os } \\
\text { excretas e cuja transmissão } \\
\text { ocorre por roedores }\end{array}$ & $\begin{array}{l}\text { Melhoria do acondicionamento } \\
\text { e da coleta do lixo de roedores }\end{array}$ \\
\hline
\end{tabular}

Fonte: MARA \& ALABASTER (1995)

Por entender a complexidade das vias de transmissão e dos fatores causais das doenças relacionadas aos resíduos sólidos e com intuito de preencher a lacuna existente na bibliografia especializada, será apresentada a seguir uma classificação ambiental para as doenças relacionadas aos resíduos sólidos. Esta classificação foi desenvolvida a partir da preocupação, da necessidade e da importância da gestão dos resíduos sólidos urbanos ser aliada aos aspectos de saúde pública. 
Para o desenvolvimento da classificação ambiental para as doenças e os agravos à saúde relacionados aos resíduos sólidos, apresentada na Tabela 13, foram considerados os seguintes aspectos:

- Toda atividade de gestão de resíduos envolve riscos diversos à saúde pública, quer seja pela própria composição ou natureza do resíduo, quer seja pela forma de gerenciamento dada aos resíduos, durante o seu ciclo de vida.

- Entender os riscos envolvidos em cada etapa do gerenciamento dos resíduos sólidos, a população exposta e sujeita a estes riscos, bem como os tipos de controle ambiental e sanitário, tornam-se fundamentais para qualquer sistema de gestão comprometida com a saúde pública.

- Os riscos para a saúde associados a fatores ambientais foram enfatizados. Mas também, foram considerados os riscos ocupacionais, aos quais estão sujeitos tanto os trabalhadores dos sistemas de limpeza urbana, quanto os trabalhadores envolvidos com as atividades formais ou informais de reciclagem - os "catadores de lixo".

- Os impactos e as alterações ambientais, avaliados nos itens 2.3 e 2.4 e compilados na Tabela 4, representam fatores de risco para a população exposta.

- Foram consideradas todas as doenças, citadas na bibliografia consultada, passíveis de ocorrerem via resíduos sólidos, como conseqüência:

a. das alterações ambientais provocadas pela disposição ambiental, pelos processos de tratamento e tecnologias empregadas nas etapas de gerenciamento dos resíduos sólidos;

b. da introdução ou da presença no ambiente, nos resíduos sólidos, no chorume ou em células de aterros sanitários, do bioagente, do agente 
químico ou do vetor mecânico ou biológico relacionados às doenças, identificados por algum dos estudos pesquisados, expressos nos itens anteriores;

c. da realização de estudos epidemiológicos que avaliaram os riscos e identificaram os efeitos sobre a saúde do manejo dos resíduos sólidos (item 2.1).

- A identificação das doenças relacionadas aos resíduos sólidos foi baseada na seguinte bibliografia: KNOLL, 1961; GOLUEKE, 1977; NEVES, 1979; WILLSON et al., 1980; BUDNICK et. al., 1984; VIANNA \& POLAN, 1984; OBENG \& WRIGHT, 1987; PAHREN, 1987; PAIGEN et al., 1987; GRIFFITH et al., 1989; MALLIN, 1990; FEDORAK \& ROGERS, 1991; GESCHWIND et al., 1992; AZEVEDO, 1993; MERCEDES et al., 1993; AZEVEDO, 1995; GOLDBERG et al. 1995a e 1995b; HELLER, 1995; HELLER \& MÖLLER, 1995; GERBA, 1996; GIROULT \& BROWN, 1996; PALMISANO \& BARLAZ, 1996; DIAZ et al., 1996; BERRY \& BOVE, 1997; JARAMILLO, 1997; KHARRAZI, et al., 1997; ACURIO et al., 1998; AHUMADA, 1998; MORAES, 1998.

- A população sujeita ao risco foi dividida em dois grandes grupos, relacionados às formas de exposição ambiental e ocupacional ao fator de risco.

- O primeiro grupo foi composto pelas pessoas que têm contato com os resíduos devido à natureza de sua atividade profissional. Incluiu-se nesta categoria os trabalhadores dos sistemas de gestão de resíduos e as pessoas que exercem atividades relacionadas à reciclagem. Este grupo está sujeito aos riscos à saúde, relativos à ocupação profissional.

- O segundo grupo foi constituído pela população residente próxima a áreas 
utilizadas para o tratamento ou a disposição final dos resíduos sólidos. Os riscos à saúde aos quais esta parcela da população está sujeita são relacionados aos fatores ou às alterações ambientais ocorrentes nestes locais.

A classificação ambiental para as doenças relacionadas aos resíduos sólidos, proposta por este estudo (Tabela 13), foi baseada na proposta metodologia apresentada por AZEVEDO et al. (2000).

\subsection{Tipos de Estudos Epidemiológicos}

Segundo ROUQUAYROL \& ALMEIDA FILHO (1999) denomina-se de metodologia epidemiológica as estratégias, as técnicas e os procedimentos estruturados de pesquisa que são aplicados na investigação dos processos saúdedoença-cuidado em populações humanas. Convencionalmente, cinco são as estratégias básicas de pesquisas: estudos ecológicos, estudos seccionais, estudo de coorte, estudos de caso-controle e ensaios clínicos. A Tabela 14 apresenta a tipologia dos desenhos de investigação em epidemiologia. 
TABELA 13 - Classificação ambiental para as doenças relacionadas aos resíduos sólidos

\begin{tabular}{|c|c|c|c|c|c|c|c|c|c|c|c|}
\hline \multirow{2}{*}{$\begin{array}{c}\text { Formas de } \\
\text { Exposição } \\
\text { Ambiental ao } \\
\text { Fator de } \\
\text { Risco } \\
\end{array}$} & \multirow[t]{2}{*}{ Categoria } & \multirow{2}{*}{$\begin{array}{c}\text { Formas de } \\
\text { Transmissão ou } \\
\text { Contágio }\end{array}$} & \multirow[t]{2}{*}{ Doença } & \multicolumn{4}{|c|}{ Agente Etiológico } & \multirow[t]{2}{*}{ Vetor } & \multirow{2}{*}{$\begin{array}{l}\text { Tipo de } \\
\text { Estudo }\end{array}$} & \multirow{2}{*}{$\begin{array}{c}\text { População Exposta ao Fator } \\
\text { de Risco }\end{array}$} & \multirow{2}{*}{$\begin{array}{c}\text { Profilaxia } \\
\text { Controle Ambiental e Sanitário }\end{array}$} \\
\hline & & & & Nomenclatura & Persistência & $\begin{array}{c}\text { Dose } \\
\text { infeccio } \\
\text { sa }\end{array}$ & \begin{tabular}{|c|} 
Reserva \\
tório
\end{tabular} & & & & \\
\hline \multirow[t]{13}{*}{$\begin{array}{l}1 . \\
\text { Contato com } \\
\text { os Resíduos } \\
\text { ou Solo Con- } \\
\text { taminado }\end{array}$} & \multirow[t]{13}{*}{$\begin{array}{l}1.1 \\
\text { Transmissão } \\
\text { Feco-oral }\end{array}$} & \multirow{13}{*}{$\begin{array}{l}\text { Transmissão } \\
\text { indireta do bio- } \\
\text { agente por meio } \\
\text { da ingestão de } \\
\text { restos de } \\
\text { alimentos } \\
\text { contaminados ou } \\
\text { pelo manuseio } \\
\text { inadequado dos } \\
\text { alimentos }\end{array}$} & Diarréia & $\begin{array}{l}\text { Campylobacter } \\
\text { fetus } \quad \text { ssp. } \\
\text { Jejuni (B) }\end{array}$ & $\begin{array}{c}10 \text { dias a } 20 \\
\text { e } 37^{\circ} \mathrm{C} \\
20 \text { dias a } 6^{\circ} \mathrm{C} \\
\text { (solo) }\end{array}$ & \begin{tabular}{|l}
$10^{6} \mathrm{C}$ \\
fetus \\
ssp. \\
jejuni $i^{(\mathrm{d})}$
\end{tabular} & $\begin{array}{l}\text { Homem, } \\
\text { suínos, } \\
\text { bovinos, } \\
\text { ovinos, } \\
\text { aves e } \\
\text { pássaros } \\
\text { domésti } \\
\text { cos }\end{array}$ & - & $\begin{array}{l}(2) ; \\
(4)^{* *}\end{array}$ & \multirow[t]{13}{*}{$\begin{array}{l}\text { - Trabalhadores da coleta } \\
\text { - Catadores de lixo e seus } \\
\text { familiares } \\
\text { - Pessoas e crianças que } \\
\text { entram em contato voluntário } \\
\text { ou acidental com os RS } \\
\text { acondicionados ou dispostos } \\
\text { inadequadamente }\end{array}$} & \multirow{13}{*}{$\begin{array}{l}\text { Para os trabalhadores dos SLU e catadores } \\
\text { de lixo: } \\
\text { Uso de roupas de proteção, botas de } \\
\text { borracha e luvas } \\
\quad \text { Cuidados com a higiene pessoal } \\
\quad \text { Educação Sanitária } \\
\text { ou de destino final dos resíduos, de } \\
\text { instalações hidráulico-sanitária para os } \\
\text { cuidados com a higiene pessoal antes do } \\
\text { retorno às residências } \\
\quad \text { Vacinar contra hepatite A e B, pólio e } \\
\text { febre tifóide } \\
\text { Realizar exames médicos anuais, } \\
\text { incluindo exames de fezes e pulmonares } \\
\text { Para a população em geral: } \\
\text { Acondicionamento adequado dos RS } \\
\text { Melhoria do sistema de coleta } \\
\text { Evitar o acesso de crianças aos locais } \\
\text { de disposição final dos RS } \\
\text { Evitar a exposição ambiental dos RS } \\
\text { com recobrimento diário do lixo nos locais } \\
\text { de disposição final } \\
\text { Evitar pontos clandestinos (bota-fora) } \\
\text { de disposição dos RS } \\
\text { pestringir e controlar o acesso de } \\
\text { pessoas as áreas de tratamento, } \\
\text { transferência e disposição de RS }\end{array}$} \\
\hline & & & Diarréia & $\begin{array}{l}\text { Escherichia } \\
\operatorname{coli}(B)\end{array}$ & $\begin{array}{c}10 \text { semanas }< \\
\mathrm{T}_{90}<\text { vários } \\
\text { meses } \\
(\text { solo) })^{(\mathrm{a})}\end{array}$ & $\begin{array}{l}10^{6}- \\
10^{10}\end{array}$ & Homem & - & $\begin{array}{l}(2) ; \\
(4)^{* *}\end{array}$ & & \\
\hline & & & $\begin{array}{l}\begin{array}{l}\text { Gastroente } \\
\text { rite }\end{array} \\
\end{array}$ & Rotavirus $(V)$ & - & - & Homem & - & $(1) ;(2)$ & & \\
\hline & & & \begin{tabular}{|l|} 
Diarréia \\
\end{tabular} & Poliovirus $($ V) & $\begin{array}{c}20-170 \\
\text { dias (RSU) }\end{array}$ & & Homem & - & (2) & & \\
\hline & & & \begin{tabular}{|l|} 
Febre \\
Tifóide
\end{tabular} & $\begin{array}{l}\text { Salmonella } \\
\text { typhi }(B)\end{array}$ & $\begin{array}{l}29-70 \text { dias } \\
\text { (RSU) }\end{array}$ & $\begin{array}{l}\mathrm{ID}_{50}= \\
10^{7}\end{array}$ & Homem & - & (2) & & \\
\hline & & & \begin{tabular}{|l|} 
Febre \\
Paratifóide \\
\end{tabular} & \begin{tabular}{|l|}
$\begin{array}{l}\text { Salmonella } \\
\text { paratyphi }(B)\end{array}$ \\
\end{tabular} & & & \begin{tabular}{|l|}
$\begin{array}{l}\text { Homem, } \\
\text { animais }\end{array}$ \\
\end{tabular} & - & $(1) ;(2)$ & & \\
\hline & & & $\begin{array}{l}\begin{array}{l}\text { Desinteria } \\
\text { bacilar }\end{array} \\
\end{array}$ & Shigella $(B)$ & & & & - & $(1) ;(2)$ & & \\
\hline & & & \begin{tabular}{|l|} 
Cólera \\
\end{tabular} & $\begin{array}{l}\text { Vibrio cholera } \\
(B) \\
\end{array}$ & & & & - & (2) & & \\
\hline & & & Jersiníase & $\begin{array}{l}\text { Yersinia } \\
\text { enterocolitica } \\
(B) \\
\end{array}$ & & & & - & (2) & & \\
\hline & & & \begin{tabular}{|l|} 
Hepatite A \\
\end{tabular} & \begin{tabular}{|l} 
HVA $(\mathrm{V})$ \\
\end{tabular} & & & & - & (1); (2) & & \\
\hline & & & $\begin{array}{l}\text { Desinteria } \\
\text { amebiana }\end{array}$ & \begin{tabular}{|l|} 
Entamoeba \\
histolytica $(P)$
\end{tabular} & $\begin{array}{l}8-12 \text { dias } \\
\text { (RSU) }\end{array}$ & & & - & $(1) ;(2)$ & & \\
\hline & & & $\begin{array}{l}\text { Ascaridía- } \\
\text { se }\end{array}$ & $\begin{array}{l}\text { Ascaris } \\
\text { lumbricoides } \\
(H)\end{array}$ & $\begin{array}{c}2000-2500 \\
\text { dias (RSU) }\end{array}$ & & & - & (4) & & \\
\hline & & & \begin{tabular}{|l|} 
Tricuríase \\
\end{tabular} & $\begin{array}{l}\text { Trichurus } \\
\text { trichiura }(H)\end{array}$ & $\begin{array}{l}\text { Vários } \\
\text { meses }\end{array}$ & & & - & (4) & & \\
\hline
\end{tabular}


Tabela 13 - Continuação

\begin{tabular}{|c|c|c|c|c|c|c|c|c|c|c|c|}
\hline \multirow{2}{*}{$\begin{array}{c}\text { Formas de } \\
\text { Exposição } \\
\text { Ambiental ao } \\
\text { Fator de } \\
\text { Risco }\end{array}$} & \multirow[t]{2}{*}{ Categoria } & \multirow{2}{*}{$\begin{array}{c}\text { Formas de } \\
\text { Transmissão ou } \\
\text { Contágio }\end{array}$} & \multirow[t]{2}{*}{ Doença } & \multicolumn{4}{|c|}{ Agente Etiológico } & \multirow[t]{2}{*}{ Vetor } & \multirow{2}{*}{$\begin{array}{l}\text { Tipo de } \\
\text { Estudo }\end{array}$} & \multirow{2}{*}{$\begin{array}{c}\text { População Exposta ao Fator } \\
\text { de Risco }\end{array}$} & \multirow{2}{*}{$\begin{array}{c}\text { Profilaxia } \\
\text { Controle Ambiental e Sanitário }\end{array}$} \\
\hline & & & & Nomenclatura & Persistência & $\begin{array}{c}\text { Dose } \\
\text { infeccio } \\
\text { sa }\end{array}$ & $\begin{array}{c}\text { Reserva } \\
\text { tório }\end{array}$ & & & & \\
\hline \multirow[t]{5}{*}{$\begin{array}{l}1 . \\
\text { Contato com } \\
\text { os Resíduos } \\
\text { ou Solo Con- } \\
\text { taminado }\end{array}$} & \multirow[t]{5}{*}{$\begin{array}{l}1.2 \\
\text { Penetração na } \\
\text { Pele }\end{array}$} & $\begin{array}{l}\text { Penetração do } \\
\text { bioagente por } \\
\text { meio de ferida } \\
\text { perfurocortante }\end{array}$ & Tétano & $\begin{array}{l}\text { Clostridium } \\
\text { tetani }(B)\end{array}$ & & & & - & $* * *$ & $\begin{array}{l}\text { Trabalhadores da coleta } \\
\quad \text { Catadores de lixo } \\
\text { entram em contato voluntário } \\
\text { ou acidental com os RS } \\
\text { acondicionados ou dispostos } \\
\text { inadequadamente }\end{array}$ & 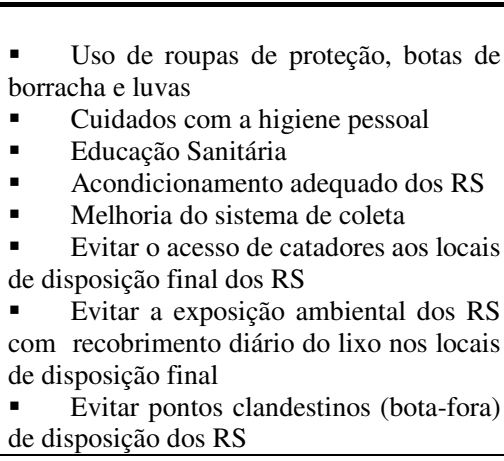 \\
\hline & & \multirow[t]{4}{*}{ 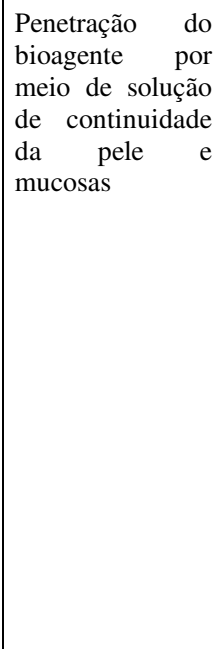 } & $\begin{array}{l}\text { Ancilosto } \\
\text { míase }\end{array}$ & \begin{tabular}{|l|} 
Ancylostomo \\
duodenale ou \\
Necator \\
americanus \\
(H)
\end{tabular} & $\begin{array}{l}25-40 \text { dias } \\
\quad(\mathrm{RSU})\end{array}$ & & & - & $\begin{array}{l}(1) ; \\
(4)^{* *}\end{array}$ & \multirow{4}{*}{$\begin{array}{l}\text { Trabalhadores da coleta } \\
\quad \text { Catadores de lixo } \\
\text { entram em contato voluntário } \\
\text { ou acidental com os RS } \\
\text { acondicionados ou dispostos } \\
\text { inadequadamente }\end{array}$} & \multirow{4}{*}{$\begin{array}{l}\text { - } \quad \text { Uso de roupas de proteção, botas de } \\
\text { borracha e luvas } \\
\text { - } \quad \text { Cuidados com a higiene pessoal } \\
\text { - } \quad \text { Educação Sanitária } \\
\text { - } \quad \text { Acondiciononamento adequado dos RS } \\
\text { - } \quad \text { Evitar o acesso de catadores aos locais } \\
\text { de disposição final dos RS } \\
\text { - } \quad \text { Evitar a exposição ambiental dos RS } \\
\text { com recobrimento diário do lixo nos locais } \\
\text { de disposição final } \\
\text { de } \quad \text { Evitar pontos clandestinos (bota-fora) } \\
\text { disposição dos RS }\end{array}$} \\
\hline & & & Escabiose & $\begin{array}{l}\text { Sacarcoptes } \\
\text { scabiei }\end{array}$ & & & & - & **** & & \\
\hline & & & $\begin{array}{l}\text { Dermatite } \\
\text { serpigino- } \\
\text { sa }\end{array}$ & $\begin{array}{l}\text { Ancylostoma } \\
\text { brasiliensis } \\
(H)\end{array}$ & & & & - & **** & & \\
\hline & & & $\begin{array}{l}\text { Piodermi- } \\
\text { tes (Impe- } \\
\text { tigo, Foli- } \\
\text { culites, } \\
\text { Furúnculo, } \\
\text { Erisipela, } \\
\text { Celulite, } \\
\text { Conjutivi- } \\
\text { te bacteri- } \\
\text { ana) }\end{array}$ & \begin{tabular}{|l|} 
Sptreptococus \\
Staphylococus \\
aureaus $(B)$
\end{tabular} & & & & & **** & & \\
\hline
\end{tabular}


Tabela 13 - Continuação

\begin{tabular}{|c|c|c|c|c|c|c|c|c|c|c|c|}
\hline \multirow{2}{*}{$\begin{array}{c}\text { Formas de } \\
\text { Exposição } \\
\text { Ambiental ao } \\
\text { Fator de } \\
\text { Risco } \\
\end{array}$} & \multirow[t]{2}{*}{ Categoria } & \multirow{2}{*}{$\begin{array}{c}\text { Formas de } \\
\text { Transmissão ou } \\
\text { Contágio }\end{array}$} & \multirow[t]{2}{*}{ Doença } & \multicolumn{4}{|c|}{ Agente Etiológico } & \multirow[t]{2}{*}{ Vetor } & \multirow{2}{*}{\begin{tabular}{|l|} 
Tipo de \\
Estudo
\end{tabular}} & \multirow{2}{*}{$\begin{array}{c}\text { População Exposta ao Fator } \\
\text { de Risco }\end{array}$} & \multirow{2}{*}{$\begin{array}{c}\text { Profilaxia } \\
\text { Controle Ambiental e Sanitário }\end{array}$} \\
\hline & & & & Nomenclatura & Persistência & $\begin{array}{c}\text { Dose } \\
\text { infeccio } \\
\text { sa }\end{array}$ & $\begin{array}{c}\text { Reser } \\
\text { vató- } \\
\text { rio }\end{array}$ & & & & \\
\hline \multirow[t]{5}{*}{$\begin{array}{l}2 . \\
\text { Contato com } \\
\text { Vetor }\end{array}$} & \multirow{5}{*}{$\begin{array}{l}2.1 \\
\text { Transmissão } \\
\text { por Vetor Me- } \\
\text { cânico }\end{array}$} & \multirow{5}{*}{$\begin{array}{l}\text { Ingestão de ali- } \\
\text { mento contami- } \\
\text { nado pelo bioa- } \\
\text { gente transpor- } \\
\text { tado mecanica- } \\
\text { mente pelo vetor }\end{array}$} & $\begin{array}{l}\text { Febre } \\
\text { tifóide }\end{array}$ & $\begin{array}{l}\text { Salmonella } \\
\text { typhi }(B)\end{array}$ & & & & $\begin{array}{l}\text { Mosca } \\
\text { barata }\end{array}$ & $\begin{array}{l}(1) ; \quad(2) ; \\
(3)\end{array}$ & \multirow{5}{*}{$\begin{array}{l}\text { - População em geral } \\
\text { residente próxima aos locais } \\
\text { de disposição final ou de } \\
\text { lançamento a céu aberto de } \\
\text { resíduos sólidos } \\
\text { - Trabalhadores da coleta } \\
\text { Catadores de lixo e seus } \\
\text { familiares }\end{array}$} & \multirow{5}{*}{$\begin{array}{l}\text { - Cuidado com preparo } \\
\text { armazenamento dos alimentos } \\
\text { Melhoria da higiene pessoal e } \\
\text { doméstica } \\
\text { - Educação Sanitária } \\
\text { com recobitar exposição ambiental dos RS } \\
\text { de disposição final } \\
\text { de Eviariar do lixo nos loc clandestinos (bota-fora) } \\
\text { de disposiçãa dos RS } \\
\text { das áreas de disposiç̧ão final dos RS }\end{array}$} \\
\hline & & & Cólera & $\begin{array}{l}\text { Vibrio cholera } \\
(B)\end{array}$ & & & & Barata & (1) & & \\
\hline & & & Giardíase & $\begin{array}{l}\text { Giardia lambia } \\
(P)\end{array}$ & & & & Barata & (1); (2) & & \\
\hline & & & \begin{tabular}{|l|}
$\begin{array}{l}\text { Peste } \\
\text { bubônica }\end{array}$ \\
\end{tabular} & $\begin{array}{l}\text { Yersinia petis } \\
(B)\end{array}$ & & & & Rato & (1); (3) & & \\
\hline & & & Diarréia & Poliovirus $(V)$ & & & & $\begin{array}{l}\text { Mosca } \\
\text { Cata- } \\
\text { dor }\end{array}$ & (2) & & \\
\hline
\end{tabular}


Tabela 13 - Continuação

\begin{tabular}{|c|c|c|c|c|c|c|c|c|c|c|c|}
\hline \multirow{2}{*}{$\begin{array}{l}\text { Formas de } \\
\text { Exposição } \\
\text { Ambiental ao } \\
\text { Fator de } \\
\text { Risco }\end{array}$} & \multirow[t]{2}{*}{ Categoria } & \multirow{2}{*}{$\begin{array}{c}\text { Formas de } \\
\text { Transmissão ou } \\
\text { Contágio }\end{array}$} & \multirow[t]{2}{*}{ Doença } & \multicolumn{4}{|c|}{ Agente Etiológico } & \multirow[t]{2}{*}{ Vetor } & \multirow{2}{*}{$\begin{array}{l}\text { Tipo de } \\
\text { Estudo }\end{array}$} & \multirow{2}{*}{$\begin{array}{c}\text { População Exposta ao Fator } \\
\text { de Risco }\end{array}$} & \multirow{2}{*}{$\begin{array}{c}\text { Profilaxia } \\
\text { Controle Ambiental e Sanitário }\end{array}$} \\
\hline & & & & $\begin{array}{c}\text { Nomenclatu } \\
\text { ra }\end{array}$ & Persistência & $\begin{array}{c}\text { Dose } \\
\text { infeccio } \\
\text { sa }\end{array}$ & $\begin{array}{c}\text { Reserva- } \\
\text { tório }\end{array}$ & & & & \\
\hline \multirow[t]{12}{*}{$\begin{array}{l}2 . \\
\text { Contato com } \\
\text { Vetor }\end{array}$} & \multirow{12}{*}{$\begin{array}{l}2.2 \\
\text { Transmissão } \\
\text { por Vetor } \\
\text { Biológico }\end{array}$} & \multirow{4}{*}{$\begin{array}{l}\text { Penetração do } \\
\text { bioagente por } \\
\text { meio da mor- } \\
\text { dedura ou picada } \\
\text { do vetor }\end{array}$} & $\begin{array}{l}\text { Leishmani } \\
\text { ose }\end{array}$ & Leshimania & & & & $\begin{array}{l}\text { Mos- } \\
\text { quito }\end{array}$ & (1); (3) & \multirow{4}{*}{$\begin{array}{l}\text { Trabalhadores da coleta } \\
\text { - Catadores de lixo } \\
\text { residente próxima aos locais } \\
\text { de disposição final ou de } \\
\text { lançamento à céu aberto de } \\
\text { resíduos sólidos }\end{array}$} & \multirow{4}{*}{ 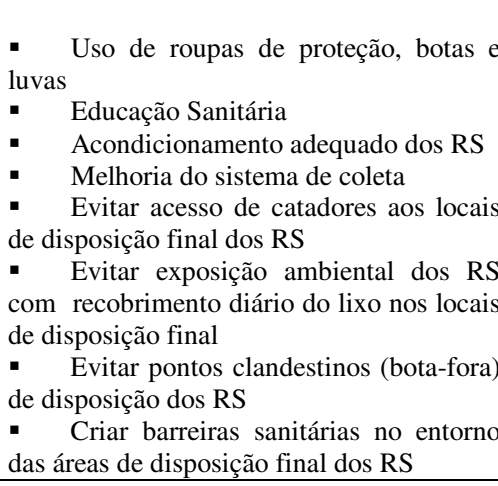 } \\
\hline & & & \begin{tabular}{|l} 
Febre \\
amarela
\end{tabular} & Flavivirus & & & & $\begin{array}{l}\text { Mos- } \\
\text { quito }\end{array}$ & (1); (3) & & \\
\hline & & & Dengue & Flavivirus & & & & $\begin{array}{l}\text { Mos- } \\
\text { quito }\end{array}$ & (1); (3) & & \\
\hline & & & Filariose & $\begin{array}{l}\text { Wuchereria } \\
\text { Bancrofti }\end{array}$ & & & & $\begin{array}{l}\text { Mos- } \\
\text { quito }\end{array}$ & (1); (3) & & \\
\hline & & \multirow{8}{*}{$\begin{array}{lr}\text { Presença } & \text { do } \\
\text { bioagente } & \text { no } \\
\text { substrato } & \text { (urina, } \\
\text { fezes e r saliva) } \\
\text { eliminado pelo } \\
\text { vetor }\end{array}$} & $\begin{array}{l}\begin{array}{l}\text { Peste } \\
\text { bubônica }\end{array} \\
\end{array}$ & $\begin{array}{l}\text { Yersinia } \\
\text { petis }\end{array}$ & & & & Rato & $(1) ;(3)$ & \multirow{8}{*}{$\begin{array}{l}\text { - Trabalhadores da coleta } \\
\text { - Patadores de lixo } \\
\text { residente próxiana aos locais } \\
\text { de disposição final ou de } \\
\text { lançamento a céu aberto de } \\
\text { resíduos sólidos }\end{array}$} & \multirow{8}{*}{ 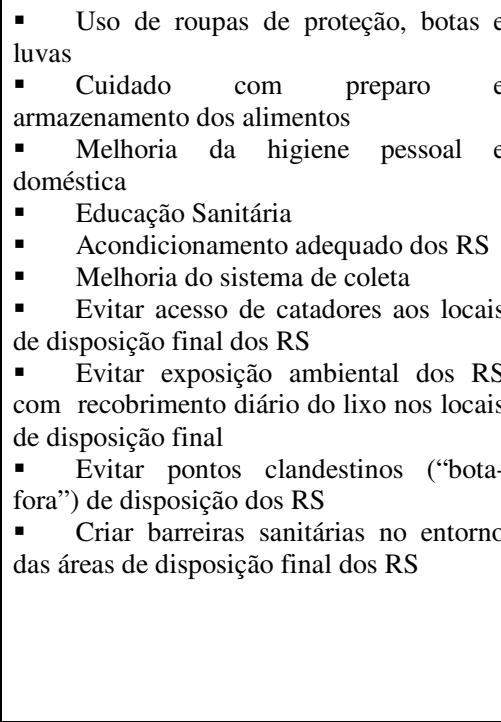 } \\
\hline & & & $\begin{array}{l}\text { Salmonelo } \\
\text { se }\end{array}$ & Salmonella & $\begin{array}{c}2 \underset{\text { semanas a } 2}{ } \text { meses }^{(\mathrm{a}, \mathrm{e})} \\
\end{array}$ & $\begin{array}{l}\mathrm{ID}_{50}= \\
10^{5}-10^{9}\end{array}$ & $\begin{array}{l}\text { Galinha, } \\
\text { peru, pa- } \\
\text { to, suí- } \\
\text { nos, bo- } \\
\text { vinos, } \\
\text { ovinos, } \\
\text { eqüinos }\end{array}$ & $\begin{array}{l}\text { Mosca } \\
\text { barata }\end{array}$ & $\begin{array}{l}(1) ;(2) ; \\
(3)\end{array}$ & & \\
\hline & & & Cólera & \begin{tabular}{|l} 
Vibrio \\
cholera \\
\end{tabular} & & & & $\begin{array}{l}\text { Mosca } \\
\text { barata }\end{array}$ & $(1) ;(3)$ & & \\
\hline & & & Amebíase & $\begin{array}{l}\text { Entamoeba } \\
\text { histolytica } \\
\end{array}$ & & & & Mosca & (1); (3) & & \\
\hline & & & Desinteria & Shigella & & & & Mosca & (1); (3) & & \\
\hline & & & Giardíase & \begin{tabular}{|l} 
Giardia \\
lambia \\
\end{tabular} & & & & $\begin{array}{l}\text { Mosca } \\
\text { barata }\end{array}$ & $(1) ;(3)$ & & \\
\hline & & & \begin{tabular}{|l|}
$\begin{array}{l}\text { Toxoplas } \\
\text { mose }\end{array}$ \\
\end{tabular} & $\begin{array}{l}\text { Toxoplasma } \\
\text { gondi }\end{array}$ & & & & Aves & (1); (3) & & \\
\hline & & & $\begin{array}{l}\text { Leptospiro } \\
\text { se }\end{array}$ & $\begin{array}{l}\text { Leptospira } \\
\text { icterohaemo } \\
\text { r-rhagiae }\end{array}$ & $\begin{array}{l}15 \text { dias } \\
(\text { solo })^{(\mathrm{e})}\end{array}$ & $\begin{array}{l}1 \text { orga- } \\
\text { nismo }^{(\mathrm{c})}\end{array}$ & $\begin{array}{l}\text { Ratos, } \\
\text { animais } \\
\text { domésti- } \\
\text { cos }\end{array}$ & Rato & (1); (3) & & \\
\hline
\end{tabular}


Tabela 13 - Continuação

\begin{tabular}{|c|c|c|c|c|c|c|c|c|c|c|c|}
\hline \multirow{2}{*}{$\begin{array}{c}\text { Formas de } \\
\text { Exposiçã̃o } \\
\text { Ambiental ao } \\
\text { Fator de } \\
\text { Risco }\end{array}$} & \multirow[t]{2}{*}{ Categoria } & \multirow{2}{*}{$\begin{array}{c}\text { Formas de } \\
\text { Transmissão ou } \\
\text { Contágio }\end{array}$} & \multirow[t]{2}{*}{ Doença } & \multicolumn{4}{|c|}{ Agente Etiológico } & \multirow[t]{2}{*}{ Vetor } & \multirow{2}{*}{$\begin{array}{l}\text { Tipo de } \\
\text { Estudo }\end{array}$} & \multirow{2}{*}{$\begin{array}{c}\text { População Exposta ao Fator } \\
\text { de Risco }\end{array}$} & \multirow{2}{*}{$\begin{array}{c}\text { Profilaxia } \\
\text { Controle Ambiental e Sanitário }\end{array}$} \\
\hline & & & & Nomenclatura & Persistência & $\begin{array}{c}\text { Dose } \\
\text { infeccio } \\
\text { sa }\end{array}$ & $\begin{array}{c}\text { Reser } \\
\text { va- } \\
\text { tório }\end{array}$ & & & & \\
\hline \multirow[t]{4}{*}{$\begin{array}{l}2 . \\
\text { Contato com } \\
\text { Vetor }\end{array}$} & \multirow{4}{*}{$\begin{array}{l}2.2 \\
\text { Transmissão } \\
\text { por Vetor } \\
\text { Biológico }\end{array}$} & \multirow[t]{4}{*}{$\begin{array}{l}\text { Ingestão de carne } \\
\text { contaminada }\end{array}$} & $\begin{array}{l}\text { Cisticerco- } \\
\text { se }\end{array}$ & Cisticerco & & & & $\begin{array}{l}\text { Suíno } \\
\text { (I) }\end{array}$ & (1); (3) & \multirow{4}{*}{$\begin{array}{l}\text { População em geral que } \\
\text { fizer uso de carne contami- } \\
\text { nada proveniente de animais } \\
\text { domésticos criados nos locais } \\
\text { de disposição de resíduos } \\
\text { sólidos }\end{array}$} & \multirow{4}{*}{$\begin{array}{l}\text { Vigilância e controle sanitário para a } \\
\text { carne de animais abatidos } \\
\text { - Cuidado com preparo dos alimentos } \\
\text { lixo }\end{array}$} \\
\hline & & & $\begin{array}{l}\text { Toxoplas- } \\
\text { mose }\end{array}$ & $\begin{array}{l}\text { Toxoplasma } \\
\text { gondi }\end{array}$ & & & & $\begin{array}{l}\text { Suíno } \\
\text { (I) }\end{array}$ & (1); (3) & & \\
\hline & & & Teníase & Taenia solium & & & & $\begin{array}{l}\text { Suíno } \\
\text { (I) }\end{array}$ & (1); (3) & & \\
\hline & & & Diarréia & \begin{tabular}{ll}
\multicolumn{2}{|l}{ Campylobacter } \\
fetus & ssp. \\
Jejuni (B) &
\end{tabular} & & $\begin{array}{l}10^{6} \quad C . \\
\text { fetus } \\
\text { ssp. } \\
\text { jejuni }^{(\mathrm{d})}\end{array}$ & $\begin{array}{l}\text { Aves e } \\
\text { pássar } \\
\text { os } \\
\text { domés } \\
\text { ticos }\end{array}$ & $\begin{array}{l}\text { Aves, } \\
\text { pássa- } \\
\text { ros } \\
\text { domés } \\
\text { ticos, } \\
\text { bovi- } \\
\text { nos (I) }\end{array}$ & (1) & & \\
\hline
\end{tabular}


Tabela 13 - Continuação

\begin{tabular}{|c|c|c|c|c|c|c|c|}
\hline $\begin{array}{c}\text { Formas de } \\
\text { Exposição } \\
\text { Ambiental ao } \\
\text { Fator de Risco } \\
\end{array}$ & Categoria & $\begin{array}{l}\text { Formas de } \\
\text { Transmissão ou } \\
\text { Contágio }\end{array}$ & Doença ou Agravo à Saúde & $\begin{array}{c}\text { Agente Químico/ Fator } \\
\text { Ambiental }\end{array}$ & $\begin{array}{l}\text { Tipo de } \\
\text { Estudo }\end{array}$ & $\begin{array}{c}\text { População Exposta ao Fator de } \\
\text { Risco }\end{array}$ & $\begin{array}{c}\text { Profilaxia } \\
\text { Controle Ambiental e Sanitário }\end{array}$ \\
\hline \multirow{4}{*}{$\begin{array}{l}3 . \\
\text { Contator com } \\
\text { Água Conta- } \\
\text { minada }\end{array}$} & \multirow[t]{4}{*}{\begin{tabular}{|l}
3.1 \\
Contaminação \\
Química
\end{tabular}} & \multirow{4}{*}{$\begin{array}{l}\text { Contaminação quí- } \\
\text { mica da água pelo } \\
\text { chorume, líquidos } \\
\text { percolados e escoa- } \\
\text { mento superficial }\end{array}$} & $\begin{array}{l}\text { Retardo no crescimento de } \\
\text { crianças (menor peso e altura) }\end{array}$ & Dioxinas & (4) & \multirow{4}{*}{$\begin{array}{l}\text { - Pessoas e crianças } \\
\text { residentes próximas aos locais } \\
\text { de disposição final de resíduos }\end{array}$} & \multirow{4}{*}{$\begin{array}{l}\text { - Coleta e tratamento dos líquidos } \\
\text { percolados nos aterros sanitários } \\
\text { - Controle da qualidade da água para } \\
\text { consumo humano } \\
\text { - Evitar o acesso de pessoas e contato } \\
\text { com a água dos corpos receptores } \\
\text { - Fixar uma distância mínima para } \\
\text { ocupação humana no entorno dos locais } \\
\text { utilizados para a disposição final dos RS }\end{array}$} \\
\hline & & & Câncer de bexiga & \begin{tabular}{|l} 
Tricloroetileno, \\
tetracloroetileno, \\
solventes
\end{tabular} & (4) & & \\
\hline & & & $\begin{array}{l}\text { Câncer de pulmão, bexiga, } \\
\text { esôfago, estômago, intestino } \\
\text { grosso, reto, mama }\end{array}$ & 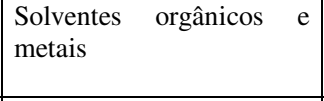 & (4) & & \\
\hline & & & Baixo peso ao nascer & Benzeno, dioxina, & (4) & & \\
\hline \multirow{7}{*}{$\begin{array}{l}4 . \\
\text { Contato com o } \\
\text { Ar Contami- } \\
\text { nado }\end{array}$} & \multirow{7}{*}{$\begin{array}{l}.1 \\
\text { Contaminação } \\
\text { Química }\end{array}$} & \multirow{7}{*}{$\begin{array}{l}\text { Inalação de poeiras, } \\
\text { gases e fumaças } \\
\text { contendo elementos } \\
\text { ou compostos quí- } \\
\text { micos perigosos }\end{array}$} & Baixo peso ao nascer & Biogás & (4) & \multirow{7}{*}{$\begin{array}{l}\text { - Pessoas e crianças } \\
\text { residentes próximas aos locais } \\
\text { de disposição final de resíduos }\end{array}$} & \multirow{7}{*}{$\begin{array}{l}\text { - Coleta e tratamento do biogás } \\
\text { outros gases gerados nos aterros } \\
\text { sanitários } \\
\text { - Fixar uma distância mínima para } \\
\text { ocupação humana no entorno dos locais } \\
\text { utilizados para a disposição final dos RS } \\
\text { - Criar um cinturão verde ao entrono } \\
\text { dos locais utilizados para a disposição } \\
\text { final dos RS }\end{array}$} \\
\hline & & & & Odor & (4) & & \\
\hline & & & & $\begin{array}{l}\text { Compostos orgânicos vo- } \\
\text { láteis }\end{array}$ & (4) & & \\
\hline & & & Menor idade gestacional & Odor & (4) & & \\
\hline & & & $\begin{array}{l}\text { Retardo no crescimento de } \\
\text { crianças (menor peso e altura) }\end{array}$ & $\begin{array}{l}\text { Benzeno. tolueno, clo- } \\
\text { roforme, tricloroetileno, } \\
\text { hexano, xileno }\end{array}$ & (4) & & \\
\hline & & & $\begin{array}{l}\text { Câncer de estômago, fígado, } \\
\text { pulmão, útero e próstata }\end{array}$ & Biogás & (4) & & \\
\hline & & & Má formação congênita & $\begin{array}{l}\text { Pesticidas, metais, sol- } \\
\text { ventes }\end{array}$ & (4) & & \\
\hline
\end{tabular}


Tabela 13 - Continuação - Índices empregados:

\author{
B - Bactéria \\ V - Vírus \\ P - Protozoário \\ $\mathrm{H}$ - Helminto \\ (I) - Hospedeiro intermediário
}

RSU - Resíduos sólidos urbanos

RS - Resíduos sólidos

RSS - Resíduos sólidos dos serviços de saúde

$\mathrm{T}_{90}$ - Tempo para $90 \%$ de redução da população inicial

(a) - Bastante variável, dependendo das condições de umidade, temperatura, conteúdo de matéria orgânica e atividade biológica do solo

(b) - Possibilidade de transmissão, contudo sem conhecimento da significância epidemiológica deste modo de transmissão

(c) - Dose infecciosa determinada para experimentos com suínos

(d) - Relato de um caso de contaminação voluntária com ingestão de leite

(e) - Sob condições ambientais favoráveis

(1) Doença ou gravo à saúde citado pelo(s) autor(es)

(2) Presença do agente etiológico citado pelo(s) autor(es)

(3) Presença do vetor citado pelo(s) autor(es)

(4) Estudo epidemiológico

* espécie não identificada pelo(s) autor(es)

** sem identificação do agente etiológico

**** proposto por AZEVEDO et al. (2000) 
TABELA 14 - Tipologia dos desenhos de investigação em epidemiologia

\begin{tabular}{|c|c|c|c|}
\hline Tipo operativo & $\begin{array}{c}\text { Posição do } \\
\text { investigador }\end{array}$ & $\begin{array}{l}\text { Referência } \\
\text { temporal }\end{array}$ & Denominações correntes \\
\hline \multirow[t]{3}{*}{ Agregado } & \multirow[t]{2}{*}{ Observacional } & Transversal & Estudos ecológicos \\
\hline & & Longitudinal & $\begin{array}{l}\text { Estudos de tendências ou séries } \\
\text { temporais }\end{array}$ \\
\hline & Intervenção & Longitudinal & Ensaios comunitários \\
\hline \multirow[t]{3}{*}{ Individualizado } & \multirow[t]{2}{*}{ Observacional } & Transversal & Inquéritos ou surveys \\
\hline & & Longitudinal & $\begin{array}{l}\text { Estudos prospectivos (coortes) } \\
\text { Estudos retrospectivos (caso-controle) }\end{array}$ \\
\hline & Intervenção & Longitudinal & Ensaios clínicos \\
\hline
\end{tabular}

Fonte: ROUQUAYROL \& ALMEIDA FILHO (1999).

A seguir serão discutidos, com maiores detalhes, cada um desses tipos de desenhos de pesquisa epidemiológica. As descrições foram extraídas de ALMEIDA FILHO \& ROUQUAYROL (1992) e ROUQUAYROL \& ALMEIDA FILHO (1999). Os ensaios clínicos não serão abordados neste texto por constituírem em um tipo de pesquisa epidemiológica não utilizada nos estudos de avaliação dos impactos das intervenções em saneamento sobre a saúde pública.

\subsubsection{Estudos Ecológicos}

Os estudos ecológicos abordam áreas geográficas, analisando comparativamente variáveis globais, quase sempre por meio de correlação entre 
indicadores ambientais (ou socioeconômicos) e indicadores de saúde. Os indicadores de cada área constituem-se em médias referentes à população total, tomada como um agregado integral, mas que na verdade é composta por subgrupos com características diferentes.

Os estudos ecológicos conseguem explorar preliminarmente hipóteses, contudo a um nível menos complexo de determinação. Neste nível de abordagem mais totalizadora, não há lugar para o isolamento de variáveis componentes de modelos causais simples, de inspiração biológica. Todavia, trata-se do único desenho habilitado ao teste de hipóteses referentes aos processos contextuais ou macro-sociais da saúde.

Nesse tipo de desenho, não se justifica a redução ao âmbito individual de padrões observados no nível do agregado, ao que se convencionou denominar "falácia ecológica". Desta forma, o principal problema analítico desse tipo de investigação é a suposição de que os mesmos indivíduos são simultaneamente portadores do problema de saúde e do atributo associado. Problemas dessa ordem podem ser bastante reduzidos por meio do estabelecimento de agregados de menor tamanho e com relativa homogeneidade interna.

\subsubsection{Estudos Seccionais}

Investigações que produzem instantâneos da situação de saúde de uma população ou comunidade, com base na avaliação individual do estado de saúde para o grupo investigado, são chamadas de estudos seccionais ou de corte-transversal. Em geral, essas pesquisas utilizam amostras representativas da população, devido às 
óbvias dificuldades para o recenseamento de grupos numerosos.

O termo estudo "seccional", no contexto metodológico da Epidemiologia, pretende dar uma idéia de seccionamento transversal, um corte no fluxo histórico da doença, evidenciando as suas características e correlações naquele momento. Assim sendo, o estudo seccional é um tipo de estudo epidemiológico no qual fator e efeito são observados num mesmo momento histórico. Este tipo de estudo é também referido na Epidemiologia como estudo transversal ou estudo de prevalência.

Geralmente, utiliza-se esse tipo de estudo para o teste de hipóteses de associação, sem definir o seu caráter etiológico, devido à simultaneidade da informação sobre o sintoma/doença e o fator associado. As conclusões derivadas dos estudos de prevalência restringem-se a relações de associação, e não de causalidade. Em termos estatísticos, pode-se estabelecer que a causa suspeita e o efeito encontram-se associados dentro de um certo nível de significância. Os fatores de exposição suspeitos passam a ser reconhecidos como fatores de risco em potencial, podendo então se tornar objeto de estudos com maior potencialidade de produção de conhecimento causal, como os estudos de coorte e de caso-controle.

Contudo, este tipo de desenho de pesquisa tem sido o mais empregado na Epidemiologia moderna, que vem gradativamente aperfeiçoando a sua arquitetura e ampliando as suas aplicações. Dentre os subtipos de estudos seccionais, inclui-se os inquéritos domiciliares de morbidade, caracterizados por técnicas de coleta direta na comunidade, por meio do emprego de entrevistas estruturadas e procedimentos diagnósticos padronizados. Neste caso, a base populacional para o estudo é definida por meio de amostragem ou recenseamento, examinando-se todos os sujeitos incluídos na investigação. Não havendo, portanto, problemas para o estabelecimento 
do denominador nas estimativas produzidas, uma das exigências desse tipo de desenho para o cálculo da prevalência.

Os estudos de prevalência podem ser planejados para testar a verdade de enunciados comparativos como: "a prevalência da doença x é maior entre os expostos ao fator y do que os não-expostos" ou "a prevalência da doença y entre os habitantes da região A, que possui o fator y, é maior do que entre os habitantes da região $B$, que não possui o dito fator". Quando, o fator sob suspeita é uma característica bioquímica ou fisiológica, ou uma característica permanente do ambiente onde vive o indivíduo doente, estudos de prevalência comparada podem substituir desenhos mais sofisticados e custosos para o teste de hipóteses.

Pelo exposto anteriormente, esse foi o tipo desenho epidemiológico empregado para testar a hipótese básica desta pesquisa.

\subsubsection{Estudos de Coorte}

Os estudos de coortes (também chamados de seguimentos ou follow-up) são os únicos capazes de abordar hipóteses etiológicas produzindo medidas de incidência e, por conseguinte, medidas diretas de risco. Os estudos de coortes são também chamados de prospectivos pelo fato de que em sua maioria partem da observação de grupos comprovadamente expostos a um fator de risco suposto como causa de doença a ser detectada no futuro.

Os estudos de coortes são empregados quando se deseja conhecer, avaliar ou confirmar a contribuição causal de uma determinada variável na produção de uma doença. Para tanto, é selecionado um grupo de pessoas consideradas sadias quanto à 
doença sob investigação, devendo ser este grupo o mais homogêneo possível em relação a sua composição por vários fatores. No que tange ao suposto fator de risco investigado, o grupo deve ser heterogêneo, parte formado por expostos ou portadores do fator suspeito, parte formado por não-expostos ou não portador.

O principal problema com estudos longitudinais é a própria dinâmica das populações humanas, o que impossibilita, na maioria dos casos, a observação de coortes fixas. A perda de participantes, seja por migração ou por morte, pode modificar profundamente os resultados desse tipo de investigação.

\subsubsection{Estudos de Caso-controle}

Para se abordar associações etiológicas com doenças de baixa incidência, em que a condução de estudos de seguimento é reconhecidamente inviável, recomendase o estudo de caso-controle. Pode-se dizer que o estudo de caso-controle consiste no inverso do estudo de coorte, porque, enquanto este último, parte do fator de risco e, prospectivamente, observa o aparecimento de doentes, o estudo de caso-controle inicia-se pelos doentes identificados, estabelece controles (sujeitos comparáveis aos casos, porém reconhecidamente não-doentes) para eles e, retrospectivamente, procura conhecer os níveis de exposição ao suposto fator de risco.

O desenho de caso-controle não é capaz de produzir medidas de ocorrência de doenças, porque não utiliza denominadores populacionais. Permite, somente, estimar uma medida de associação tipo proporcionalidade, denominada de odds ratio, que tem a propriedade matematicamente demonstrável de aproximar-se do risco relativo no caso de doenças de baixa incidência na população. 
A Tabela 15 apresenta uma compilação das características fundamentais dos métodos epidemiológicos descritos anteriormente.

\subsection{Estudos Epidemiológicos Relacionados ao Saneamento}

Os estudos epidemiológicos relacionados ao saneamento tiveram, segundo HELLER (1995), um maior desenvolvimento a partir do início da década de 80, motivados pela declaração pela Organização das Nações Unidas da Década Internacional do Abastecimento de Água e Esgotamento Sanitário como o período de 1981 a 1990. Os estudos buscaram formular mais rigorosamente os mecanismos responsáveis pelo comprometimento das condições de saúde da população, na ausência de condições adequadas de saneamento. Contudo, o autor ressalta que quase a totalidade das pesquisas voltou-se para o abastecimento de água e o esgotamento sanitário, mantendo ainda bastante obscuros os mecanismos envolvidos com a limpeza urbana, a drenagem pluvial e a presença de vetores.

HELLER (1995) afirma que há uma lacuna na sistematização de procedimentos metodológicos, sobretudo adequados às condições nacionais, para a elaboração de estudos epidemiológicos relacionados ao saneamento. O autor apresenta uma revisão dos estudos epidemiológicos considerando a associação saneamento e saúde, distribuindo-os segundo o período de realização do estudo; o continente onde o estudo foi realizado; a variável de saneamento avaliada; o resultado obtido na associação e os indicadores de saúde utilizados. 
TABELA 15 - Características dos desenhos de investigação em epidemiologia

\begin{tabular}{|c|c|c|c|c|}
\hline \multirow[t]{2}{*}{ Característica } & \multicolumn{4}{|c|}{ Tipo de estudos } \\
\hline & Ecológicos & Seccionais & Coorte & Caso-controle \\
\hline Sub-tipos & $\begin{array}{l}\text { - } \quad \text { Estudos territoriais (condi- } \\
\text { ções de vida) } \\
\text { - } \quad \text { Estudos de agregados insti- } \\
\text { tucionais (riscos parciais) }\end{array}$ & $\begin{array}{l}\text { - } \text { Estudos de grupos em } \\
\text { tratamento } \\
\text { - Inquéritos na atenção primária } \\
\text { - } \quad \text { Estudos em populações espe- } \\
\text { ciais (escolares, idosos, etc.) } \\
\text { - Inquéritos domiciliares com } \\
\text { identificação direta de caso } \\
\text { - } \quad \text { Estudos multifásicos }\end{array}$ & 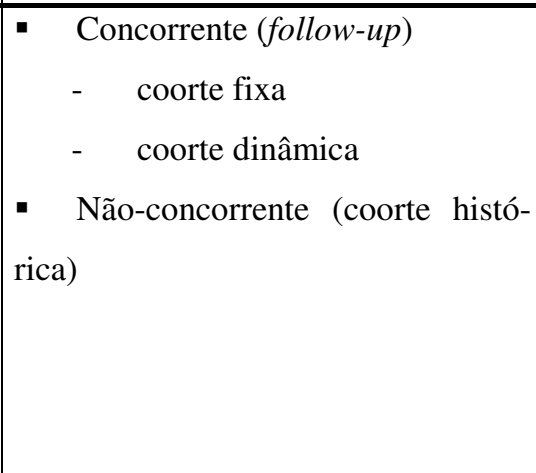 & 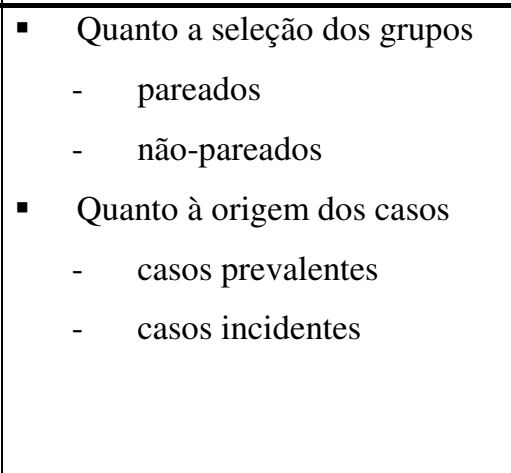 \\
\hline Vantagens & $\begin{array}{l}\text { - } \quad \text { Facilidade de execução; bai- } \\
\text { xo custo relativo } \\
\text { - } \quad \text { Simplicidade analítica } \\
\text { - } \quad \text { Capacidade de geração de } \\
\text { hipóteses }\end{array}$ & $\begin{array}{l}\text { - } \quad \text { Baixo custo } \\
\text { - } \quad \text { Alto potencial descritivo (sub- } \\
\text { sídio ao planejamento) } \\
\text { - } \quad \text { Simplicidade analítica }\end{array}$ & $\begin{array}{ll}\text { - } & \text { Produz medidas diretas de risco } \\
\text { - } & \text { Alto poder analítico } \\
\text { - } & \text { Facilidade de análise }\end{array}$ & $\begin{array}{l}\text { - } \quad \text { Baixo custo relativo } \\
\text { - } \quad \text { Alto potencial analítico } \\
\text { - } \quad \text { Adequado para estudar doen- } \\
\text { ças raras }\end{array}$ \\
\hline Problemas & $\begin{array}{l}\text { - } \quad \text { Baixo poder analítico } \\
\text { - Pouco desenvolvimento das } \\
\text { técnicas de análise de dados } \\
\text { - Vulnerável à chamada "falá- } \\
\text { cia ecológica" }\end{array}$ & $\begin{array}{l}\text { - Vulnerabilidade de biases } \\
\text { (especialmente de seleção) } \\
\text { - Baixo poder analítico (inade- } \\
\text { quado para testar hipótese causais) }\end{array}$ & $\begin{array}{l}\text { - Vulnerável a perdas (attrition } \\
\text { bias) } \\
\text { - Inadequado para doenças de } \\
\text { baixa frequiência } \\
\text { - Alto custo relativo }\end{array}$ & $\begin{array}{l}\text { - Incapaz de estimar risco } \\
\text { (reduzido poder descritivo) } \\
\text { - Vulnerável a inúmeros biases } \\
\text { (seleção, rememoração, etc.) } \\
\text { - Complexidade analítica }\end{array}$ \\
\hline $\begin{array}{l}\text { Formas } \\
\text { de análise }\end{array}$ & $\begin{array}{l}\text { - } \quad \text { Análise gráfica } \\
\text { - } \quad \text { Comparação de indicadores } \\
\text { - } \quad \text { Análise de correlação linear } \\
\text { (univariada e multivariada) }\end{array}$ & $\begin{array}{l}\text { - } \quad \text { Comparação de indicadores de } \\
\text { saúde e de exposição } \\
\text { - } \quad \text { Testagem da significância esta- } \\
\text { tística }\end{array}$ & $\begin{array}{l}\text { - } \quad \text { Cálculo do risco relativo } \\
\text { - } \quad \text { Risco atribuível } \\
\text { - } \quad \text { Pessoas/ano (estudos de coorte } \\
\text { dinâmica) }\end{array}$ & $\begin{array}{l}\text { - Estimativa de risco relativo - } \\
\text { “Odds Ratio" } \\
\text { - Risco atribuível percentual de } \\
\text { Levin }\end{array}$ \\
\hline
\end{tabular}


Em relação ao tipo de estudos empregados, BRISCOE et al. (1986) recomendam o uso do método de caso-controle para avaliações do impacto do abastecimento de água e esgotamento sanitário sobre doenças diarréicas, por ser este um método válido, de baixo custo e de rápido desenvolvimento. Contudo, para estudos de avaliação de múltiplos efeitos sobre a saúde, os autores afirmam que o emprego dos estudos seccionais é mais conveniente, uma vez que os estudos de casocontrole permitem a avaliação de apenas uma doença por vez.

\subsection{Indicadores de Saúde}

HELLER (1997), comentando sobre as variáveis aplicáveis a estudos de impacto de intervenções em saneamento, diz que a escolha de uma variável ou de um indicador, que reflita o estado de saúde de um grupo populacional, deve conciliar o compromisso entre a necessidade de efetivamente expressar a condição de saúde coletiva, por um lado, e a sua adequabilidade à pesquisa em questão, por meio de sua validade, de sua confiabilidade e de sua habilidade de representar o efeito da exposição, por outro.

Nos estudos de casos levantados por HELLER (1995), quando foram analisados 238 estudos sobre a avaliação da associação entre condições de saneamento e de saúde, verificou-se a maior freqüência do emprego da morbidade por enfermidades diarréicas como indicador de saúde nos estudos pesquisados.

Segundo BRISCOE et al. (1986), a morbidade por enfermidades diarréicas é adotada como indicador de saúde na avaliação de impactos de intervenções em saneamento, devido: a sua importância sobre a saúde pública; à validade e 
confiabilidade dos instrumentos empregados na sua determinação; a sua capacidade de resposta à alteração nas condições de saneamento e o custo e exeqüibilidade demonstrados na sua determinação. Em relação à importância no âmbito da saúde pública, os autores dizem que as doenças diarréicas são a principal causa de morbidade em crianças nos países em desenvolvimento.

A diarréia é usualmente definida como a passagem de três ou mais movimentos intestinais líquidos, que assumem a forma do recipiente, em 24 horas. Um episódio de diarréia, por outro lado, é convencionalmente definido como aquele que se inicia no primeiro período de 24 horas, no qual se verifica a definição de diarréia, e termina no último dia anterior a pelo menos dois dias consecutivos, em que não ocorre o evento da definição (LIMA \& GUERRANT, 1992 apud HELLER, $1997)^{5}$

HELLER (1995) salienta que a diarréia constitui um sintoma de diversas etiologias diferentes, cada qual com seus respectivos fatores de risco. Entretanto, segundo o autor, o estudo das enfermidades diarréicas e seus determinantes tem sido habitual, dado a seu significado em termos de saúde pública e à possibilidade do desenvolvimento de estratégias comuns de controle para a diarréia, independente da etiologia.

Outros indicadores de saúde vêm sendo empregados nos estudos epidemiológicos de ações de saneamento, destacando-se o estado nutricional, nematóides intestinais, enfermidades oculares e enfermidades dermatológicas.

O estado nutricional é, provavelmente, o indicador mais simples do estado

${ }^{5}$ LIMA, A. A. M., GUERRANT, R. L. Persistent diarrhea in children: epidemiology, risk factors, pathophysiology, nutricional impact, and management. Epidemiologic Reviews, v.14, p. 222-242, 1992. 
de saúde de uma população. O estado nutricional pode ser expresso por meio dos índices antropométricos: peso-por-idade, peso-por-altura e altura-por-idade. O pesopor-idade é a medida mais utilizada em estudos de coorte, nos quais são tomadas medidas repetitivas de uma criança em particular. Entretanto, o peso-por-idade tem a desvantagem de não distinguir entre uma má nutrição presente ou passada. Desta forma, para avaliações do estado nutricional em estudos seccionais o peso-por-altura deve ser utilizado como o indicador de diarréia recente e de desnutrição, enquanto a altura-por-idade, como o indicador do efeito cumulativo de desnutrição por um longo período (BRISCOE et al., 1986).

Uma das vantagens da utilização dos índices antropométricos é que eles constituem determinações objetivas (medidas do peso, altura e conhecimento da idade da criança), as quais independem de informações ou percepções da mãe, como no caso das doenças diarréicas. Contudo, devem ser tomados alguns cuidados especiais na avaliação das medidas antropométricas.

Segundo BRISCOE et al. (1986), os índices antropométricos mais comumente usados para avaliar o impacto sobre a saúde das condições de saneamento são a percentagem de crianças que estão abaixo $100 \%$ ou $90 \%$ dos níveis de referência de peso-por-altura e peso-por-idade. Os autores sugerem que, para as avaliações de intervenções em abastecimento de água e esgotamento sanitário, as medidas dos índices antropométricos sejam realizadas somente em crianças realmente desnutridas, a fim de aumentar a resposta da variável e que uma medida apropriada pode ser a prevalência de crianças que situam abaixo dois desvios-padrão, segundo o United Satates National Center for Health Statistics Reference Standards.

Os nematóides intestinais mais comuns, especificamente o ancilóstomo, 
Ascaris e Trichurius, podem ser uma medida apropriada do impacto de intervenções em esgotamento sanitário, adotando-se como medida a prevalência da infecção ou, no caso que se deseje categorizar grupos diferenciados de indivíduos, a intensidade da infecção (BRISCOE et al., 1986).

O tracoma é uma doença infecciosa da conjuntiva e da córnea, causada pela Chlamydia trachomatis. Sua importância para a saúde pública está associada a hábitos de higiene inadequados. Segundo BRISCOE et al. (1986), o tracoma é um importante indicador na avaliação dos impactos advindos com a melhoria do abastecimento de água e de hábitos higiênicos. A variável recomendada é a medida da prevalência do tracoma inflamatório.

As doenças dermatológicas são comuns nos países em desenvolvimento, principalmente, entre crianças de 6 meses a 10 anos de idade. A epidemiologia das doenças de pele nos países em desenvolvimento não é bem conhecida, contudo, a melhoria do abastecimento de água e da prática de higiene pessoal são fatores preventivos de algumas enfermidades, principalmente, as escabioses. As piodermites, doenças de pele com casca, são causadas, em $75 \%$ dos casos, por bactérias, fungos, vírus ou parasitas. Nestas doenças, as moscas e mosquitos exercem um papel importante e os programas de saneamento podem reduzir os locais de criadouros destes insetos. A prevalência de piodermites é maior em crianças abaixo de 10 anos de idade e, excluindo as escabioses, varia de 10 a 35\% (BRISCOE et al., 1986).

\subsection{Caracterização da Área de Estudo}

A seguir, serão descritas algumas características da área onde foi desenvolvida a 
presente pesquisa. O presente estudo foi desenvolvido junto à população residente no Bairro de Perus, situado no entorno da área de pesquisa, o Aterro Sanitário Bandeirantes, no município de São Paulo, SP.

\subsubsection{O Município de São Paulo e a Questão dos Resíduos Sólidos}

O município de São Paulo com $1.509 \mathrm{~km}^{2}$ e área urbana correspondendo a 54,8\% do território municipal. A cidade de São Paulo possui cerca de 10 milhões de habitantes e densidade demográfica de 67,2 habitantes /ha, sendo a maior cidade do hemisfério sul é uma das maiores do mundo.

Atualmente, São Paulo produz cerca de 15.000 toneladas de resíduos sólidos que são coletadas diariamente. Sendo que dos resíduos coletados, 62,5\% são compostos por resíduos domiciliares, $32 \%$ por entulho, 1,0\% resíduos infectantes e 4,5\% por resíduos industriais (BARREIRA \& PHILIPPI JR., 2001).

Os resíduos, gerados e coletados no município, têm as seguintes destinações (PREFEITURA MUNICIPAL DE SÃO PAULO, 1995):

- $90,1 \%$ são depositados em aterros sanitários;

- $\quad 6,2 \%$ são transformados em composto orgânico;

- $0,1 \%$ são vendidos para empresas e industrias recicladoras;

- $1,6 \%$ são incinerados e;

- $2,0 \%$ encaminhados para aterros de inertes.

Os resíduos sólidos urbanos produzidos em São Paulo são compostos basicamente por materiais que possuem um grande potencial de reaproveitamento econômico. A Figura 2 apresenta a composição gravimétrica dos resíduos sólidos 
produzidos em São Paulo.

O LIMPURB, Departamento de Limpeza Pública, é o órgão, pertencente à Secretaria de Serviços e Obras da Prefeitura Municipal de São Paulo, responsável pela limpeza urbana no município e, portanto, pela execução dos serviços de coleta, transporte, tratamento e destinação final dos resíduos sólidos produzidos no município.

\section{Histórico da Limpeza Urbana em São Paulo}

A seguir será apresentado um breve histórico da limpeza urbana do município de São Paulo, baseado em dados e informações constantes em PREFEITURA MUNICIPAL DE SÃO PAULO (1995).

Durante o século XIX, a cidade de São Paulo apresentou um processo acentuado de industrialização, atraindo grandes massas de mão-de-obra operária, tanto do interior do Estado, como de outros estados e do exterior. Este crescimento populacional repentino promoveu a ocupação de terrenos vagos, existentes na cidade, que sediavam pequenas propriedades hortigranjeiras com edificações urbanas, aumentando rapidamente a concentração populacional. A cidade, no entanto, não estava preparada do ponto de vista da infra-estrutura dos serviços públicos em geral para essa inesperada expansão, ocasionando, particularmente, em relação ao aspecto dos resíduos sólidos urbanos um aumento de sua geração e a necessidade de reformulação do modelo adotado até então. Até essa época a questão dos resíduos sólidos era equacionada pela simples definição de áreas especiais para a disposição, feita a céu aberto, e situadas nos limites da cidade. O encaminhamento dos resíduos 
até essas áreas era feito pelos próprios munícipes. A produção de resíduos sólidos industriais era incipiente, não representando motivo de preocupação.

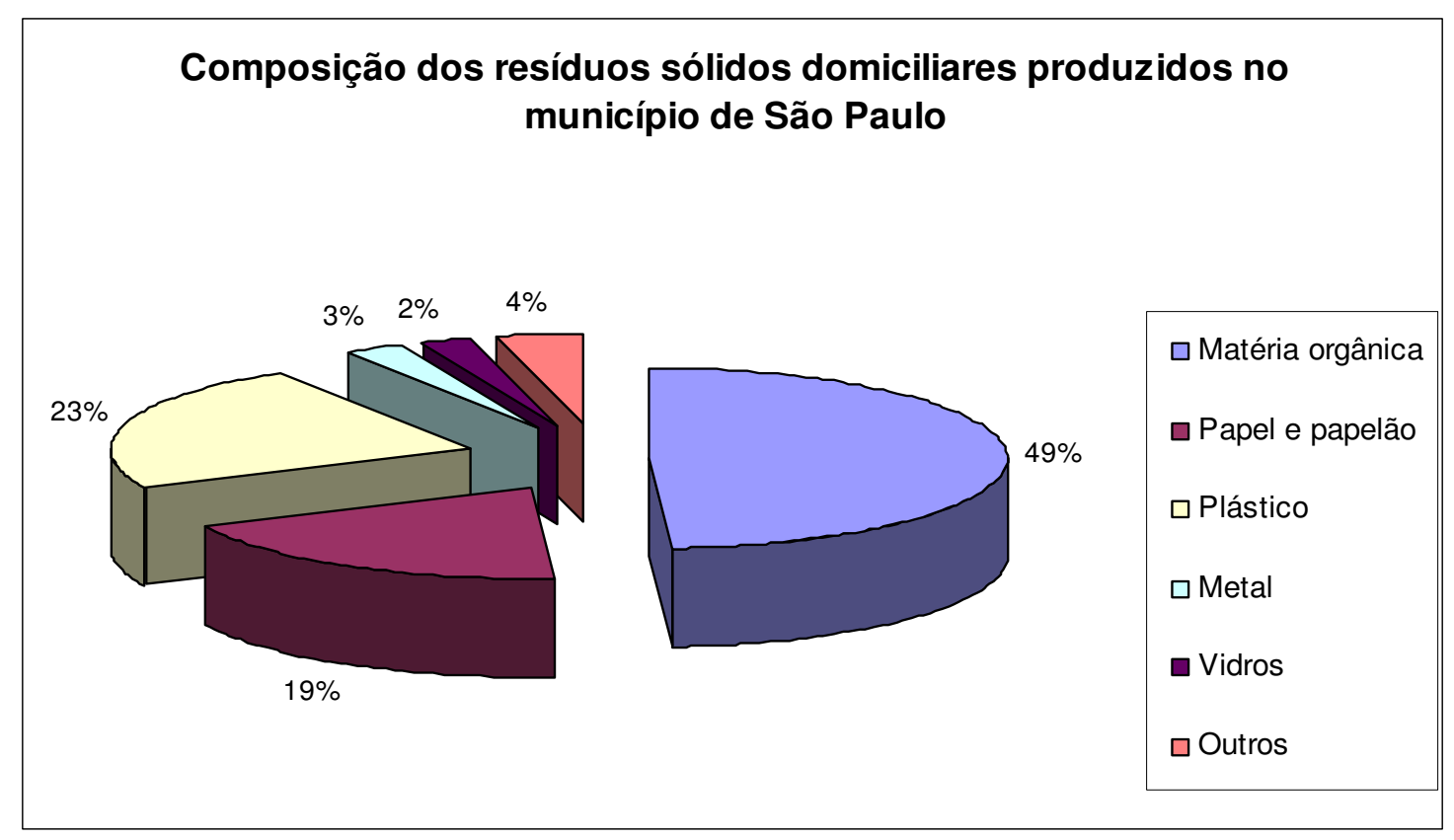

Fonte: PREFEITURA MUNICIPAL DE SÃO PAULO (1995).

FIGURA 2 - Composição dos resíduos sólidos produzidos no município de São Paulo.

Em 1869, foi firmado em São Paulo o primeiro contrato de prestação de serviços de limpeza pública e, em 1892, inaugurado o primeiro incinerador. São Paulo assumia assim, uma posição de vanguarda no atendimento a destinação final dos resíduos sólidos urbanos, em relação ao restante do País.

No início do século XX, a população de São Paulo aproximava-se a 240 mil habitantes. O serviço de coleta de resíduos permaneceu terceirizado até o ano de 
1913. Nessa época eram recolhidas cerca de 99 toneladas diárias de resíduos, resultando em uma taxa per capta média de, aproximadamente, 0,40kg por habitante/dia. A distribuição dos resíduos sólidos urbanos por unidade de destinação era a seguinte, na época:

- $65,5 \%$ depositados a céu aberto em lixões;

- 23,2\% entregues a chacareiros para uso como adubo orgânico;

- $10,6 \%$ eram incinerados;

- $0,7 \%$ reciclados e utilizados como matéria prima pelas indústrias.

Em 1913, foi inaugurado um novo incinerador, localizado no bairro de Araçá, com capacidade para queimar diariamente 40 toneladas de resíduos sólidos. Em 1914, por meio de um ato do então prefeito municipal, Washington Luiz, os serviços de limpeza urbana passaram para a administração direta, operada pela municipalidade. Nessa época, as autoridades, preocupadas com as condições sanitárias do processo da entrega dos resíduos sólidos "in natura" aos chacareiros, começaram a criticar esse processo e, a partir de 1925, foi empregado um processo de fermentação para a destinação dos resíduos de natureza orgânica. Os serviços de coleta utilizavam a tração animal, atingindo naquele ano, o número de 1500 muares. Os serviços eram dotados de infra-estrutura apropriada, composta por: tratores, cavalariços, veterinários, farmacêuticos, cocheiras, pastos, selaria, farmácia, depósito de feno e outras instalações. Para as condições da época, São Paulo era considerada uma cidade limpa, quando comparada às grandes cidades do mundo.

Entre 1940 e 1950, a conversão da matéria orgânica em adubo atingiu o clímax, chegando a representar mais da metade da capacidade das destinações disponíveis para o aproveitamento dos resíduos. 
Em 1948, o incinerador do bairro Araçá foi desativado, sendo inaugurado, no ano seguinte, o incinerador de Pinheiros, mais moderno e com capacidade de processar 200 toneladas de resíduos por dia.

No início da década de 50, a população de São Paulo, ultrapassou os dois milhões de habitantes e a cidade começou a adquirir características de metrópole. Em 1959, foi inaugurado o incinerador da Ponte Pequena, com a capacidade de queimar 300 toneladas de resíduos por dia.

Na década de 60, a coleta realizada até então por tração animal, foi sendo gradativamente substituída por veículos automotores. Em 1968, a frota coletora da cidade de São Paulo já era toda mecanizada. Neste mesmo ano, as Administrações Regionais (A.R.s), implantadas por Decreto Municipal em 1965, passaram a ser responsáveis pelos serviços de coleta regular dos resíduos sólidos urbanos; remoções especiais; lavagem de vias públicas e feiras-livres; capinação; raspagem; limpeza dos sistema de drenagem pluvial e pintura de meio-fio. O Departamento de Limpeza Pública - LIMPU ficou responsável pelo tratamento e destinação final dos resíduos coletados, bem como pelo planejamento, controle e contratação de serviços de terceiros, caracterizando uma função predominantemente normativa.

Ainda nesse mesmo ano, foi inaugurado o incinerador de Vergueiro, com capacidade de processamento de 300 toneladas por dia. Este incinerador, pela tecnologia empregada, encontra-se em operação até os dias de hoje, sendo utilizado para a incineração de resíduos de natureza patogênica, provenientes dos serviços de saúde.

Em 1970, foi inaugurada a primeira usina de compostagem nos moldes modernos, empregando a tecnologia DANO. A Usina de São Matheus tinha a 
capacidade de processar 200 toneladas de resíduos sólidos domiciliares por dia. Nesse mesmo ano, foi desativado o incinerador de Ponte Pequena e, nas instalações, foi implantada a primeira estação de transferência com prensagem do País. Em área vizinha ao incinerador de Vergueiro, foi construída a segunda estação de transbordo para movimentar 100 toneladas por dia. Nessa estação o transbordo era feito pela descarga direta dos resíduos nas carretas.

Em 1974, foi inaugurada a Usina de Compostagem de Vila Leopoldina, empregando a tecnologia DANO. A usina possuía capacidade original de processar 410 toneladas de resíduos por dia.

Até 1973, o destino final dado aos resíduos gerados na cidade de São Paulo era quase que exclusivamente a disposição em "lixões" municipais e clandestinos, apesar de serem chamados pela Prefeitura de aterros. Contudo, não eram operados de acordo com as exigências ambientais. Assim, eram os aterros de Vila Guilherme, de Eng ${ }^{\circ}$. Goulart, do km 14,5 da Rodovia Raposo Tavares, da $3^{\text {a }}$. Divisão e outros menores, utilizados pelas A.R.s para a disposição local dos resíduos sólidos urbanos, coletados na área de sua atuação e responsabilidade. Nesses locais era freqüente a presença de catadores.

Em 1977 foi elaborado o primeiro Plano Diretor de Limpeza Urbana do município, que elegeu o aterro sanitário como o método mais econômico e adequado para a destinação dos resíduos sólidos gerados em São Paulo. Em conseqüência, o plano propôs a implantação sucessiva de 16 aterros sanitários, em um prazo de 15 anos, e de 4 novas estações de transbordo, para a racionalização do transporte dos resíduos até os aterros. Com essa política de estímulo ao aterramento dos resíduos, observou-se uma gradativa diminuição da quantidade de resíduos destinada aos 
incineradores e um aumento do número de aterros em operação no município. Datam dessa época os aterros de Jardim Damasceno, Engo. Goulart, Fernão Dias, Bandeirantes, Sapopemba, Jacuí, Vila Albertina, Santo Amaro, São Matheus e Sítio São João.

Contudo, das proposições apresentadas pelo Plano Diretor, poucas foram implantadas, acarretando um fato gravíssimo para o município, a escassez de áreas potenciais para a disposição dos resíduos sólidos. A este fato, acrescentou-se o aumento acentuado da geração de resíduos verificado na época, ocasionando o encerramento de vários aterros, pelo esgotamento de suas capacidades úteis. $\mathrm{O}$ Departamento de Limpeza Urbana - LIMPURB que, em 1976, substituiu o LIMPU, sem que houvesse alterações em sua estrutura e competências, via-se em uma situação bastante difícil, uma vez que, dos resíduos produzidos na época, 90,9\% eram destinados aos aterros; 4,9\% para as usinas de compostagem e 4,2\% aos incineradores.

A capacidade das usinas de compostagem de São Matheus e Vila Leopoldina foram ampliadas para 600 e 1000 toneladas diárias. Contudo, tais providências ainda foram insuficientes para o equacionamento das destinações dos resíduos gerados no município, face ao iminente esgotamento da capacidade de alguns aterros em operação. A década de 80 encerrou-se com os aterros sanitários recebendo a grande maioria dos resíduos gerados, $86,8 \%$, enquanto as usinas de compostagem e os incineradores, em operação na época, respondiam por $10,4 \%$ e $2,8 \%$, respectivamente, da destinação final dada aos resíduos sólidos produzidos em São Paulo.

A década de 90 iniciou-se com quatro aterros em operação: os aterros de 
Santo Amaro, Vila Albertina, Bandeirantes e Itatinga. Os aterros de Santo Amaro e Vila Albertina, por estarem com suas capacidades esgotadas, foram desativados no início dos anos 90.

$\mathrm{O}$ aterro Itatinga, inicialmente operado apenas com resíduos inertes, passou a ser utilizado, logo após o fechamento do aterro Santo Amaro, para a deposição de resíduos sólidos domiciliares. Contudo, por ação da população local que foi contra a esse procedimento, $\mathrm{o}$ aterro foi desativado.

Em 1992, entrou em operação o aterro São João, situado na A.R.s São Matheus. Este aterro recebe atualmente os resíduos sólidos oriundos, principalmente, da Zona Leste e da estação de transbordo de Vergueiro. Portanto, atualmente, o município de São Paulo conta com apenas dois aterros em operação: o Aterro Sanitário São João e o Aterro Sanitário Bandeirantes, no entorno do qual se realizou a presente pesquisa.

As usinas de compostagem de São Matheus e Vila Leopoldina mantêm-se em operação. Juntas recebem, atualmente, cerca de 38 mil toneladas mensais de resíduos, das quais 53 \% são transformadas em composto orgânico.

Dos incineradores, apenas dois encontram-se, atualmente, em operação: Vergueiro e Ponte Pequena. Estas unidades recebem juntas cerca de 5.400 toneladas de resíduos por mês. Recebendo, basicamente, os resíduos provenientes dos estabelecimentos dos serviços de saúde. Nesses incineradores são queimados resíduos domiciliares apenas com o objetivo de aumentar o poder calorífico dos resíduos, mantendo a temperatura de queima na faixa de 750 a $800^{\circ} \mathrm{C}$.

Desta forma, a distribuição atual das destinações das 360 mil toneladas mensais de resíduos coletadas no município de São Paulo, segue a proporção 
apresentada na Figura 3.

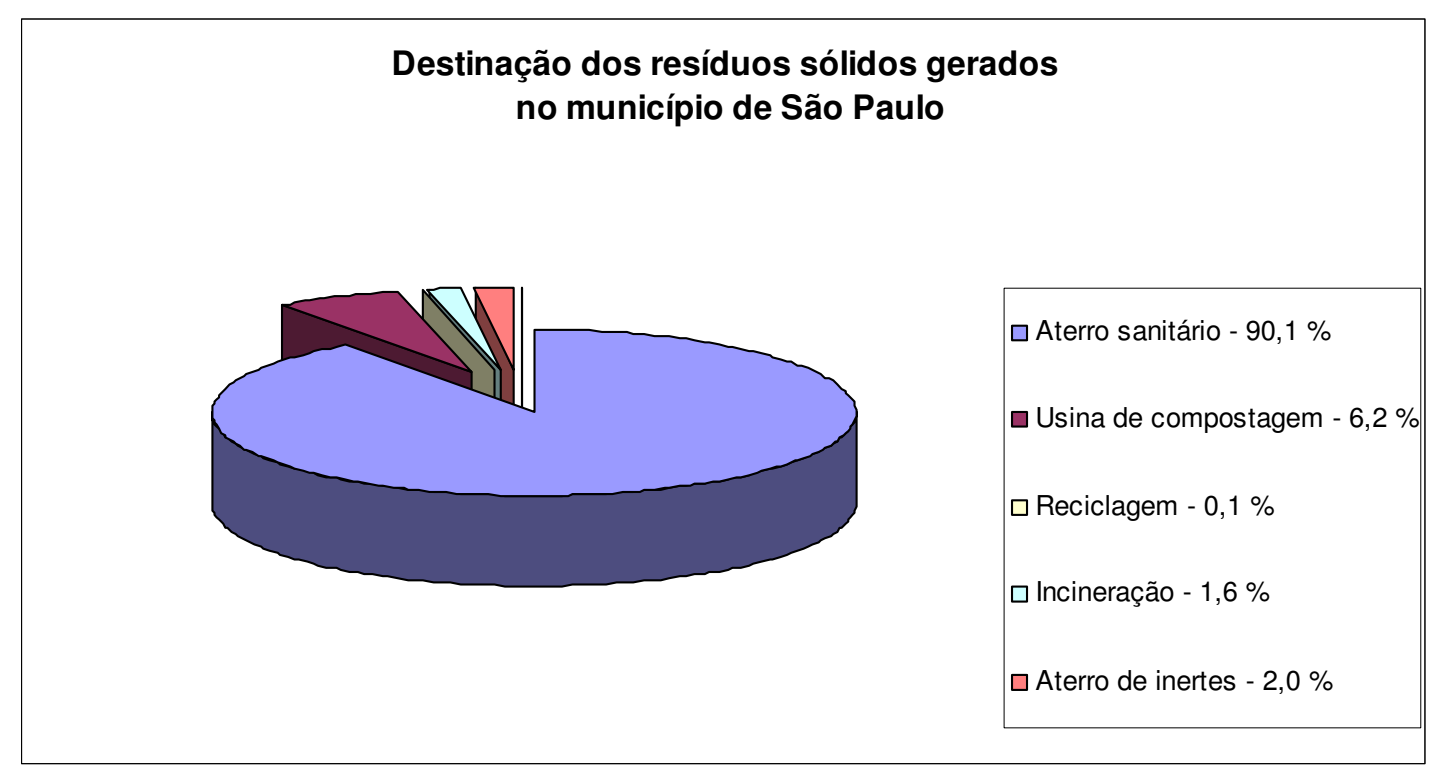

Fonte: PREFEITURA MUNICIPAL DE SÃO PAULO (1995).

FIGURA 3 - Destinação dos resíduos sólidos gerados no município de São Paulo.

Na Figura 4 é apresentado o mapa de localização das unidades de tratamento e destinação final dada aos resíduos sólidos gerados no município de São Paulo. A seguir serão descritas algumas características do Aterro Sanitário Bandeirantes, local de realização do presente estudo. 


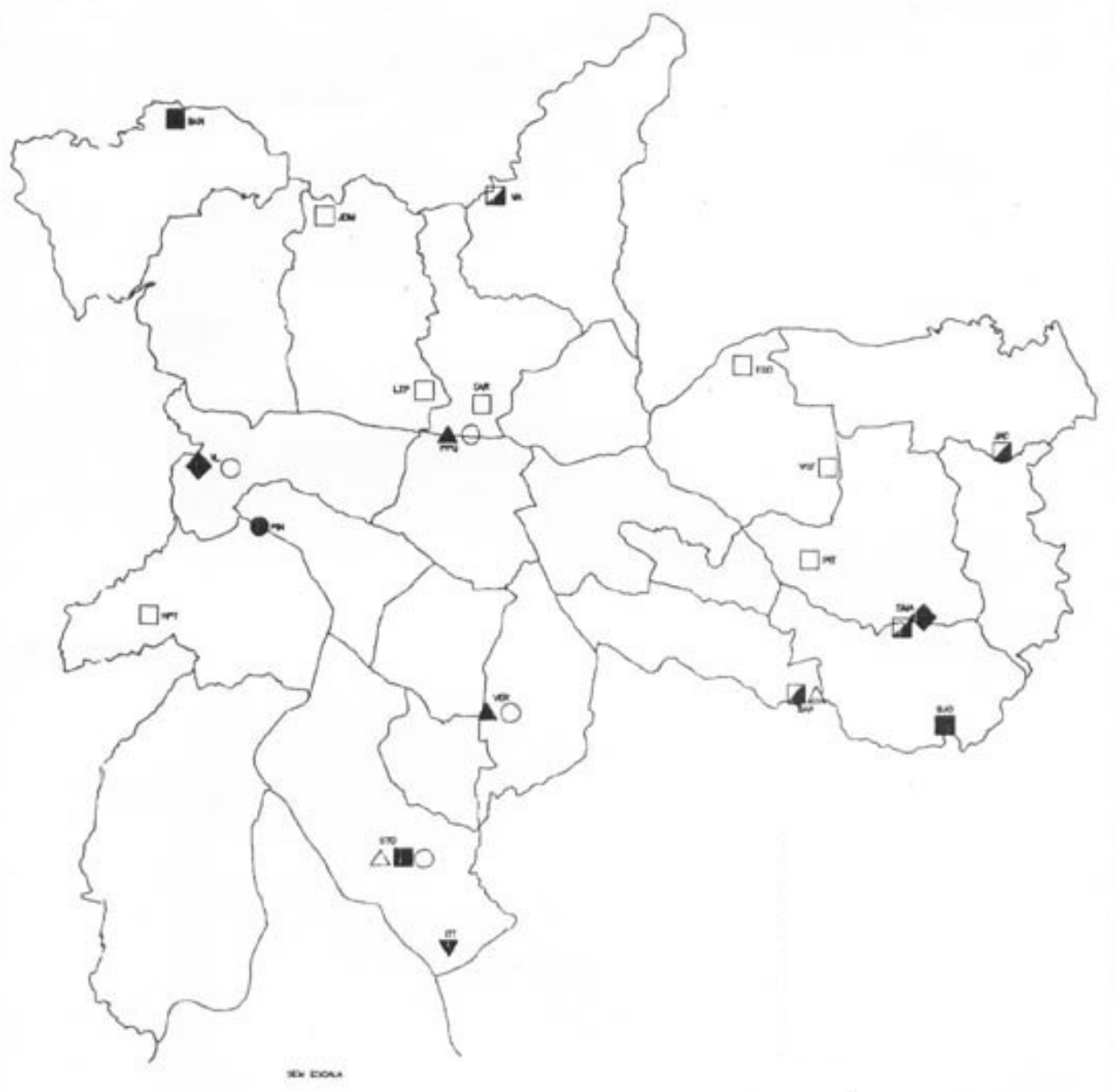

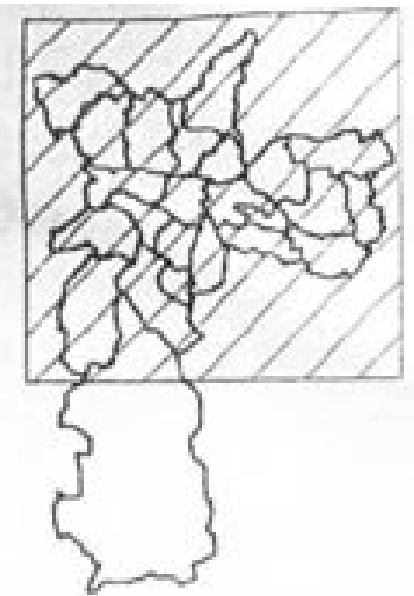

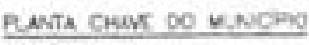
now

\section{Legenda:}

$\square$ Aterro sanitário encerrado

- Aterro sanitário em operação

$\square$ Aterro sanitário em manutenção

$\Delta$ Incinerador em operação

$\Delta$ Incinerador em projeto

- Centro de triagem

$\diamond$ Compostagem

$\nabla$ Inertes

○ Estação de transbordo

FIGURA 4 - Mapa de localização das unidades de tratamento e destinação dos resíduos sólidos em São Paulo. 


\subsubsection{Aterro Sanitário Bandeirantes}

O Aterro Sanitário Bandeirantes localiza-se no km 26,5 da Rodovia dos Bandeirantes, na zona noroeste da cidade de São Paulo, no Bairro de Perus, que faz parte da Administração Regional de Perus da Prefeitura de São Paulo.

A operação do aterro teve início em 01 de setembro de 1979 e tem o término previsto para junho de 2006. Até o ano de 2000, 24.250.000 toneladas de resíduos sólidos haviam sido dispostas na área, sendo que o aterro possui capacidade total, no fim de sua vida útil, estimada para 30.000.000 toneladas. $\mathrm{O}$ aterro encontra-se com a altura máxima de disposição de resíduos de 104m.

O Aterro Sanitário Bandeirantes é dividido em cinco sub-aterros, designados por: AS-1, AS-2, AS-3, AS-4 e AS-5, ocupando uma área de aproximadamente 1.400.000 $\mathrm{m}^{2}$, o que faz do Aterro Bandeirantes um dos maiores aterros em operação do País. Atualmente, o aterro recebe cerca de 6.000 toneladas de resíduos sólidos por dia, provenientes, principalmente, da unidade de transbordo Ponte Pequena, da usina de compostagem de Vila Leopoldina e das A.R.s de Pirituba, Jaraguá e Perus. No aterro são também depositados resíduos industriais Classe II (não perigoso) e inertes e resíduos da estação de tratamento de resíduos de saúde de Jaraguá. Os resíduos de varrição são provenientes das A.R.s de Pirituba, Jaraguá, Freguesia do Ó, Casa Verde, Perus e Butantã. A origem dos resíduos da coleta de entulhos, limpeza de boca de lobo e de podas, dispostos no aterro, é das A.R.s da Lapa, Sé, Butantã, Pirituba, Jaraguá, Perus, Pinheiros, Freguesia do Ó e Casa Verde.

O chorume produzido no aterro, a uma vazão média anual de 151/s, é 
armazenado em lagoas de $27.000 \mathrm{~m}^{3}$ de capacidade e transportado para a Estação de Tratamento de Esgotos de Piqueri, pertencente a SABESP, onde é tratado em conjunto com o esgoto sanitário. $\mathrm{O}$ tratamento, portanto, do chorume não é realizado "in situ", na própria área do aterro.

O Aterro Sanitário Bandeirantes é operado pela empresa concessionária Heleno e Fonseca Construtécnica. As instalações administrativas ocupam uma área de $20.000 \mathrm{~m}^{2}$, sendo compostas por balança, prédio da administração, oficinas, alojamentos, cantina e refeitório. As lagoas, projetadas inicialmente para o tratamento de chorume, ocupam uma área de $20.000 \mathrm{~m}^{2}$. No aterro é destinada uma área de $50.000 \mathrm{~m}^{2}$ para a disposição dos resíduos inertes. Também existe uma área destinada à preservação ambiental de $50.000 \mathrm{~m}^{2}$.

Na Tabela 16 é apresentado um histórico resumido da disposição de resíduos sólidos no Aterro Sanitário Bandeirantes.

Nas Figuras 5 e 6 são apresentadas as localizações do Aterro Sanitário Bandeirantes em relação à cidade de São Paulo e ao Bairro de Perus, respectivamente. A Figura 7 apresenta o arranjo geral do Aterro Sanitário Bandeirantes.

\subsubsection{O Bairro de Perus}

A seguir será apresentada uma compilação de alguns dados levantados que caracterizam e descrevem a área onde foram desenvolvidas as investigações de campo da presente pesquisa, o Bairro de Perus, situado no entorno do Aterro Sanitário Bandeirantes, na região noroeste do município de São Paulo. O Bairro de 
Perus faz parte da regional administrativa de Perus, onde foram levantados, junto à população residente, os dados de morbidade por doenças diarréicas, parasitárias e realizadas as medidas antropométricas na população de estudo. As informações apresentadas a seguir foram baseadas em informações levantadas junto à Administração Regional de Perus, ao Distrito de Saúde de Perus, à Unidade Básica de Saúde e em creches e escolas locais e no documento PREFEITURA MUNICIPAL DE SÃO PAULO (2002).

TABELA 16 - Histórico da disposição dos resíduos sólidos urbanos no Aterro Sanitário Bandeirantes, SP

\begin{tabular}{|c|c|c|c|c|c|}
\hline \multirow[t]{2}{*}{ Sub-aterro } & \multicolumn{2}{|c|}{ Operação (ano) } & \multicolumn{2}{|c|}{$\begin{array}{c}\text { Cota do aterro - operação } \\
\text { (m) }\end{array}$} & \multirow[t]{2}{*}{$\begin{array}{l}\text { Área } \\
\left(\mathbf{m}^{2}\right)\end{array}$} \\
\hline & Início & Fim & Início & Fim & \\
\hline $\begin{array}{c}\text { AS-1 } \\
\text { 1ª }^{\mathrm{a}} \text { Fase } \\
2^{\mathrm{a}} \text {. Fase }\end{array}$ & $\begin{array}{l}1979 \\
1991\end{array}$ & $\begin{array}{l}1986 \\
1995\end{array}$ & 43 & 148 & 200.000 \\
\hline AS-2 & 1980 & 1990 & 57 & 148 & 300.000 \\
\hline AS-3 & 1992 & 1995 & 53 & 148 & 180.000 \\
\hline $\begin{array}{c}\text { AS-4 } \\
\text { Emergência } \\
\text { Implantação } \\
\text { Operação }\end{array}$ & $\begin{array}{c}\text { Fev./1995 } \\
\text { Março/1995 } \\
\text { Jan./1996 }\end{array}$ & Maio/1995 & 110 & 143 & 280.000 \\
\hline $\begin{array}{c}\text { AS-5 } \\
\text { Implantação } \\
\text { Operação }\end{array}$ & $\begin{array}{c}\text { Março/1996 } \\
\text { Nov./1996 }\end{array}$ & & & & \\
\hline AS-4 + AS-5 & & & 55 & $\begin{array}{c}143 \\
\text { (prevista) }\end{array}$ & $\begin{array}{c}280.000+ \\
125.000= \\
405.000\end{array}$ \\
\hline
\end{tabular}


A região administrativa de Perus faz parte, junto com as regionais de Anhanguera e Jaraguá, do Distrito de Saúde de Perus, componente do cinturão da Região Metropolitana da Grande Norte. Faz limites geográficos ao norte com o município de Caieiras; a oeste com Santana de Parnaíba, Cajamar, Barueri e Osasco; a leste com os Distritos Administrativos de Brasilândia e ao sul com os distritos de São Domingos e Pirituba.

As principais vias de acesso e que atravessam a região são a Rodovia Anhanguera e a Estrada Velha de Campinas, que dão acesso ao noroeste do Estado, além da estrada de ferro CPTM - Santos à Jundiaí que corta os Distritos de Perus e Jaraguá.

Segundo dados censitários de 2000, a população do Distrito de Saúde de Perus é de 254.742 habitantes, sendo 168.998 habitantes na zona urbana e 85.744 habitantes na zona rural. Nas Tabelas 17 e 18 são apresentadas, respectivamente, a distribuição da população por zona urbana e rural e a distribuição por faixa etária, segundo o distrito administrativo.

Tabela 17 - Distribuição da população urbana e rural por regional administrativa - Distrito de Saúde de Perus

\begin{tabular}{l|c|c|c}
\hline \multirow{2}{*}{ Distrito } & \multicolumn{3}{|c}{ População } \\
\cline { 2 - 4 } & Urbana & Rural & Total \\
\hline Perus & 50.975 & 19.740 & 70.715 \\
\hline Parque Anhanguera & 20.794 & 17.708 & 38.502 \\
\hline Jaraguá & 97229 & 48.296 & 145.525 \\
\hline Total & 168.998 & 85.744 & 254.742 \\
\hline
\end{tabular}

Fonte: PREFEITURA MUNICIPAL DE SÃO PAULO (2002). 


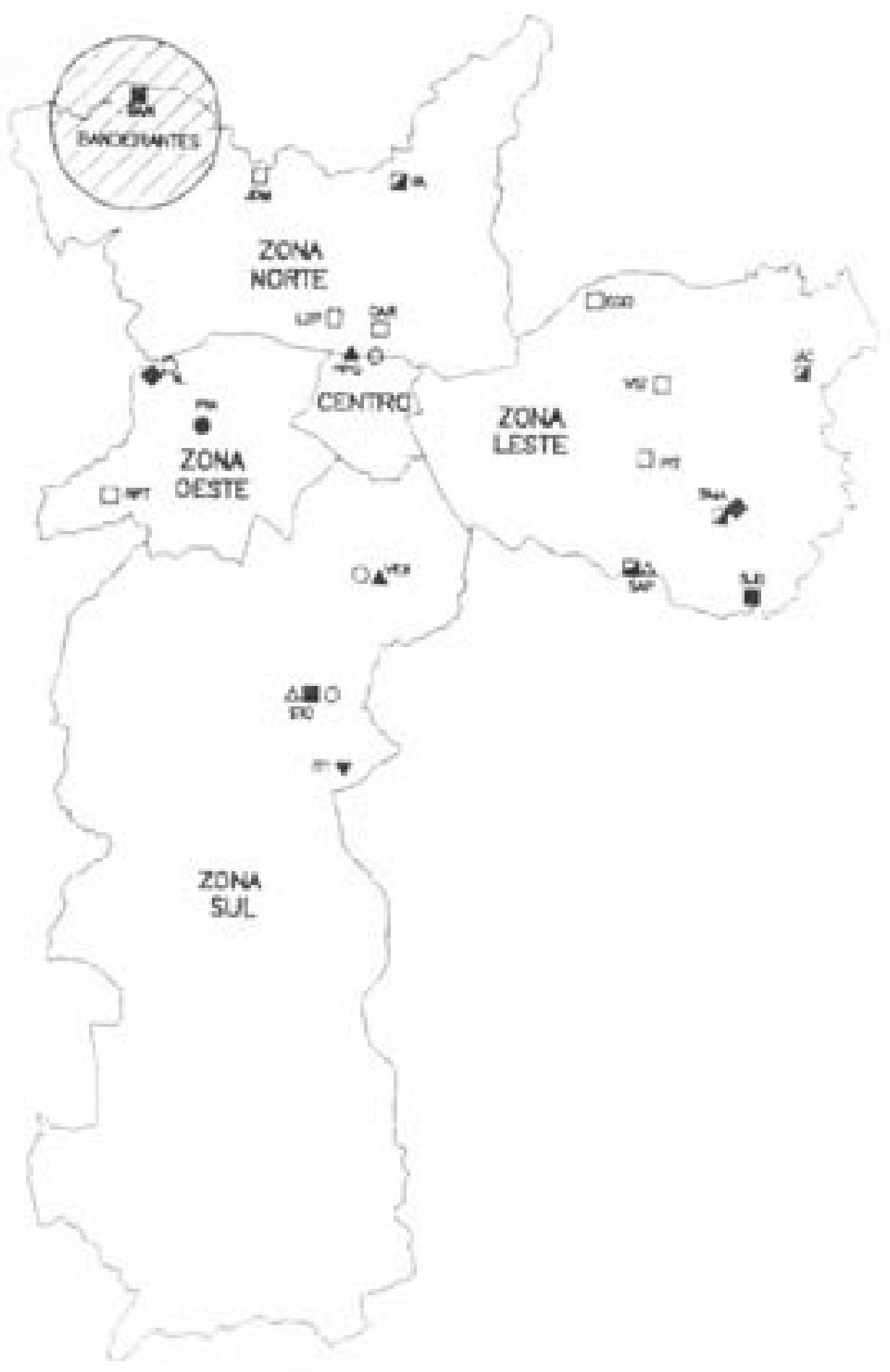

FIGURA 5 - Localização do Aterro Sanitário Bandeirantes em relação à cidade de São Paulo. 


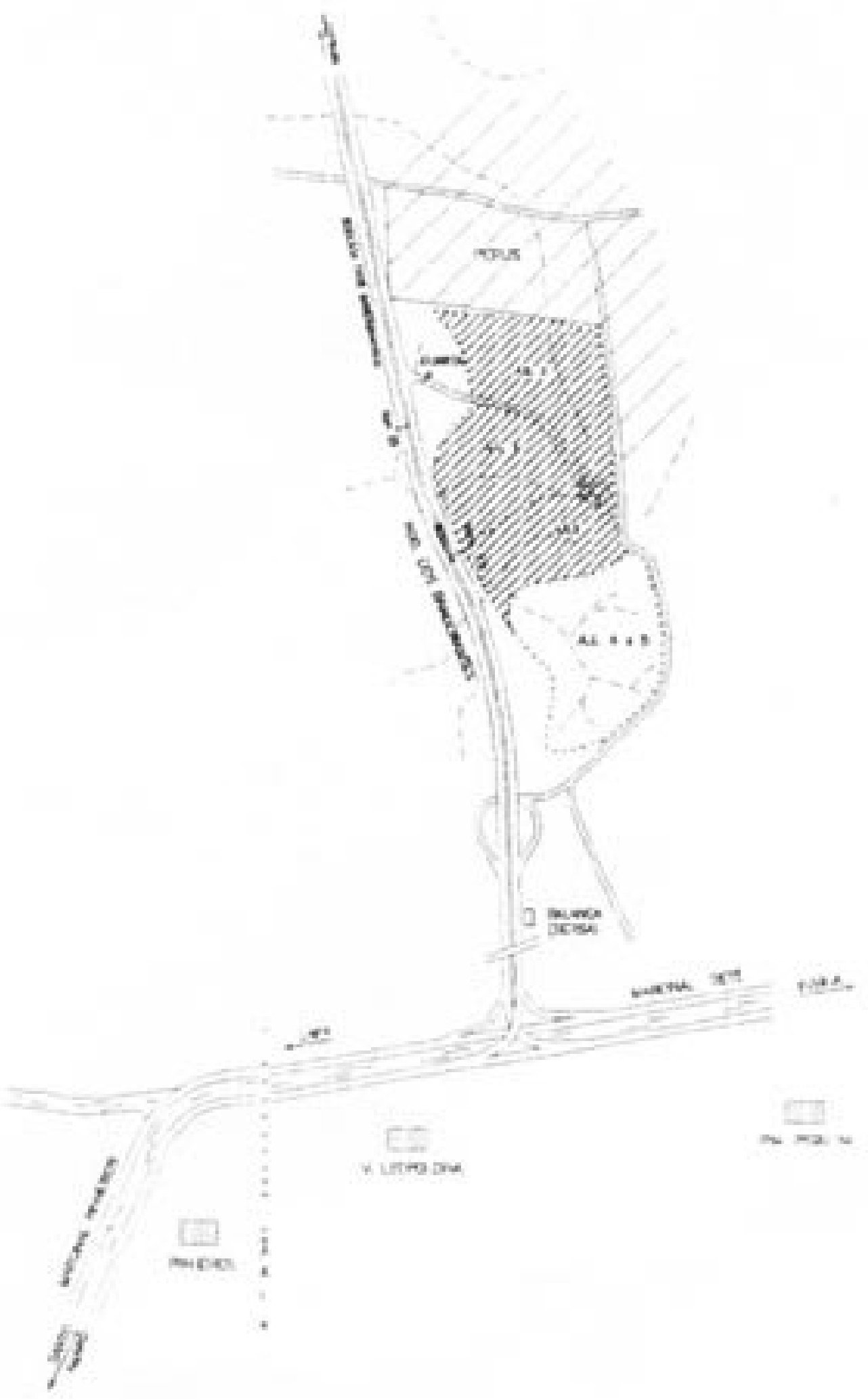

FIGURA 6 - Localização do Aterro Sanitário Bandeirantes em relação ao bairro de Perus da cidade de São Paulo. 


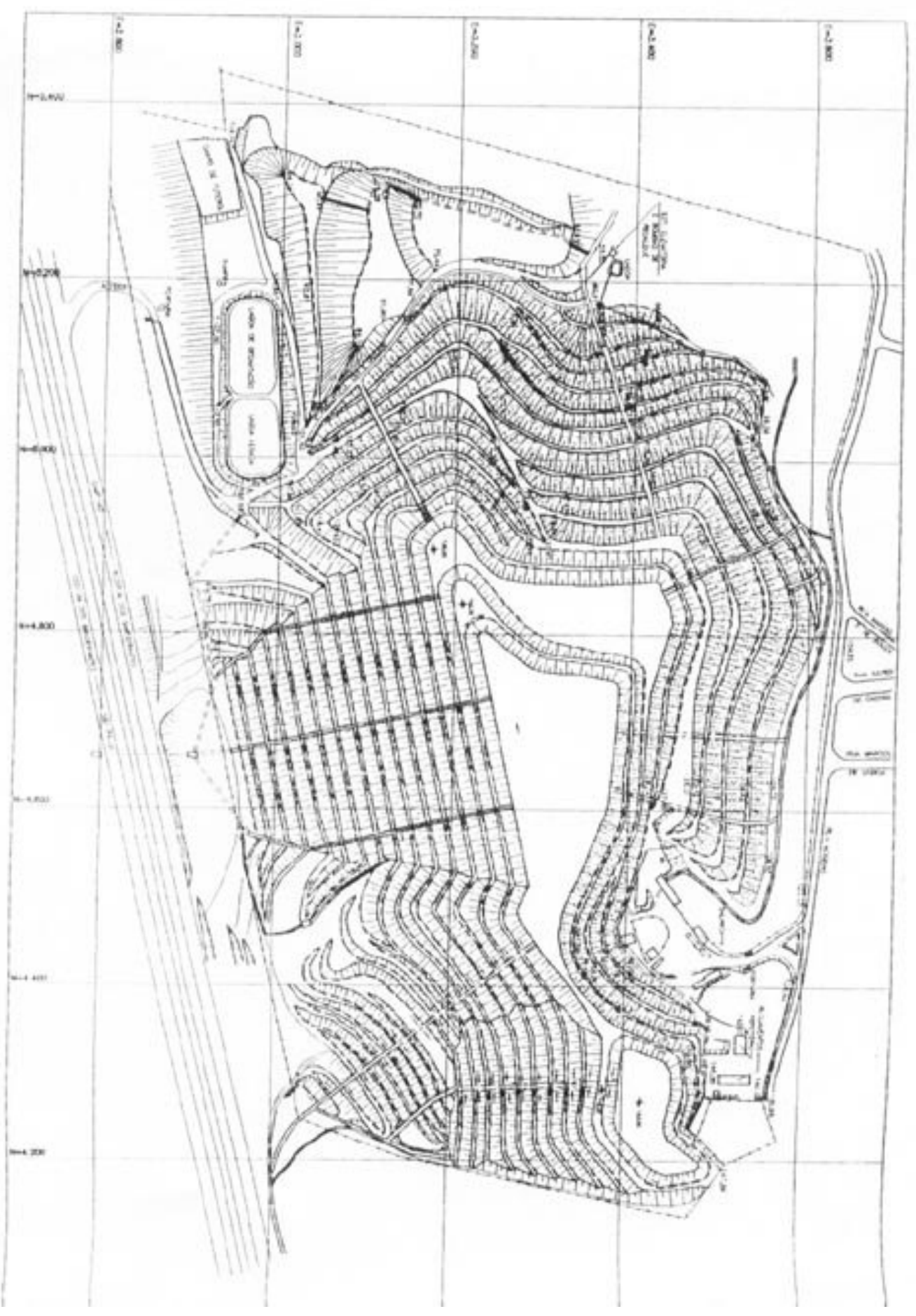

FIGURA 7 - Arranjo geral do Aterro Sanitário Bandeirantes. 
O índice de crescimento populacional de Perus é de 3,88\% ao ano. Os fatores preponderantes que determinaram a formação do distrito de Perus foram a inauguração, em 1914, da Estrada de Ferro Santos à Jundiaí e, em 1926, da Companhia de Cimento Portland S/A. A Companhia Cimento Portland S/A foi por mais de 40 anos a base econômica do bairro Perus e regiões do Distrito. As atividades da Companhia foram encerradas em 1981, após quase vinte anos de protestos e ações da população contra a imensa poluição gerada pelo pó-de-cimento. Atualmente, o Distrito de Saúde de Perus tem nas atividades do comércio, da indústria de transformação e da prestação de serviços os principais setores de atividade econômica, absorvendo junto com a indústria mineral a mão de obra ativa da população local. A Tabela 19 apresenta a distribuição do número de empregos por setor de atividade econômica nas regiões do Distrito de Saúde de Perus.

Na Tabela 20 é apresentada a distribuição da renda mensal por domicílio na regional de Perus. 
TABELA 18 - Distribuição da população por faixa etária e por regional administrativa no Distrito de Saúde de Perus

\begin{tabular}{|c|c|c|c|c|}
\hline \multirow{2}{*}{$\begin{array}{c}\text { Faixa Etária } \\
(\text { anos })\end{array}$} & \multicolumn{4}{|c|}{ População por distrito } \\
\hline & Perus & Anhanguera & Jaraguá & Total \\
\hline 0 a 4 & 7378 & 4093 & 10661 & 22132 \\
\hline 5 a 9 & 7101 & 4129 & 11278 & 22508 \\
\hline 10 a 14 & 7340 & 3894 & 12882 & 24116 \\
\hline 15 a 19 & 7149 & 3488 & 14611 & 25248 \\
\hline 20 a 24 & 7236 & 3755 & 14269 & 25260 \\
\hline 25 a 29 & 6728 & 4186 & 14039 & 24953 \\
\hline 30 a 34 & 6163 & 3800 & 12608 & 22571 \\
\hline 35 a 39 & 5443 & 3342 & 11367 & 20152 \\
\hline 40 a 44 & 4486 & 2379 & 9984 & 16849 \\
\hline 45 a 49 & 3379 & 1784 & 7997 & 13160 \\
\hline 50 a 54 & 2474 & 1142 & 6969 & 10585 \\
\hline 55 a 59 & 1778 & 853 & 5655 & 8286 \\
\hline 60 a 64 & 1460 & 524 & 4458 & 6442 \\
\hline 65 a 69 & 1008 & 395 & 3430 & 4833 \\
\hline 70 a 74 & 627 & 231 & 2209 & 3067 \\
\hline 75 a 79 & 415 & 173 & 1286 & 1874 \\
\hline 80 ou mais & 350 & 111 & 1233 & 1694 \\
\hline Ignorada & 200 & 224 & 589 & 1013 \\
\hline Total & 70.715 & 38.503 & 145.525 & 254.743 \\
\hline
\end{tabular}

Fonte: PREFEITURA MUNICIPAL DE SÃO PAULO (2002) 
TABELA 19 - Amostragem de empregos por setor de atividade econômica no Distrito de Saúde de Perus

\begin{tabular}{l|c|c|c|c|c|c|c|c}
\hline \multirow{2}{*}{ Distrito } & \multicolumn{7}{c}{ Setor de Atividade Econômica } \\
\cline { 2 - 9 } & $\begin{array}{c}\text { Agrope } \\
\text { cuária }\end{array}$ & $\begin{array}{c}\text { Extra } \\
\text { ção }\end{array}$ & $\begin{array}{c}\text { Ind. } \\
\text { Mineral }\end{array}$ & $\begin{array}{c}\text { Ind. } \\
\text { Transform }\end{array}$ & $\begin{array}{c}\text { Constru } \\
\text { ção } \\
\text { Útil.Públ. }\end{array}$ & $\begin{array}{c}\text { Comer } \\
\text { cio }\end{array}$ & $\begin{array}{c}\text { Servi } \\
\text { ços }\end{array}$ & $\begin{array}{c}\text { To } \\
\text { tal }\end{array}$ \\
\hline Perus & - & 7 & 317 & 10 & 61 & 605 & 568 & 1568 \\
\hline Anhanguera & 4 & - & 105 & - & 15 & 42 & 52 & 218 \\
\hline Jaraguá & - & 221 & 3082 & 118 & 115 & 1032 & 7560 & 1212 \\
\hline Total & 4 & 228 & 3504 & 128 & 191 & 1679 & 8180 & 1391 \\
\hline
\end{tabular}

Fonte: SEPLAM, 1997 apud PREFEITURA MUNICIPAL DE SÃO PAULO (2002)

TABELA 20 - Renda mensal por domicílio na regional de Perus

\begin{tabular}{l|c|c}
\hline \multicolumn{1}{c|}{ Rendimento Mensal } & $\mathbf{N}^{\mathbf{0}}$. domicílios & Percentagem \\
\hline Sem rendimento & 1042 & 7,37 \\
\hline Sem declaração & 283 & 8,30 \\
\hline Até 1 salário mínimo (SM) & 1174 & 20,03 \\
\hline Mais de 1 até 2 SM & 2833 & 20,56 \\
\hline Mais de 2 até 3 SM & 2970 & 21,00 \\
\hline Mais de 3 até 5 SM & 2339 & 16,54 \\
\hline Mais de 5 até 10 SM & 377 & 2,67 \\
\hline Mais de 10 até 15 SM & 107 & 0,76 \\
\hline Mais de 15 até 20 SM & 109 & 0,77 \\
\hline Mais de 20 SM & 14.142 & 100,00 \\
\hline Total & & \\
\hline
\end{tabular}




\section{CAPÍTULO III}

\section{MATERIAL E MÉTODOS}

\section{1. Área de Investigação}

\subsubsection{Critérios Utilizados para Seleção da Área de Investigação}

Pelos critérios estipulados para o desenvolvimento desta pesquisa e utilizados para a definição das condições de exposição a serem pesquisadas, o grupo exposto seria composto pela população residente no entorno de áreas utilizadas para a disposição final dos resíduos sólidos, até a uma distância de 1000 m do limite desses locais. Desta forma, a existência de uma ocupação urbana densa e contígua a essas áreas foi a condição precípua para a seleção da área de investigação.

Os critérios básicos utilizados na seleção da área de investigação foram:

- Disposição dos resíduos sólidos urbanos gerados no município em aterro sanitário.

- Ocupação urbana densa e consolidada no entorno da área do aterro sanitário. 
- Ocupação urbana no entorno do aterro sanitário iniciando no limite da área e ao longo da maior extensão do seu perímetro.

- População urbana no entorno do aterro sanitário em número compatível à amostra de estudo, definida pelo pré-dimensionamento da amostra.

- Condições socioeconômicas similares para as populações residentes no entorno das áreas a serem investigadas.

- Condições semelhantes de moradia, de saneamento básico e de infraestrutura para a área no entorno do aterro sanitário.

A definição da distância máxima de 1000 m, utilizada para a definição das condições de exposição, foi baseada em estudos realizados por BERRY \& BOVE (1997), e fixada com o intuito de não perder a especificidade entre a exposição estudada e as doenças pesquisadas. Baseada nesta distância a área de investigação foi classificada em três sub-áreas, conforme o distanciamento do local de disposição de resíduos sólidos. A Tabela 21 apresenta a classificação das sub-áreas de investigação, adotada para a definição do grau de exposição ambiental.

\subsubsection{Seleção da Área de Investigação}

A seleção da área de investigação foi realizada dentre as cidades do Estado de São Paulo, que realizavam a disposição final de resíduos sólidos urbanos segundo a prática do aterro sanitário. Baseado em informações levantadas junto a técnicos da CETESB - Companhia de Tecnologia de Saneamento Ambiental do Estado de São Paulo, algumas cidades foram pré-eleitas como possíveis áreas de estudo, uma vez 
que apresentavam ocupação urbana no entorno da área de aterramento de resíduos sólidos urbanos.

TABELA 21 - Classificação das sub-áreas de investigação

\begin{tabular}{|c|c|c|c|}
\hline $\begin{array}{l}\text { Sub- } \\
\text { área }\end{array}$ & $\begin{array}{l}\text { Distância do local } \\
\text { de disposição final }\end{array}$ & $\begin{array}{c}\text { Condição de exposição } \\
\text { considerada }\end{array}$ & $\begin{array}{c}\text { População considerada } \\
\text { exposta }\end{array}$ \\
\hline 1 & 0 a $500 \mathrm{~m}$ & Alta exposição & $\begin{array}{l}\text { - } \text { Catadores de lixo } \\
\text { área de disposição final de } \\
\text { resíduos sólidos } \\
\text { - Pessoas residentes próximas } \\
\text { ao local até a distância } \\
\text { especificada }\end{array}$ \\
\hline 2 & 500 a $1000 \mathrm{~m}$ & Exposição moderada & $\begin{array}{l}\text { - Pessoas residentes próximas } \\
\text { ao local até a distância } \\
\text { especificada }\end{array}$ \\
\hline 3 & $>1000 \mathrm{~m}$ & Não exposto & $\begin{array}{l}\text { - Pessoas residentes fora da } \\
\text { área considerada de } \\
\text { exposição ou risco }\end{array}$ \\
\hline
\end{tabular}

A princípio, as cidades do Consórcio Intermunicipal das Bacias dos Rios Piracicaba, Capivari e Jundiaí foram eleitas para a pré-seleção. Esta escolha foi baseada no fato do Consórcio apresentar uma estrutura consolidada e uma tradição de realização de trabalhos em parcerias com outras Universidades, o que poderia contribuir para a estruturação dos trabalhos de campo e facilitar a coleta dos dados. Além disto, as cidades componentes do Consórcio situam-se a uma distância 
razoável da cidade de São Carlos, o que, logisticamente, facilitaria o deslocamento dos membros da equipe de pesquisa, bem como a execução das análises laboratoriais.

Os dados e as informações, referentes à distribuição da população por faixa etária nos 42 municípios consorciados do Estado de São Paulo, foram coletados e levantados, bem como as informações referentes às condições de disposição de resíduos sólidos, praticada em cada cidade, e a existência de ocupação urbana no entorno dessas áreas.

Baseado nas informações referentes: às condições e aos tipos de disposição final praticada em cada município; à distribuição da população por faixa etária; à existência de ocupação urbana próxima ao local de disposição dos resíduos, e tendo como fator limitante o valor da amostra necessária para a população de estudo, foram pré-selecionadas as cidades de Piracicaba, Capivari, Nova Odessa, Atibaia, São Pedro, Santo Antônio da Posse e Cordeirópolis. As cidades pré-selecionadas foram visitadas para a verificação, "in loco", das condições de disposição final praticadas e das características de urbanização no entorno dessas áreas.

Dentre essas, a cidade de Piracicaba foi selecionada como representativa da condição de exposição ambiental a ser pesquisada: o aterro sanitário. Esta cidade foi escolhida por apresentar maior população residente próxima ao aterro; facilidade de acesso aos dados globais de morbidade referentes às doenças pesquisadas e uma parceria já consolidada de desenvolvimento e realização de trabalhos de investigação científica em conjunto com a Escola de Engenharia de São Carlos, na área do aterro sanitário.

Pré-selecionada a cidade de Piracicaba, deu-se início a fase do levantamento preliminar dos dados e das informações necessários à estruturação dos trabalhos de 
campo e ao redimensionamento da amostra de estudo. Esta fase de levantamento constitui uma etapa importante para a estruturação e adequação dos trabalhos de pesquisa à realidade da área de estudo. Durante esse período foram levantadas informações mais detalhadas sobre as condições de disposição dos resíduos sólidos; o histórico da disposição de resíduos na área; o controle ambiental praticado; os dados sobre a população residente nos bairros no entorno; os dados demográficos; os dados epidemiológicos referentes à população de estudo e, as informações sobre as condições de urbanização, habitação e de saneamento existentes na área. Esta fase preliminar de levantamento de dados e escolha da cidade de estudo despendeu um período de 4 meses.

Após a análise desses dados e a locação em mapa do aterro em relação à malha urbana, verificou-se que o aterro situava-se a uma distância superior a $1000 \mathrm{~m}$ das habitações. Também foi constatado que as condições de disposição de resíduos sólidos, que estavam sendo praticadas naquele momento no município, não estavam de acordo com as condições de exposição ambiental, que a pesquisa se propunha a investigar. $\mathrm{O}$ desenho epidemiológico proposto pela pesquisa teria que ser profundamente alterado, uma vez que as condições de exposição a serem pesquisadas foram definidas e classificadas em função de raios distantes até mil metros do limite das áreas utilizadas para a disposição final de resíduos sólidos urbanos. Este fato poderia ocasionar a perda de especificidade entre as relações a serem pesquisadas.

Desta forma, optou-se pela manutenção do desenho epidemiológico proposto pela metodologia desta pesquisa e pelo abandono da cidade selecionada. O processo de seleção da cidade, onde o estudo se desenvolveria, foi reiniciado. 
Para a pré-seleção de novas cidades, foram realizados contatos, reuniões e visitas às regionais da CETESB de São Paulo, Jundiaí e Santos, quando foram coletas informações sobre as condições de disposição de resíduos sólidos praticadas nos municípios sob jurisdição dessas regionais. Também foram levantadas informações sobre outros municípios do Estado de São Paulo, junto à Regional de Saúde de Caraguatatuba e ao Centro de Vigilância em Saúde. Com base nessas informações levantadas, treze cidades foram pré-selecionadas. Estas cidades foram visitadas, para o levantamento "in loco" das condições de disposição final praticada em cada cidade, bem como das condições de urbanização próximas a essas áreas. Esta etapa de re-escolha da cidade de estudo demandou um período de dois meses.

A cidade de São Paulo foi escolhida, especificamente, o Bairro de Perus, localizado no entorno da área do Aterro Sanitário Bandeirantes, como a área de investigação do presente estudo, por apresentar as condições de ocupação urbana compatíveis aos critérios eleitos para a seleção da área de investigação e as melhores condições de operação do aterro sanitário.

Logo após a definição da área de estudo, o órgão responsável pela limpeza urbana do município de São Paulo, o Departamento Municipal de Limpeza Urbana LIMPURB, foi contatado, por meio da Divisão de Aterros Sanitários, para a exposição dos objetivos da pesquisa e para a solicitação de autorização e cooperação técnica para a realização dos trabalhos na área.

Após reuniões realizadas com técnicos e com a assessoria da Diretoria Geral do LIMPURB, responsável pelo Aterro Sanitário Bandeirantes, foi obtida a autorização para a realização dos trabalhos de pesquisa e o compromisso dessa instituição de apoiar logisticamente a realização dos trabalhos de campo. Foram, 
também, realizadas reuniões com os engenheiros do setor de aterros sanitários do LIMPURB e da Empresa Heleno \& Fonseca Construtécnica, responsável pela operação do Aterro Sanitário Bandeirantes. Nessas reuniões foram definidos a estruturação dos trabalhos e o tipo de apoio e cooperação a serem prestados. Durante este período, iniciou-se a coleta dos dados e informações referentes ao Aterro Sanitário Bandeirantes.

\subsubsection{Características da Área de Investigação}

Algumas características da área onde foi desenvolvida a presente pesquisa, o Bairro de Perus, no entorno do Aterro Sanitário Bandeirantes do município de São Paulo, SP, foram descritas no item 2.9.

O Bairro de Perus, no entorno do Aterro Sanitário Bandeirantes, foi escolhido como a área geográfica para a realização deste estudo, por apresentar, conforme apresentado na Figura 6, uma ocupação contígua à área limítrofe ao aterro. Além disto, por levantamentos de dados realizados junto ao Distrito de Saúde de Perus (Tabelas 17 e 18), a população infantil residente no bairro estava de acordo com o valor da amostra definido, preliminarmente, para a seleção da área de estudo.

\subsection{Delineamento Epidemiológico Adotado}

O delineamento epidemiológico adotado nesta investigação foi um estudo do tipo seccional, também denominado de "estudo transversal" ou "estudo de prevalência”, por meio do qual foram coletados os dados referentes às enfermidades 
diarréicas e parasitárias e avaliados os índices antropométricos. Nesse tipo de estudo os dados referentes à exposição e às doenças pesquisadas são coletados no mesmo momento histórico. Para avaliação do risco referente às enfermidades diarréicas, empregou-se também, um tipo de estudo longitudinal, por meio do qual foi determinada a prevalência longitudinal por enfermidades diarréicas, por apresentar um alto poder analítico em casos de avaliação de risco de doenças com baixa frequiência na população.

A população de estudo foi composta por crianças na faixa etária de 1 a 5 anos de idade incompletos. Esta foi a faixa etária que apresentou a maior incidência de diarréia durante o ano de 2001, segundo um levantamento efetuado junto ao Distrito de Saúde de Perus. Este levantamento compreendeu a identificação de todos os registros de episódios de diarréia, diagnosticados por meio das consultas médicas atendidas no Distrito e notificados durante as 52 semanas epidemiológicas do ano de 2001. A Figura 8 apresenta a distribuição mensal dos casos de diarréia na população infantil do bairro de Perus, durante o ano de 2001, obtida pelo levantamento desses dados.

As condições de exposição foram definidas, conforme apresentado na Tabela 22, em três graus distintos. O grupo dos "não - expostos" (área 3 - SPC) foi considerado como a população em geral, residente fora da área considerada de risco, acima de $1.000 \mathrm{~m}$ do limite do aterro sanitário. Os expostos foram considerados os indivíduos residentes até a distância de $1.000 \mathrm{~m}$ do aterro sanitário. O grupo de expostos foi dividido em dois (áreas 1 e 2, respectivamente designadas por SPA e SPB), conforme apresentado na Tabela 22, a fim de avaliar se a maior proximidade de residência em relação ao aterro sanitário, significava uma maior prevalência dos 
indicadores de saúde utilizados neste estudo. Como também, para testar se haveria um efeito "dose-resposta", ou seja, um gradiente de distribuição para as prevalências dos indicadores de saúde pesquisados e para a freqüência dos indicadores ambientais levantados.

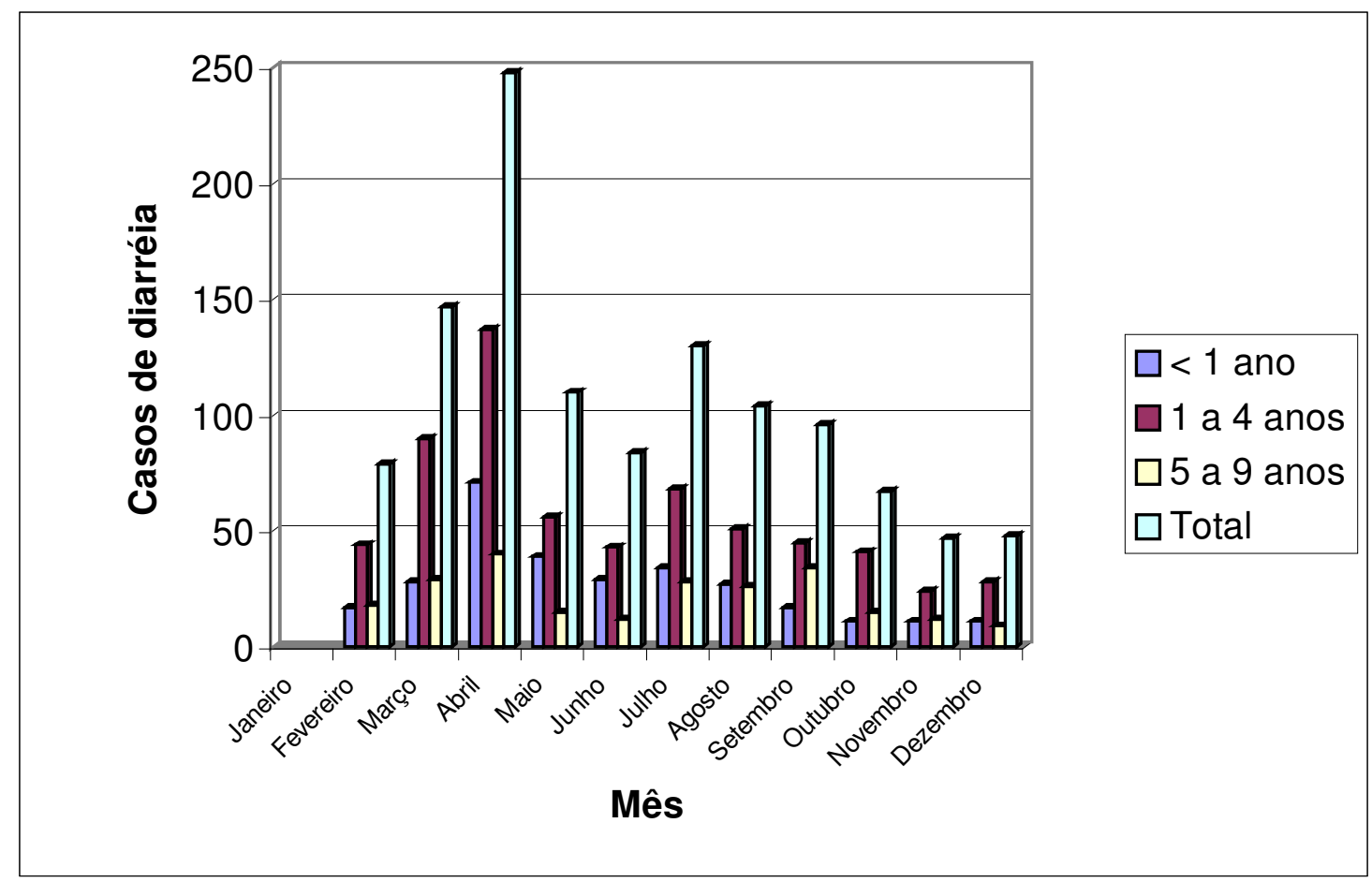

FIGURA 8 - Distribuição mensal dos casos de diarréia na população infantil do bairro de Perus no ano de 2001

Na Tabela 22 é apresentado um resumo do método de estudo epidemiológico empregado por esta pesquisa. 
TABELA 22 - Método de estudo epidemiológico empregado na pesquisa

\begin{tabular}{|c|c|c|c|c|c|c|c|}
\hline Área & $\begin{array}{c}\text { Sigla } \\
\text { adotada }\end{array}$ & $\begin{array}{l}\text { Distância ao } \\
\text { Aterro }\end{array}$ & $\begin{array}{l}\text { Condição de } \\
\text { exposição }\end{array}$ & População de estudo & Indicadores de saúde pesquisados & \multicolumn{2}{|c|}{$\begin{array}{l}\text { Condição de saúde } \\
\text { encontrada }\end{array}$} \\
\hline \multirow[t]{2}{*}{1} & \multirow[t]{2}{*}{ SPA } & \multirow[t]{2}{*}{0 a $500 \mathrm{~m}$} & \multirow[t]{2}{*}{$\begin{array}{l}\text { Alta } \\
\text { exposição }\end{array}$} & $\begin{array}{l}\text { Criança na faixa etária de } 1 \text { a } 5 \\
\text { anos de idade incompletos }\end{array}$ & $\begin{array}{l}\text { Prevalência por enfermidades diarréicas } \\
\text { Prevalência longitudinal por enfermi- } \\
\text { dades diarréicas } \\
\text { Morbidade por parasitoses intestinais } \\
\text { Estado nutricional }\end{array}$ & Doente & $\begin{array}{l}\text { Não - } \\
\text { doente }\end{array}$ \\
\hline & & & & $\begin{array}{l}\text { População em geral residente no } \\
\text { local até a distância especificada }\end{array}$ & $\begin{array}{l}\text { Morbidade por dengue, doenças } \\
\text { respiratórias e alguns tipos de câncer }\end{array}$ & Doente & $\begin{array}{l}\text { Não - } \\
\text { doente }\end{array}$ \\
\hline \multirow[t]{2}{*}{2} & \multirow[t]{2}{*}{ SPB } & \multirow[t]{2}{*}{500 a $1000 \mathrm{~m}$} & \multirow[t]{2}{*}{$\begin{array}{l}\text { Exposição } \\
\text { moderada }\end{array}$} & $\begin{array}{l}\text { Criança na faixa etária de } 1 \text { a } 5 \\
\text { anos de idade incompletos }\end{array}$ & $\begin{array}{l}\text { Prevalência por enfermidades diarréicas } \\
\text { Prevalência longitudinal por enfermi- } \\
\text { dades diarréicas } \\
\text { Morbidade por parasitoses intestinais } \\
\text { Estado nutricional }\end{array}$ & Doente & $\begin{array}{l}\text { Não - } \\
\text { doente }\end{array}$ \\
\hline & & & & $\begin{array}{l}\text { População em geral residente no } \\
\text { local até a distância especificada }\end{array}$ & $\begin{array}{l}\text { Morbidade por dengue, doenças } \\
\text { respiratórias e alguns tipos de câncer }\end{array}$ & Doente & $\begin{array}{l}\text { Não - } \\
\text { doente }\end{array}$ \\
\hline \multirow[t]{2}{*}{3} & \multirow[t]{2}{*}{ SPC } & \multirow[t]{2}{*}{$>1000 \mathrm{~m}$} & \multirow[t]{2}{*}{ Não exposto } & $\begin{array}{l}\text { Criança na faixa etária de } 1 \text { a } 5 \\
\text { anos de idade incompletos }\end{array}$ & $\begin{array}{l}\text { Prevalência por enfermidades diarréicas } \\
\text { Prevalência longitudinal por enfermi- } \\
\text { dades diarréicas } \\
\text { Morbidade por parasitoses intestinais } \\
\text { Estado nutricional }\end{array}$ & Doente & $\begin{array}{l}\text { Não - } \\
\text { doente }\end{array}$ \\
\hline & & & & $\begin{array}{l}\text { População em geral residente no } \\
\text { local até a distância especificada }\end{array}$ & $\begin{array}{l}\text { Morbidade por dengue, doenças } \\
\text { respiratórias e alguns tipos de câncer }\end{array}$ & Doente & $\begin{array}{l}\text { Não - } \\
\text { doente }\end{array}$ \\
\hline
\end{tabular}


Para cada grupo definido, foram considerados "doentes", os indivíduos residentes na área que apresentaram casos de enfermidades diarréicas e das doenças parasitárias avaliadas por este estudo, cujo ciclo de transmissão ou cuja causa pudessem estar relacionados à disposição inadequada de resíduos sólidos urbanos. "Não - doente" foram os indivíduos, na mesma faixa etária estabelecida para o grupo "doente", que não apresentaram episódios de diarréia ou das doenças parasitárias, selecionadas por este estudo, como os indicadores de saúde.

Os índices antropométricos foram levantados na população infantil de 1 a 5 anos de idade incompletos. Para cada faixa de exposição, foram determinados os escores-Z entre as relações peso/altura, peso/idade e altura/idade. Os índices antropométricos foram obtidos através de duas avaliações do peso e altura, realizadas na população de estudo em um período distanciado de seis meses.

As enfermidades diarréicas foram determinadas em dois tipos de levantamentos realizados por este estudo. O primeiro por meio de um estudo seccional, no qual foram levantados os episódios de diarréia ocorridos na população de estudo nas últimas $48 \mathrm{~h}$, quando da realização do inquérito domiciliar (aplicação dos Protocolos de Pesquisa 1 e 2). O segundo por meio de um estudo longitudinal realizado por um período de quatro meses na população de estudo, por meio do qual pode-se levantar a prevalência longitudinal dos episódios de diarréia ocorridos na população no período de análise. Este levantamento foi proposto pelo presente estudo com o intuito de aprimorar e avaliar o indicador diarréia, bastante utilizado nos estudos de avaliação de impactos sobre a saúde das condições de saneamento (BRISCOE et al., 1986), porém ainda inédito como indicador das condições de exposição ambiental pesquisadas por este estudo. 


\subsection{Indicadores de Saúde}

Os indicadores de saúde, adotados por este estudo, que foram levantados junto a população de estudo, formada por crianças de 1 a 5 anos de idade incompletos, foram:

- A prevalência por enfermidades diarréicas, ocorridas na população de estudo, nas últimas $48 \mathrm{~h}$, quando da realização do inquérito domiciliar.

- A prevalência longitudinal por enfermidades diarréicas, expressa pela proporção de dias com diarréia sobre o total de dias de observação, em crianças entre 1 e 5 anos de idade incompletos. Alguns autores consideram um preditor melhor do que a incidência, em relação aos efeitos em longo prazo da diarréia sobre a saúde infantil (MORRIS et al., 1996).

- A morbidade por parasitoses intestinais na população de estudo, expressa pela prevalência de:

a. Protozoários: Entamoeba histolytica, Entamoeba coli, Giardia lambia, Chilomastix mesnili, Iodamoeba bütschlii, Endolimax nana, Trichomonas hominis, Embadomonas intes., Balantidium coli, Isospora hominis, Isospora belli.

b. Helmintos: Ascaris lumbricoides, Trichocephalus trichiurus, Ancylostomidae, Schistosoma mansoni, Hymenolepis nana, Enterobius vermicularis, Taenia sp., Strongyloides stercoralis, Trichostrongylidae, Hymenolepis diminuta. 
- O estado nutricional expresso pelos índices antropométricos, escores-z de altura/idade, peso/idade e peso/altura, determinados para a população infantil de 1 a 5 anos de idade incompletos.

Os indicadores de saúde, escolhidos para efeito deste estudo, são amplamente adotados e recomendados em estudos para avaliação de intervenções em saneamento ou em estudos de avaliação dos impactos do abastecimento de água ou do esgotamento sanitário sobre a saúde pública (BRISCOE et al., 1986; BORJA \& MORAES, 2000). Contudo, poucos são os estudos, referidos na bibliografia, que utilizaram esses indicadores para a avaliação dos impactos de resíduos sólidos sobre a saúde humana. Nenhum estudo que pesquisasse os efeitos da disposição ambiental dos resíduos sólidos urbanos sobre a saúde da população, utilizando esses indicadores, foi encontrado na revisão da literatura, ressaltando-se, desta forma, o caráter inédito da metodologia ora empregada e a importância da realização deste estudo para a elucidação dos efeitos sobre a saúde ocasionados pela disposição ambiental de resíduos sólidos urbanos.

Também foram levantadas, junto a população residente de forma geral, através do inquérito domiciliar, com a aplicação dos Protocolos de Pesquisa 1, as morbidades por:

- Dengue.

- Doenças respiratórias: asma, bronquite, pneumonia, rinite, sinusite.

- Câncer de: colo de útero, mama, estômago, intestino, pulmão, traquéia e fígado. 


\subsection{Indicadores Ambientais}

Os indicadores da qualidade ambiental, para a área de estudo, escolhidos para efeito deste estudo foram:

- A população de vetores mecânicos e biológicos (mosca, mosquito, rato e barata), avaliada em função das faixas de exposição, definidas conforme expresso na Tabela 22.

- Os parâmetros físicos, químicos e bacteriológicos, referentes à qualidade da água (subterrânea ou fornecida pelo sistema de abastecimento), consumida pela população de estudo, amostrada nas áreas de exposição consideradas (SPA, SPB e SPC).

$\mathrm{Na}$ avaliação da qualidade ambiental das áreas pesquisadas, optou-se por não serem considerados os parâmetros referentes à qualidade do ar, uma vez que, os gases emitidos nos locais de disposição de resíduos sólidos urbanos, que teriam um efeito prejudicial à saúde pública, seriam os compostos orgânicos voláteis, como o cloreto de vinila e benzeno, e as dioxinas e furanos. Estes compostos são associados a efeitos cancerígenos sobre a saúde humana, que não foram os indicadores de saúde específicos adotados neste estudo, apesar de investigados por esta pesquisa.

Para que o efeito desse tipo de exposição ambiental fosse avaliado sobre a saúde da população residente na área de estudo, seria mais adequada a realização de um estudo epidemiológico longitudinal ou de coorte. Este tipo de desenho epidemiológico apresenta diferenças metodológicas bastante significativas em relação ao estudo transversal ou seccional, adotado por esta investigação (Tabela 15). 
Apesar das considerações feitas e reconhecendo a forma não tão adequada de coleta desse tipo de informação, por meio de um estudo do tipo seccional, a morbidade por câncer foi levantada junto à população residente na área de estudo, com o intuito especulativo de avaliação da hipótese de associação entre esses fatores. Assim, poder-se-ia avaliar a necessidade ou não do desenvolvimento de estudos futuros de correlação entre esses fatores, já que este tipo de estudo constitui-se, ainda, inédito a nível nacional.

\subsection{Dimensionamento da Amostra de Estudo}

Para o dimensionamento da amostra de estudo, adequando o valor calculado, preliminarmente e adotado para a seleção da área de investigação, à realidade da população residente na área de estudo selecionada, houve a necessidade do levantamento e da realização de uma pesquisa de dados e informações sobre as prevalências de doenças diarréicas e parasitárias.

Como essas informações não eram imediatamente disponíveis nos serviços públicos de saúde, localizados no Bairro de Perus, houve a necessidade de um levantamento minucioso nos registros anuais de diarréias por faixa etária, realizado pela Secretária Municipal de Saúde de São Paulo. Esse registro constituía em um prontuário onde são preenchidas informações sobre a idade dos pacientes atendidos, nome, endereço e a doença diagnosticada. O levantamento das informações necessárias foi realizado pela consulta desses registros, junto ao Distrito de Saúde de Perus. 
Para cada caso de diarréia, registrado para a faixa etária de 0 a 9 anos de idade, foi identificado o endereço da criança, para que se pudesse selecionar os casos de diarréia ocorrentes somente com as crianças residentes no Bairro de Perus. Com isto, foi possível obter o número de casos de diarréia na população do bairro e estimar um valor de prevalência para as enfermidades diarréicas, por faixa etária na população infantil, mais próximo da realidade da população de estudo.

Este levantamento de dados foi bastante exaustivo e o resultado é apresentado na Figura 8. Com os dados levantados foi possível estimar a prevalência de doenças diarréicas na população infantil do Bairro de Perus, por faixa etária infantil, e redimensionar de forma mais precisa a amostra de estudo. A análise desses dados levantados permitiu, também, a redefinição da faixa etária da população de estudo, anteriormente, considerada como sendo crianças na faixa etária de 0 a 5 nos de idade. Esses dados também foram utilizados para a análise e a comparação dos resultados obtidos pelos levantamentos realizados por esta pesquisa.

Baseado nos resultados obtidos (Figura 8), constatou-se que a maior prevalência de doenças diarréicas na população infantil, residente no Bairro de Perus, ocorria na faixa etária de 1 a 4 anos de idade. Com isto, a faixa etária adotada para a população de estudo foi de 1 a 5 anos de idade incompletos.

Esta alteração na faixa etária da população de estudo foi realizada com o intuito de aumentar a associação entre as relações pesquisadas e de testar a utilização desta faixa etária em estudos de avaliação de impacto sobre a saúde de sistemas de saneamento, que utilizem doenças diarréicas como o indicador de saúde. 
Baseado nos dados levantados e nas informações coletadas, expressos anteriormente, a amostra de estudo foi dimensionada, adequando o valor às características da população residente no Bairro de Perus.

O cálculo do valor da amostra foi feito considerando a amostragem aleatória simples. Utilizou-se o programa nQuery Advisor 4.0, que emprega a fórmula apresentada abaixo. Por meio do programa, foram feitas várias simulações, considerando a variação de prevalência de diarréia entre 1 e $3 \%$. Esta faixa de variação para os valores de prevalência de enfermidades diarréicas foi adotada após o cálculo da prevalência para a população infantil entre 1 a 5 anos de idade do bairro de Perus, baseado no levantamento realizado no registro dos dados referentes às enfermidades diarréicas, apresentado na Figura 8.

As seguintes considerações foram feitas para a realização dos cálculos. Adotou-se o nível de significância de 95\%; teste bilateral; precisão de 1\%; população infantil, entre 1 a 5 anos no bairro de Perus, de 5877 habitantes e prevalência por enfermidades diarréicas de 2,8\%. Com estas considerações, obteve-se, para cada uma das situações de exposição pesquisada, uma amostra total de 900 crianças. O valor total da amostra foi dividido eqüitativamente entre as três áreas de exposição consideradas (Tabela 22). Desta forma, em cada faixa de exposição considerada terse-iam 300 crianças a serem amostradas.

$$
\mathrm{n}=\frac{\mathrm{Z}_{(1-\mathrm{a} / 2)}{ }^{2} \mathrm{P}(1-\mathrm{P}) \mathrm{N}}{\mathrm{d} 2(\mathrm{~N}-1)+\mathrm{Z}_{(1-\mathrm{a} / 2)}{ }^{2} \mathrm{P}(1-\mathrm{p})}
$$




\subsection{Plano de Amostragem}

A seleção da população de estudo foi feita para cada faixa de exposição considerada (Tabela 22). A população de estudo, definida pelo dimensionamento da amostra (900 crianças na faixa etária de 1 a 5 anos de idade incompletos), foi dividida igualmente para as três faixas de exposição, uma vez que a ocupação urbana nestas faixas ocorre de forma similar, não apresentando tendências diferenciadas.

Como as condições de exposição foram definidas mediante critérios geográficos, em função da proximidade da área do Aterro Sanitário Bandeirantes, para a seleção da população de estudo, houve a necessidade do desenvolvimento de uma metodologia para a realização da amostragem em campo.

Esta metodologia foi desenvolvida em conjunto com a equipe do Laboratório de Bioestatística, do Departamento de Estatística da UFMG, coordenado pela Professora Arminda Lúcia Siqueira.

Para o desenvolvimento e emprego desta metodologia, foram levantadas e identificadas todas as quadras existentes no setor do Bairro de Perus (Setor 187 da cidade de São Paulo). Para cada quadra, foi identificada, junto ao Setor de Cadastro da Administração Regional de Perus - Prefeitura de São Paulo, sua planta cadastral. Nesta planta eram registrados os lotes e as residências existentes na quadra. Foi levantado um total de 216 quadras na área de pesquisa. Para cada quadra, foi contado o número de residências existentes. As quadras, com o número de residências, foram agrupadas em tabelas em função das áreas de exposição consideradas (SPA e SPC). A área 2 - SPB, representativa da condição de exposição moderada (Tabela 22), não 
apresentava cadastro junto à Administração Regional de Perus, por constituir-se em uma área de loteamento irregular e em áreas de invasão.

Nos Apêndices 1 e 3 são apresentadas as tabelas de distribuição do número de residência por quadra confeccionadas para as áreas de exposição SPA e SPC, respectivamente.

As informações contidas nessas tabelas foram utilizadas na definição da metodologia de amostragem, por meio da qual foram determinados os números de residências a serem amostrados por quadra e por área de exposição para que a população de estudo fosse atingida e para que fosse obtida uma distribuição aleatória da amostra de estudo em cada faixa de exposição. A seguir, será apresentada a metodologia desenvolvida, por esta pesquisa, para a definição do plano de amostragem.

Pelo plano amostral desenvolvido, foi proposto primeiramente uma Amostragem Estratificada com alocação proporcional ao tamanho dos estratos (as três áreas de exposição consideradas), isto é, ao número de residências contidas em cada área considerada. As justificativas de se ter utilizado a amostragem estratificada são: o aumento da precisão da estimativa global, a necessidade de obter estimativas para diversos segmentos da população e a conveniência administrativa ou operacional da realização da amostragem.

A segunda etapa na metodologia empregada foi fazer uma amostragem por conglomerados (quadras), que baseou no sorteio das residências que seriam pesquisadas dentro de cada quadra de forma proporcional, ou seja, o número de residências a ser amostrado seria proporcional ao número total de residências da quadra sorteada. 
Para as áreas de exposição 1 e 3 (SPA e SPC), foi aplicada essa metodologia de conglomerados, enquanto que para a área de exposição 2 (SPB), foi proposta uma “Amostragem Sistemática" dos domicílios, uma vez que, pelos dados obtidos da área, não foi possível conhecer a divisão da área em quadras residenciais, por se tratar de uma área de ocupação irregular. Os sorteios foram obtidos via macros implementados no software estatístico MINITAB for Windows.

A Tabela 23 apresenta a distribuição do número de residências por quadra nas vilas do Bairro de Perus, por faixa de exposição considerada para efeito desta pesquisa. A Tabela 24 apresenta os pesos calculados em função do número de residências por quadra, para fins de proporcionalidade na amostragem e o número de casas a ser amostrado por faixa de exposição e por vila, no Bairro de Perus.

TABELA 23 - Número de quadras e residências por área de exposição

\begin{tabular}{c|c|c|c|c|c}
\hline Área de exposição & $\begin{array}{c}\mathbf{N}^{\circ} \text { de } \\
\text { quadras }\end{array}$ & $\begin{array}{c}\mathbf{N}^{\circ} \text { quadras c/ } \\
\text { residências }\end{array}$ & $\begin{array}{c}\text { Número de } \\
\text { residências }\end{array}$ & $\begin{array}{c}\text { Número } \\
\text { médio de } \\
\text { residências } \\
\text { por quadra }\end{array}$ & $\begin{array}{c}\text { Desvio-padrão } \\
\text { do número } \\
\text { médio de } \\
\text { residências } \\
\text { por quadra }\end{array}$ \\
\hline SPA & 57 & 51 & 1.577 & 30,44 & 21,48 \\
Sub-área 1 & 44 & 44 & 1.268 & 28,34 & 14,76 \\
Sub-área 2 & - & & 695 & & \\
\hline SPB & 85 & 78 & 2.974 & 38,13 & 31,75 \\
\hline SPC & & & & & \\
\hline
\end{tabular}


TABELA 24 - Total de residências, pesos para fins de proporcionalidade, número de crianças e residências a serem amostradas por área de exposição considerada

\begin{tabular}{|c|c|c|c|c|c|c|c|}
\hline \multirow{2}{*}{$\begin{array}{c}\text { Área de } \\
\text { exposição } \\
\text { SPA }\end{array}$} & \multirow{2}{*}{$\begin{array}{c}\begin{array}{c}\text { Total de } \\
\text { residências }\end{array} \\
2.845\end{array}$} & \multirow[t]{2}{*}{ Peso } & \multicolumn{2}{|c|}{$\begin{array}{c}\mathrm{N}^{0} \text { de crianças a } \\
\text { serem amostradas }\end{array}$} & \multicolumn{2}{|c|}{$\begin{array}{c}\mathbf{N}^{0} \text { de residências } \\
\text { a serem } \\
\text { amostradas }(*)\end{array}$} & \multirow{2}{*}{$\begin{array}{c}\begin{array}{c}\mathrm{N}^{0} \mathrm{de} \\
\text { residências }\end{array} \\
200\end{array}$} \\
\hline & & & & 393 & & 197 & \\
\hline Sub-área 1 & 1577 & 0,24209395 & 217,884556 & 218 & 109 & 109 & 110 \\
\hline Sub-área 2 & 1268 & 0,19465766 & 175,191894 & 175 & 87,5 & 88 & 90 \\
\hline SPB & 695 & 0,10669328 & 96,0239484 & 96 & 48 & 48 & 50 \\
\hline SPC & 2.974 & 0,45655511 & 410,899601 & 411 & 205,5 & 206 & 210 \\
\hline Total & 6.514 & 1 & 900 & 900 & 450 & 451 & 460 \\
\hline
\end{tabular}

(*) Como a média de crianças por domicílio foi estimada baseada nos dados levantados como sendo de aproximadamente duas, o número de crianças a serem amostradas em cada faixa de exposição foi dividido por dois, para se obter o número de residências a serem amostradas.

Os pesos foram obtidos da seguinte maneira:

$$
\operatorname{PesO}_{h k}=\frac{N_{h k}}{N}
$$

onde,

$h$ é o índice da faixa, $k$ é o índice da área, $N_{h k}$ é o número total de faixa $h, N$ é o número total de residências; $k=1,2 ; h=1,2,3$ 
O número de crianças a serem amostradas foi calculado por:

$$
n_{h k}=\operatorname{PesO}_{h k} * 900,
$$

onde,

$n_{h k}$ é o número de casas a serem amostradas na faixa $h$

Baseado no número de residências a ser amostrado por área de exposição e considerando os pesos relativos, referentes ao número de residência existente em cada quadra, foi realizado, por meio de uma rotina de computador desenvolvida especialmente para esta pesquisa, um sorteio aleatório das quadras a serem amostradas, bem como foi determinado o número de residências a ser amostrado por quadra.

Os dados referentes à distribuição da população por faixa etária; ao número de domicílios existentes no bairro por faixa de exposição considerada (Tabela 22); ao número de famílias com crianças na faixa etária de 1 a 4 anos de idade, e ao número de crianças por família, dentro da faixa etária de estudo, foram levantados junto à Administração Regional de Perus, ao Distrito de Saúde de Perus, à Unidade Básica de Saúde e em creches e escolas locais.

A área 2 - SPB, representativa da condição de exposição moderada (Tabela 22), não apresentava cadastro junto à Administração Regional de Perus,como já exposto, por constituir-se em uma área de loteamento irregular e em áreas de invasão. Portanto, o número de residências por quadras não é uma informação 
disponível. Para a amostragem desta área foi utilizada a técnica de amostragem sistemática para o sorteio das residências com o seguinte intervalo de sorteio:

$$
\frac{695}{50}=13,9 \cong 14
$$

Assim, após a definição da primeira residência a ser amostrada, o ponto de partida, dever-se-ia saltar 14 residências até que o número total de crianças a ser amostrado nessa área fosse completado.

\subsection{Protocolo de Pesquisa Adotado pelo Estudo}

O protocolo de pesquisa adotado por este estudo constitui:

1. Termo de consentimento informado de participação na pesquisa;

2. Aplicação do Protocolo de Pesquisa 1 ao adulto responsável, presente no momento da entrevista;

3. Termo de consentimento informado de participação da criança na pesquisa;

4. Termo de autorização para a participação da criança;

5. Aplicação do Protocolo de Pesquisa 2 à mãe biológica da criança ou pessoa responsável pela criança;

6. Aferição dos dados antropométricos da criança;

7. Coleta do material fecal para os exames parasitológicos de fezes;

8. Aplicação do Protocolo de Pesquisa 3 à mãe biológica da criança ou pessoa responsável pela criança, durante o período de 17 semanas;

9. Repasse dos resultados dos exames parasitológicos de fezes ao responsável pela criança;

10. Aferição dos dados antropométricos da criança, ao final da pesquisa. 
11. Orientação para procura do atendimento médico, junto a Unidade Básica de Saúde de Perus para as crianças, cujos exames de fezes foram positivos.

O protocolo de pesquisa foi submetido e aprovado pelo Comitê de Ética em Pesquisa do Instituto Adolfo Lutz, da Secretaria de Estado da Saúde de São Paulo, onde foram realizados todos os exames parasitológicos de fezes da população de estudo.

A elaboração dos protocolos de pesquisa, utilizados para o levantamento dos dados de campo, referentes ao estudo epidemiológico, foi baseada em AZEVEDO (1988); AZEVEDO (1999); AZEVEDO (2003); HELLER (1995) e STRINA (2000).

Os protocolos de pesquisa, desenvolvidos para a coleta dos dados foram:

- O Protocolo de Pesquisa 1 foi empregado para a coleta dos dados referentes à identificação da habitação; à identificação da pessoa entrevistada; à composição familiar; às condições sócio-econômicas; às condições da habitação e esgotamento sanitário; ao abastecimento de água; aos resíduos sólidos domiciliares; à drenagem urbana; aos vetores biológicos e mecânicos e às condições de saúde da família e às condições do peridomicílio.

- O Protocolo de Pesquisa 2 foi utilizado para a coleta específica de informações referentes a cada criança participante do estudo. Por meio deste protocolo foram levantadas informações sobre a história reprodutiva da mãe; o histórico pré e pós natal da criança; as condições de saúde; os hábitos e comportamentos higiênicos da criança; os hábitos alimentares e, levantada a prevalência de enfermidades diarréicas, por meio da informação se a criança apresentou diarréia nas últimas 48 horas, quando da realização do inquérito domiciliar. 
- O Protocolo de Pesquisa 3, foi empregado para o registro semanal das doenças diarréicas apresentadas pela criança. Por meio da aplicação deste protocolo de pesquisa foi possível a coleta dos dados referentes à prevalência longitudinal de diarréia, bem como a investigação da natureza dos episódios de diarréia apresentados pela criança.

Nos Anexos A, B e C são apresentados, respectivamente, os Protocolos de Pesquisa 1, 2 e 3, utilizadas na coleta e no levantamento dos dados. O Anexo D contém a carta enviada ou entregue ao responsável pela criança, agradecendo a participação na pesquisa e encaminhando o resultado dos exames parasitológicos de fezes.

\subsection{Coleta de Dados}

A prevalência das enfermidades diarréicas foi obtida pela aplicação do Protocolo de Pesquisa 2, quando a mãe ou responsável pela criança na faixa etária de 1 a 5 anos de idade incompletos, foi indagada se a criança apresentou um episódio de diarréia nas últimas 48 horas, quando da realização do inquérito domiciliar. Esta etapa da pesquisa teve início em outubro e conclusão no início mês de dezembro 2002.

Os dados, referentes à incidência das enfermidades diarréicas, foram coletados na população de estudo, por meio de um estudo longitudinal, para estimar o número de episódios de diarréia ocorridos no período. Neste levantamento foi adotado um sistema para o registro diário dos episódios de diarréias ocorridos com a criança, por meio do preenchimento de um calendário semanal (Protocolo de 
Pesquisa 3). Este calendário foi preenchido semanalmente pelas entrevistadoras. A mãe ou a pessoa responsável pela criança foi entrevistada sobre os episódios de diarréia e as condições de saúde apresentadas pela criança durante a última semana. Este estudo longitudinal teve a duração de 17 semanas, sendo iniciado logo após a aplicação dos Protocolos de Pesquisa 1 e 2, iniciando-se, portanto, em dezembro de 2002 e terminado no mês de abril de 2003.

A morbidade por parasitoses intestinais foi avaliada na população de estudo, por meio de um estudo seccional, realizado durante um período de três meses. Nesse estudo, foram coletadas amostras de fezes da população para avaliar a infecção por parasitas intestinais. A pesquisa de parasitas intestinais no material fecal ocorreu logo após o término da aplicação dos Protocolos de Pesquisa 1 e 2 e realização das medições antropométricas. As mães das crianças, cujos exames de fezes foram positivos, foram orientadas a procurarem a Unidade Básica de Saúde de Perus e algumas receberam o tratamento medicamentoso por conta da pesquisa.

A realização dos exames de fezes para o isolamento de protozoários e helmintos foi executada na Seção de Enteroparasitose do Instituto Adolfo Lutz, da Secretaria de Estado da Saúde de São Paulo.

O método de análise empregado, nos exames de pesquisa de protozoário e helmintos em fezes, foi o método da sedimentação espontânea em água, segundo a técnica de Lutz, 1919; Hoffman, Pons \& Janer, 1934 (DE CARLI, 1994).

Os exames parasitológicos na população de estudo foram realizados no período de dezembro de 2002 a abril de 2003.

As morbidades por dengue, leptospirose, doenças respiratórias e casos de câncer foram determinadas na população em geral (qualquer faixa etária), por meio 
do inquérito domiciliar (aplicação do Protocolo de Pesquisa 1), realizado no início da pesquisa.

As medições antropométricas foram realizadas em dois momentos da pesquisa. No início quando da aplicação dos Protocolos de Pesquisa 1 e 2, e após o término do período de acompanhamento semanal das crianças em relação aos possíveis episódios ocorridos de diarréia (término da aplicação do Protocolo de Pesquisa 3).

Para fins de controle das análises estatísticas, os fatores de confusão ${ }^{1}$ foram levantados pela aplicação do Protocolo de Pesquisa 1, por meio do qual foram recolhidas informações sobre:

- A composição familiar, os membros da família e as condições sócioeconômicas (dados de identificação; idade; endereço de residência; local de nascimento; tempo de residência no local; perfil de migração; nível de escolaridade dos membros da família, em especial a escolaridade materna e paterna; renda familiar; setor de atividade do chefe de família).

- As condições de moradia e do peridomicílio (condições gerais da residência; tipo de materiais de construção, de revestimento e do piso; número de cômodos; característica do abastecimento e do uso da água; características do sistema de eliminação de excretas e de coleta e eliminação do lixo; características das instalações hidráulico-prediais; condições de limpeza e drenagem do lote; presença de vetores mecânicos e biológicos).

- As condições de saúde da população selecionada para estudo (para cada criança, foram levantados dados relativos à história reprodutiva da mãe, ao peso ao

\footnotetext{
${ }^{1}$ Fator de confusão ou variável de confusão designa uma situação em que os efeitos de duas exposições, sobre o risco de desenvolver uma doença, não estão separados. A variável de confusão constitui o terceiro fator que explica a associação ilusória entre as duas variáveis centrais de uma investigação, a exposição principal e a doença.
} 
nascer, ao histórico de vacinação, às características de amamentação e desmame, dentre outros).

Os dados e as informações contidas no questionário foram coletados mediante visitas domiciliares realizadas pela equipe de entrevistadoras no início da pesquisa. Este levantamento de dados ocorreu em dois meses, quando foram coletadas as informações e realizadas as medições antropométricas em 972 crianças na faixa etária de 1 a 5 anos de idade incompletos.

Os fatores de confusão foram coletados, quando da visita domiciliar do entrevistador, que foi treinado para avaliar as condições do domicílio, bem como a prática de hábitos higiênicos familiares.

A estimativa da população de vetores mecânicos e biológicos foi realizada como intuito de verificar o desempenho da solução de disposição final pesquisada no controle ambiental desses organismos. Tal levantamento foi também realizado com o objetivo de verificar a existência de uma possível associação estatística entre a presença dos vetores biológicos e mecânicos e a prevalência dos indicadores de saúde investigados. Essa avaliação foi feita por meio de perguntas específicas contidas no Protocolo de Pesquisa 1.

A avaliação da qualidade da água, consumida pela população de estudo, nas três áreas de exposição, foi realizada por meio da coleta de amostras em 14 pontos, distribuídos aleatoriamente em toda a área de pesquisa. A amostragem foi feita nos pontos de consumo de água nas residências para bebida e preparo de alimentos. 
Foi, também, coletada uma amostra de água de uma mina de nascente existente na área SPA, próxima ao Aterro Sanitário, utilizada como fonte alternativa de abastecimento pela população local, devido a problemas de falta d'água.

Os parâmetros relativos à qualidade da água monitorizados foram: $\mathrm{pH}$, cor aparente, turbidez, dureza total, fluoretos, sulfatos, sulfetos, nitrogênio amoniacal, nitrogênio nitrato, nitrogênio nitrito, sólidos dissolvidos totais, cloretos, cianetos, sódio, coliformes fecais, coliformes totais, zinco, chumbo, cádmio, níquel, ferro total, manganês, cobre, cromo total, alumínio, arsênio, selênio, bário, mercúrio, estanho. As análises foram efetuadas de acordo com a $20^{\mathrm{a}}$ edição do STANDARD METHODS FOR THE EXAMINATION OF WATER AND WASTE WATER.

Para a caracterização da qualidade ambiental da área de disposição final dos resíduos sólidos urbanos investigada, o Aterro Sanitário Bandeirantes, os dados foram levantados junto ao Departamento de Limpeza Urbana da Prefeitura Municipal de São Paulo, que realiza, por meio da empresa responsável pela operação do aterro, monitorização ambiental periódica. Essa monitorização compreende a monitorização geotécnica, a monitorização de chorume gerado, a monitorização do lençol freático e a monitorização de resíduos industriais classe II. (PREFEITURA MUNICIPAL DE SÃO PAULO, 2003).

\subsection{Seleção e Treinamento da Equipe de Pesquisa}

O processo de seleção da equipe de entrevistadoras que participaram da pesquisa, realizando a coleta dos dados epidemiológicos referentes à aplicação dos Protocolos de Pesquisa 1, 2 e 3; à realização das medições antropométricas, e à 
coleta de material fecal para a realização dos exames parasitológicos na população de estudo, foi feita entre membros da comunidade local.

Foram selecionadas seis pessoas. Cada entrevistadora ficou responsável pela execução do protocolo de pesquisa em 150 crianças. A equipe selecionada foi treinada para a aplicação dos questionários, cumprimento do protocolo de pesquisa e aferição das medidas antropométricas. O treinamento da equipe serviu, também, para a reestruturação dos Protocolos de Pesquisa, adequando-os à realidade da população de estudo.

Posteriormente, a equipe de pesquisa foi treinada e instruída para a execução e o cumprimento dos procedimentos de amostragem em campo, definidos pela metodologia e pelo plano de amostragem, elaborados por esta pesquisa.

\subsection{Resumo do Levantamento de Dados Realizado}

A Tabela 25 contém o resumo do estudo realizado, apresentando a freqüência e a forma por meio das quais os dados foram coletados e levantados.

\subsection{Análise dos Dados}

\subsubsection{Banco de Dados e Recursos de Informática}

Todos os questionários aplicados na população de estudo foram revisados e as perguntas foram codificadas para facilitar a digitação. 
As informações obtidas pela aplicação do Protocolo de Pesquisa 1, 2 e 3 foram gravadas em meio magnético, por meio de programa de entrada de dados elaborado especificamente para a pesquisa, utilizando-se o Programa Microsoft Acess. A transcrição dos dados foi realizada por processo de digitação.

A verificação da consistência dos dados gravados foi realizada por meio da conferência visual, por meio da qual foram comparadas as informações registradas no formulário de campo a espelhos do banco de dados impressos em papel. A distribuição de frequiência de cada variável foi utilizada na verificação final da consistência do banco de dados. Os dados foram analisados em computador, utilizando-se o pacote estatístico SPSS for Windows - 10 .

\subsubsection{Definição da Base de Dados Geográficos}

Um mapa da área de estudo em escala 1:5000 foi digitalizado, usando-se o Programa ArcInfo (ESRI, 1994). As informações contidas no banco de dados foram associadas geograficamente pelo endereço de cada uma das 972 crianças avaliadas pelo estudo, utilizando-se o Programa ArcView (ESRI, 1994). A cada criança foi associada uma informação geográfica. Desta forma, foi possível trabalhar os dados em função da distribuição espacial das variáveis levantadas e dos indicadores de saúde pesquisados.

Os trabalhos, executados em ambiente SIG, iniciaram-se pela definição das feições mínimas necessárias em relação à base cartográfica e aos mapas temáticos com seus respectivos atributos. Desta forma, o banco de dados ficou constituído pelos planos de informação pertencentes à base cartográfica digital (quadras e ruas), 
TABELA 25 - Levantamento de dados realizado

\begin{tabular}{|c|c|c|c|c|}
\hline \multicolumn{2}{|c|}{ Indicadores } & $\begin{array}{c}\text { Faixa de } \\
\text { Exposição }\end{array}$ & $\begin{array}{c}\text { Aterro } \\
\text { Sanitário }\end{array}$ & $\begin{array}{l}\text { Frequiêencia e Período de } \\
\text { Coleta dos Dado }\end{array}$ \\
\hline \multirow{9}{*}{$\begin{array}{l}\text { Saúde } \\
\text { Pública }\end{array}$} & \multirow[t]{3}{*}{ Doenças Diarréicas } & 0 a 500 & $\overline{\text { i e p }}$ & \multirow{3}{*}{$\begin{array}{l}\text { Frequiência diária } \\
\text { Calendário semanal } \\
\text { Período: } 4 \text { meses }\end{array}$} \\
\hline & & 500 a 1000 & i e p & \\
\hline & & $>1000$ & i e p & \\
\hline & \multirow{3}{*}{\begin{tabular}{|l|} 
Doenças \\
Parasitárias, \\
Respiratórias, casos \\
de dengue e câncer
\end{tabular}} & 0 a 500 & $\mathrm{P}$ & \multirow{3}{*}{$\begin{array}{l}\text { Freq.: } 1 \text { vez } \\
\text { Calendário: do } 2^{\circ} \text { ao } 4^{\circ} \\
\text { mês de estudo } \\
\text { Período: } 2 \text { meses }\end{array}$} \\
\hline & & 500 a 1000 & $\mathrm{p}$ & \\
\hline & & $>1000$ & $\mathrm{p}$ & \\
\hline & \multirow{3}{*}{$\begin{array}{l}\text { Índices } \\
\text { Antropométricos }\end{array}$} & 0 a 500 & escore-z & \multirow{3}{*}{$\begin{array}{l}\text { Frequiência semestral } \\
\text { Calendário: } 1^{\circ} \text { e } 6^{\circ} \text { mês } \\
\text { Período: } 6 \text { meses }\end{array}$} \\
\hline & & 500 a 1000 & escore-z & \\
\hline & & $>1000$ & escore-z & \\
\hline \multirow[t]{6}{*}{ Ambientais } & \multirow{3}{*}{$\begin{array}{l}\text { Vetores biológicos e } \\
\text { mecânicos }\end{array}$} & 0 a 500 & est. pop & \multirow{3}{*}{$\begin{array}{l}\text { Freq.: } 1 \text { vez } \\
\text { Calendário: } 1^{\circ} \text { e } 2^{\circ} \text { mês } \\
\text { Período: } 2 \text { meses }\end{array}$} \\
\hline & & 500 a 1000 & est. pop & \\
\hline & & $>1000$ & est. pop & \\
\hline & \multirow{3}{*}{\begin{tabular}{|l} 
Parâmetros de \\
qualidade \\
da água
\end{tabular}} & 0 a 500 & $\mathrm{QA}$ & \multirow{3}{*}{$\begin{array}{l}\text { Freq.: } 1 \mathrm{vez} \\
\text { Calendário: } 6^{\circ} \text { mês } \\
\text { Período: } 1 \text { meses }\end{array}$} \\
\hline & & 500 a 1000 & QA & \\
\hline & & $>1000$ & QA & \\
\hline \multirow{4}{*}{$\begin{array}{l}\text { Caracteriza- } \\
\text { ção ambien- } \\
\text { tal da área de } \\
\text { disposição } \\
\text { final dos } \\
\text { RSU }\end{array}$} & $\begin{array}{l}\text { Características } \\
\text { físicas }\end{array}$ & - & $\begin{array}{l}\mathrm{PF} \\
\mathrm{PB}\end{array}$ & Inicio do estudo \\
\hline & $\begin{array}{l}\text { Características } \\
\text { químicas }\end{array}$ & - & PQ & \multirow[t]{2}{*}{ Fim do estudo } \\
\hline & $\begin{array}{l}\text { Características } \\
\text { bacteriológicas }\end{array}$ & - & $\mathrm{PB}$ & \\
\hline & $\begin{array}{l}\text { Tipologia dos RSU } \\
\text { dispostos }\end{array}$ & - & Tipo & Fim do estudo \\
\hline
\end{tabular}

$\mathrm{p}$ - prevalência da doença

i - incidência da doença

est. pop. - estimativa da população de mosca, mosquito, barata e ratos

QA - pH, cor aparente, turbidez, dureza total, fluoretos, sulfatos, sulfetos, nitrogênio amoniacal, nitrogênio nitrato, nitrogênio nitrito, sólidos dissolvidos totais, cloretos, cianetos, sódio, coliformes fecais, coliformes totais, zinco, chumbo, cádmio, níquel, ferro total, manganês, cobre, cromo total, alumínio, arsênio, selênio, bário, mercúrio, estanho

$\mathrm{PF}$ - parâmetros de caracterização física da área do aterro: composição gravimétrica, quantidade/volume diário PQ - parâmetros de caracterização química da área do aterro: aspecto, cor, odor, turbidez, condutividade, alumínio, alumínio solúvel, arsênio, bário, cádmio, chumbo, chumbo solúvel, cobre, cromo total, dureza, ferro solúvel, ferro total, manganês, manganês solúvel, mercúrio, prata, selênio, zinco, cianeto, sulfato fluoreto, fenóis, orto-fosfato, surfactantes, nitrato, cloreto, sólidos dissolvidos totais, COT

PB - parâmetros de caracterização biológica da área do aterro: contagem padrão de bactérias, coliformes totais e Escherichia coli

Tipo - determinação do tipo de resíduos disposto 
e à população de estudo amostrada (972 crianças na faixa etária de 1 a 5 anos de idade incompletos).

Com relação ao plano de informação referente à população de estudo, cada criança foi identificada como um ponto amostrado. Para cada criança amostrada foi especificado um ponto na área de estudo, identificado por meio da correlação entre o endereço residencial da criança - nome da rua, e o número da quadra.

Devido à natureza da informação espacial deste trabalho, estabeleceu-se a estrutura de armazenamento vetorial, com feições de polígonos para as quadras e a localização do Aterro Sanitário Bandeirantes; de linhas para as ruas e de pontos para os Protocolos de Pesquisa aplicados. Foi criado no banco de dados um identificador único para cada criança em função da numeração dos Protocolos de Pesquisa.

A aquisição dos dados para a elaboração do projeto em um sistema de informação geográfica foi feita a partir das seguintes fontes secundárias:

- Mapa do Setor Fiscal 187 (escala 1:5.000), obtido junto ao setor de cadastro da Administração Regional de Perus, Prefeitura de São Paulo;

- Mapas ilustrativos do Bairro de Perus, obtidos junto a Editora $X$, responsável pela elaboração do Guia Comercial de Perus.

\section{Construção da base de dados}

Para o desenvolvimento deste trabalho foram selecionados e utilizados os seguintes aplicativos:

- ArcInfo (ESRI, 1994), com a finalidade de digitalizar os mapas, visto que este aplicativo fornece uma estrutura bastante eficiente para a entrada de dados no 
formato vetorial, bem como possibilita a transferência dos dados para outros aplicativos;

- ArcView (ESRI, 1994), para complementar a análise de resultados e elaborar as saídas gráficas na forma de mapas e tabelas.

Desta forma, a base cartográfica e os mapas temáticos foram digitalizados no ambiente SIG do aplicativo ArcInfo, enquanto os dados alfanuméricos foram digitados na forma de tabelas em planilhas eletrônicas.

A etapa de geocodificação, que trata da associação dos dados alfanuméricos às suas respectivas representações nos mapas temáticos, foi efetuada no ambiente SIG do aplicativo ArcInfo. Após esta etapa, as feições cartográficas dos planos de informação passam a representar as características temáticas descritas pelos dados alfanuméricos. Neste caso, o plano de informação de pontos amostrados possui como atributo um identificador numérico, único para cada ponto no espaço. Por meio deste atributo, foi estabelecido o relacionamento com a tabela que continha os atributos (todas as variáveis levantadas durante a coleta de dados), associando-os aos pontos pesquisados. Dentre os atributos tratados, foram abordados, mais especificamente, as variáveis empregadas como:

- Indicadores ambientais da área de estudo:

a. Freqüência da ocorrência de vetores (mosca, barata e rato);

b. Ocorrência de problemas ambientais correlatos ao aterro sanitário.

- Indicadores de saúde:

a. Distribuição da ocorrência de doenças respiratórias na população em geral; 
b. Distribuição da ocorrência de caso de dengue e câncer na população em geral;

c. Distribuição da ocorrência de diarréia na população de estudo;

d. Distribuição da ocorrência de parasitose intestinal (protozoários e helmintos) na população de estudo.

Esta operação foi realizada no módulo TABLES do ArcInfo. O comando utilizado foi o JOINITEM, que une dois arquivos de dados, baseado em um item comum. No caso da presente pesquisa foi empregado o identificador numérico. Desta maneira, o banco de dados geográficos foi materializado em ambiente SIG.

\subsubsection{Análise Univariada}

O método de análise adotado baseou-se no estudo da freqüência de todas as variáveis coletadas para cada criança e na comparação das três áreas de estudo, segundo seleção dessas variáveis.

Para as variáveis qualitativas, as diferenças das freqüências encontradas, entre as três áreas, foram testadas estatisticamente por meio dos testes do qui-quadrado ou o teste exato de Fischer para proporções, quando indicado.

Todas as variáveis levantadas foram agrupadas em 11 categorias ou blocos, assim constituídos:

1. Estrutura familiar;

2. Condição socioeconômica;

3. Condição da habitação; 
4. Esgotamento sanitário;

5. Abastecimento de água

6. Resíduos sólidos;

7. Drenagem urbana;

8. Condições ambientais do peridomicílio;

9. Informações sobre a criança

10. Hábitos higiênicos

11. Indicadores ambientais

A análise univariada foi realizada para cada grupo ou bloco de variáveis tendo como variável resposta a ocorrência ou não de diarréia. As variáveis explicativas que tiveram um valor-p menor que 0,25 , na análise univariada, foram selecionadas como candidatas para entrar no modelo multivariado final de regressão logística.

\subsubsection{Análise Multivariada}

O modelo de regressão logística foi utilizado para investigar os fatores associados à ocorrência de diarréia - a variável resposta considerada na análise. Para a construção do modelo final, foi utilizado o procedimento forward, que consiste na inclusão de uma variável explicativa por vez. Em decorrência da grande quantidade de variáveis, o ajuste se processou por blocos ou categorias, conforme expresso na seção anterior.

Apenas as variáveis que alteraram os valores da Razão de chances (OR) original e que estiveram associadas a $\mathrm{p}<0,05$, na análise de cada categoria ou bloco 
de variável, entraram no modelo de regressão. Algumas variáveis foram agrupadas com o objetivo de dicotomizar suas categorias. O nível de significância estatística adotado foi de $5 \%$. Foi utilizado o software estatístico SPSS for Windows. 


\section{CAPÍTULO IV}

\section{RESULTADOS}

\subsection{Introdução}

Os resultados apresentados a seguir, correspondem a análise dos Protocolos de Pesquisa 1 e 2, aplicados aos responsáveis por 972 crianças, na faixa etária de 1 a 5 anos de idade incompletos - a amostra de estudo; bem como a análise dos resultados dos exames parasitológicos de fezes realizados em 721 crianças. A Figura 9 mostra a distribuição da amostra e o número de exames realizados, segundo as três áreas de exposição ambiental consideradas.

Apesar dos resultados apresentados neste capítulo e as relações pesquisadas se aterem à amostra de estudo, salienta-se que as condições ambientais, socioeconômicas, sanitárias, de habitação e de saúde, avaliadas pela aplicação do Protocolo de Pesquisa 1, descrevem a realidade das condições de vida de 4.496 pessoas, residentes no Bairro de Perus, limítrofe ao Aterro Sanitário Bandeirantes, São Paulo. 
Na Tabela 26 é apresentada a distribuição da população residente nas habitações que fizeram parte do estudo, por área e faixa etária.

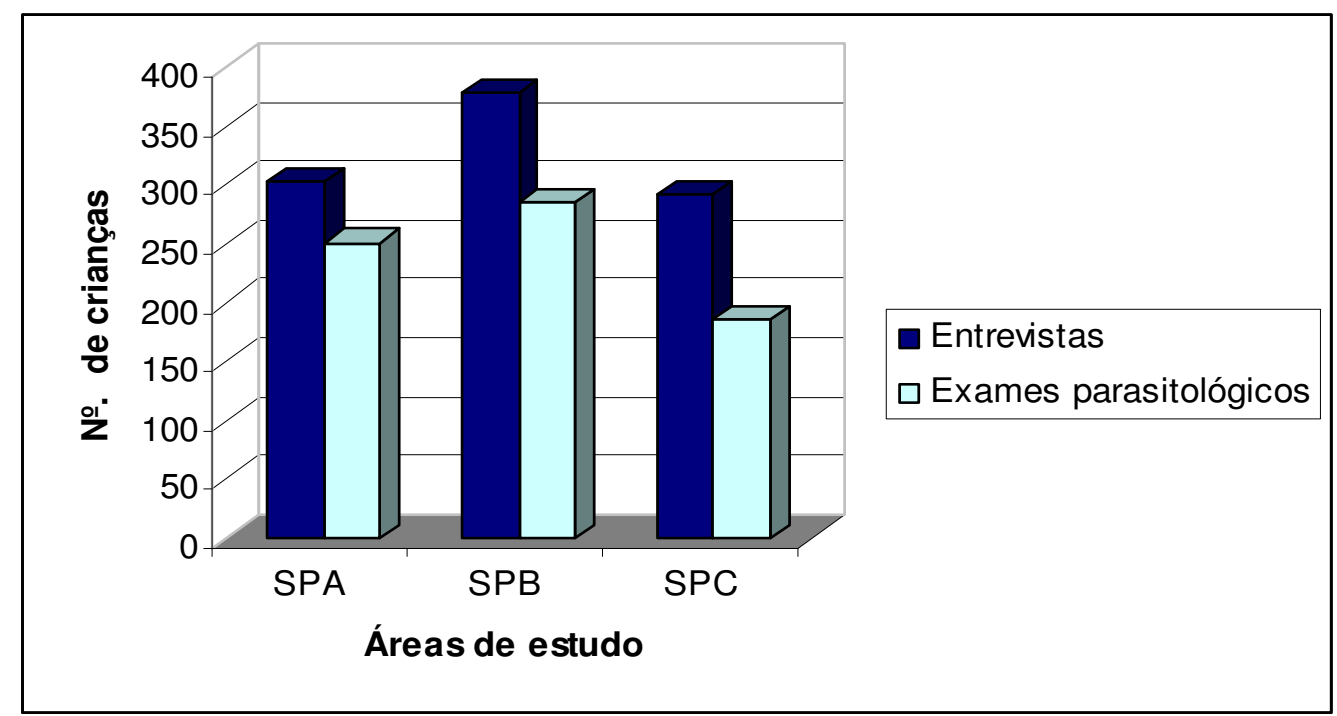

FIGURA 9 - Distribuição da amostra em função dos números de entrevistas e de exames parasitológicos realizados nas três áreas de exposição pesquisadas

TABELA 26 - Distribuição da população por área de estudo e faixa etária

\begin{tabular}{l|c|c|c|c|c}
\hline \multirow{2}{*}{ Área } & \multicolumn{4}{|c|}{ Idade } & \multirow{2}{*}{ Total } \\
\cline { 2 - 5 } & $\begin{array}{c}\text { Menor de 1 } \\
\text { ano }\end{array}$ & $\begin{array}{c}\text { Entre 1 e 4 } \\
\text { anos }\end{array}$ & $\begin{array}{c}\text { Entre 5 e 14 } \\
\text { anos }\end{array}$ & \multirow{2}{*}{ Adultos } & \\
\hline SPA & $54(4,28 \%)$ & $428(33,91 \%)$ & $349(27,65 \%)$ & $431(34,15 \%)$ & $1262(28,07 \%)$ \\
\hline SPB & $65(3,59 \%)$ & $627(34,64 \%)$ & $336(18,56 \%)$ & $782(43,20 \%)$ & $1810(40,26 \%)$ \\
\hline SPC & $39(2,74 \%)$ & $462(32,44 \%)$ & $249(17,49 \%)$ & $674(47,33 \%)$ & $1424(31,67 \%)$ \\
\hline Total & $\mathbf{1 5 8}(\mathbf{3 , 5 1 \% )}$ & $\mathbf{1 5 1 7}(\mathbf{3 3 , 7 4 \% )}$ & $\mathbf{9 3 4}(\mathbf{2 0 , 7 7 \% )}$ & $\mathbf{1 8 8 7}(\mathbf{4 1 , 9 7 \% )}$ & $\mathbf{4 4 9 6 ( 1 0 0 \% )}$ \\
\hline
\end{tabular}


Na Tabela 27 é apresentada a composição média familiar por residência, em função da faixa etária e das áreas de estudo pesquisadas.

TABELA 27 - Número médio de pessoas por residência e faixa etária, segundo as áreas de estudo

\begin{tabular}{c|c|c|c|c}
\hline \multirow{2}{*}{ Área } & \multicolumn{4}{|c}{ Idade } \\
\cline { 2 - 5 } & Menor que 1 ano & Entre 1 e 4 anos & Entre 5 e 14 anos & Adultos \\
\hline \multirow{2}{*}{ SPA } & 0,180 & 1,417 & 1,156 & 2,506 \\
SPB & 0,173 & 1,668 & 0,894 & 2,131 \\
SPC & 0,134 & 1,582 & 0,853 & 2,424 \\
\hline
\end{tabular}

\subsection{Caracterização da Amostra de Estudo}

Das pessoas que responderam ao questionário, $96,8 \%$ eram do sexo feminino, sendo $85,8 \%$ dos questionários respondidos pela mãe natural da criança. Dessas pessoas, $2,7 \%$ não sabiam ler nem escrever; $77,3 \%$ tinham estudado até a $8^{\mathrm{a}}$ série do ensino fundamental e, 85,2\% residiam na habitação há mais de um ano. Mais da metade das pessoas entrevistadas $(55,7 \%)$ tinha nascido em outro estado brasileiro, principalmente, da região Nordeste $(33,1 \%)$.

As crianças que fizeram parte no estudo foram amostradas por residência. Sendo que $72,6 \%$ das residências tiveram apenas uma criança participando do estudo; $22,5 \%$ duas; $4,2 \%$ três e, apenas, $0,6 \%$ das residências tinham quatro crianças participando do estudo. A Figura 10 mostra o número de crianças por residência que participou do estudo em função das áreas de exposição pesquisadas. Na área SPA 
participaram em média 1,5 crianças por residência no estudo $(\mathrm{DP}=0,59)$, com o máximo de 3 crianças. Na área SPB o número médio de crianças por residência foi de $1,8(\mathrm{DP}=0,79)$ e o número máximo de 4 crianças por residência. Na área SPC essa média foi de 1,7 crianças $(\mathrm{DP}=0,86)$ e o número máximo de 4 crianças por residência. A comparação do número de crianças, participante do estudo por residência, em relação as três áreas de exposição apresentou qui-quadrado de 42,012; com 6 graus de liberdade e a probabilidade de significância, $\mathrm{p}<0,000$.

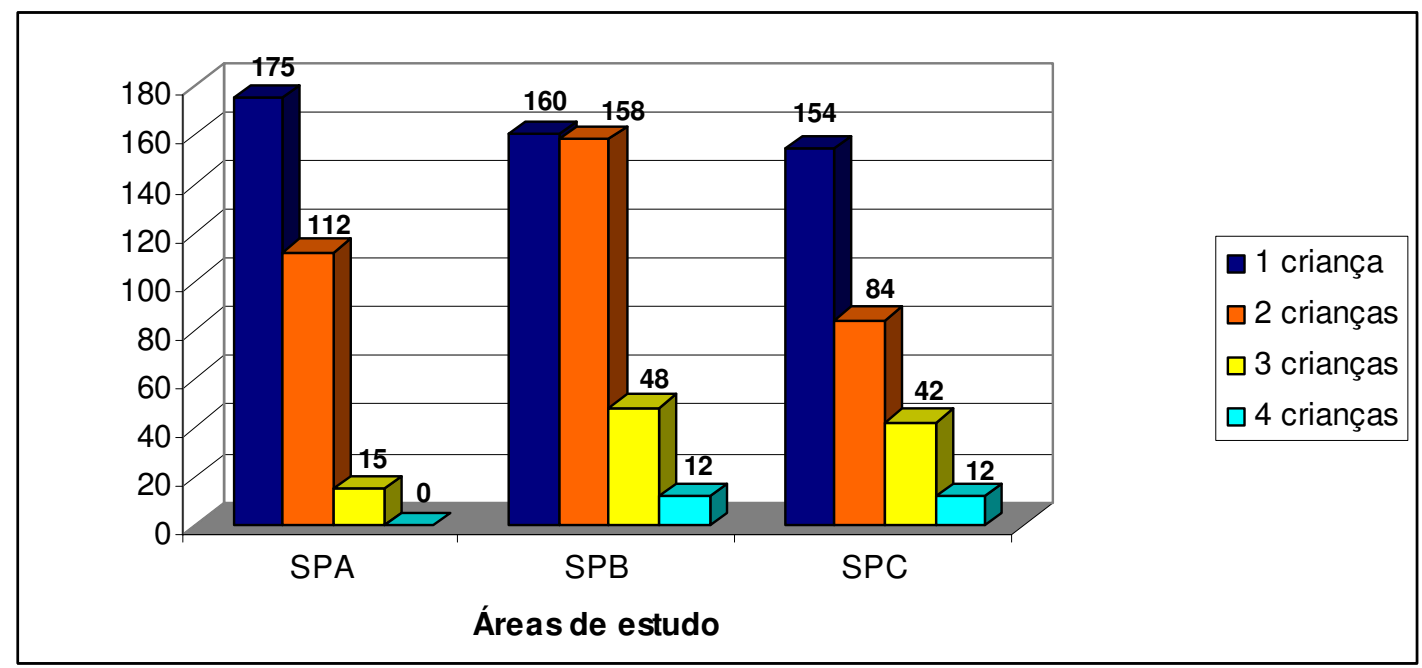

FIGURA 10 - Número de crianças participantes no estudo por residência

As crianças que participaram do estudo, $47,9 \%$ eram do sexo feminino e 51,3\% do sexo masculino. A análise comparativa entre as três áreas de exposição apresentou $X_{(2 \mathrm{GL})}^{2}=2,304$ e $\mathrm{p}=0,316$. A Figura 11 apresenta a distribuição da população de estudo por sexo, segundo as áreas de exposição pesquisadas. 
A renda de $64,1 \%$ das famílias que participaram do estudo não excedia a dois salários mínimos mensais, sendo que 93,2\% das residências possuíam geladeira e 92,7\%, televisão. Destas famílias, 11,4\%, do principal responsável pelo sustento familiar, estavam desempregados, no momento da realização da pesquisa. O percentual de famílias, cuja residência era própria, foi de $68,6 \%$, sendo que $85,1 \%$ das famílias residiam em casas; 5,7\% em apartamentos e 8,3\% em quarto ou barraco. As habitações investigadas localizavam-se 43,8\% em loteamento regular e 43,9\% em área de ocupação

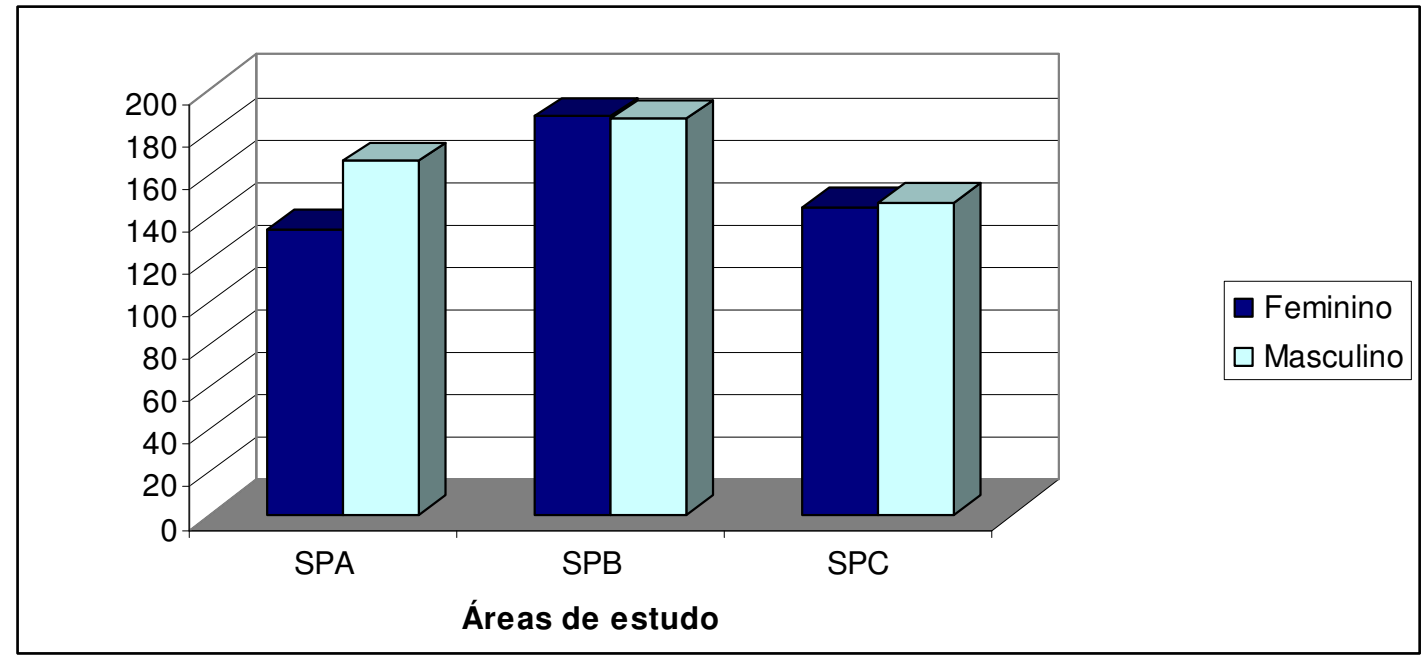

FIGURA 11 - Distribuição da população de estudo por sexo

Das residências que participaram do estudo, 87,9\% tinham pelo menos um banheiro dentro de casa e $81,0 \%$ tinham, no banheiro, o vaso sanitário com descarga d'água. O destino dos esgotos de 53,3\% das residências era adequado do ponto de vista sanitário, sendo lançados na rede pública coletora ou em fossas sépticas, 
seguidas de poços de infiltração. Em 40,4\% das habitações, o esgoto era disposto de forma inadequada, quer seja por meio do lançamento na rede de drenagem pluvial; em fossas sépticas com lançamento dos efluentes na rede de drenagem, na rua ou no terreno, ou por meio, do lançamento direto no córrego ou no próprio terreno da habitação. A análise comparativa entre as áreas apresentou $X_{(2 \mathrm{GL})}^{2}=61,720 \mathrm{e} \mathrm{p}$ $<0,000$.

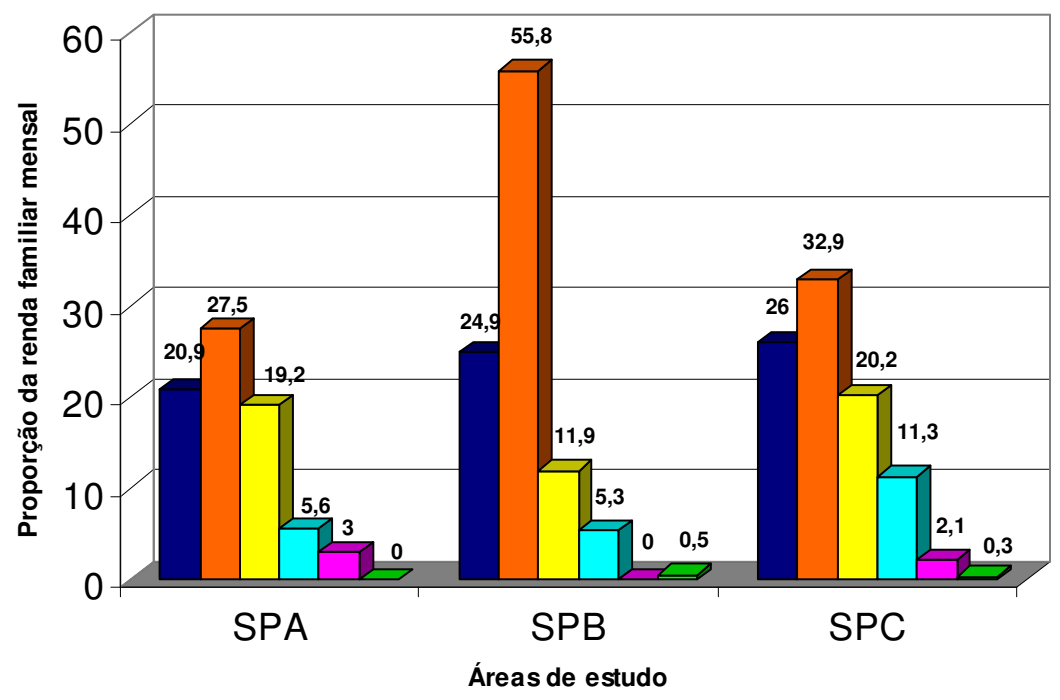

FIGURA 12 - Renda média mensal das famílias que participaram do estudo

A Figura 13 demonstra, de forma proporcional, o destino dado aos esgotos sanitários gerados nas habitações em função da área de estudo.

A água consumida em $96,5 \%$ das residências era proveniente da rede pública de abastecimento de água, embora 18,9\% não fossem ligadas à rede. A freqüência com que a água chegava às residências foi relatada em $86,2 \%$ das habitações como 
sendo diária. Apenas, 4,9\% das residências entrevistadas indicaram problemas de alterações organolépticas na água consumida. Em relação às áreas pesquisadas, o qui-quadrado obtido da análise comparativa das frequiências, para a procedência da água consumida na habitação, foi de 18,592 e p =0,001. O reservatório superior de água existia em 60,6\% das residências na área SPA; em 79,1\%, na área SPB, e em 66,8\% das residências localizadas na área SPC. Destas residências, 96,2\% relataram que os reservatórios de água eram cobertos e esvaziados em 69,5\% das residências, pelo menos uma vez a cada seis meses para limpeza. Os cuidados adicionais com a água antes de beber, como a filtração, a fervura ou a adição de cloro ou água sanitária, foram relatados em $55,3 \%$ das residências, sendo que 4,1\% informaram que só consumiam água mineral engarrafada.

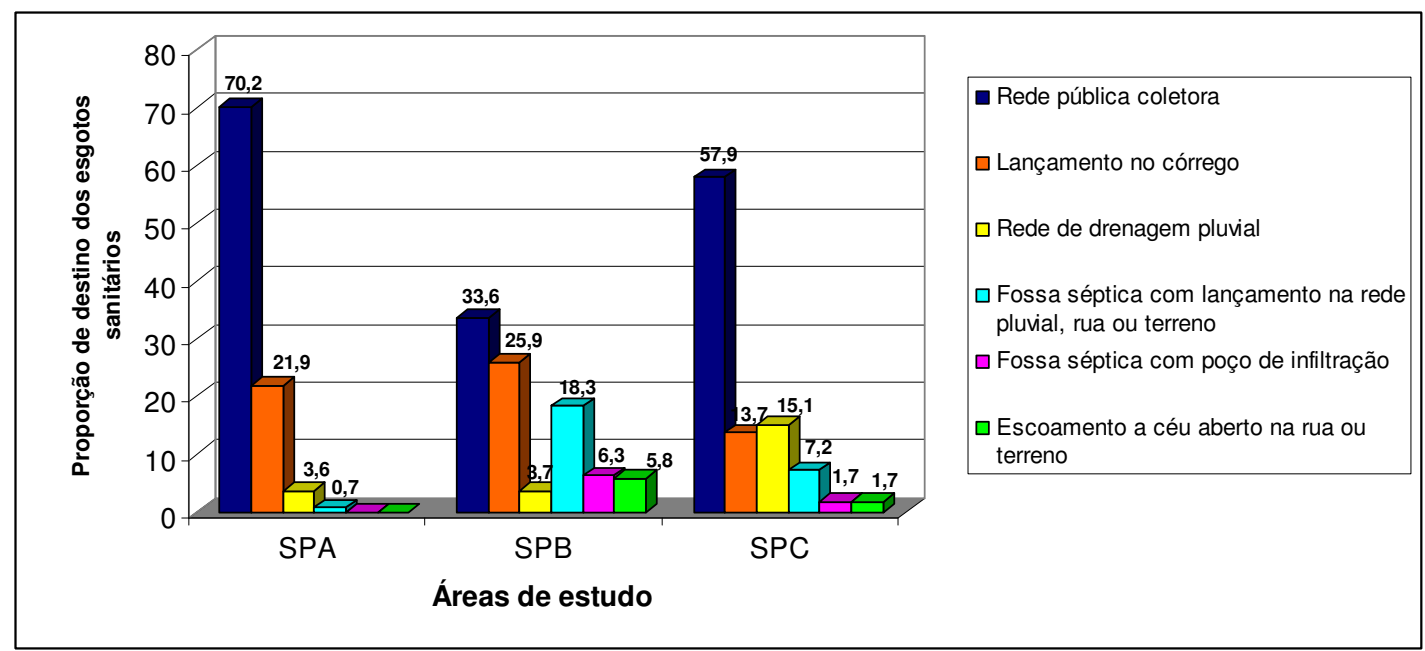

FIGURA 13 - Destino dados aos esgotos sanitários gerados nas residências 
Em relação aos resíduos sólidos produzidos, 56,0\% das casas têm o hábito de separar os restos de alimentos, do lixo do banheiro e dos materiais recicláveis. O acondicionamento realizado em sacos ou sacolas plásticas foi relatado em $83,4 \%$ das habitações. A disposição dos resíduos sólidos acondicionados na rua ou em caçamba estacionária para a coleta municipal foi a prática mais comum de destinação dada aos resíduos nas três áreas de estudo, sendo praticada em 96,4\% das residências na área SPA; $91,3 \%$ e 83,3\%, respectivamente, nas áreas SPB e SPC. A análise comparativa entre as áreas apresentou $X^{2}{ }_{(2 \mathrm{GL})}=3,131$ e $\mathrm{p}=0,209$.

A frequiência de coleta em dias alternados foi relatada em 91,7\%; 46,0\% e $66,1 \%$ das residências entrevistadas, nas áreas SPA, SPB e SPC, respectivamente. A coleta diária ou em duas vezes por semana ocorre, respectivamente nas três áreas, em $2,6 \%$ e 2,0\% das residências da área SPA; em 8,5\% e 56\% na área SPB e, em 22,9\% e 7,2\% na área SPC. A coleta de lixo foi declarada satisfatória por 87,4\% das pessoas entrevistadas na área SPA; 50,3\% na área SPB e 87,3\% na área SPC.

Em 70,9\% das residências, as fezes das fraldas são dispostas juntas ao lixo da casa. Nas residências em que as crianças usam fraldas descartáveis, estas são dispostas, em 94,6\% dos casos, junto com o lixo doméstico.

A inundação do lote em épocas de chuva foi relatada em 9,9\% das habitações e o empoçamento de água no lote em $16,8 \%$ das residências entrevistadas.

Em $81,0 \%$ das residências, a cozinha era um cômodo independente. A média de cômodos por residência foi de 2,8 , sendo o mínimo de 1 cômodo e o máximo de 10 cômodos nas residências componentes do estudo. Existiam, em média, em cada casa, 2,5 torneiras para a utilização familiar. A maioria das habitações $(92,0 \%)$, nas três áreas, era construída de tijolo ou bloco, com ou sem reboco, e tinham o piso 
revestido por cimento ou cerâmica em $96,2 \%$ das vezes. A cobertura das habitações era de laje e telhado em 31,5\% das casas na área SPA; 9,3\% na área SPB e 18,5\% na área SPC. Somente de laje em 30,5\% das casas na área SPA; 71,7\% na área SPB, e $36,3 \%$ na área SPC e, de telhado sem laje, em 33,8\%; 17,2\% e 36,3\%, nas áreas SPA, SPB e SPC, respectivamente.

Em relação às condições do peridomicílio, o tipo de via de acesso mais freqüente à habitação era, para as três áreas, a rua (63,0\%); seguida da escada $(14,7 \%)$; viela $(14,7 \%)$ e de caminho $(6,0 \%)$. Em 88,7 \% das habitações na área SPA, as vias de acesso eram pavimentadas; enquanto somente, $23,8 \%$ das habitações na área SPB tinham acesso pavimentado. Este valor para a área SPC era de 92,1\%. A existência de calçada em frente à habitação foi verificada em $81,5 \%$ das casas na área SPA, em 89,7\% na área SPC e, somente, em 32\% das residências na área SPB.

Na Figura 14 são apresentadas as proporções de casas, por área de estudo, onde foram verificadas a presença de valas de esgoto e a existência de córregos e de lixo acumulado, nas proximidades das habitações.

As famílias das crianças que fizeram parte no estudo, e residiam há mais de um ano na habitação $(85,1 \%)$, moravam em média 8,7 anos na mesma casa. As famílias residentes, há menos de um ano na habitação, apresentaram um tempo médio de residência de 4,9 meses na residência investigada.

Das crianças investigadas na pesquisa, $97,9 \%$ das mães viviam em casa, enquanto que para os pais esse percentual era de 73,2\% para a área SPA; 73,3\% para a área SPB e de 57,5\% para a área SPC. 


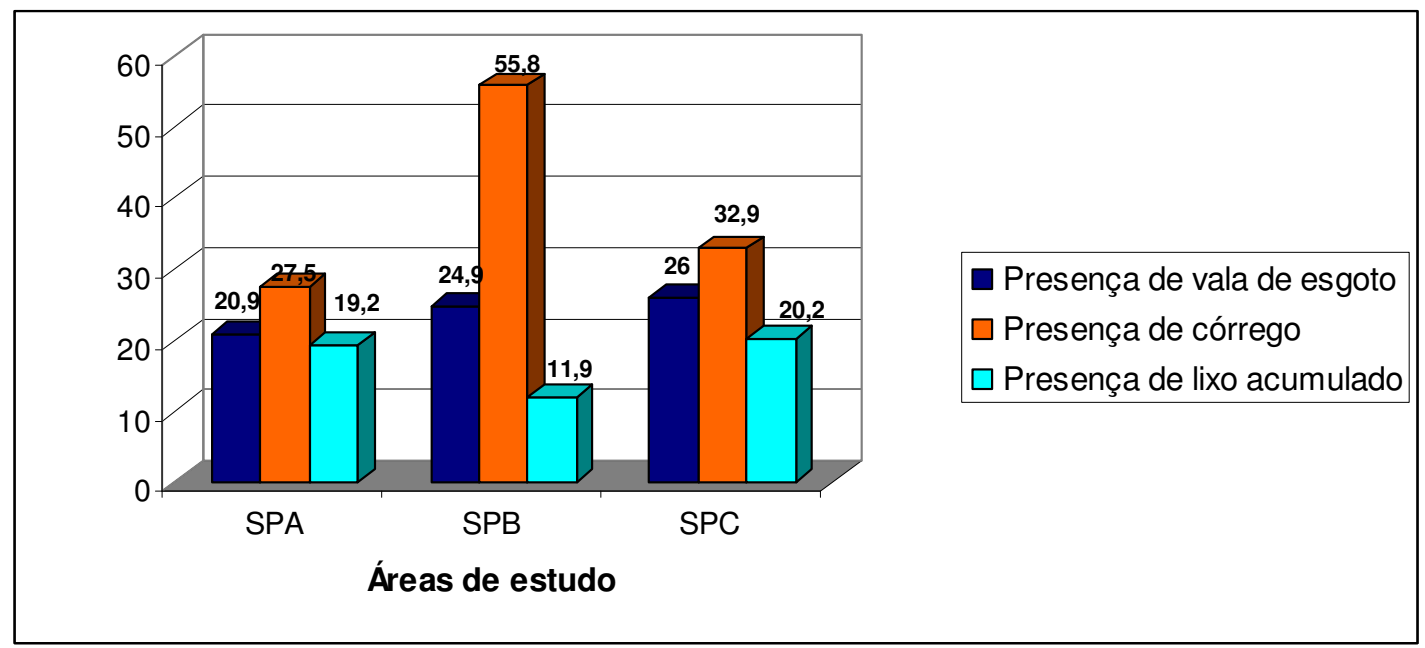

FIGURA 14 - Condições ambientais do peridomicílio das habitações do estudo

O Protocolo de Pesquisa 2, que compreendia as perguntas referentes às crianças do estudo, foi respondido em $85,8 \%$ das vezes pela mãe biológica da criança. Dessas, 69,8\%; 78,6\% e 59,9\%, respectivamente para as áreas SPA, SPB e SPC, eram donas de casa, exercendo um trabalho familiar não remunerado. A percentagem de mães que estavam desempregadas era de 13,6\% para a área SPA; 6,9\% para a área SPB e de 18,5\% para a área SPC. As mães das crianças apresentaram a média de idade de 28,3 anos $(\mathrm{DP}=7,8)$ na área SPA; de 28,7 anos $(\mathrm{DP}=7,2)$ na área SPB e de 29,8 anos $(\mathrm{DP}=8,7)$ na área SPC. A idade mínima das mães foi de 13 anos e a máxima de 69 anos. A proporção do grau de escolaridade das mães e dos pais das crianças, nas três áreas de investigação, é apresentada na Figura 15.

Das crianças que fizeram parte do estudo, $69,5 \%$ nasceram de parto natural e 27,0\% de cesariana; $36,2 \%$ das crianças foram a primeira gestação da mãe; 90,3\% 
das crianças nasceram após nove meses completos de gestação; 95,0\% tinham tomado a vacinação completa para a idade e $84,1 \%$ das crianças não freqüentavam creche ou escola, passando a maior parte do dia $(90,7 \%)$ em casa, totalizando em média, 22,5 horas em casa ( $\mathrm{DP}=4,2)$. A altura média das crianças foi de $0,96 \mathrm{~m}$ (DP $=0,9)$ e peso de $15,6 \mathrm{~kg}(\mathrm{DP}=8,0)$.

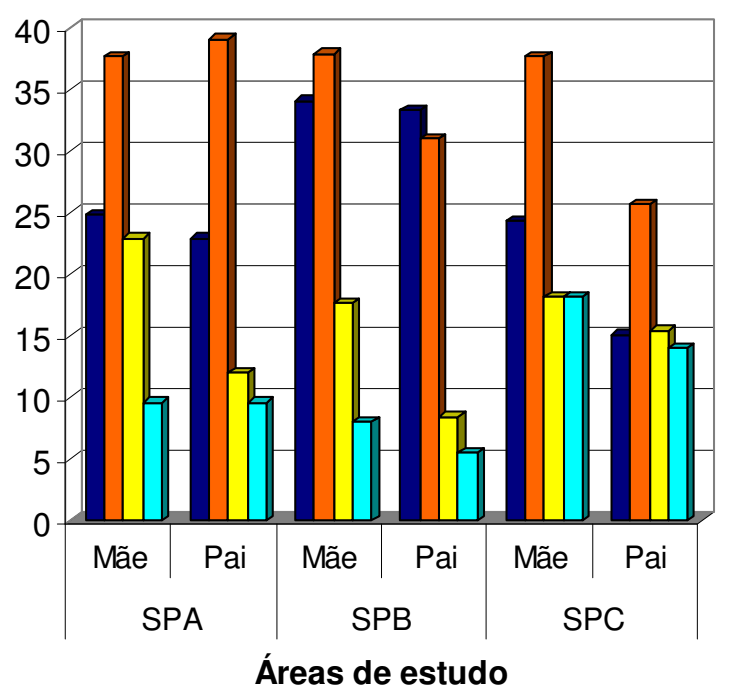

- Não estudou

FIGURA 15 - Percentagem de escolaridade dos pais

Em relação à procedência da água consumida pela criança, foi relatado que 96,4\%; 93,4\% e 90,4\% das crianças nas áreas SPA, SPB e SPC, respectivamente, consumiam água proveniente da rede pública de abastecimento. A água consumida sofria algum preparo antes do consumo para 56,2\% das crianças, na área SPA; $64,5 \%$ na área SPB e 44,8\% na área SPC. O consumo somente de água mineral foi relatado para 5,8\% das crianças nas três áreas. 
Em relação aos hábitos e práticas de higiene, 98,7\%; 99,2\%; 95,6\% das crianças nas áreas SPA, SPB e SPC, respectivamente, tinham suas frutas lavadas e preparadas antes de serem consumidas pelas crianças. Foi relatado que 19,9\% das crianças não tinham hábito de lavar as mãos antes de alimentar, enquanto esta proporção para as áreas SPB e SPC foi, respectivamente, de 11,1\% e 11,3\%.

A Figura 16 apresenta a percentagem das crianças que apresentavam o hábito de brincar em córrego ou em local onde existia esgoto escorrendo a céu aberto ou lixo disposto inadequadamente. A análise comparativa entre as áreas apresentou um teste do qui-quadrado de 82,970 com 4 graus de liberdade e $\mathrm{p}<0,000$, para o hábito da criança brincar próxima a locais onde existia córrego; e $X^{2}{ }_{(2 \mathrm{GL})}=78,873$ e p $<0,000$, para a existência de esgoto em local freqüentado pela criança. O hábito de brincar em local com lixo, diferentemente das variáveis anteriores, apresentou um $X^{2}$ $(2 \mathrm{GL})=5,294$ e $\mathrm{p}=0,71$.

Para melhor análise dos resultados obtidos pela aplicação dos Protocolos de Pesquisa 1 e 2, as variáveis foram agrupadas nas seguintes classes:

1. Estrutura familiar;

2. Condição socioeconômica;

3. Condição da habitação;

4. Esgotamento sanitário;

5. Abastecimento de água;

6. Resíduos sólidos;

7. Drenagem urbana;

8. Condições ambientais do peridomicílio;

9. Informações sobre a criança; 
10. Hábitos higiênicos;

11. Indicadores ambientais;

12. Indicadores de saúde.

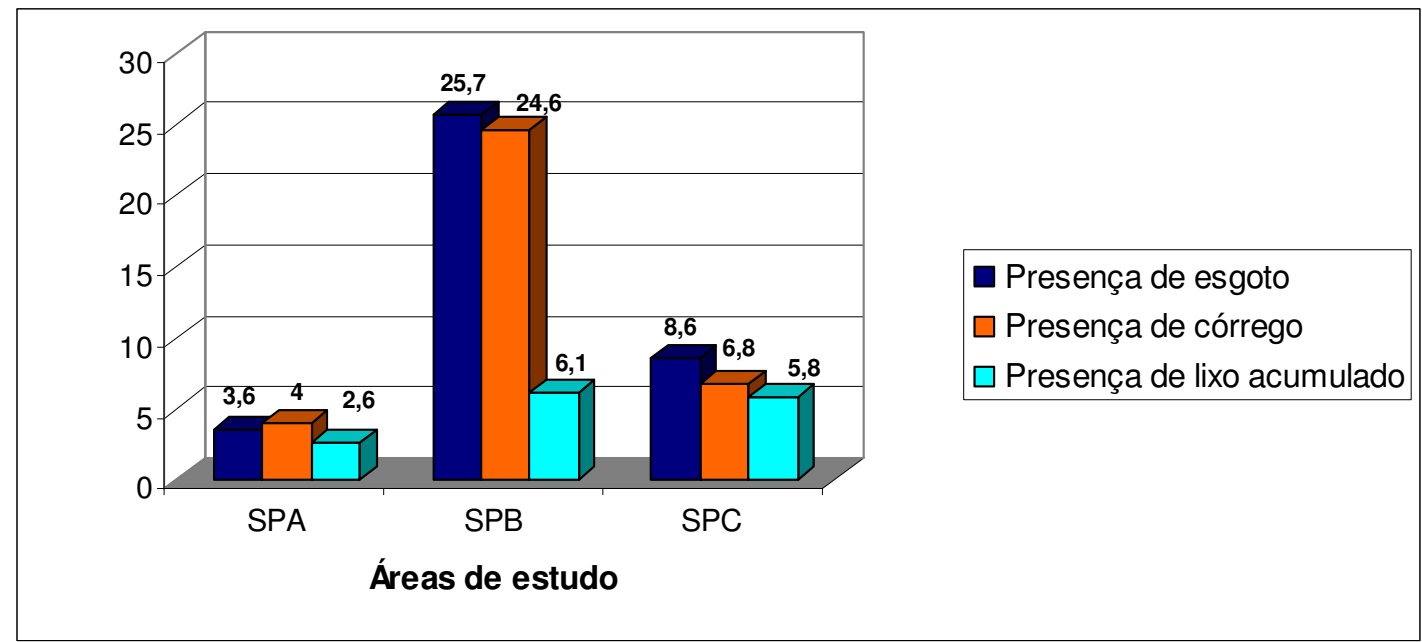

FIGURA 16 - Percentagem das crianças que têm habito de brincar em locais em condições sanitárias inadequadas

Na Figura 17 é apresentada a distribuição geográfica da amostra de estudo. Cada ponto no mapa representa uma criança amostrada.

As distribuições das freqüências das variáveis qualitativas, que caracterizaram a amostra de estudo, na comparação das três áreas, com os respectivos valores do qui-quadrado, que obtiveram um valor de p abaixo do limite correspondente ao nível de significância de 5\%, são apresentadas na Tabela 28. Nesta tabela, as variáveis foram agrupadas segundo as classes expressas anteriormente. 


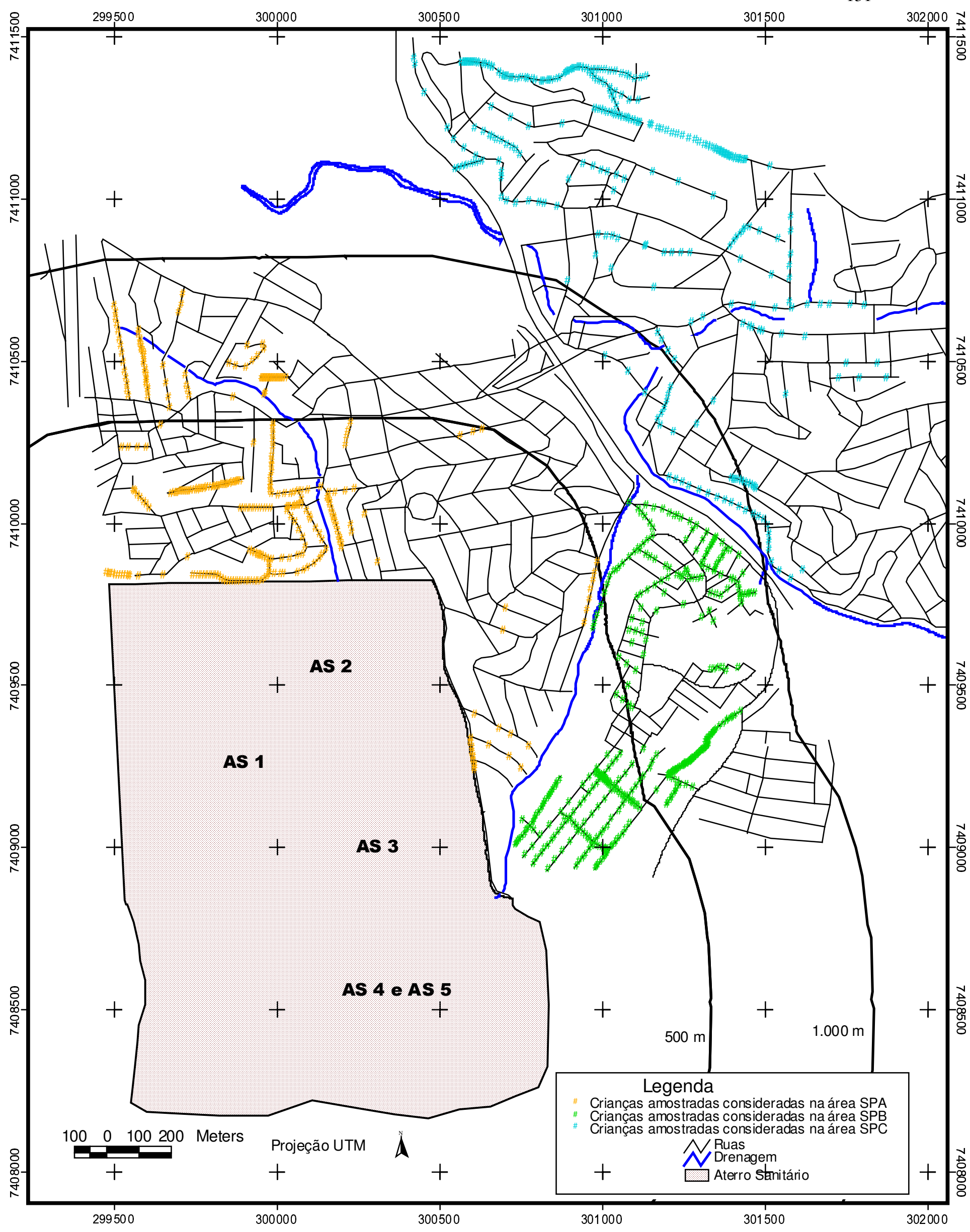

FIGURA 17 - Distribuição geográfica da amostra de estudo. 
TABELA 28 - Caracterização das áreas de estudo segundo a freqüência das variáveis qualitativas que obtiveram o valor de p inferior ao limite de significância de $5 \%$

\begin{tabular}{|c|c|c|c|c|c|c|c|}
\hline Variável & Atributo & Freq. & SPA & SPB & SPC & $X^{2}(1)$ & $\mathbf{p}_{(2)}$ \\
\hline \multicolumn{8}{|c|}{ 1. ESTRUTURA FAMILIAR } \\
\hline \multirow[t]{4}{*}{ Estado civil da mãe } & \multirow[t]{2}{*}{ Casada/união livre } & $\mathbf{n}$ & 230 & 309 & 205 & \multirow[t]{4}{*}{10,408} & \multirow[t]{4}{*}{0,005} \\
\hline & & $\%$ & 76,9 & 83,1 & 72,7 & & \\
\hline & \multirow{2}{*}{$\begin{array}{l}\text { Solteira/separada/ } \\
\text { divorciada/viúva }\end{array}$} & $\mathbf{n}$ & 69 & 63 & 77 & & \\
\hline & & $\%$ & 16,9 & 27,3 & 21,9 & & \\
\hline \multirow[t]{8}{*}{ Escolaridade da mãe } & \multirow[t]{2}{*}{ Ensino médio } & $\mathbf{n}$ & 29 & 30 & 53 & \multirow[t]{8}{*}{26,072} & \multirow[t]{8}{*}{0,000} \\
\hline & & $\%$ & 10,1 & 8,1 & 18,5 & & \\
\hline & \multirow[t]{2}{*}{ Fundamental ( $5^{\mathrm{a}}$ a $8^{\mathrm{a}}$ série $)$} & $\mathbf{n}$ & 69 & 67 & 53 & & \\
\hline & & $\%$ & 24,0 & 18,2 & 18,5 & & \\
\hline & \multirow[t]{2}{*}{ Fundamental $\left(1^{\mathrm{a}}\right.$ a $4^{\mathrm{a}}$ série $)$} & $\mathbf{n}$ & 114 & 143 & 110 & & \\
\hline & & $\%$ & 39,7 & 38,8 & 38,3 & & \\
\hline & \multirow[t]{2}{*}{ Não estudou } & $\mathbf{n}$ & 75 & 129 & 71 & & \\
\hline & & $\%$ & 26,1 & 35 & 24,7 & & \\
\hline \multirow[t]{4}{*}{ Pai vive na casa } & \multirow[t]{2}{*}{ Não } & $\mathbf{n}$ & 81 & 94 & 114 & \multirow[t]{4}{*}{19,761} & \multirow[t]{4}{*}{0,000} \\
\hline & & $\%$ & 26,8 & 25,3 & 40,4 & & \\
\hline & \multirow[t]{2}{*}{ Sim } & $\mathbf{n}$ & 221 & 277 & 158 & & \\
\hline & & $\%$ & 73,2 & 74,7 & 59,6 & & \\
\hline \multirow[t]{8}{*}{ Escolaridade do pai } & \multirow[t]{2}{*}{ Ensino médio } & $\mathbf{n}$ & 29 & 21 & 41 & \multirow[t]{8}{*}{49,406} & \multirow[t]{8}{*}{0,000} \\
\hline & & $\%$ & 11,5 & 7,1 & 20,0 & & \\
\hline & \multirow[t]{2}{*}{ Fundamental ( $5^{\mathrm{a}}$ a $8^{\mathrm{a}}$ série $)$} & $\mathbf{n}$ & 36 & 32 & 45 & & \\
\hline & & $\%$ & 14,3 & 10,8 & 22,0 & & \\
\hline & \multirow[t]{2}{*}{ Fundamental ( $1^{\mathrm{a}}$ a $4^{\mathrm{a}}$ série $)$} & $\mathbf{n}$ & 118 & 117 & 75 & & \\
\hline & & $\%$ & 46,8 & 39,5 & 36,6 & & \\
\hline & \multirow{2}{*}{ Não estudou } & $\mathbf{n}$ & 69 & 126 & 44 & & \\
\hline & & $\%$ & 27,4 & 42,6 & 21,5 & & \\
\hline Relação com trabalho & Dona de casa & n & 210 & 297 & 175 & 31,205 & 0,000 \\
\hline da mãe & & $\%$ & 69,8 & 79,0 & 61,2 & & \\
\hline & Empregadora/empregada & n & 39 & 48 & 48 & & \\
\hline & & $\%$ & 13,0 & 12,8 & 16,8 & & \\
\hline & Desempregada & $\mathbf{n}$ & 52 & 31 & 63 & & \\
\hline & & $\%$ & 8,2 & 22 & 15,2 & & \\
\hline & 2. CONDIÇÃO SOC & ONÔI & IICA & & & & \\
\hline Posse de geladeira & Não & $\mathbf{n}$ & 31 & 11 & 16 & 16,543 & 0,000 \\
\hline & & $\%$ & 10,4 & 2,9 & 5,5 & & \\
\hline & Sim & $\mathbf{n}$ & 267 & 363 & 276 & & \\
\hline & & $\%$ & 89,6 & 97,1 & 94,5 & & \\
\hline Posse de televisão & Não & $\mathbf{n}$ & 28 & 19 & 15 & 6,268 & 0,044 \\
\hline & & $\%$ & 9,4 & 5,1 & 5,1 & & \\
\hline & Sim & $\mathrm{n}$ & 270 & 354 & 277 & & \\
\hline & & $\%$ & 90,6 & 94,9 & 94,9 & & \\
\hline
\end{tabular}


TABELA 28 - Continuação

\begin{tabular}{|c|c|c|c|c|c|c|c|}
\hline Variável & Atributo & Freq. & SPA & SPB & SPC & $X_{(1)}^{2}$ & $\overline{\mathbf{p}_{(2)}}$ \\
\hline \multirow[t]{12}{*}{ Renda familiar } & \multirow[t]{2}{*}{ Menos de 1 SM } & $\bar{n}$ & 63 & 94 & 76 & \multirow[t]{12}{*}{60,581} & \multirow[t]{12}{*}{0,000} \\
\hline & & $\%$ & 27,4 & 25,3 & 28,0 & & \\
\hline & \multirow[t]{2}{*}{$1<=\mathrm{SM}<2$} & $\mathbf{n}$ & 211 & 96 & 390 & & \\
\hline & & $\%$ & 36,1 & 56,7 & 35,4 & & \\
\hline & \multirow[t]{2}{*}{$2<=\mathrm{SM}<3$} & $\mathbf{n}$ & 58 & 45 & 59 & & \\
\hline & & $\%$ & 25,2 & 21,8 & 18,6 & & \\
\hline & \multirow[t]{2}{*}{$3<=\mathrm{SM}<5$} & $\mathbf{n}$ & 17 & 20 & 33 & & \\
\hline & & $\%$ & 7,4 & 5,4 & 12,2 & & \\
\hline & \multirow{2}{*}{$5<=\mathrm{SM}<10$} & $\mathbf{n}$ & 9 & & 6 & & \\
\hline & & $\%$ & 3,9 & & 2,2 & & \\
\hline & \multirow{2}{*}{$>=10 \mathrm{SM}$} & $\mathbf{n}$ & & 2 & 1 & & \\
\hline & & $\%$ & & 0,5 & 0,4 & & \\
\hline \multicolumn{8}{|c|}{ 3. CONDIÇÃO DA HABITAÇÃO } \\
\hline \multirow[t]{4}{*}{ Localização da casa } & \multirow[t]{2}{*}{ Loteamento irregular } & $\mathbf{n}$ & 90 & 285 & 51 & \multirow[t]{4}{*}{218,55} & \multirow[t]{4}{*}{0,000} \\
\hline & & $\%$ & 44,3 & 76,6 & 18,4 & & \\
\hline & \multirow[t]{2}{*}{ Loteamento regular } & $\mathbf{n}$ & 113 & 87 & 226 & & \\
\hline & & $\%$ & 55,7 & 23,4 & 81,6 & & \\
\hline \multirow[t]{4}{*}{ Tipo de habitação } & \multirow[t]{2}{*}{ Casa/apartamento } & $\mathbf{n}$ & 276 & 332 & 274 & \multirow[t]{4}{*}{7,510} & \multirow[t]{4}{*}{0,023} \\
\hline & & $\%$ & 93,6 & 88,5 & 93,8 & & \\
\hline & \multirow[t]{2}{*}{ Barraco/quarto } & $\mathbf{n}$ & 20 & 43 & 18 & & \\
\hline & & $\%$ & 6,8 & 11,5 & 6,2 & & \\
\hline \multirow{4}{*}{ Tipo de Banheiro } & \multirow{2}{*}{ Incompleto } & $\mathbf{n}$ & 102 & 125 & 73 & 7,546 & 0,023 \\
\hline & & $\%$ & 34,6 & 34,0 & 25,3 & & \\
\hline & Completo & $\mathbf{n}$ & 193 & 243 & 216 & & \\
\hline & & $\%$ & 65,4 & 66,0 & 74,7 & & \\
\hline Existência de cozinha & Não & $\mathbf{n}$ & 79 & 65 & 28 & 28,566 & 0,000 \\
\hline independente & & $\%$ & 26,6 & 17,4 & 9,7 & & \\
\hline & Sim & $\mathbf{n}$ & 218 & 308 & 261 & & \\
\hline & & $\%$ & 73,4 & 82,6 & 90,3 & & \\
\hline Piso da habitação & Sem revestimento & $\mathbf{n}$ & 5 & 14 & 3 & 6,072 & 0,048 \\
\hline & & $\%$ & 1,7 & 3,7 & 1,0 & & \\
\hline & Com revestimento & $\mathbf{n}$ & 293 & 361 & 288 & & \\
\hline & & $\%$ & 98,3 & 96,3 & 99,0 & & \\
\hline Cobertura da & Laje e telhado & $\mathbf{n}$ & 95 & 35 & 54 & 134,01 & 0,000 \\
\hline habitação & & $\%$ & 32,0 & 9,3 & 18,6 & & \\
\hline & Laje sem telhado & $\mathbf{n}$ & 92 & 271 & 130 & & \\
\hline & & $\%$ & 31,0 & 72,3 & 44,8 & & \\
\hline & Telhado sem laje & $\mathbf{n}$ & 110 & 67 & 106 & & \\
\hline & & $\%$ & 37,0 & 17,9 & 36,6 & & \\
\hline & Lona ou plástico & $\mathbf{n}$ & & 2 & & & \\
\hline & & $\%$ & & 0,5 & & & \\
\hline Existência de caixa & Não & $\mathbf{n}$ & 86 & 73 & 92 & 17,342 & 0,000 \\
\hline d'água & & $\%$ & 32,0 & 19,6 & 32,1 & & \\
\hline & Sim & $\mathbf{n}$ & 183 & 299 & 195 & & \\
\hline & & $\%$ & 68,0 & 80,4 & 67,9 & & \\
\hline
\end{tabular}


TABELA 28 - Continuação

\begin{tabular}{|c|c|c|c|c|c|c|c|}
\hline Variável & Atributo & Freq. & SPA & SPB & SPC & $X_{(1)}^{2}$ & $\mathbf{p}_{(2)}$ \\
\hline \multirow[t]{4}{*}{ Caixa d'água coberta } & Não & $\mathbf{n}$ & 3 & 18 & 6 & \multirow[t]{4}{*}{6,203} & \multirow[t]{4}{*}{0,045} \\
\hline & & $\%$ & 1,6 & 5,7 & 2,9 & & \\
\hline & Sim & $\mathrm{n}$ & 189 & 297 & 198 & & \\
\hline & & $\%$ & 98,4 & 94,3 & 97,1 & & \\
\hline \multirow{6}{*}{$\begin{array}{l}\text { Freqüência de } \\
\text { limpeza da caixa } \\
\text { d'água }\end{array}$} & A cada seis meses & $\mathbf{n}$ & 148 & 230 & 116 & \multirow[t]{6}{*}{28,117} & \multirow[t]{6}{*}{0,000} \\
\hline & & $\%$ & 80,0 & 75,2 & 58,6 & & \\
\hline & Uma vez por ano & $\mathbf{n}$ & 34 & 70 & 80 & & \\
\hline & & $\%$ & 18,4 & 22,9 & 40,4 & & \\
\hline & Nunca foi lavada & $\mathbf{n}$ & 3 & 6 & 2 & & \\
\hline & & $\%$ & 1,6 & 2,0 & 1,0 & & \\
\hline \multicolumn{8}{|c|}{ 4. ESGOTAMENTO SANITÁRIO } \\
\hline \multirow{4}{*}{$\begin{array}{l}\text { Destino do esgoto da } \\
\text { casa }\end{array}$} & Sanitariamente inadequado & $\mathbf{n}$ & 79 & 203 & 110 & \multirow[t]{4}{*}{61,720} & \multirow[t]{4}{*}{0,000} \\
\hline & & $\%$ & 27,1 & 57,3 & 38,7 & & \\
\hline & Sanitariamente adequado & $\mathbf{n}$ & 212 & 151 & 174 & & \\
\hline & & $\%$ & 72,9 & 42,7 & 61,3 & & \\
\hline \multicolumn{8}{|c|}{ 5. ABASTECIMENTO DE ÁGUA } \\
\hline \multirow{4}{*}{$\begin{array}{l}\text { Procedência da água } \\
\text { consumida na } \\
\text { habitação }\end{array}$} & \multirow{2}{*}{ Rede pública de abastecimento } & $\mathbf{n}$ & 292 & 363 & 283 & \multirow[t]{4}{*}{6,886} & \multirow[t]{4}{*}{0,032} \\
\hline & & $\%$ & 99,7 & 96,8 & 97,3 & & \\
\hline & \multirow[t]{2}{*}{ Outra fonte } & n & 1 & 12 & 8 & & \\
\hline & & $\%$ & 0,3 & 3,2 & 2,7 & & \\
\hline \multirow{4}{*}{$\begin{array}{l}\text { Problemas de falta } \\
\text { água na habitação }\end{array}$} & \multirow[t]{2}{*}{ Não } & $\mathbf{n}$ & 254 & 260 & 167 & \multirow[t]{4}{*}{58,670} & \multirow[t]{4}{*}{0,000} \\
\hline & & $\%$ & 86,7 & 69,7 & 58,2 & & \\
\hline & \multirow[t]{2}{*}{ Sim } & $\mathbf{n}$ & 39 & 113 & 120 & & \\
\hline & & $\%$ & 13,3 & 30,3 & 41,8 & & \\
\hline \multirow{6}{*}{$\begin{array}{l}\text { Freqüiência do } \\
\text { abastecimento de } \\
\text { água }\end{array}$} & \multirow[t]{2}{*}{ Todos os dias } & n & 277 & 364 & 269 & 26,976 & 0,000 \\
\hline & & $\%$ & 93,9 & 97,8 & 97,8 & & \\
\hline & A cada três dias & $\mathbf{n}$ & 1 & 7 & 2 & & \\
\hline & & $\%$ & 0,3 & 1,9 & 0,7 & & \\
\hline & Demora mais de uma semana & $\mathbf{n}$ & 17 & 1 & 4 & & \\
\hline & & $\%$ & 5,8 & 0,3 & 1,5 & & \\
\hline Alterações nas & Não & $\mathbf{n}$ & 275 & 351 & 204 & 7,026 & 0,030 \\
\hline características & & $\%$ & 95,5 & 95,9 & 91,1 & & \\
\hline organolépticas da & Sim & $\mathbf{n}$ & 13 & 15 & 20 & & \\
\hline água & & $\%$ & 4,5 & 4,1 & 8,9 & & \\
\hline Cuidados com a água & Só é consumida água mineral & $\mathbf{n}$ & 12 & 14 & 14 & 32,946 & 0,000 \\
\hline de beber & & $\%$ & 4,4 & 4,0 & 5,0 & & \\
\hline & Filtrada e/ou fervida & $\mathbf{n}$ & 157 & 247 & 134 & & \\
\hline & & $\%$ & 57,7 & 70,0 & 47,9 & & \\
\hline & Consumida sem cuidado & $\mathbf{n}$ & 103 & 92 & 132 & & \\
\hline & adicional & $\%$ & 37,9 & 26,1 & 47,1 & & \\
\hline Preparo da água & Não & $\mathbf{n}$ & 145 & 223 & 123 & 17,203 & 0,000 \\
\hline bebida pela criança & & $\%$ & 48,2 & 59,3 & 43,8 & & \\
\hline & Sim & n & 156 & 153 & 158 & & \\
\hline & & $\%$ & 51,8 & 40,7 & 56,2 & & \\
\hline
\end{tabular}


TABELA 28 - Continuação

\begin{tabular}{|c|c|c|c|c|c|c|c|}
\hline Variável & Atributo & Freq. & SPA & SPB & SPC & $X_{(1)}^{2}$ & $\mathbf{p}_{(2)}$ \\
\hline \multicolumn{8}{|c|}{ 6. RESÍDUOS SÓLIDOS } \\
\hline \multirow{4}{*}{$\begin{array}{l}\text { Separação do lixo da } \\
\text { casa }\end{array}$} & Não & $\mathbf{n}$ & 29 & 243 & 134 & 210,54 & 0,000 \\
\hline & & $\%$ & 9,9 & 65,9 & 446,4 & 0 & \\
\hline & Sim & $\mathbf{n}$ & 263 & 126 & 155 & & \\
\hline & & $\%$ & 90,1 & 34,1 & 53,6 & & \\
\hline \multirow{4}{*}{$\begin{array}{l}\text { Acondicionamento do } \\
\text { lixo da casa }\end{array}$} & Não & $\mathrm{n}$ & 1 & 27 & 28 & 33,907 & 0,000 \\
\hline & & $\%$ & 0,3 & 7,3 & 12,8 & & \\
\hline & Sim & $\mathbf{n}$ & 293 & 345 & 190 & & \\
\hline & & $\%$ & 92,7 & 87,2 & 93,7 & & \\
\hline \multirow{4}{*}{$\begin{array}{l}\text { Recipiente para } \\
\text { colocar lixo }\end{array}$} & Tampado & $\mathbf{n}$ & & & 69 & 173,94 & 0,000 \\
\hline & & $\%$ & & & 23,8 & 1 & \\
\hline & Aberto & $\mathbf{n}$ & 301 & 378 & 221 & & \\
\hline & & $\%$ & 100 & 100 & 76,2 & & \\
\hline \multirow{6}{*}{$\begin{array}{l}\text { Freqüiência da coleta } \\
\text { de lixo }\end{array}$} & Diária & n & 283 & 195 & 214 & 70,761 & 0,000 \\
\hline & & $\%$ & 96,9 & 81,6 & 75,1 & & \\
\hline & Três ou duas vezes por semana & $\mathbf{n}$ & 1 & 12 & 4 & & \\
\hline & & $\%$ & 0,3 & 5,0 & 1,4 & & \\
\hline & Não há coleta de lixo & n & 8 & 32 & 67 & & \\
\hline & & $\%$ & 2,7 & 13,4 & 23,5 & & \\
\hline \multicolumn{8}{|c|}{ 7. DRENAGEM } \\
\hline \multirow{4}{*}{ Inundação do lote } & Não & $\mathbf{n}$ & 250 & 349 & 199 & 12,119 & 0,002 \\
\hline & & $\%$ & 84,5 & 92,8 & 89,6 & & \\
\hline & Sim & $\mathbf{n}$ & 46 & 27 & 23 & & \\
\hline & & $\%$ & 15,5 & 7,2 & 10,4 & & \\
\hline \multirow[t]{4}{*}{ Empoçamento do lote } & Não & n & 246 & 328 & 215 & 25,880 & 0,000 \\
\hline & & $\%$ & 83,7 & 89,1 & 74,1 & & \\
\hline & Sim & $\mathbf{n}$ & 48 & 40 & 75 & & \\
\hline & & $\%$ & 16,3 & 10,9 & 25,9 & & \\
\hline & 8. CONDIÇÃO AMBIENTAL D & PERI & OMIC & 吕IO & & & \\
\hline \multirow{4}{*}{$\begin{array}{l}\text { Via de acesso } \\
\text { pavimentada }\end{array}$} & Não & $\mathbf{n}$ & 34 & 288 & 23 & 448,18 & 0,000 \\
\hline & & $\%$ & 11,3 & 76,2 & 7,9 & & \\
\hline & Sim & n & 268 & 90 & 269 & & \\
\hline & & $\%$ & 88,7 & 23,8 & 92,1 & & \\
\hline \multirow[t]{4}{*}{ Calçada pavimentada } & Não & n & 35 & 252 & 34 & 313,91 & 0,000 \\
\hline & & $\%$ & 12,7 & 69,2 & $\overline{12,1}$ & & \\
\hline & Sim & $\mathrm{n}$ & 241 & 112 & 248 & & \\
\hline & & $\%$ & 87,3 & 30,8 & 87,9 & & \\
\hline \multirow{4}{*}{$\begin{array}{l}\text { Presença de vala de } \\
\text { esgoto }\end{array}$} & Não & $\mathrm{n}$ & 198 & 223 & 213 & 14,316 & 0,001 \\
\hline & & $\%$ & 65,6 & 59,2 & 73,2 & & \\
\hline & Sim & $\mathbf{n}$ & 104 & 154 & 78 & & \\
\hline & & $\%$ & 34,4 & 40,8 & 26,8 & & \\
\hline \multirow{4}{*}{$\begin{array}{l}\text { Presença de córrego } \\
\text { na área }\end{array}$} & Não & $\mathrm{n}$ & 189 & 239 & 219 & 13,754 & 0,001 \\
\hline & & $\%$ & 62,6 & 63,4 & 75,3 & & \\
\hline & Sim & $\mathbf{n}$ & 113 & 138 & 72 & & \\
\hline & & $\%$ & 37,4 & 36,6 & 24,7 & & \\
\hline
\end{tabular}


TABELA 28 - Continuação

\begin{tabular}{|c|c|c|c|c|c|c|c|}
\hline Variável & Atributo & Freq. & SPA & SPB & SPC & $X_{(1)}^{2}$ & $\mathbf{p}_{(2)}$ \\
\hline \multicolumn{8}{|c|}{ 9. INFORMAÇÃO SOBRE A CRIANÇA } \\
\hline \multirow{4}{*}{$\begin{array}{l}\text { Mãe necessitou de } \\
\text { internação durante a } \\
\text { gravidez }\end{array}$} & \multirow[t]{2}{*}{ Não } & $\mathbf{n}$ & 266 & 334 & 268 & \multirow[t]{4}{*}{7,731} & \multirow[t]{4}{*}{0,021} \\
\hline & & $\%$ & 88,4 & 89,8 & 94,7 & & \\
\hline & \multirow[t]{2}{*}{ Sim } & $\mathbf{n}$ & 35 & 38 & 15 & & \\
\hline & & $\%$ & 11,6 & 10,2 & 5,3 & & \\
\hline \multirow{4}{*}{$\begin{array}{l}\text { Vacinação completa } \\
\text { para a idade }\end{array}$} & \multirow[t]{2}{*}{ Não } & $\mathbf{n}$ & 19 & 9 & 10 & \multirow[t]{4}{*}{6,997} & \multirow[t]{4}{*}{0,030} \\
\hline & & $\%$ & 6,3 & 2,4 & 3,5 & & \\
\hline & \multirow[t]{2}{*}{ Sim } & $\mathbf{n}$ & 281 & 365 & 277 & & \\
\hline & & $\%$ & 93,7 & 97,6 & 96,5 & & \\
\hline \multirow{6}{*}{$\begin{array}{l}\text { Local onde a criança } \\
\text { passa o dia }\end{array}$} & \multirow[t]{2}{*}{ Em casa } & $\mathbf{n}$ & 258 & 353 & 270 & \multirow[t]{6}{*}{30,852} & \multirow[t]{6}{*}{0,000} \\
\hline & & $\%$ & 86,0 & 94,1 & 96,8 & & \\
\hline & \multirow[t]{2}{*}{ Casa de parentes ou vizinhos } & $\mathbf{n}$ & 3 & 4 & 3 & & \\
\hline & & $\%$ & 1,0 & 1,1 & 1,1 & & \\
\hline & \multirow{2}{*}{ Creche ou escola } & $\mathbf{n}$ & 39 & 18 & 6 & & \\
\hline & & $\%$ & 13,0 & 4,8 & 2,2 & & \\
\hline \multirow{6}{*}{$\begin{array}{l}\text { Pessoa que toma } \\
\text { conta da criança }\end{array}$} & \multirow[t]{2}{*}{ Mãe } & $\mathbf{n}$ & 276 & 322 & 243 & \multirow[t]{6}{*}{12,891} & \multirow[t]{6}{*}{0,012} \\
\hline & & $\%$ & 92,6 & 87,0 & 86,8 & & \\
\hline & \multirow[t]{2}{*}{ Pai } & $\mathbf{n}$ & 11 & 9 & 8 & & \\
\hline & & $\%$ & 3,7 & 2,4 & 2,9 & & \\
\hline & \multirow[t]{2}{*}{ Outra pessoa } & n & 11 & 39 & 29 & & \\
\hline & & $\%$ & 3,7 & 10,5 & 10,4 & & \\
\hline \multirow{4}{*}{$\begin{array}{l}\text { Hábito de brincar no } \\
\text { córrego }\end{array}$} & Não & $\mathbf{n}$ & 290 & 278 & 264 & 82,970 & 0,000 \\
\hline & & $\%$ & 96,0 & 74,9 & 93,0 & & \\
\hline & Sim & $\mathbf{n}$ & 10 & 92 & 19 & & \\
\hline & & $\%$ & 3,3 & 24,8 & 6,7 & & \\
\hline Existência de esgoto & Não & $\mathbf{n}$ & 291 & 275 & 259 & 78,873 & 0,000 \\
\hline em local freqüentado & & $\%$ & 96,4 & 73,9 & 91,2 & & \\
\hline pela criança & Sim & $\mathbf{n}$ & 11 & 97 & 25 & & \\
\hline & & $\%$ & 3,6 & 26,1 & 8,8 & & \\
\hline & 10. HÁBITOS HI & NICO & & & & & \\
\hline Preparo das frutas e & Não & $\mathbf{n}$ & 20 & 7 & 12 & 9,900 & 0,007 \\
\hline verduras & & $\%$ & 6,7 & 1,9 & 4,3 & & \\
\hline & Sim & n & 280 & 369 & 270 & & \\
\hline & & $\%$ & 93,3 & 98,1 & 95,7 & & \\
\hline Lavagem da mão & Não & n & 137 & 113 & 73 & 29,871 & 0,000 \\
\hline antes de se alimentar & & $\%$ & 46,0 & 30,1 & 25,9 & & \\
\hline & Sim & $\mathbf{n}$ & 161 & 262 & 209 & & \\
\hline & & $\%$ & 54,0 & 69,9 & 74,1 & & \\
\hline Lavagem da mão & Não & $\mathbf{n}$ & 115 & 92 & 64 & 21,530 & 0,000 \\
\hline após defecar & & $\%$ & 38,5 & 24,7 & 22,9 & & \\
\hline & Sim & $\mathbf{n}$ & 184 & 280 & 216 & & \\
\hline & & $\%$ & 61,5 & 73,3 & 77,1 & & \\
\hline
\end{tabular}

(1) Teste do qui-quadrado para os respectivos graus de liberdade

(2) Probabilidade de significância 
Na Tabela 29 são apresentas as freqüências, o qui-quadrado e o valor de $\mathrm{p}$ obtidos para as variáveis qualitativas, que na comparação das três áreas de estudo, não apresentaram uma diferença estatística ao nível de significância de 5\%. As variáveis referentes às classes dos indicadores ambientais e de saúde são apresentadas nos itens a seguir.

\subsection{Indicadores Ambientais - Caracterização da Área de Estudo}

Por meio da aplicação do Protocolo de Pesquisa 1, alguns parâmetros referentes à qualidade ambiental da área de estudo foram levantados. A seguir são apresentados os resultados obtidos e a análise comparativa desses parâmetros em relação às três áreas de exposição investigadas.

Na Tabela 30 são apresentadas as frequiências que foram observadas as presenças dos vetores: mosca, barata e rato, nas três áreas de exposição e o valor do qui-quadrado $\left(X^{2}\right)$ para os respectivos graus de liberdade e o valor da probabilidade de significância (p), encontrado na comparação das três áreas.

Na Tabela 31 são apresentadas as freqüências com que foram relatadas as presenças dos vetores nas residências, em função das estações do ano e das três áreas de estudo, com os respectivos valores da probabilidade de significância.

Nas Figuras 18, 19 e 20 são apresentadas as distribuições geográficas das frequiências relatadas do aparecimento de mosca, barata e rato, respectivamente. 
TABELA 29 - Caracterização das áreas de estudo segundo a freqüência das variáveis qualitativas que obtiveram o valor de p superior ao limite de significância de $5 \%$

\begin{tabular}{|c|c|c|c|c|c|c|c|}
\hline Variável & Atributo & Freq. & SPA & SPB & SPC & $X_{(1)}^{2}$ & $\mathbf{p}_{(2)}$ \\
\hline \multicolumn{8}{|c|}{ 1. ESTRUTURA FAMILIAR } \\
\hline \multirow[t]{4}{*}{ Tempo de residência } & \multirow{2}{*}{ Mais de 1 ano } & $\mathbf{n}$ & 258 & 322 & 248 & \multirow[t]{4}{*}{0,895} & \multirow[t]{4}{*}{0,639} \\
\hline & & $\%$ & 86,3 & 87,5 & 88,9 & & \\
\hline & \multirow[t]{2}{*}{ Menos de 1 ano } & $\mathbf{n}$ & 41 & 46 & 31 & & \\
\hline & & $\%$ & 13,7 & 12,5 & 11,1 & & \\
\hline \multirow[t]{4}{*}{ Presença da mãe na casa } & \multirow[t]{2}{*}{ Não } & $\mathbf{n}$ & 5 & 8 & 4 & \multirow[t]{4}{*}{0,544} & \multirow[t]{4}{*}{0,762} \\
\hline & & $\%$ & 1,7 & 2,1 & 1,4 & & \\
\hline & \multirow[t]{2}{*}{ Sim } & $\mathbf{n}$ & 295 & 370 & 287 & & \\
\hline & & $\%$ & 98,3 & 97,9 & 98,6 & & \\
\hline \multirow{8}{*}{$\begin{array}{l}\text { Escolaridade da pessoa que } \\
\text { toma conta da criança }\end{array}$} & \multirow[t]{2}{*}{ Ensino médio } & $\mathbf{n}$ & 1 & 4 & 5 & \multirow[t]{8}{*}{5,076} & \multirow[t]{8}{*}{0,534} \\
\hline & & $\%$ & 3,6 & 8,0 & 12,5 & & \\
\hline & \multirow{2}{*}{$\begin{array}{l}\text { Fundamental } \\
\left(5^{\mathrm{a}} \text { a } 8^{\mathrm{a}} \text { série }\right)\end{array}$} & $\mathbf{n}$ & 2 & 8 & 5 & & \\
\hline & & $\%$ & 7,1 & 16,0 & 12,5 & & \\
\hline & \multirow{2}{*}{$\begin{array}{l}\text { Fundamental } \\
\left(1^{\mathrm{a}} \text { a } 4^{\mathrm{a}} \text { série }\right)\end{array}$} & $\mathbf{n}$ & 12 & 12 & 11 & & \\
\hline & & $\%$ & 42,9 & 24,0 & 27,5 & & \\
\hline & \multirow[t]{2}{*}{ Não estudou } & $\mathbf{n}$ & 13 & 26 & 19 & & \\
\hline & & $\%$ & 46,4 & 62,0 & 47,5 & & \\
\hline \multirow{4}{*}{$\begin{array}{l}\text { Relação de trabalho do } \\
\text { responsável pelo sustento } \\
\text { familiar }\end{array}$} & \multirow{2}{*}{$\begin{array}{l}\text { Empregador } \\
\text { /empregado }\end{array}$} & $\mathbf{n}$ & 277 & 286 & 210 & \multirow[t]{4}{*}{1,304} & \multirow[t]{4}{*}{0,521} \\
\hline & & $\%$ & 76,7 & 78,8 & 75,0 & & \\
\hline & \multirow[t]{2}{*}{ Desempregado } & $\mathbf{n}$ & 69 & 77 & 70 & & \\
\hline & & $\%$ & 23,3 & 21,2 & 25,0 & & \\
\hline Membro da família que exerce & Não & $\mathbf{n}$ & 289 & 363 & 273 & 0,283 & 0,868 \\
\hline atividade relacionada ao lixo & & $\%$ & 96,3 & 97,1 & 96,8 & & \\
\hline & $\overline{\text { Sim }}$ & $\mathbf{n}$ & 11 & 11 & 9 & & \\
\hline & & $\%$ & 3,7 & 2,9 & 3,2 & & \\
\hline & 3. CONDIÇÃO D & $\overline{\text { ABITA }}$ & $\bar{c} \tilde{A} \mathbf{O}$ & & & & \\
\hline Existência de banheiro na & Não & $\mathbf{n}$ & 5 & 4 & 6 & 1,162 & 0,559 \\
\hline casa & & $\%$ & 1,7 & 1,1 & 2,1 & & \\
\hline & Sm & $\mathbf{n}$ & 292 & 369 & 278 & & \\
\hline & & $\%$ & 98,3 & 98,9 & 97,9 & & \\
\hline Instalação de água na cozinha & Não & $\mathbf{n}$ & 35 & 32 & 23 & 2,956 & 0,228 \\
\hline & & $\%$ & 11,8 & 8,6 & 8,0 & & \\
\hline & Sim & $\mathbf{n}$ & 262 & 341 & 265 & & \\
\hline & & $\%$ & 88,2 & 91,4 & 92 & & \\
\hline Material de revestimento da & Tijolo ou bloco & $\mathbf{n}$ & 280 & 342 & 272 & 2,434 & 0,296 \\
\hline habitação & & $\%$ & 94,3 & 91,2 & 93,2 & & \\
\hline & Madeira/lata/ & $\mathbf{n}$ & 17 & 33 & 20 & & \\
\hline & papelão & $\%$ & 5,7 & 8,8 & 6,8 & & \\
\hline & 5. ABASTECIMH & O DE Á & GUA & & & & \\
\hline Procedência da água & Rede pública & $\mathbf{n}$ & 291 & 353 & 264 & 2,115 & 0,347 \\
\hline consumida pela criança & & $\%$ & 99,7 & 100 & 100 & & \\
\hline & Caixa d'água & $\mathbf{n}$ & 1 & & & & \\
\hline & comunitária & $\%$ & 0,3 & & & & \\
\hline
\end{tabular}


TABELA 29 - Continuação

\begin{tabular}{|c|c|c|c|c|c|c|c|}
\hline Variável & Atributo & Freq. & $\overline{\text { SPA }}$ & $\overline{\text { SPB }}$ & $\overline{\text { SPC }}$ & $\overline{X^{2}{ }_{(1)}}$ & $\mathbf{p}_{(2)}$ \\
\hline \multicolumn{8}{|c|}{ 6. RESÍDUOS SÓLIDOS } \\
\hline \multirow{4}{*}{ Destino do lixo da casa } & \multirow{2}{*}{$\begin{array}{l}\text { Sanitariamente } \\
\text { inadequado }\end{array}$} & n & 2 & 1 & 4 & \multirow{4}{*}{3,131} & \multirow[t]{4}{*}{0,209} \\
\hline & & $\%$ & 0,7 & 0,3 & 1,5 & & \\
\hline & \multirow{2}{*}{$\begin{array}{l}\text { Sanitariamente } \\
\text { adequado }\end{array}$} & $\mathbf{n}$ & 293 & 371 & 266 & & \\
\hline & & $\%$ & 99,3 & 99,7 & 98,5 & & \\
\hline \multirow{4}{*}{$\begin{array}{l}\text { Disposição das fezes das } \\
\text { fraldas }\end{array}$} & \multirow{2}{*}{$\begin{array}{l}\text { Sanitariamente } \\
\text { inadequado }\end{array}$} & $\mathbf{n}$ & 10 & 10 & 16 & \multirow[t]{4}{*}{4,238} & \multirow[t]{4}{*}{0,120} \\
\hline & & $\%$ & 5,0 & 3,2 & 7,0 & & \\
\hline & \multirow{2}{*}{$\begin{array}{l}\text { Sanitariamente } \\
\text { adequado }\end{array}$} & $\mathbf{n}$ & 192 & 303 & 211 & & \\
\hline & & $\%$ & 95,0 & 96,8 & 93,0 & & \\
\hline \multirow{4}{*}{$\begin{array}{l}\text { Disposição das fraldas descar- } \\
\text { táveis no lixo }\end{array}$} & \multirow[t]{2}{*}{ Não } & n & 12 & 16 & 12 & \multirow[t]{4}{*}{0,145} & \multirow[t]{4}{*}{0,930} \\
\hline & & $\%$ & 5,9 & 5,3 & 5,1 & & \\
\hline & \multirow{2}{*}{$\overline{\text { Sim }}$} & n & 192 & 286 & 224 & & \\
\hline & & $\%$ & 94,1 & 94,7 & 94,9 & & \\
\hline \multicolumn{8}{|c|}{ 8. CONDIÇÃO AMBIENTAL DO PERIDOMICÍLIO } \\
\hline \multirow[t]{4}{*}{ Presença de lixo acumulado } & \multirow[t]{2}{*}{ Não } & $\mathbf{n}$ & 269 & 354 & 266 & \multirow[t]{4}{*}{4,088} & \multirow[t]{4}{*}{0,130} \\
\hline & & $\%$ & 89,4 & 93,7 & 91,1 & & \\
\hline & \multirow[t]{2}{*}{ Sim } & $\mathbf{n}$ & 32 & 24 & 26 & & \\
\hline & & $\%$ & 10,6 & 6,3 & 8,9 & & \\
\hline & NFORMAÇÃO SOB] & E A C & IANC & & & & \\
\hline Tipo de nascimento & Parto natural & $\mathbf{n}$ & 209 & 261 & 199 & 3,450 & 0,485 \\
\hline & & $\%$ & 69,9 & 70,2 & 70,6 & & \\
\hline & Parto por cesariana & $\mathbf{n}$ & 83 & 99 & 80 & & \\
\hline & & $\%$ & 27,8 & 26,6 & 28,4 & & \\
\hline & Parto com & $\mathbf{n}$ & 7 & 12 & 3 & & \\
\hline & $\begin{array}{l}\text { aplicação de } \\
\text { fórceps }\end{array}$ & $\%$ & 2,3 & 3,2 & 1,1 & & \\
\hline Gestação da criança & Primeira & $\mathbf{n}$ & 100 & 139 & 113 & 2,586 & 0,274 \\
\hline & & $\%$ & 33,4 & 37,4 & 39,8 & & \\
\hline & Segunda ou mais & n & 199 & 233 & 171 & & \\
\hline & & $\%$ & 66,6 & 62,6 & 60,2 & & \\
\hline Tempo de gestação da criança & Nove meses & $\mathbf{n}$ & 277 & 345 & 256 & 1,838 & 0,399 \\
\hline & completos & $\%$ & 92,6 & 93,2 & 90,5 & & \\
\hline & Menos de nove & $\mathbf{n}$ & 22 & 25 & 27 & & \\
\hline & meses & $\%$ & 7,4 & 6,8 & 9,5 & & \\
\hline Doença no primeiro mês de & Não & $\mathbf{n}$ & 274 & 343 & 252 & 4,032 & 0,133 \\
\hline vida & & $\%$ & 91,3 & 91,0 & 86,9 & & \\
\hline & Sim & $\mathbf{n}$ & 26 & 34 & 38 & & \\
\hline & & $\%$ & 8,7 & 9,0 & 13,1 & & \\
\hline Criança mama no peito & Não & $\mathbf{n}$ & 260 & 326 & 246 & 0,553 & 0,758 \\
\hline & & $\%$ & 86,7 & 87,4 & 85,4 & & \\
\hline & Sim & $\mathbf{n}$ & 40 & 47 & 42 & & \\
\hline & & $\%$ & 12,6 & 14,6 & 13,4 & & \\
\hline Idade máxima de aleitamento & Mais de seis meses & $\mathbf{n}$ & 101 & 144 & 98 & 2,019 & 0,364 \\
\hline materno & & $\%$ & 35,8 & 41,1 & 37,4 & & \\
\hline & Menos de seis meses & $\mathbf{n}$ & 181 & 206 & 164 & & \\
\hline & & $\%$ & 64,2 & 58,9 & 62,6 & & \\
\hline
\end{tabular}


TABELA 29 - Continuação

\begin{tabular}{|c|c|c|c|c|c|c|c|}
\hline Variável & Atributo & Freq. & SPA & SPB & SPC & $X_{(1)}^{2}$ & $\mathbf{p}_{(2)}$ \\
\hline \multirow{4}{*}{$\begin{array}{l}\text { Participa do programa da } \\
\text { Pastoral da Criança }\end{array}$} & \multirow[t]{2}{*}{ Não } & $\mathbf{n}$ & 271 & 343 & 255 & \multirow[t]{4}{*}{0,781} & \multirow[t]{4}{*}{0,677} \\
\hline & & $\%$ & 90,3 & 91,7 & 89,8 & & \\
\hline & \multirow[t]{2}{*}{ Sim } & $\mathrm{n}$ & 29 & 31 & 29 & & \\
\hline & & $\%$ & 9,7 & 8,3 & 10,2 & & \\
\hline \multirow[t]{4}{*}{ Uso de medicação regular } & \multirow[t]{2}{*}{ Não } & $\mathbf{n}$ & 270 & 337 & 253 & \multirow[t]{4}{*}{1,115} & \multirow[t]{4}{*}{0,573} \\
\hline & & $\%$ & 897 & 90,3 & 87,8 & & \\
\hline & \multirow[t]{2}{*}{ Sim } & $\mathbf{n}$ & 31 & 36 & 35 & & \\
\hline & & $\%$ & 10,3 & 9,7 & 12,2 & & \\
\hline \multirow{4}{*}{$\begin{array}{l}\text { Criança apresenta alguma } \\
\text { doença }\end{array}$} & \multirow[t]{2}{*}{ Não } & $\mathbf{n}$ & 260 & 311 & 244 & \multirow[t]{4}{*}{3,368} & \multirow[t]{4}{*}{0,186} \\
\hline & & $\%$ & 87,0 & 82,9 & 87,5 & & \\
\hline & \multirow[t]{2}{*}{ Sim } & $\mathbf{n}$ & 39 & 64 & 35 & & \\
\hline & & $\%$ & 13,0 & 17,1 & 12,5 & & \\
\hline \multirow{4}{*}{$\begin{array}{l}\text { Criança freqüenta creche ou } \\
\text { escola }\end{array}$} & \multirow[t]{2}{*}{ Não } & $\mathbf{n}$ & 245 & 323 & 249 & \multirow[t]{4}{*}{6,015} & \multirow[t]{4}{*}{$0,04 C$} \\
\hline & & $\%$ & 81,4 & 86,8 & 88,0 & & \\
\hline & \multirow[t]{2}{*}{ Sim } & $\mathbf{n}$ & 56 & 49 & 34 & & \\
\hline & & $\%$ & 18,6 & 13,2 & 12,0 & & \\
\hline \multirow{6}{*}{$\begin{array}{l}\text { Pessoa que toma conta da } \\
\text { criança }\end{array}$} & \multirow[t]{2}{*}{ Mãe } & $\mathbf{n}$ & 276 & 322 & 243 & \multirow[t]{6}{*}{12,891} & \multirow[t]{6}{*}{0,012} \\
\hline & & $\%$ & 92,6 & 87,0 & 86,8 & & \\
\hline & \multirow[t]{2}{*}{ Pai } & $\mathbf{n}$ & 11 & 9 & 8 & & \\
\hline & & $\%$ & 3,7 & 2,4 & 2,9 & & \\
\hline & \multirow[t]{2}{*}{ Outra pessoa } & $\mathbf{n}$ & 11 & 39 & 29 & & \\
\hline & & $\%$ & 3,7 & 10,5 & 10,4 & & \\
\hline \multirow{4}{*}{$\begin{array}{l}\text { Hábito de brincar em local } \\
\text { com o lixo }\end{array}$} & \multirow[t]{2}{*}{ Não } & $\mathbf{n}$ & 294 & 348 & 262 & \multirow[t]{4}{*}{5,294} & \multirow[t]{4}{*}{0,71} \\
\hline & & $\%$ & 97,4 & 93,8 & 93,9 & & \\
\hline & Sim & $\mathbf{n}$ & 8 & 23 & 17 & & \\
\hline & & $\%$ & 6,2 & 6,1 & 5,0 & & \\
\hline Sexo da criança & Feminino & n & 134 & 187 & 145 & 2,304 & 0,312 \\
\hline & & $\%$ & 44,7 & 50,1 & 49,7 & & \\
\hline & Masculino & $\mathbf{n}$ & 166 & 186 & 147 & & \\
\hline & & $\%$ & 55,3 & 49,9 & 50,3 & & \\
\hline
\end{tabular}

(1) Teste do qui-quadrado para os respectivos graus de liberdade

(2) Probabilidade de significância 
TABELA 30 - Caracterização das três áreas de estudo, segundo a freqüência de observação de vetores

\begin{tabular}{|c|c|c|c|c|c|c|c|c|}
\hline \multirow[t]{2}{*}{ Atributos } & \multicolumn{2}{|c|}{ SPA } & \multicolumn{2}{|c|}{ SPB } & \multicolumn{2}{|c|}{ SPC } & \multirow[t]{2}{*}{$X^{2}(1)$} & \multirow[t]{2}{*}{$\mathbf{p}_{(2)}$} \\
\hline & $\mathbf{n}$ & $\%$ & $\mathbf{n}$ & $\%$ & $\mathbf{n}$ & $\%$ & & \\
\hline \multicolumn{9}{|c|}{ 1. Freqüência de mosca } \\
\hline Nunca aparece & 57 & 19,4 & 74 & 20,4 & 107 & 50,2 & 261028 & -0000 \\
\hline $\begin{array}{l}\text { Aparece pelo menos uma } \\
\text { vez a cada seis meses }\end{array}$ & 60 & 20,4 & 20 & 5,5 & 23 & 10,8 & & \\
\hline $\begin{array}{l}\text { Aparece pelo menos uma } \\
\text { vez a cada mês }\end{array}$ & 57 & 19,4 & 21 & 5,8 & 23 & 10,8 & & \\
\hline $\begin{array}{l}\text { Aparece pelo menos uma } \\
\text { vez por semana }\end{array}$ & 69 & 23,5 & 24 & 6,6 & 10 & 4,7 & & \\
\hline Aparece todo dia & 51 & 17,3 & 223 & 61,6 & 50 & 23,5 & & \\
\hline
\end{tabular}

\section{Freqüência de barata}

\begin{tabular}{lcccccccc} 
Nunca aparece & 57 & 19,3 & 84 & 22,7 & 69 & 31,7 & & \\
& & & & & & & 159,066 & $<0,000$ \\
$\begin{array}{l}\text { Aparece pelo menos uma } \\
\text { vez a cada seis meses }\end{array}$ & 32 & 10,8 & 12 & 3,2 & 18 & 8,3 & & \\
$\begin{array}{l}\text { Aparece pelo menos uma } \\
\text { vez a cada mês }\end{array}$ & 40 & 13,6 & 6 & 1,6 & 7 & 3,2 & \\
$\begin{array}{l}\text { Aparece pelo menos uma } \\
\text { vez por semana }\end{array}$ & 71 & 24,1 & 25 & 6,8 & 8 & 3,7 & \\
Aparece todo dia & 95 & 32,2 & 243 & 65,7 & 116 & 53,2 & & \\
\hline
\end{tabular}

\section{Freqüência de rato}

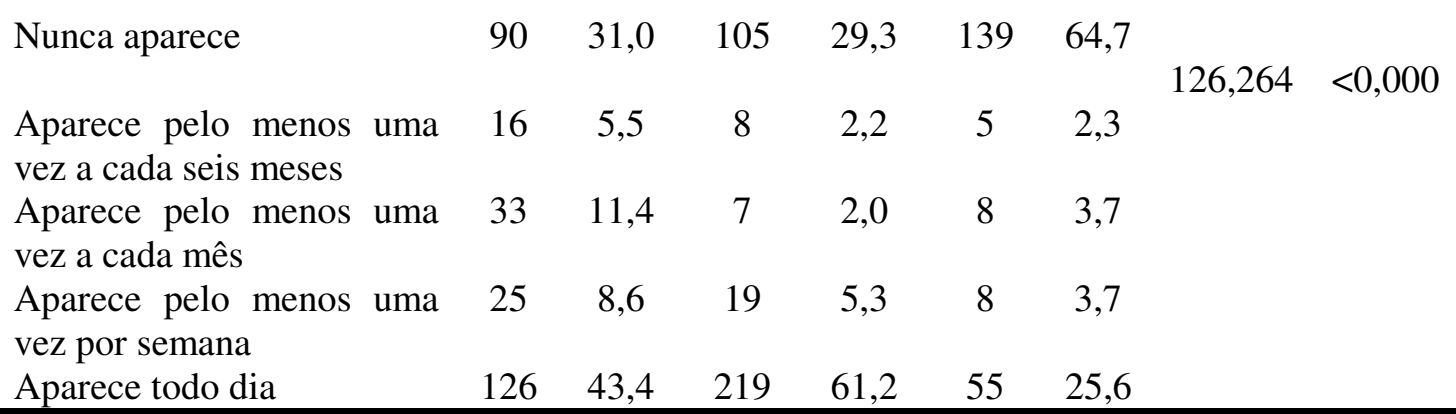
(1) Teste do qui-quadrado para os respectivos graus de liberdade
(2) Probabilidade de significância 
TABELA 31 - Freqüência de observação de vetores, segundo as estações do ano, nas três áreas de estudo

\begin{tabular}{|c|c|c|c|c|c|}
\hline \multirow{2}{*}{ Vetor } & \multirow{2}{*}{$\begin{array}{l}\text { Estação } \\
\text { do ano } \\
\end{array}$} & \multicolumn{3}{|c|}{ Área } & \multirow[t]{2}{*}{$\mathbf{P}_{(\mathbf{1})}$} \\
\hline & & SPA & SPB & SPC & \\
\hline \multirow{4}{*}{ Mosca } & Verão & 141 & 278 & 149 & \multirow[t]{4}{*}{0,1223} \\
\hline & Outono & 157 & 243 & 127 & \\
\hline & Inverno & 92 & 206 & 118 & \\
\hline & Primavera & 150 & 233 & 134 & \\
\hline \multirow{4}{*}{ Barata } & Verão & 165 & 285 & 145 & \multirow[t]{4}{*}{0,6780} \\
\hline & Outono & 180 & 260 & 130 & \\
\hline & Inverno & 152 & 233 & 124 & \\
\hline & Primavera & 181 & 246 & 141 & \\
\hline \multirow{4}{*}{ Rato } & Verão & 165 & 241 & 87 & \multirow[t]{4}{*}{0,9772} \\
\hline & Outono & 165 & 230 & 77 & \\
\hline & Inverno & 165 & 234 & 79 & \\
\hline & Primavera & 172 & 236 & 92 & \\
\hline
\end{tabular}

(1) Probabilidade de significância 


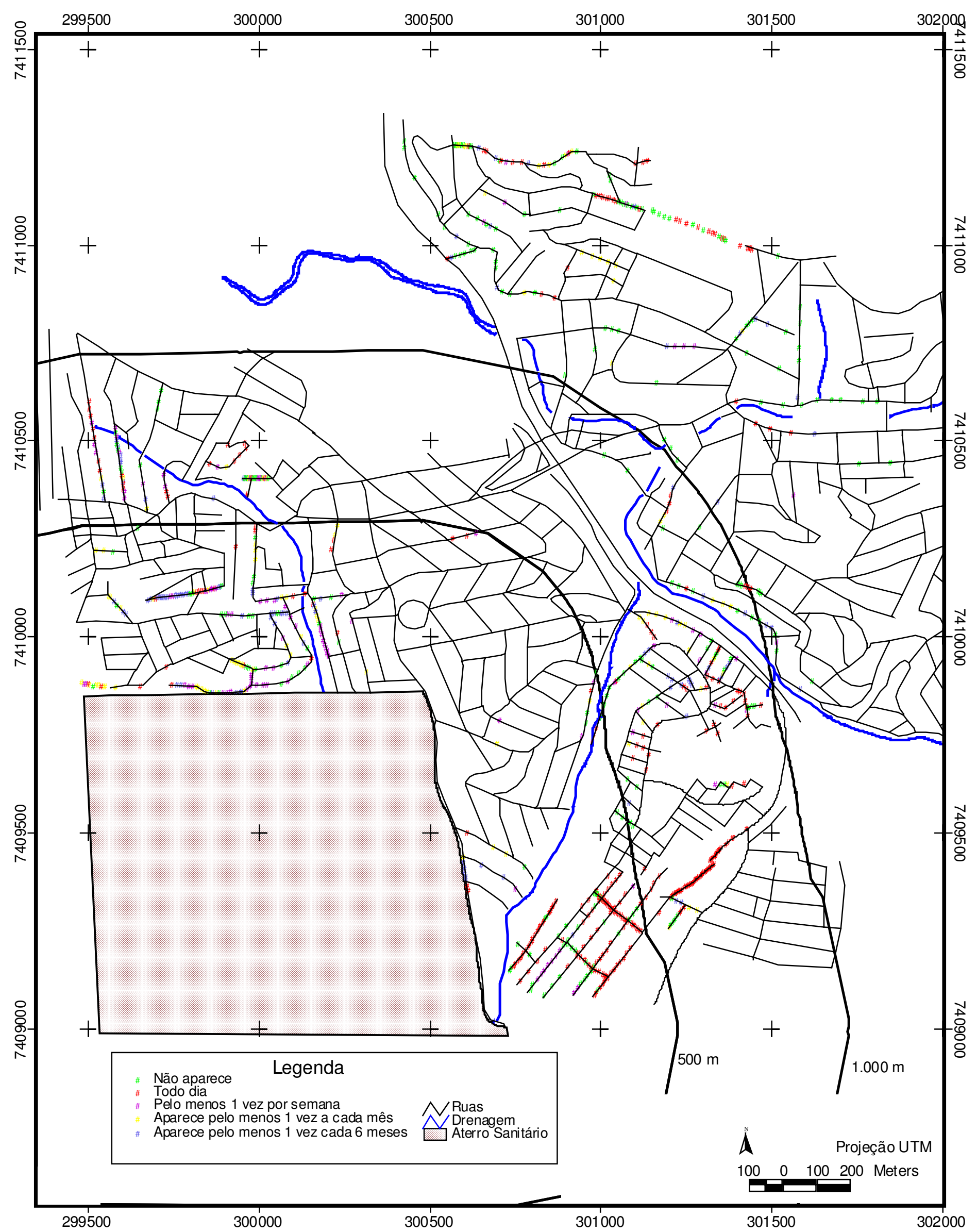

FIGURA 18 - Distribuição da frequência do aparecimento de mosca. 


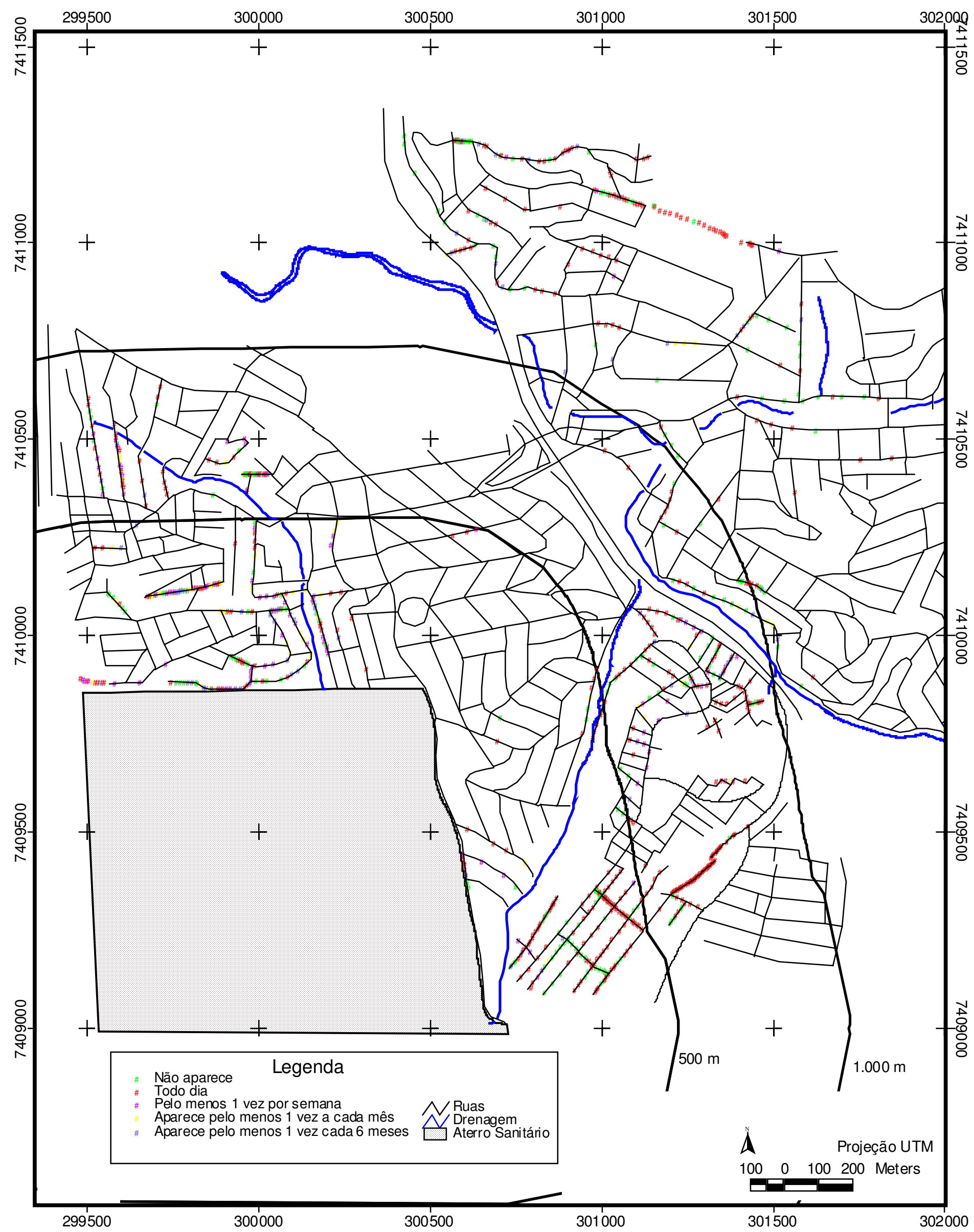

FIGURA 19 - Distribuição da frequência do aparecimento de barata. 


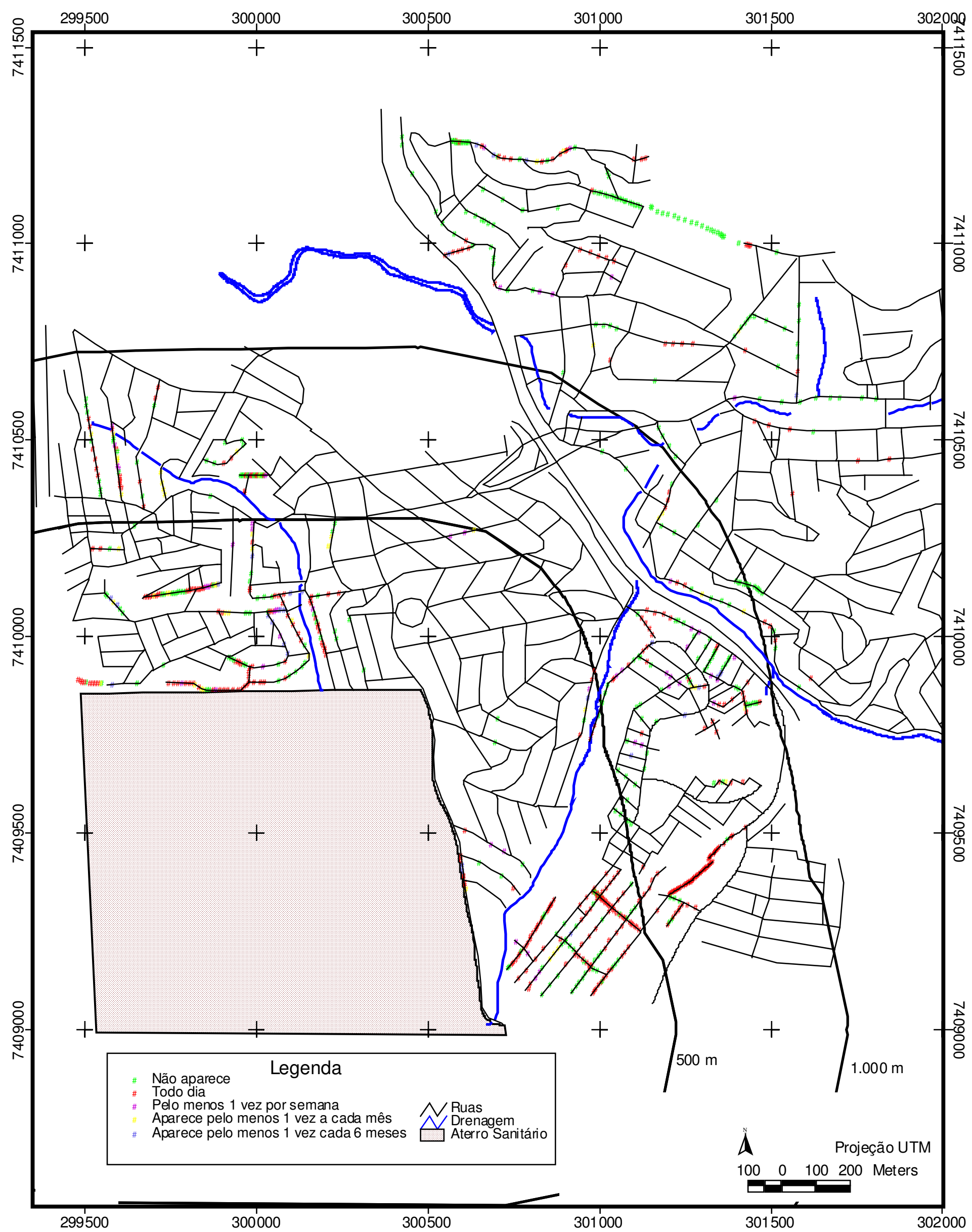


Por meio da aplicação do Protocolo de Pesquisa 1, foi indagado, se na opinião da pessoa entrevistada, a residência era afetada por algum problema relacionado ao Aterro Sanitário Bandeirantes. A Tabela 32 apresenta a freqüência das respostas dadas aos problemas ambientais correlatos e os respectivos valores do qui-quadrado e da probabilidade de significância. Pela análise da tabela 32, observase que $51,9 \%$ das pessoas entrevistadas, nas três áreas de estudo, consideram que sua residência é afetada por algum problema relacionado ao aterro sanitário. Esta proporção é de 55,6\% para a área SPA, 65,3\% para a área SPB e de 24,4\% para a área SPC. O mau cheiro foi relatado em 56,6\% das residências do estudo na área SPA; $68,8 \%$ na área SPB e apenas em $14,8 \%$ das residências na área SPC. O problema relacionado à poeira foi identificado em $46,7 \%$ dos casos na área SPA e, em apenas, $18,3 \%$ e 8,6\%, das residências das áreas SPB e SPC, respectivamente. Os problemas relativos à fumaça, devido à queima de resíduos foi citado como problema em apenas 13,9\% das residências, nas três áreas de estudo; enquanto o problema com chorume perto da habitação, em apenas 3,0\% das residências. $\mathrm{O}$ aumento da população de insetos vetores foi identificado como problema em $41,4 \%$ das residências na área SPA e em 51,1\% na área SPB. Na área SPC, esta proporção foi de apenas $5,5 \%$. Já o aumento da população de roedores foi citado como problema em 37,6\% das residências em média para as três áreas de estudo.

Na Tabela 33 são apresentados os resultados das análises da qualidade da água, consumida pela população de estudo, amostrada em 14 pontos, nas três áreas de exposição pesquisadas. 
TABELA 32 - Caracterização da área de estudo em função de possíveis problemas correlatos ao aterro sanitário

\begin{tabular}{|c|c|c|c|c|c|c|c|c|c|}
\hline \multirow[b]{2}{*}{ Variável } & \multirow[b]{2}{*}{ Atributos } & \multicolumn{2}{|c|}{ SPA } & \multicolumn{2}{|c|}{ SPB } & \multicolumn{2}{|c|}{ SPC } & \multirow[t]{2}{*}{$X_{(1)}^{2}$} & \multirow[t]{2}{*}{$\overline{\mathbf{p}_{(2)}}$} \\
\hline & & $\bar{n}$ & $\%$ & $\bar{n}$ & $\%$ & n & $\%$ & & \\
\hline \multirow{2}{*}{$\begin{array}{l}\text { Residência afetada por } \\
\text { problemas com o aterro }\end{array}$} & Não & 131 & 44,4 & 129 & 34,7 & 167 & 75,6 & \multirow[t]{2}{*}{95,243} & \multirow[t]{2}{*}{0,000} \\
\hline & Sim & 164 & 55,6 & 243 & 65,3 & 54 & 24,4 & & \\
\hline \multirow[t]{2}{*}{ Mau cheiro } & Não & 131 & 43,4 & 118 & 31,2 & 248 & 85,2 & \multirow[t]{2}{*}{202,627} & \multirow[t]{2}{*}{0,000} \\
\hline & Sim & 171 & 56,6 & 260 & 68,8 & 43 & 14,8 & & \\
\hline \multirow[t]{2}{*}{ Poeira } & Não & 161 & 53,3 & 309 & 81,7 & 266 & 91,4 & \multirow[t]{2}{*}{129,192} & \multirow[t]{2}{*}{0,000} \\
\hline & Sim & 141 & 46,7 & 69 & 18,3 & 25 & 8,6 & & \\
\hline \multirow{2}{*}{$\begin{array}{l}\text { Fumaça devido a } \\
\text { queima de lixo }\end{array}$} & Não & 224 & 74,2 & 332 & 87,8 & 280 & 96,2 & \multirow[t]{2}{*}{61,737} & \multirow[t]{2}{*}{0,000} \\
\hline & Sim & 78 & 25,8 & 46 & 12,2 & 11 & 3,8 & & \\
\hline \multirow{2}{*}{$\begin{array}{l}\text { Chorume perto da } \\
\text { habitação }\end{array}$} & Não & 286 & 94,7 & 372 & 98,4 & 284 & 97,6 & \multirow[t]{2}{*}{8,462} & \multirow[t]{2}{*}{0,015} \\
\hline & Sim & 16 & 5,3 & 6 & 1,6 & 7 & 2,4 & & \\
\hline \multirow{2}{*}{$\begin{array}{l}\text { Aumento da população } \\
\text { de insetos }\end{array}$} & Não & 177 & 58,6 & 185 & 48,9 & 275 & 94,5 & \multirow[t]{2}{*}{160,743} & \multirow[t]{2}{*}{0,000} \\
\hline & Sim & 125 & 41,4 & 193 & 51,1 & 16 & 5,5 & & \\
\hline \multirow{2}{*}{$\begin{array}{l}\text { Aumento da população } \\
\text { de roedores }\end{array}$} & Não & 187 & 61,9 & 201 & 53,2 & 218 & 74,9 & \multirow[t]{2}{*}{33,168} & \multirow[t]{2}{*}{0,000} \\
\hline & Sim & 115 & 38,1 & 177 & 46,8 & 73 & 25,1 & & \\
\hline \multirow{2}{*}{$\begin{array}{l}\text { Barulho com tráfego de } \\
\text { veículos }\end{array}$} & Não & 283 & 93,7 & 369 & 97,6 & 241 & 82,8 & \multirow[t]{2}{*}{56,396} & \multirow[t]{2}{*}{0,000} \\
\hline & Sim & 19 & 6,3 & 9 & 2,4 & 42 & 14,4 & & \\
\hline \multirow[t]{2}{*}{ Doenças na família } & Não & 289 & 95,7 & 362 & 95,8 & 246 & 84,5 & \multirow[t]{2}{*}{36,307} & \multirow[t]{2}{*}{0,000} \\
\hline & Sim & 13 & 4,3 & 16 & 4,2 & 45 & 15,5 & & \\
\hline
\end{tabular}

(1) Teste do qui-quadrado para os respectivos graus de liberdade

(2) Probabilidade de significância 
TABELA 33 - Resultados das análises de qualidade da água consumida pela população de estudo

\begin{tabular}{|c|c|c|c|c|c|c|c|c|c|}
\hline \multirow{2}{*}{ Parâmetros } & \multirow{2}{*}{ Unidade } & \multicolumn{8}{|c|}{ Amostras } \\
\hline & & 01 & 02 & $\mathbf{0 3}$ & 04 & 05 & 06 & 07 & $(*)$ \\
\hline $\mathrm{pH}$ & & 7,5 & 7,5 & 8,3 & 7,7 & 7,6 & 7,6 & 7,6 & $6,0-9,5$ \\
\hline Cor aparente & $\mathrm{uc}$ & 6 & 5 & 4 & 2 & $<1$ & 2 & 2 & 15 \\
\hline Turbidez & ut & 0,85 & 0,51 & 0,49 & 0,43 & 0,43 & 0,60 & 0,48 & 5,0 \\
\hline Dureza total & $(\mathrm{mg} \mathrm{caco} / \mathrm{l})$ & 21,0 & 22,0 & 27,0 & 22,0 & 21,0 & 20,0 & 22,0 & 500 \\
\hline Fluoretos & $\left(\mathrm{mg}^{-} / \mathrm{l}\right)$ & 0,72 & 0,68 & 0,70 & 0,71 & 0,70 & 0,67 & 0,71 & 1,5 \\
\hline Sulfatos & $(\mathrm{mg} / \mathrm{l})$ & 1 & $<1$ & $<1$ & $<1$ & $<1$ & $<1$ & $<1$ & 250 \\
\hline Sulfetos & $\left(\mathrm{mg}^{-} / \mathrm{l}\right)$ & $<0,001$ & 0,001 & $<0,001$ & $<0,001$ & $<0,001$ & $<0,001$ & $<0,001$ & $\mathbf{0 , 0 5}$ \\
\hline Nitrogênio amoniacal & $(\mathrm{mg} / \mathrm{l})$ & $<0,01$ & $<0,01$ & $<0,01$ & $<0,01$ & $<0,01$ & $<0,01$ & 0,01 & 1,5 \\
\hline Nitrogênio nitrato & $(\mathrm{mg} / \mathrm{l})$ & 0,32 & 0,34 & 0,33 & 0,33 & 0,34 & 0,34 & 0,35 & 10 \\
\hline Nitrogênio nitrito & $(\mathrm{mg} / \mathrm{l})$ & $<0,001$ & $<0,001$ & $<0,001$ & $<0,001$ & $<0,001$ & $<0,001$ & $<0,001$ & 1 \\
\hline Sólidos dissolvidos totais & $(\mathrm{mg} / \mathrm{l})$ & 201,0 & 51,0 & 135,0 & 51,0 & 54,0 & 49,0 & 50,0 & 1000 \\
\hline Cloretos & $\left(\mathrm{mg}^{-} / \mathrm{l}\right)$ & 3,7 & 3,6 & 3,8 & 3,7 & 3,6 & 3,9 & 3,6 & 250 \\
\hline Cianetos & $\left(\mathrm{mg}^{-} / \mathrm{l}\right)$ & $<0,001$ & $<0,001$ & $<0,001$ & $<0,001$ & $<0,001$ & $<0,001$ & $<0,001$ & $\mathbf{0 , 0 7}$ \\
\hline Sódio & $(\mathrm{mg} / \mathrm{l})$ & 5,0 & 5,0 & 5,3 & 5,2 & 5,1 & 5,4 & 5,1 & 200 \\
\hline NNP coliformes totais & $(\mathrm{nmp} / 100 \mathrm{ml})$ & Ausente & Ausente & Ausente & Ausente & Ausente & Ausente & Ausente & Ausente \\
\hline NMP coliformes fecais & $(\mathrm{nmp} / 100 \mathrm{ml})$ & Ausente & Ausente & Ausente & Ausente & Ausente & Ausente & Ausente & Ausente \\
\hline \multicolumn{2}{|c|}{ Área de amostragem } & SPB & SPB & SPB & SPB & SPC & SPC & SPC & - \\
\hline & Vila & SPRH & SPRH & SPRH & SPRH & SPVC & SPVC & SPVC & - \\
\hline
\end{tabular}

(*) Padrões de Potabilidade - PORTARIA Nํㅡ 1469 do MINISTÉRIO DA SAÚDE, de 29 de dezembro de 2000

Valor Máximo Permitido (mg/L). 
TABELA 33 - Continuação

\begin{tabular}{|c|c|c|c|c|c|c|c|c|c|}
\hline \multirow{2}{*}{ Parâmetros } & \multirow{2}{*}{ Unidade } & \multicolumn{8}{|c|}{ Amostras } \\
\hline & & 01 & 02 & 03 & 04 & 05 & 06 & 07 & $(*)$ \\
\hline Zinco & $\left(\mathrm{mg}^{-} / \mathrm{l}\right)$ & $<0,001$ & $<0,001$ & $<0,001$ & $<0,001$ & $<0,001$ & $<0,001$ & 0,004 & 5 \\
\hline Chumbo & $\left(\mathrm{mg}^{-} / \mathrm{l}\right)$ & $<0,001$ & $<0,001$ & 0,001 & $<0,001$ & $<0,001$ & 0,008 & $<0,001$ & $\mathbf{0 , 0 1}$ \\
\hline Cádmio & $\left(\mathrm{mg}^{-} / \mathrm{l}\right)$ & 0,002 & 0,001 & 0,001 & 0,002 & 0,003 & 0,003 & 0,003 & 0,005 \\
\hline Níquel & $\left(\mathrm{mg}^{-} / \mathrm{l}\right)$ & $<0,001$ & 0,001 & $<0,001$ & $<0,001$ & $<0,001$ & $<0,001$ & $<0,001$ & $\mathbf{X}$ \\
\hline Ferro total & $\left(\mathrm{mg}^{-} / \mathrm{l}\right)$ & $<0,006$ & $<0,006$ & $<0,006$ & $<0,006$ & $<0,006$ & $<0,006$ & $<0,006$ & $\mathbf{0 , 3}$ \\
\hline Manganês & $(\mathrm{mg} / \mathrm{l})$ & 0,002 & $<0,001$ & 0,004 & 0,001 & $<0,001$ & 0,001 & 0,001 & 0,1 \\
\hline Cobre & $\left(\mathrm{mg}^{-} / \mathrm{l}\right)$ & $<0,003$ & $<0,003$ & $<0,003$ & $<0,003$ & $<0,003$ & $<0,003$ & $<0,003$ & 2 \\
\hline Cromo total & $(\mathrm{mg} / \mathrm{l})$ & $<0,006$ & $<0,006$ & $<0,006$ & $<0,006$ & $<0,006$ & $<0,006$ & $<0,006$ & 0,05 \\
\hline Alumínio & $(\mu \mathrm{g} / \mathrm{l})$ & 83,8 & 66,5 & 64,7 & 66,0 & 68,3 & 75,4 & 75,1 & 0,2 \\
\hline Arsênio & $(\mu \mathrm{g} / \mathrm{l})$ & $<0,01$ & 0,07 & 0,17 & $<0,01$ & $<0,01$ & $<0,01$ & $<0,01$ & $\mathbf{0 , 0 1}$ \\
\hline Selênio & $(\mu \mathrm{g} / \mathrm{l})$ & 0,002 & $<0,001$ & $<0,01$ & $<0,01$ & $<0,01$ & $<0,01$ & 0,003 & $\mathbf{0 , 0 1}$ \\
\hline Bário & $\left(\mu \mathrm{g}^{-} / \mathrm{l}\right)$ & 49,7 & 46,8 & 52,3 & 49,6 & 46,8 & 38,3 & 44,8 & 0,7 \\
\hline Mercúrio & $\left(\mu \mathrm{g}^{-} / \mathrm{l}\right)$ & $<0,01$ & 0,02 & 0,016 & $<0,01$ & $<0,01$ & $<0,01$ & $<0,01$ & 0,001 \\
\hline Estanho & $(\mu \mathrm{g} / \mathrm{l})$ & $<0,01$ & $<0,01$ & $<0,01$ & $<0,01$ & $<0,01$ & $<0,01$ & $<0,01$ & $\mathbf{X}$ \\
\hline \multirow{2}{*}{\multicolumn{2}{|c|}{ Área de amostragem }} & SPB & SPB & SPB & SPB & SPC & SPC & SPC & - \\
\hline & & SPRH & SPRH & SPRH & SPRH & SPVC & SPVC & SPVC & - \\
\hline
\end{tabular}

(*) Padrões de Potabilidade - PORTARIA No 1469 do MINISTÉRIO DA SAÚDE, de 29 de dezembro de 2000

Valor Máximo Permitido (mg/L). 
TABELA 33 - Continuação

\begin{tabular}{|c|c|c|c|c|c|c|c|c|c|}
\hline \multirow{2}{*}{ Parâmetros } & \multirow{2}{*}{ Unidade } & \multicolumn{8}{|c|}{ Amostras } \\
\hline & & 08 & 09 & 10 & 11 & 12 & 13 & 14 & $(*)$ \\
\hline$\overline{\mathrm{pH}}$ & & 6,0 & 6,9 & 7,3 & 7,4 & 7,5 & 7,5 & 7,5 & $6,0-9,5$ \\
\hline Cor aparente & uc & $<1$ & $<1$ & $<1$ & $<1$ & $<1$ & $<1$ & $<1$ & 15 \\
\hline Turbidez & ut & 0,36 & 0,70 & 0,51 & 0,53 & 0,47 & 0,57 & 0,52 & 5,0 \\
\hline Dureza total & $\left(\mathrm{mg} \mathrm{Caco}_{3} / \mathrm{l}\right)$ & 73,0 & 19,0 & 21,0 & 21,0 & 23,0 & 22,0 & 21,0 & 500 \\
\hline Fluoretos & $\left(\mathrm{mg}^{-} / \mathrm{l}\right)$ & 0,04 & 0,69 & 0,73 & 0,67 & 0,69 & 0,67 & 0,68 & 1,5 \\
\hline Sulfatos & $(\mathrm{mg} / \mathrm{l})$ & 26 & $<1$ & $<1$ & $<1$ & 1 & $<1$ & 1 & 250 \\
\hline Sulfetos & $\left(\mathrm{mg}^{-} / \mathrm{l}\right)$ & 0,001 & 0,001 & 0,001 & 0,001 & 0,001 & 0,001 & 0,001 & $\mathbf{0 , 0 5}$ \\
\hline Nitrogênio amoniacal & $(\mathrm{mg} / \mathrm{l})$ & 2,43 & $<0,01$ & $<0,01$ & $<0,01$ & 0,02 & $<0,01$ & $<0,01$ & 1,5 \\
\hline Nitrogênio nitrato & $(\mathrm{mg} / \mathrm{l})$ & 12,8 & 0,39 & 0,33 & 0,33 & 0,32 & 0,34 & 0,32 & 10 \\
\hline Nitrogênio nitrito & $(\mathrm{mg} / \mathrm{l})$ & 0,002 & $<0,001$ & 0,003 & $<0,001$ & $<0,001$ & 0,001 & $<0,001$ & 1 \\
\hline Sólidos dissolvidos totais & $(\mathrm{mg} / \mathrm{l})$ & 215,0 & 54,0 & 50,0 & 134,0 & 179,0 & 104,0 & 53,0 & 1000 \\
\hline Cloretos & $\left(\mathrm{mg}^{-} / \mathrm{l}\right)$ & 21,1 & 3,9 & 3,6 & 3,6 & 3,8 & 3,7 & 3,8 & 250 \\
\hline Cianetos & $\left(\mathrm{mg}^{-} / \mathrm{l}\right)$ & $<0,001$ & $<0,001$ & $<0,001$ & $<0,001$ & $<0,001$ & $<0,001$ & $<0,001$ & $\mathbf{0 , 0 7}$ \\
\hline Sódio & $(\mathrm{mg} / \mathrm{l})$ & 62,0 & 5,2 & 5,2 & 5,3 & 5,4 & 5,3 & 5,4 & 200 \\
\hline NNP coliformes totais & $(\mathrm{nmp} / 100 \mathrm{ml})$ & Ausente & 1,0 & Ausente & Ausente & Ausente & Ausente & Ausente & Ausente \\
\hline NMP coliformes fecais & $(\mathrm{nmp} / 100 \mathrm{ml})$ & Ausente & 1,0 & Ausente & Ausente & Ausente & Ausente & Ausente & Ausente \\
\hline \multicolumn{2}{|c|}{ Área de amostragem } & SPA & SPA & SPA & SPA & SPB & SPB & SPB & - \\
\hline & Vila & MINA & SPJM & SPJR & SPJR & SPRP & SPRP & SPRP & - \\
\hline
\end{tabular}

(*) Padrões de Potabilidade - PORTARIA Noํ 1469 do MINISTÉRIO DA SAÚDE, de 29 de dezembro de 2000

Valor Máximo Permitido (mg/L) 
TABELA 33 - Continuação

\begin{tabular}{|c|c|c|c|c|c|c|c|c|c|}
\hline \multirow{2}{*}{ Parâmetros } & \multirow{2}{*}{ Unidade } & \multicolumn{8}{|c|}{ Amostras } \\
\hline & & 08 & 09 & 10 & 11 & 12 & 13 & 14 & $(*)$ \\
\hline Zinco & $\left(\mathrm{mg}^{-} / \mathrm{l}\right)$ & 0,080 & $<0,001$ & $<0,001$ & $<0,001$ & $<0,001$ & $<0,001$ & 0,003 & 5 \\
\hline Chumbo & $\left(\mathrm{mg}^{-} / \mathrm{l}\right)$ & 0,009 & 0,002 & $<0,001$ & $<0,001$ & $<0,001$ & $<0,001$ & $<0,001$ & $\mathbf{0 , 0 1}$ \\
\hline Cádmio & $\left(\mathrm{mg}^{-} / \mathrm{l}\right)$ & 0,004 & 0,004 & 0,003 & 0,004 & 0,004 & 0,005 & 0,004 & 0,005 \\
\hline Níquel & $\left(\mathrm{mg}^{-} / \mathrm{l}\right)$ & 0,005 & 0,006 & $<0,001$ & $<0,001$ & 0,004 & $<0,001$ & 0,001 & $\mathbf{X}$ \\
\hline Ferro total & $\left(\mathrm{mg}^{-} / \mathrm{l}\right)$ & $<0,006$ & $<0,006$ & $<0,006$ & $<0,006$ & $<0,006$ & $<0,006$ & $<0,006$ & $\mathbf{0 , 3}$ \\
\hline Manganês & $(\mathrm{mg} / \mathrm{l})$ & 0,049 & 0,001 & 0,001 & $<0,001$ & 0,001 & $<0,001$ & 0,002 & 0,1 \\
\hline Cobre & $\left(\mathrm{mg}^{-} / \mathrm{l}\right)$ & $<0,003$ & $<0,003$ & $<0,003$ & $<0,003$ & $<0,003$ & $<0,003$ & $<0,003$ & 2 \\
\hline Cromo total & $(\mathrm{mg} / \mathrm{l})$ & $<0,006$ & $<0,006$ & $<0,006$ & $<0,006$ & $<0,006$ & $<0,006$ & $<0,006$ & 0,05 \\
\hline Alumínio & $(\mu \mathrm{g} / \mathrm{l})$ & 28,6 & 80,3 & 101,0 & 84,7 & 76,2 & 86,6 & 67,6 & 0,2 \\
\hline Arsênio & $(\mu \mathrm{g} / \mathrm{l})$ & 0,04 & $<0,01$ & 0,05 & 0,02 & 0,26 & $<0,01$ & $<0,01$ & $\mathbf{0 , 0 1}$ \\
\hline Selênio & $(\mu \mathrm{g} / \mathrm{l})$ & 0,007 & $<0,001$ & 0,003 & 0,004 & 0,002 & 0,001 & $<0,001$ & $\mathbf{0 , 0 1}$ \\
\hline Bário & $\left(\mu \mathrm{g}^{-} / \mathrm{l}\right)$ & 96,9 & 48,8 & 56,4 & 47,0 & 37,3 & 37,6 & 42,5 & $\mathbf{0 , 7}$ \\
\hline Mercúrio & $\left(\mu \mathrm{g}^{-} / \mathrm{l}\right)$ & $<0,01$ & 0,085 & 0,422 & 0,490 & $<0,01$ & 0,157 & 0,015 & $\mathbf{0 , 0 0 1}$ \\
\hline Estanho & $(\mu \mathrm{g} / \mathrm{l})$ & $<0,01$ & $<0,01$ & $<0,01$ & $<0,01$ & $<0,01$ & $<0,01$ & $<0,01$ & $\mathbf{X}$ \\
\hline \multicolumn{2}{|c|}{ Área de amostragem } & SPA & SPA & SPA & SPA & SPB & SPB & SPB & - \\
\hline & Vila & MINA & SPJM & SPJR & SPJR & SPRP & SPRP & SPRP & - \\
\hline
\end{tabular}

(*) Padrões de Potabilidade - PORTARIA No 1469 do MINISTÉRIO DA SAÚDE, de 29 de dezembro de 2000 Valor Máximo Permitido (mg/L). 


\subsection{Indicadores de Saúde}

Por meio do Protocolo de Pesquisa 1, foram levantadas algumas condições de saúde da população residente nas áreas de estudo. Na comparação entre as áreas, apenas as doenças respiratórias apresentaram uma diferença estatisticamente significativa $\left(X^{2}=52,167\right.$ e $\left.\mathrm{p}<0,000\right)$. As demais doenças avaliadas não demonstraram diferença entre as áreas. Na Tabela 34 são apresentadas as frequiências das variáveis, empregadas como indicadores das condições de saúde da população em geral, com os respectivos valores do qui-quadrado e da probabilidade de significância.

Na Figura 21 e 22 são apresentadas, respectivamente, as distribuições da ocorrência de doenças respiratórias e de casos de dengue e câncer na população em geral.

As variáveis, referentes aos indicadores de saúde da população de estudo crianças na faixa etária de 1 a 5 anos de idade incompletos, são apresentadas comparativamente em relação às três áreas de estudo, na Tabela 35.

A Figura 23 apresenta a distribuição geográfica da ocorrência de diarréia na população de estudo e as Figuras 24 e 25, respectivamente, as distribuições de ocorrência de parasitos intestinais, protozoários e helmintos, obtidas pelos resultados dos exames de fezes realizados na população de estudo.

As freqüências das respostas às questões, referentes à ocorrência de diarréia, não foram estatisticamente diferentes nas três áreas de estudo. A duração da diarréia, as necessidades de tratar a diarréia em serviço de saúde e de internação apresentaram a probabilidade de significância acima de $5 \%$. 
TABELA 34 - Caracterização das áreas de estudo segundo a freqüência das variáveis qualitativas empregadas como indicadores de saúde da população em geral

\begin{tabular}{|c|c|c|c|c|c|c|c|}
\hline Variável & Atributo & Freq. & SPA & SPB & SPC & $X_{(1)}^{2}$ & $\mathbf{p}_{(2)}$ \\
\hline \multirow[t]{4}{*}{ Doença respiratória } & \multirow[t]{2}{*}{ Não } & $\bar{n}$ & 185 & 320 & 185 & \multirow[t]{4}{*}{52,167} & \multirow[t]{4}{*}{0,000} \\
\hline & & $\%$ & 62,5 & 85,3 & 81,5 & & \\
\hline & \multirow[t]{2}{*}{ Sim } & $\mathbf{n}$ & 111 & 55 & 42 & & \\
\hline & & $\%$ & 37,5 & 14,7 & 18,5 & & \\
\hline \multirow[t]{4}{*}{ Casos de dengue } & \multirow[t]{2}{*}{ Não } & $\mathbf{n}$ & 293 & 376 & 223 & \multirow[t]{4}{*}{3,826} & \multirow[t]{4}{*}{0,147} \\
\hline & & $\%$ & 99,0 & 100 & 99,6 & & \\
\hline & \multirow[t]{2}{*}{ Sim } & $\mathbf{n}$ & 3 & & 1 & & \\
\hline & & $\%$ & 1,0 & & 0,4 & & \\
\hline \multirow{4}{*}{ Casos de câncer em geral } & \multirow[t]{2}{*}{ Não } & $\mathbf{n}$ & 295 & 370 & 286 & \multirow[t]{4}{*}{0,628} & \multirow[t]{4}{*}{0,731} \\
\hline & & $\%$ & 98,3 & 98,9 & 99,0 & & \\
\hline & \multirow[t]{2}{*}{ Sim } & $\mathbf{n}$ & 5 & 4 & 3 & & \\
\hline & & $\%$ & 1,7 & 1,1 & 1,0 & & \\
\hline \multirow[t]{4}{*}{ Câncer de colo de útero } & \multirow[t]{2}{*}{ Não } & $\mathbf{n}$ & 301 & 374 & 291 & \multirow[t]{4}{*}{1,960} & \multirow[t]{4}{*}{0,375} \\
\hline & & $\%$ & 99,7 & 98,9 & 99,7 & & \\
\hline & \multirow[t]{2}{*}{ Sim } & $\mathbf{n}$ & 1 & 4 & 1 & & \\
\hline & & $\%$ & 0,3 & 1,1 & 0,3 & & \\
\hline \multirow{4}{*}{ Câncer de mama } & \multirow{2}{*}{ Não } & $\mathbf{n}$ & 302 & 378 & 291 & \multirow[t]{4}{*}{2,331} & \multirow[t]{4}{*}{0,312} \\
\hline & & $\%$ & 100 & 100 & 99,7 & & \\
\hline & \multirow[t]{2}{*}{ Sim } & $\mathbf{n}$ & & & 1 & & \\
\hline & & $\%$ & & & 0,3 & & \\
\hline Câncer de estômago & Não & $\mathbf{n}$ & 302 & 377 & 291 & 0,952 & 0,621 \\
\hline & & $\%$ & 100 & 99,7 & 99,7 & & \\
\hline & Sim & $\mathbf{n}$ & & 1 & 1 & & \\
\hline & & $\%$ & & 0,3 & 0,3 & & \\
\hline Câncer de intestino & Não & $\mathbf{n}$ & 302 & 378 & 291 & 2,331 & 0,312 \\
\hline & & $\%$ & 100 & 100 & 99,7 & & \\
\hline & Sim & $\mathbf{n}$ & & & 1 & & \\
\hline & & $\%$ & & & 0,3 & & \\
\hline Câncer de pulmão & Não & $\mathbf{n}$ & 301 & 378 & 292 & 2,221 & 0,329 \\
\hline & & $\%$ & 99,7 & 100 & 100 & & \\
\hline & Sim & $\mathbf{n}$ & 1 & & & & \\
\hline & & $\%$ & 0,3 & & & & \\
\hline Câncer de traquéia & Não & $\mathbf{n}$ & 302 & 378 & 291 & 2,331 & 0,312 \\
\hline & & $\%$ & 100 & 100 & 99,7 & & \\
\hline & Sim & $\mathbf{n}$ & & & 1 & & \\
\hline & & $\%$ & & & 0,3 & & \\
\hline Câncer de fígado & Não & $\mathbf{n}$ & 301 & 378 & 292 & 2,221 & 0,329 \\
\hline & & $\%$ & 99,7 & 100 & 100 & & \\
\hline & Sim & $\mathbf{n}$ & 1 & & & & \\
\hline & & $\%$ & 0,3 & & & & \\
\hline
\end{tabular}

(1) Teste do qui-quadrado para os respectivos graus de liberdade

(2) Probabilidade de significância 


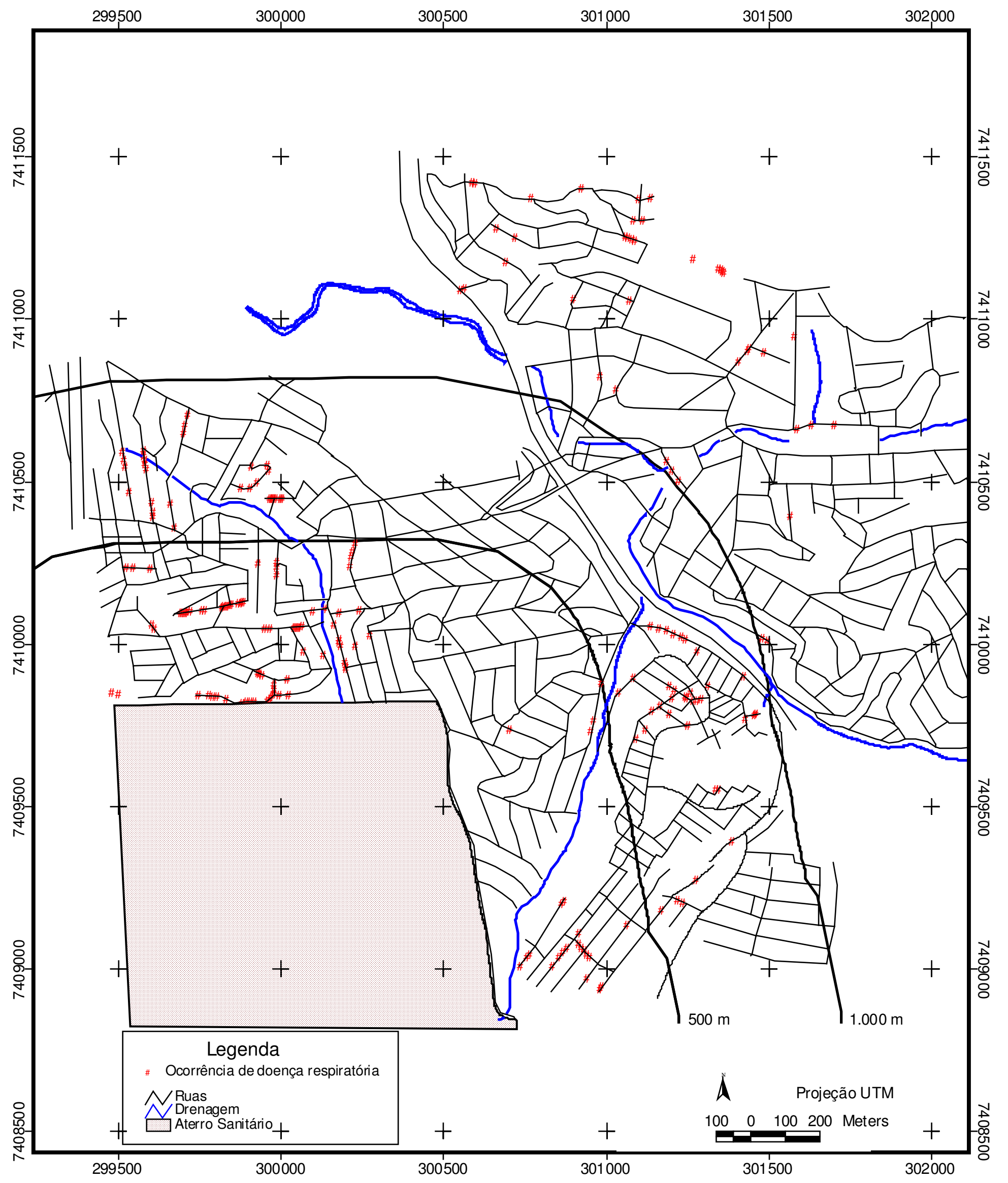

FIGURA 21 - Distribuição da ocorrência de doenças respiratórias na população em geral. 


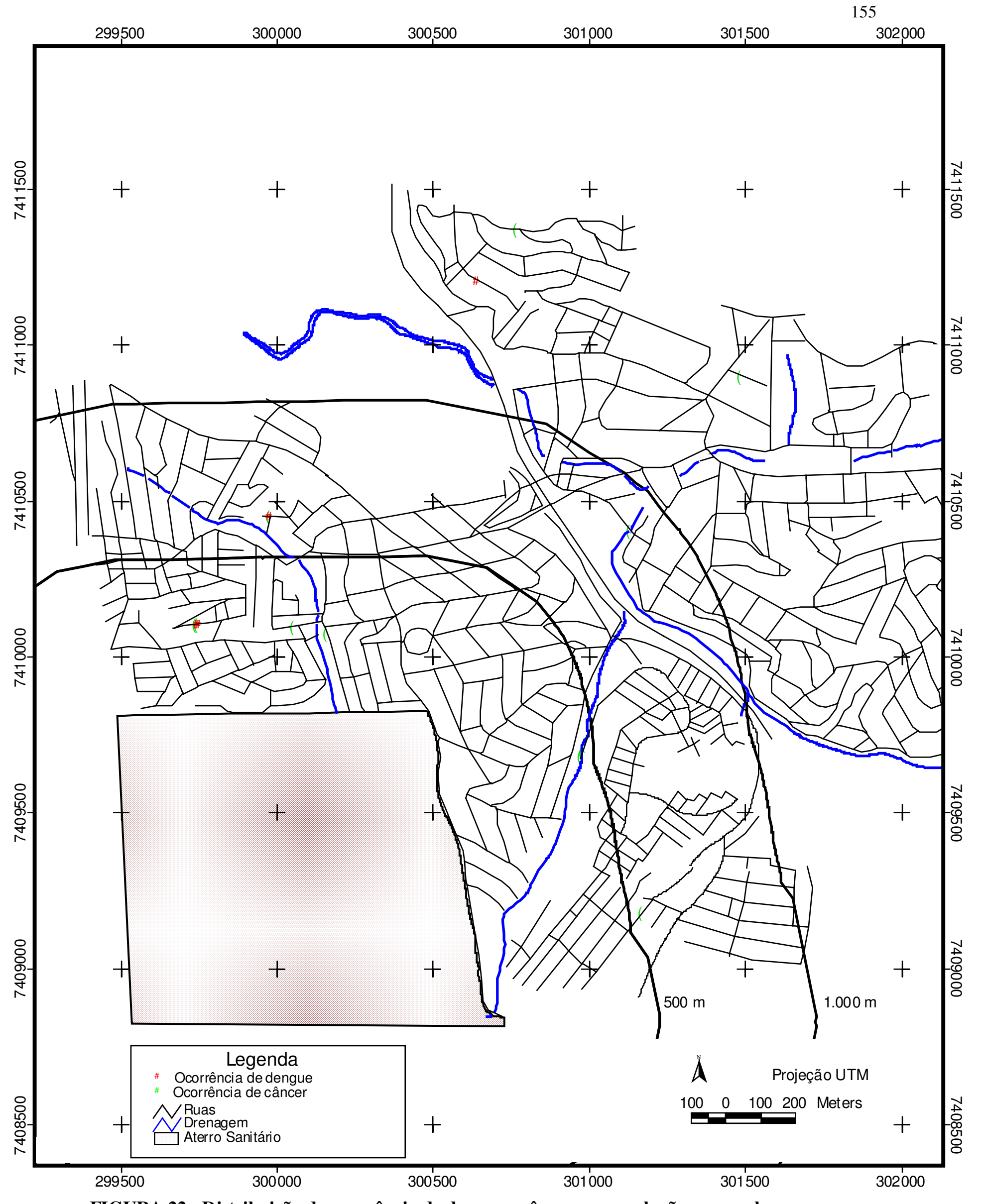

FIGURA 22 - Distribuição da ocorrência de dengue e câncer na população em geral. 
TABELA 35 - Caracterização das três áreas de estudo segundo a freqüência das variáveis qualitativas empregadas como indicadores de saúde da população de estudo

\begin{tabular}{|c|c|c|c|c|c|c|c|}
\hline Variável & Atributo & Freq. & $\overline{\text { SPA }}$ & SPB & SPC & $X^{2}{ }_{(1)}$ & $\mathbf{p}_{(2)}$ \\
\hline \multirow{4}{*}{$\begin{array}{l}\text { Doença respiratória na } \\
\text { criança }\end{array}$} & \multirow[t]{2}{*}{ Não } & $\mathbf{n}$ & 250 & 302 & 235 & \multirow[t]{4}{*}{1,187} & \multirow[t]{4}{*}{0,552} \\
\hline & & $\%$ & 83,3 & 80,3 & 82,7 & & \\
\hline & \multirow[t]{2}{*}{ Sim } & $\mathbf{n}$ & 50 & 74 & 49 & & \\
\hline & & $\%$ & 16,7 & 19,7 & 17,3 & & \\
\hline \multirow[t]{4}{*}{ Diarréia nas últimas 48 horas } & \multirow[t]{2}{*}{ Não } & $\mathbf{n}$ & 282 & 333 & 251 & \multirow[t]{4}{*}{8,721} & \multirow[t]{4}{*}{0,013} \\
\hline & & $\%$ & 95,3 & 89,3 & 89,6 & & \\
\hline & \multirow[t]{2}{*}{ Sim } & $\mathbf{n}$ & 14 & 40 & 29 & & \\
\hline & & $\%$ & 4,7 & 10,7 & 10,4 & & \\
\hline \multirow{4}{*}{$\begin{array}{l}\text { Resultado do exame de } \\
\text { protozoário }\end{array}$} & \multirow[t]{2}{*}{ Negativo } & $\mathbf{n}$ & 202 & 204 & 155 & \multirow[t]{4}{*}{11,267} & \multirow[t]{4}{*}{0,004} \\
\hline & & $\%$ & 80,5 & 71,6 & 83,8 & & \\
\hline & \multirow[t]{2}{*}{ Positivo } & $\mathbf{n}$ & 49 & 81 & 30 & & \\
\hline & & $\%$ & 19,5 & 28,4 & 16,2 & & \\
\hline \multirow[t]{4}{*}{ Entamoeba coli } & \multirow[t]{2}{*}{ Negativo } & $\mathbf{n}$ & 283 & 346 & 280 & \multirow[t]{4}{*}{5,183} & \multirow[t]{4}{*}{0,075} \\
\hline & & $\%$ & 93,7 & 91,5 & 95,9 & & \\
\hline & \multirow[t]{2}{*}{ Positivo } & $\mathbf{n}$ & 19 & 32 & 12 & & \\
\hline & & $\%$ & 6,3 & 8,5 & 4,1 & & \\
\hline \multirow[t]{4}{*}{ Entamoeba histolytica } & \multirow[t]{2}{*}{ Negativo } & $\mathbf{n}$ & 296 & 366 & 285 & \multirow[t]{4}{*}{0,996} & \multirow[t]{4}{*}{0,608} \\
\hline & & $\%$ & 98,0 & 96,8 & 97,6 & & \\
\hline & \multirow[t]{2}{*}{ Positivo } & $\mathrm{n}$ & 6 & 12 & 7 & & \\
\hline & & $\%$ & 2,0 & 3,2 & 2,4 & & \\
\hline Giardia lamblia & Negativo & $\mathbf{n}$ & 273 & 338 & 280 & 9,959 & 0,007 \\
\hline & & $\%$ & 90,4 & 89,4 & 95,9 & & \\
\hline & Positivo & n & 29 & 40 & 12 & & \\
\hline & & $\%$ & 9,6 & 10,6 & 4,1 & & \\
\hline Iodamoeba bütschlii & Negativo & $\mathbf{n}$ & 302 & 378 & 291 & 2,331 & 0,312 \\
\hline & & $\%$ & 100 & 100 & 99,7 & & \\
\hline & Positivo & $\mathbf{n}$ & & & 1 & & \\
\hline & & $\%$ & & & 0,3 & & \\
\hline Endolimax nana & Negativo & $\mathbf{n}$ & 290 & 350 & 285 & 9,694 & 0,008 \\
\hline & & $\%$ & 96,0 & 92,6 & 97,6 & & \\
\hline & Positivo & $\mathbf{n}$ & 12 & 28 & 7 & & \\
\hline & & $\%$ & 4,0 & 7,4 & 2,4 & & \\
\hline Resultado do exame de & Negativo & $\mathbf{n}$ & 221 & 251 & 165 & 32,850 & 0,000 \\
\hline helmintos & & $\%$ & 73,2 & 66,4 & 56,5 & & \\
\hline & Positivo & $\mathbf{n}$ & 31 & 32 & 19 & & \\
\hline & & $\%$ & 10,3 & 8,5 & 6,5 & & \\
\hline Ascaris lumbricoides & Negativo & n & 286 & 352 & 277 & 1,159 & 0,560 \\
\hline & & $\%$ & 94,7 & 93,1 & 94,9 & & \\
\hline & Positivo & n & 16 & 25 & 15 & & \\
\hline & & $\%$ & 5,3 & 6,9 & 5,1 & & \\
\hline
\end{tabular}

(1) Teste do qui-quadrado para os respectivos graus de liberdade

(2) Probabilidade de significância 
TABELA 35 - Continuação

\begin{tabular}{|c|c|c|c|c|c|c|c|}
\hline Variável & Atributo & Freq. & SPA & $\overline{\text { SPB }}$ & $\overline{\text { SPC }}$ & $\mathbf{X}_{(1)}^{2}$ & $\mathbf{p}_{(2)}$ \\
\hline \multirow[t]{4}{*}{ Trichocephalus trichiurus } & \multirow[t]{2}{*}{ Negativo } & $\bar{n}$ & 282 & 370 & 286 & \multirow[t]{4}{*}{12,673} & \multirow[t]{4}{*}{0,002} \\
\hline & & $\%$ & 93,4 & 97,9 & 97,9 & & \\
\hline & \multirow[t]{2}{*}{ Positivo } & $\mathbf{n}$ & 20 & 8 & 6 & & \\
\hline & & $\%$ & 6,6 & 2,1 & 2,1 & & \\
\hline \multirow[t]{4}{*}{ Ancylostomidae } & \multirow[t]{2}{*}{ Negativo } & $\mathbf{n}$ & 300 & 378 & 292 & \multirow[t]{4}{*}{4,446} & \multirow[t]{4}{*}{0,108} \\
\hline & & $\%$ & 99,3 & 100 & 100 & & \\
\hline & \multirow[t]{2}{*}{ Positivo } & $\mathbf{n}$ & 2 & & & & \\
\hline & & $\%$ & & & & & \\
\hline \multirow[t]{4}{*}{ Hymenolepis nana } & \multirow[t]{2}{*}{ Negativo } & $\mathbf{n}$ & 302 & 377 & 292 & \multirow[t]{4}{*}{1,573} & \multirow[t]{4}{*}{0,445} \\
\hline & & $\%$ & 100 & 99,7 & 100 & & \\
\hline & \multirow[t]{2}{*}{ Positivo } & $\mathbf{n}$ & & 1 & & & \\
\hline & & $\%$ & & 0,3 & & & \\
\hline \multirow[t]{4}{*}{ Enterobius vermicularis } & \multirow[t]{2}{*}{ Negativo } & $\mathbf{n}$ & 299 & 376 & 291 & \multirow[t]{4}{*}{1,104} & \multirow[t]{4}{*}{0,576} \\
\hline & & $\%$ & 99,0 & 99,5 & 99,7 & & \\
\hline & \multirow[t]{2}{*}{ Positivo } & $\mathbf{n}$ & 3 & 2 & 1 & & \\
\hline & & $\%$ & 1,0 & 0,5 & 0,3 & & \\
\hline \multirow[t]{4}{*}{ Strongyloides stercoralis } & \multirow[t]{2}{*}{ Negativo } & $\mathbf{n}$ & 301 & 378 & 292 & \multirow[t]{4}{*}{2,221} & \multirow[t]{4}{*}{0,329} \\
\hline & & $\%$ & 99,7 & 100 & 100 & & \\
\hline & \multirow[t]{2}{*}{ Positivo } & $\mathrm{n}$ & 1 & & & & \\
\hline & & $\%$ & 0,3 & & & & \\
\hline
\end{tabular}

(1) Teste do qui-quadrado para os respectivos graus de liberdade

(2) Probabilidade de significância

Ressalta-se que na tabela 35 são apresentados os resultados obtidos apenas para os parasitos intestinais investigados, cuja presença foi detectada por meio do exame parasitológico nas fezes de alguma criança participante da pesquisa. Os protozoários e helmintos, que não foram detectados nos exames realizados, foram excluídos da análise estatística do presente estudo. 


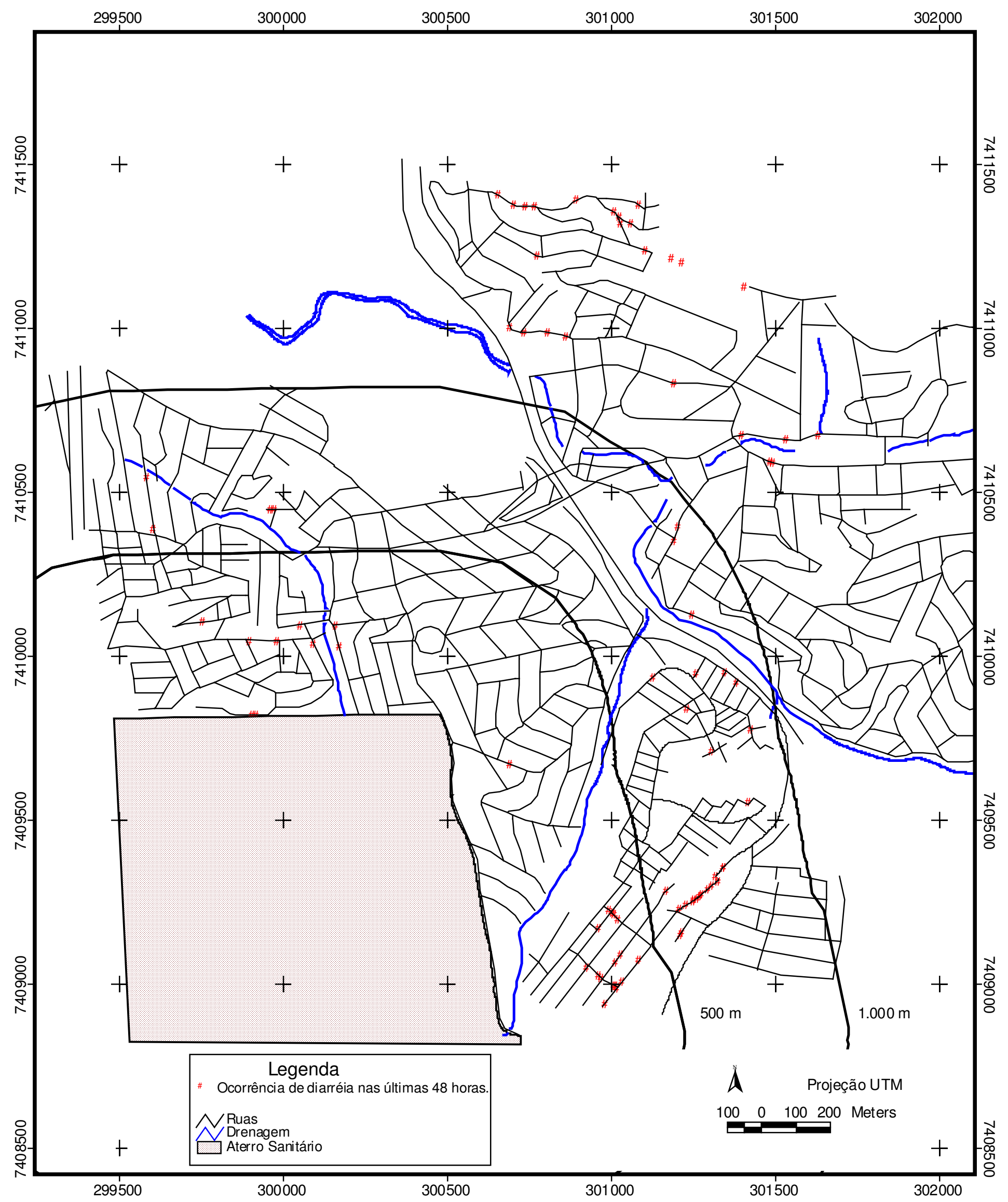

FIGURA 23 - Distribuição da ocorrência de diarréia na população de estudo. 


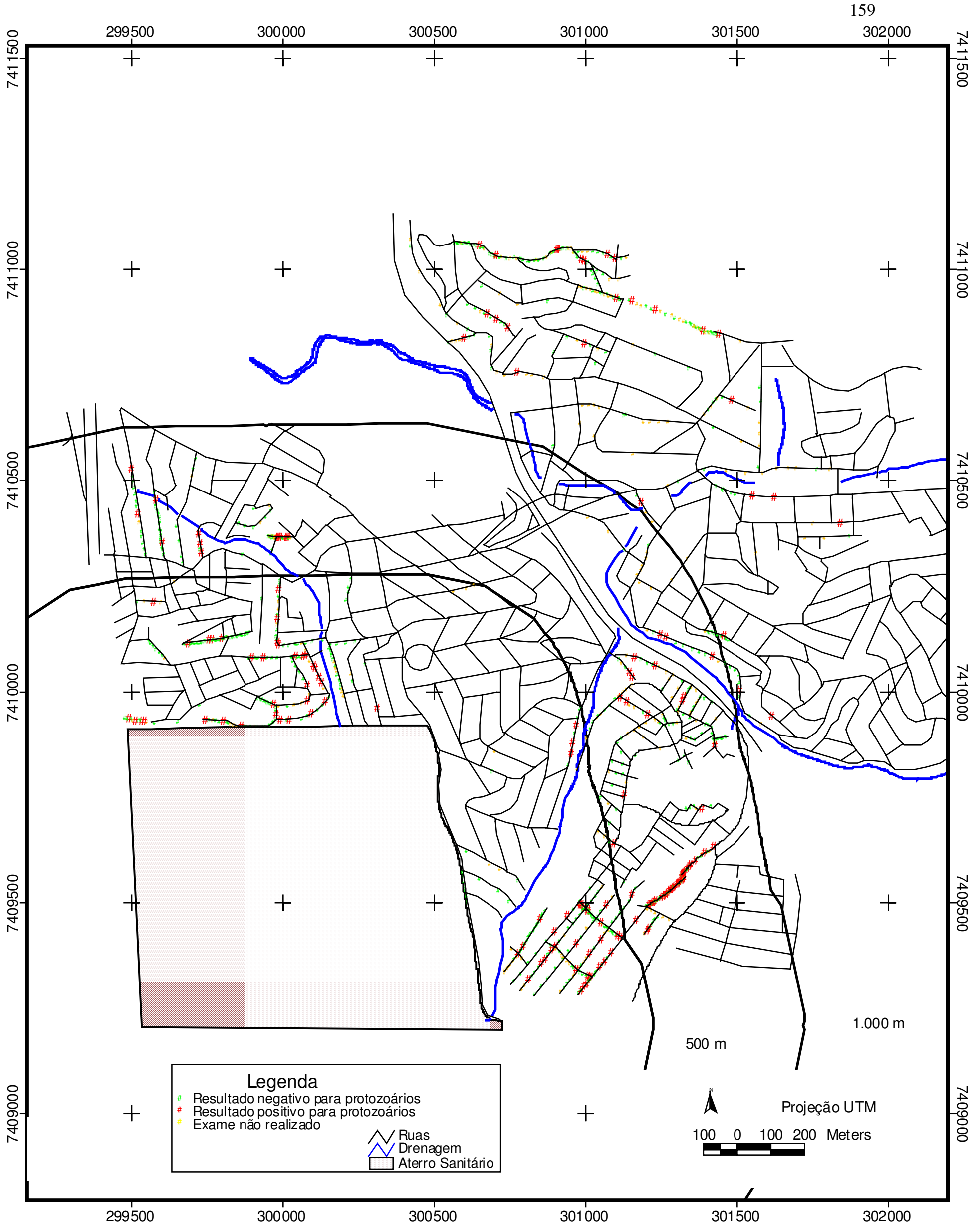

FIGURA 24 - Distribuição da ocorrência de parasitose intestinal (Protozoários) na população de estudo. 


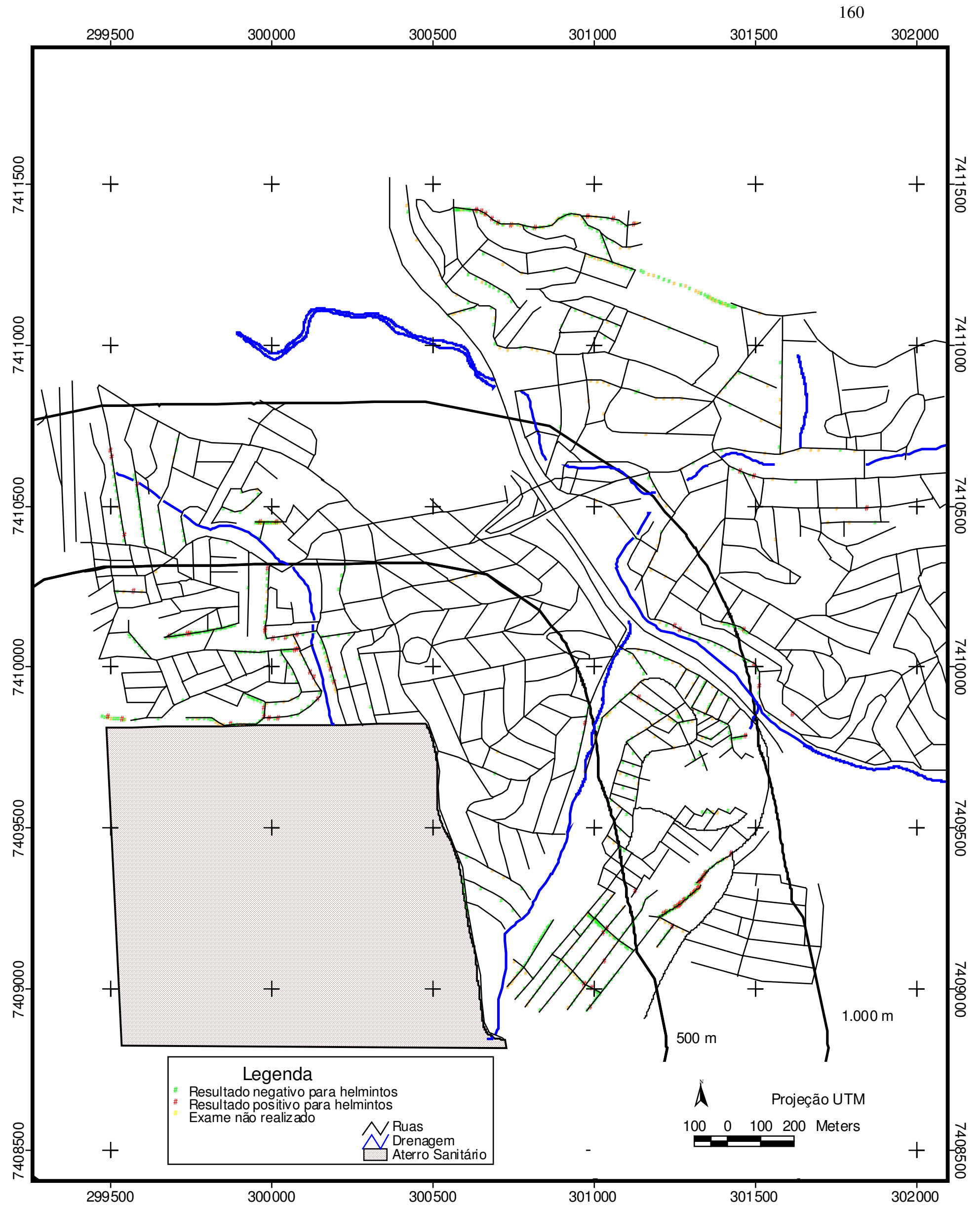

FIGURA 25 - Distribuição da ocorrência de parasitose intestinal (Helmintos) na população de estudo. 


\subsection{Caracterização do Aterro Sanitário Bandeirantes}

Os dados referentes ao Aterro Sanitário Bandeirantes baseiam-se em dados e informações prestados pela Divisão Técnica de Aterros Sanitários, do Departamento de Limpeza Urbana (PREFEITURA MUNICIPAL DE SÃO PAULO, 2003), e nos dados constantes no Relatório Ambiental HFCT - 300503, de maio de 2003 (CEPOLLINA, 2003), encaminhado à CETESB pela empresa Heleno \& Fonseca Construtécnica, responsável pela operação do referido aterro.

A operação do Aterro Sanitário Bandeirantes iniciou-se em 01/09/1979, na área referente ao sub-aterro AS-1. Este sub-aterro esteve em operação até o ano de 1986. Em 1984, teve início a operação do sub-aterro AS-2, extendendo-se até 1992, quando foi iniciada a operação do sub-aterro AS-3, prosseguindo até o ano de 1994.

Os sub-aterros AS-4 e AS-5 tiveram operação iniciada em 1994 e têm previsão de encerramento em junho de 2006. O Aterro Sanitário Bandeirantes está em operação há mais de 24 anos, totalizando uma quantidade aproximada de 33 milhões de toneladas de resíduos sólidos dispostos na área. No encerramento do aterro, prevê-se a disposição de 40 milhões de toneladas de resíduos sólidos.

O Aterro ocupa uma área total de $1.400 .000 \mathrm{~m}^{2}$, sendo $1.000 .000 \mathrm{~m}^{2}$ ocupados, somente, para a disposição de resíduos sólidos. A altura média das células do aterro é de $5 \mathrm{~m}$ e, a altura total do aterro, de $143 \mathrm{~m}$.

Por dia, são dispostas no Aterro cerca de 6.000 toneladas de resíduos domiciliares e industriais Classe II e Classe III. O volume de chorume produzido por dia no Aterro é, aproximadamente, $1.200 \mathrm{~m}^{3} /$ dia. O chorume é transportado por caminhões tanque até a estação de recebimento da SABESP e co-tratado com os 
esgotos sanitários. Os gases gerados no Aterro são drenados por meio de drenos verticais e queimados.

Na Tabela 36 são apresentados os resultados das análises físico-químicas e bacteriológicas realizadas por meio da coleta de amostras de água subterrânea na rede de poços de monitorização do Aterro Sanitário Bandeirantes. Esses dados apresentados referem-se ao período de março de 2003. No Apêndice 4 são apresentadas as figuras obtidas pelos resultados da monitorização do lençol freático, realizado no Aterro Bandeirantes no mesmo período.

Nas Figuras 26 a 31 são apresentados os mapas da distribuição geográfica dos relatos de problemas relacionados ao Aterro Sanitário Bandeirantes.

Para fins de comparação e com intuito de controlar o possível efeito do fator de confusão relacionado aos esgotos sanitários, na análise do relato dos problemas ambientais, são apresentadas, respectivamente, nas Figuras 32 e 33 a solução dada aos esgotos sanitários e a existência de esgoto a céu aberto na área de estudo. 
TABELA 36 - Resultados da monitorização da água subterrânea no Aterro Sanitário Bandeirantes

\begin{tabular}{|c|c|c|c|c|c|c|c|c|c|c|c|c|}
\hline \multirow[t]{2}{*}{ Parâmetro } & \multirow[t]{2}{*}{ Unidade } & \multicolumn{11}{|c|}{ Poços de monitorização } \\
\hline & & P 1 & P 2 & PM 1 & PM 2 & PM 6 & PM 3 & P 6 & P 6A & P 3 & P 5 & P 4 \\
\hline Aspecto & & Turvo & Turvo & Límpido & Turvo & Límpido & Límpido & Turvo & Límpido & Límpido & Turvo & Límpido \\
\hline Cor & $\mathrm{mg} \mathrm{Pt} / 1$ & 9 & 12 & 17 & 69 & 13 & n.d & 37 & n.d & 12 & 197 & 12 \\
\hline Odor & & Nenhum & Nenhum & Nenhum & Nenhum & Nenhum & Nenhum & Nenhum & Nenhum & Nenhum & Nenhum & Nenhum \\
\hline Turbidez & N.T.U. & 14,1 & 10,0 & 4,45 & 61,3 & 8,59 & 2,31 & $1,18 \times 10^{3}$ & 1,56 & 1,94 & 42,3 & 8,97 \\
\hline Condutividade & $\mu \mathrm{S} / \mathrm{cm}$ & 6,1 & 12,3 & 32,6 & 18,4 & 98,9 & 197,1 & 368 & 71,1 & 46,5 & 77,8 & 24,8 \\
\hline Alumínio & $\mathrm{mg} / \mathrm{l}$ & n.d & 0,15 & n.d & 6,16 & 0,22 & 0,84 & 25,4 & n.d & n.d & 0,20 & n.d \\
\hline $\begin{array}{l}\text { Alumínio } \\
\text { solúvel }\end{array}$ & $\mathrm{mg} / \mathrm{l}$ & n.d & n.d & n.d & n.d & n.d & n.d & n.d & n.d & n.d & n.d & n.d \\
\hline Arsênio & $\mathrm{mg} / \mathrm{l}$ & n.d & n.d & n.d & n.d & n.d & n.d & n.d & n.d & n.d & n.d & n.d \\
\hline Bário & $\mathrm{mg} / \mathrm{l}$ & n.d & n.d & n.d & n.d & n.d & 0,36 & n.d & n.d & n.d & n.d & n.d \\
\hline Cádmio & $\mathrm{mg} / \mathrm{l}$ & n.d & n.d & n.d & n.d & n.d & n.d & n.d & n.d & n.d & n.d & n.d \\
\hline Chumbo & $\mathrm{mg} / \mathrm{l}$ & n.d & n.d & n.d & n.d & n.d & n.d & n.d & n.d & n.d & n.d & n.d \\
\hline $\begin{array}{l}\text { Chumbo } \\
\text { solúvel }\end{array}$ & $\mathrm{mg} / \mathrm{l}$ & n.d & n.d & n.d & n.d & n.d & n.d & n.d & n.d & n.d & n.d & n.d \\
\hline Cobre & $\mathrm{mg} / \mathrm{l}$ & n.d & n.d & n.d & n.d & n.d & 0,011 & 0,014 & n.d & n.d & n.d & n.d \\
\hline Cromo total & $\mathrm{mg} / \mathrm{l}$ & n.d & n.d & n.d & n.d & n.d & n.d & 0,019 & n.d & n.d & n.d & n.d \\
\hline Dureza & $\begin{array}{c}\mathrm{Mg} \\
\mathrm{CaCO}_{3} / 1\end{array}$ & n.d & 7,1 & 16 & 6,7 & 69 & 72 & 71 & 23 & 15 & 56 & 7,4 \\
\hline Ferro solúvel & $\mathrm{mg} / \mathrm{l}$ & n.d & n.d & n.d & n.d & n.d & 0,151 & 0,306 & n.d & 0,143 & n.d & n.d \\
\hline Ferro total & $\mathrm{mg} / \mathrm{l}$ & 3,1 & 0,65 & 0,373 & 8,23 & 0,558 & n.d & 12,1 & 0,116 & 0,454 & 11,3 & 0,102 \\
\hline Manganês & $\mathrm{mg} / \mathrm{l}$ & 0,184 & 0,091 & 0,485 & 0,485 & 0,576 & 0,151 & 3,82 & 6,59 & 0,038 & 3,11 & 0,023 \\
\hline $\begin{array}{l}\text { Manganês } \\
\text { solúvel }\end{array}$ & $\mathrm{mg} / \mathrm{l}$ & 0,126 & 0,091 & 0,358 & 0,142 & 0,154 & 2,44 & 3,23 & 6,43 & 0,032 & n.d & 0,024 \\
\hline Mercúro & $\mathrm{mg} / \mathrm{l}$ & n.d & n.d & n.d & n.d & n.d & n.d & n.d & n.d & n.d & n.d & n.d \\
\hline Prata & $\mathrm{mg} / \mathrm{l}$ & n.d & n.d & n.d & n.d & n.d & n.d & n.d & n.d & n.d & n.d & n.d \\
\hline Selênio & $\mathrm{mg} / \mathrm{l}$ & n.d & n.d & n.d & n.d & n.d & n.d & n.d & n.d & n.d & n.d & n.d \\
\hline
\end{tabular}


TABELA 36 - Continuação

\begin{tabular}{|c|c|c|c|c|c|c|c|c|c|c|c|c|}
\hline \multirow[t]{2}{*}{ Parâmetro } & \multirow[t]{2}{*}{ Unidade } & \multicolumn{11}{|c|}{ Poços de monitorização } \\
\hline & & P 1 & P 2 & PM 1 & PM 2 & PM 6 & PM 3 & P 6 & P 6A & P 3 & P 5 & P 4 \\
\hline Zinco & $\mathrm{mg} / \mathrm{l}$ & 0,03 & 0,036 & 0,070 & 0,093 & 0,012 & 0,073 & 0,153 & 0,029 & 0,008 & 0,003 & 0,009 \\
\hline Cianeto & $\mathrm{mg} / \mathrm{l}$ & n.d & n.d & n.d & n.d & n.d & n.d & n.d & n.d & n.d & n.d & n.d \\
\hline Sulfato & $\mathrm{mg} / \mathrm{l}$ & 3 & n.d & 3 & n.d & 34 & 29 & 9 & 12 & n.d & 11 & 3 \\
\hline Fluoreto & $\mathrm{mg} / \mathrm{l}$ & n.d & n.d & n.d & n.d & 0,12 & 0,38 & 0,13 & n.d & n.d & n.d & n.d \\
\hline Fenóis & $\mathrm{mg} / \mathrm{l}$ & n.d & n.d & n.d & n.d & n.d & n.d & n.d & n.d & n.d & n.d & n.d \\
\hline Orto-fosfato & $\mathrm{mg} / \mathrm{l}$ & n.d & n.d & n.d & n.d & n.d & n.d & n.d & n.d & n.d & n.d & n.d \\
\hline Surfactantes & $\mathrm{mg} / \mathrm{l}$ & n.d & n.d & n.d & n.d & n.d & n.d & n.d & n.d & n.d & n.d & n.d \\
\hline $\mathrm{N}$ nitrato & $\mathrm{mg} / \mathrm{l}$ & 0,07 & 0,06 & 1,7 & 0,08 & 0,11 & 22 & $<0,10$ & 0,30 & $<0,10$ & $<0,10$ & 0,42 \\
\hline Cloreto & $\mathrm{mg} / \mathrm{l}$ & 2 & 1,6 & 3,1 & 2,7 & 30,0 & 57,9 & 67,4 & 14,2 & 14,7 & 7,7 & 6,8 \\
\hline $\begin{array}{l}\text { Sólidos } \\
\text { dissolvidos } \\
\text { totais }\end{array}$ & $\mathrm{mg} / \mathrm{l}$ & 20 & 77 & 156 & 70 & 194 & 256 & 318 & 102 & 72 & 101 & 40 \\
\hline COT & $\mathrm{mg} / \mathrm{l}$ & 4,3 & 3,1 & 13,9 & 7,0 & 5,5 & 13,3 & 7,2 & 19,0 & 3,3 & 13,3 & 4,3 \\
\hline $\begin{array}{l}\text { Contagem } \\
\text { padrão de } \\
\text { bactérias } \\
\end{array}$ & $\mathrm{UFC} / \mathrm{ml}$ & $5,38 \times 10^{3}$ & $44,2 \times 10^{3}$ & $4,9 \times 10^{3}$ & $131 \times 10^{3}$ & $5,3 \times 10^{3}$ & $4,59 \times 10^{3}$ & $13,2 \times 10^{3}$ & $15,4 \times 10^{3}$ & $16,7 \times 10^{3}$ & $83,8 \times 10^{3}$ & $101 \times 10^{3}$ \\
\hline $\begin{array}{l}\text { Coliformes } \\
\text { totais }\end{array}$ & $\mathrm{NMP} / 100 \mathrm{ml}$ & Ausente & Ausente & Ausente & $>23$ & Ausente & Ausente & Ausente & Ausente & Ausente & $9,0 \times 10^{3}$ & Ausente \\
\hline $\begin{array}{l}\text { Escherichia } \\
\text { coli }\end{array}$ & $\mathrm{NMP} / 100 \mathrm{ml}$ & Ausente & Ausente & Ausente & Ausente & Ausente & Ausente & Ausente & Ausente & Ausente & $2,4 \times 10^{3}$ & Ausente \\
\hline Profundidade & $\mathrm{m}$ & 53,00 & 45,35 & 45,35 & 41,75 & 10,25 & 14,60 & 5,15 & 13,70 & 13,95 & 41,60 & 24,70 \\
\hline Nível d'água & $\mathrm{m}$ & 35,00 & 37,52 & 31,78 & 34,77 & 2,07 & 3,27 & 4,55 & 5,20 & 1,80 & 25,00 & 15,67 \\
\hline
\end{tabular}

(n.d) - Não detectado

(1.d) - Limite de detecção do método 


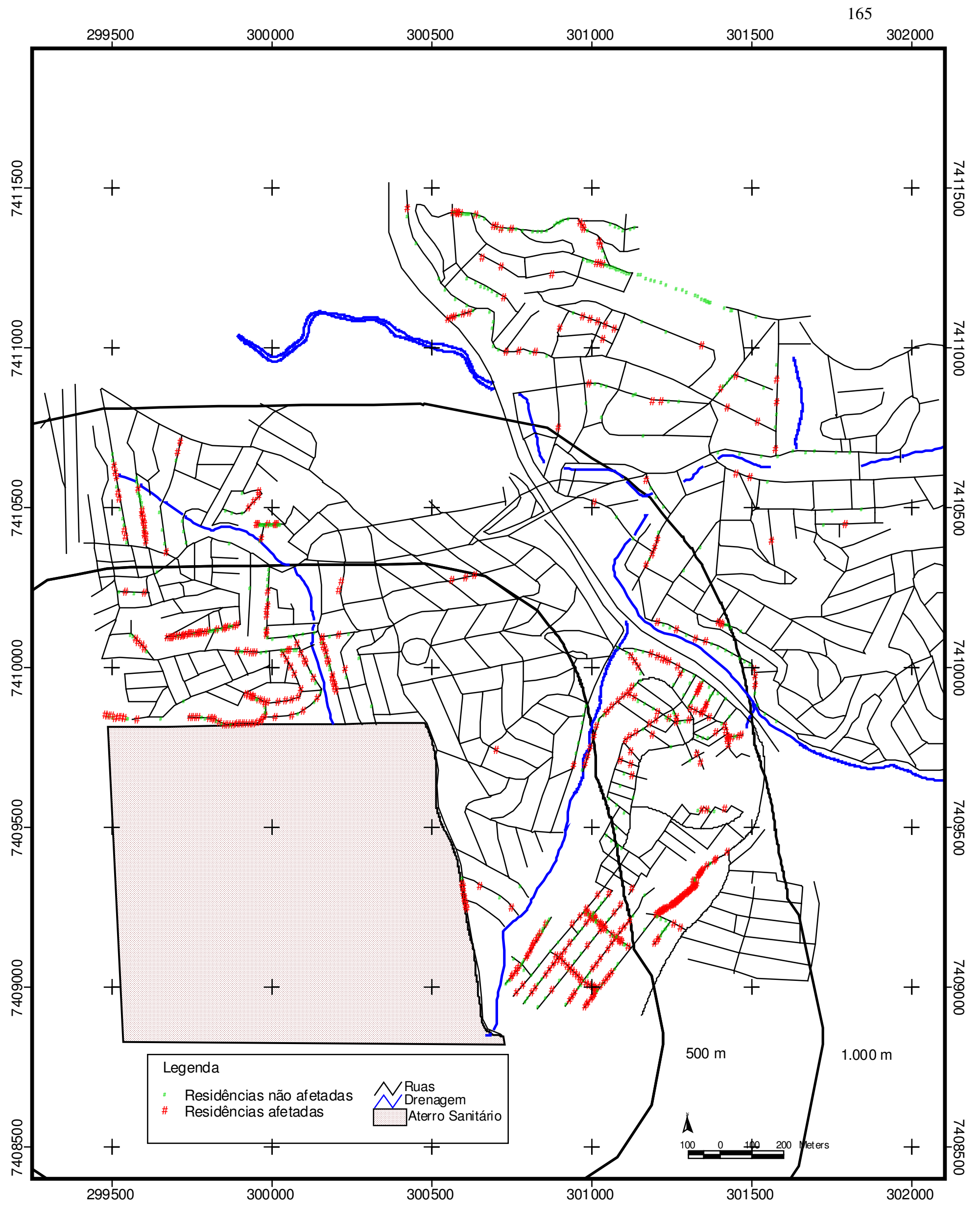

FIGURA 26 - Relato de problemas relacionados ao aterro sanitário na área de estudo. 


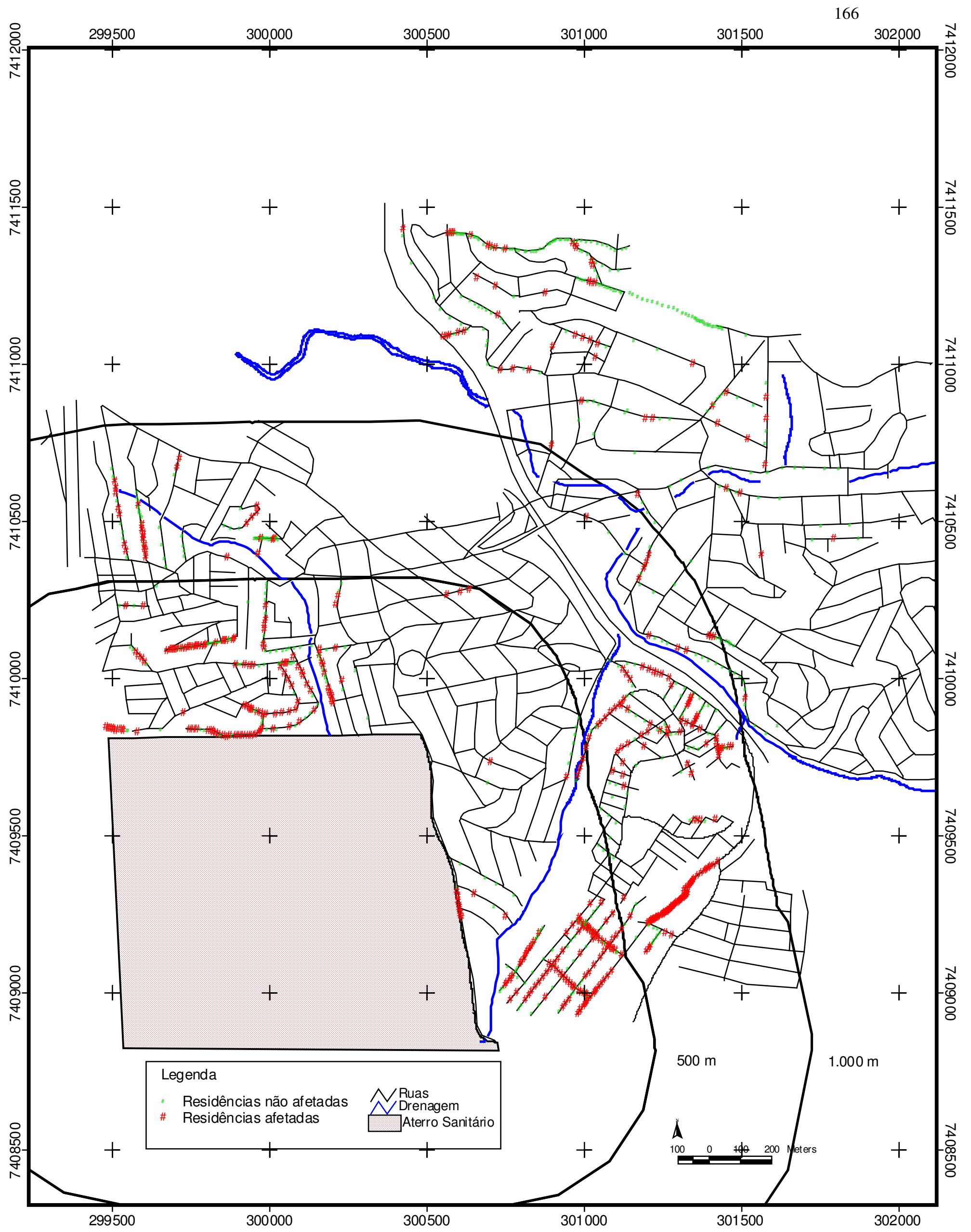

FIGURA 27 - Relato de problemas relacionados ao aterro sanitário na área de estudo (Odor). 


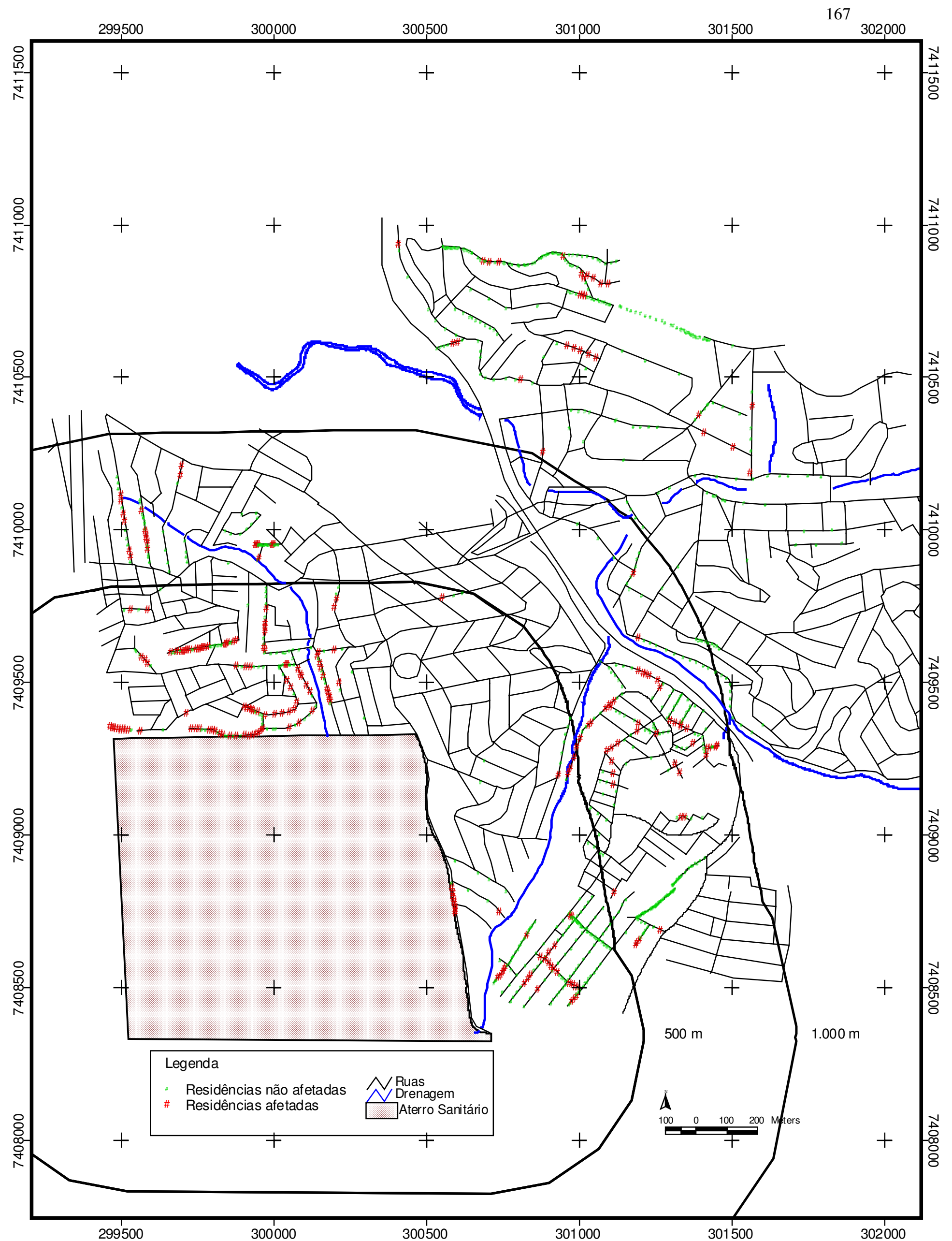

FIGURA 28 - Relato de problemas relacionados ao aterro sanitário na área de estudo (Poeira). 


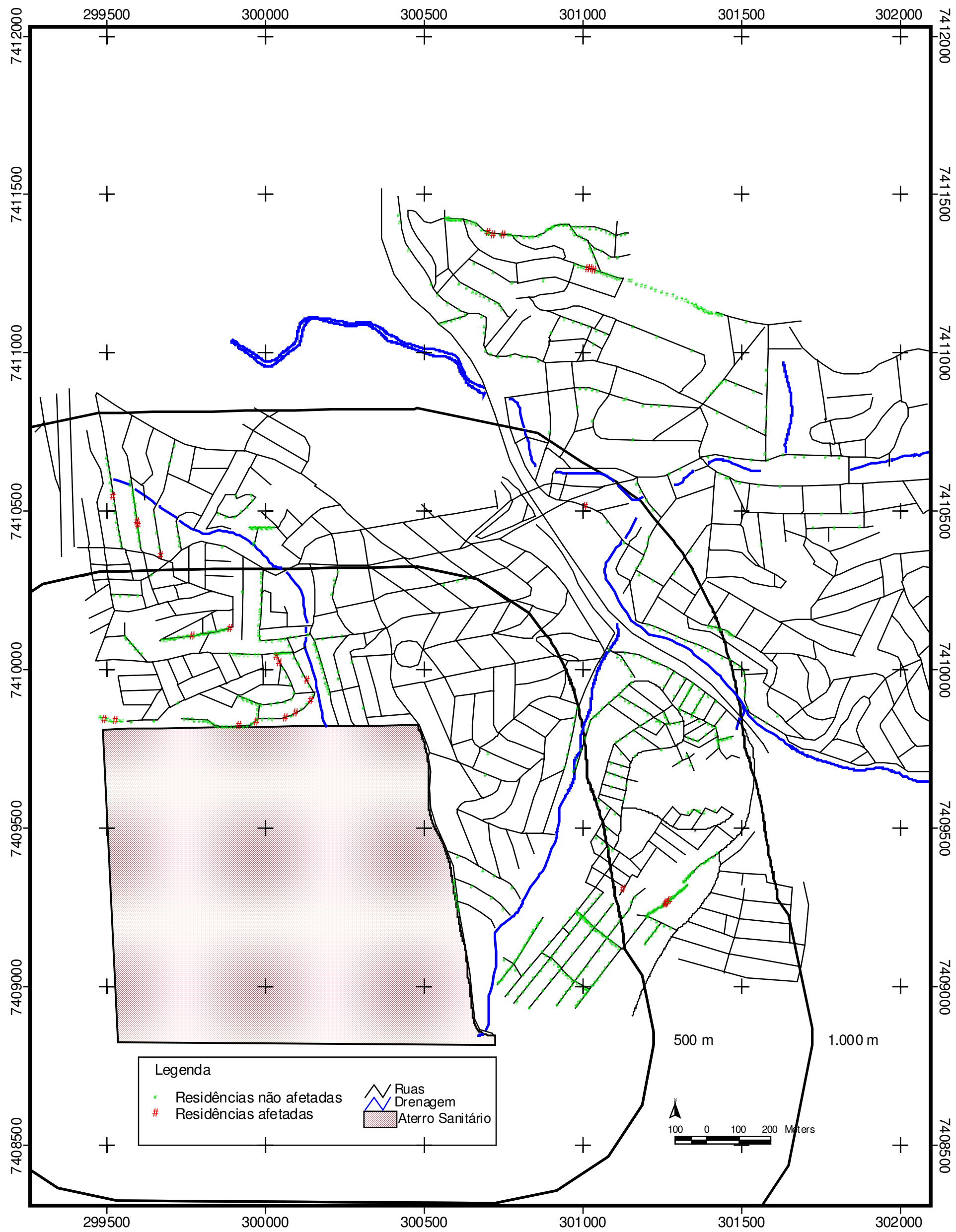

FIGURA 29 - Relato de problemas relacionados ao aterro sanitário na área de estudo (Chorume). 


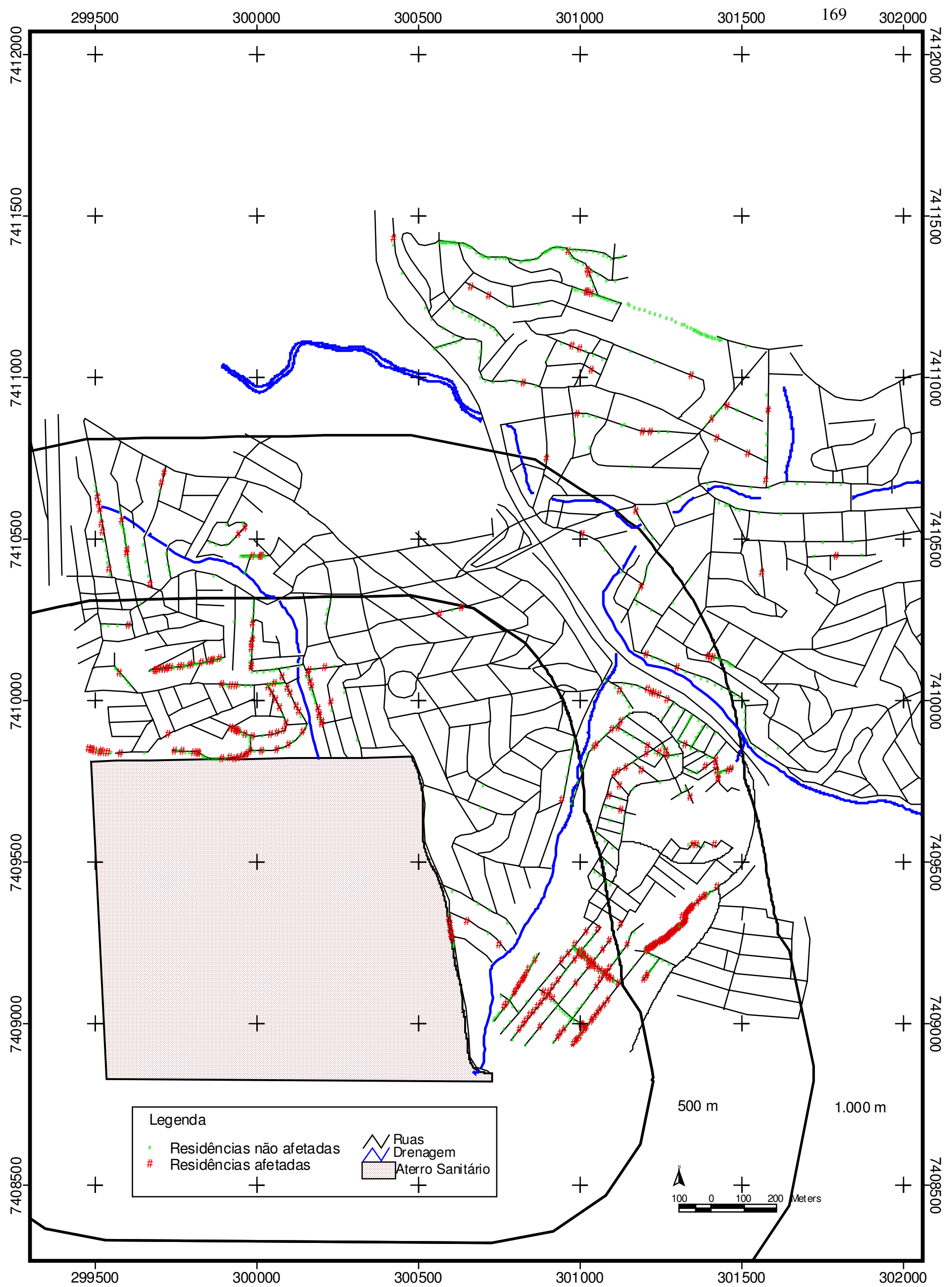

FIGURA 30 - Relato de problemas relacionados ao aterro sanitário na área de estudo (Presença de insetos). 


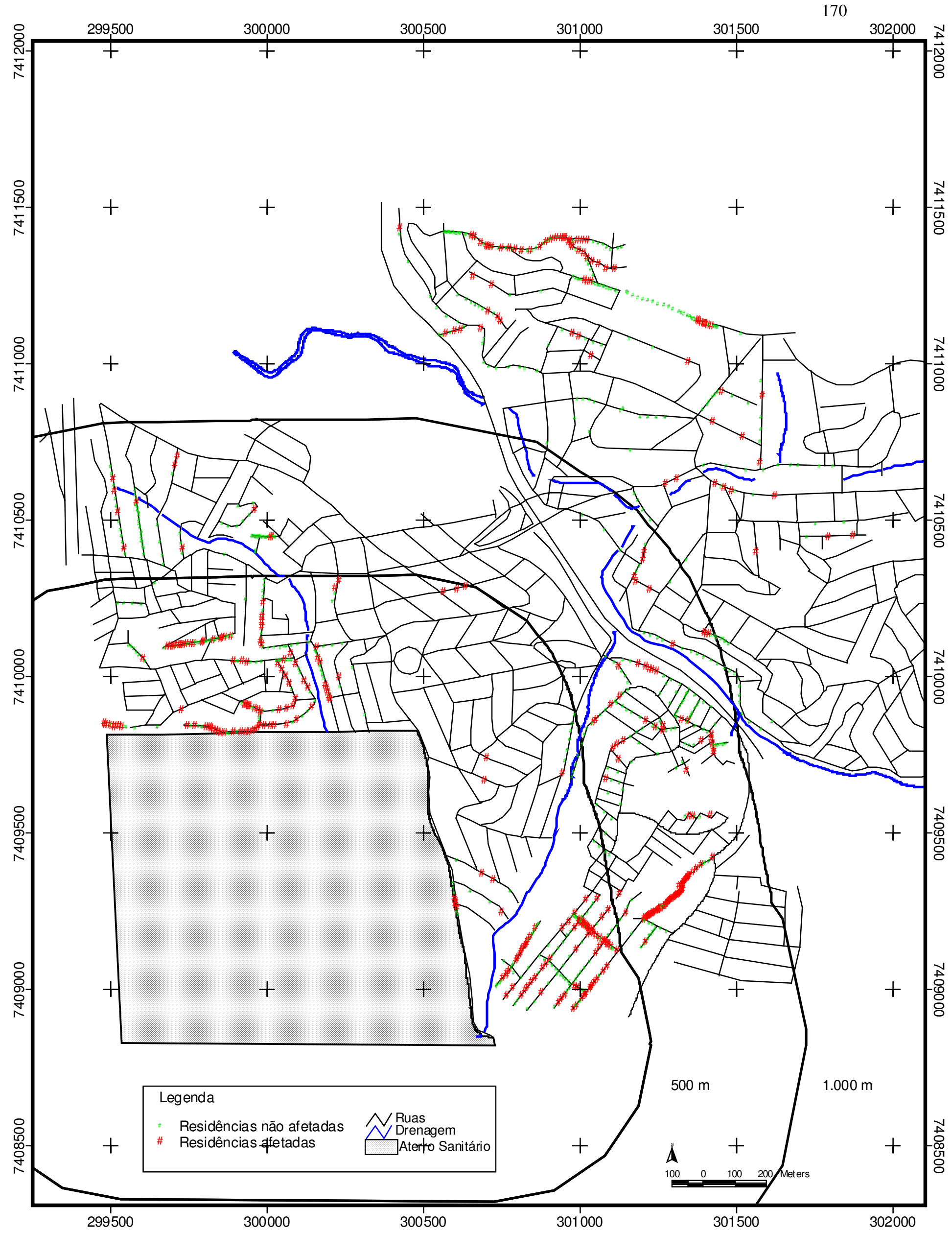

FIGURA 31 - Relato de problemas relacionados ao aterro sanitário na área de estudo (Presença de roedores). 


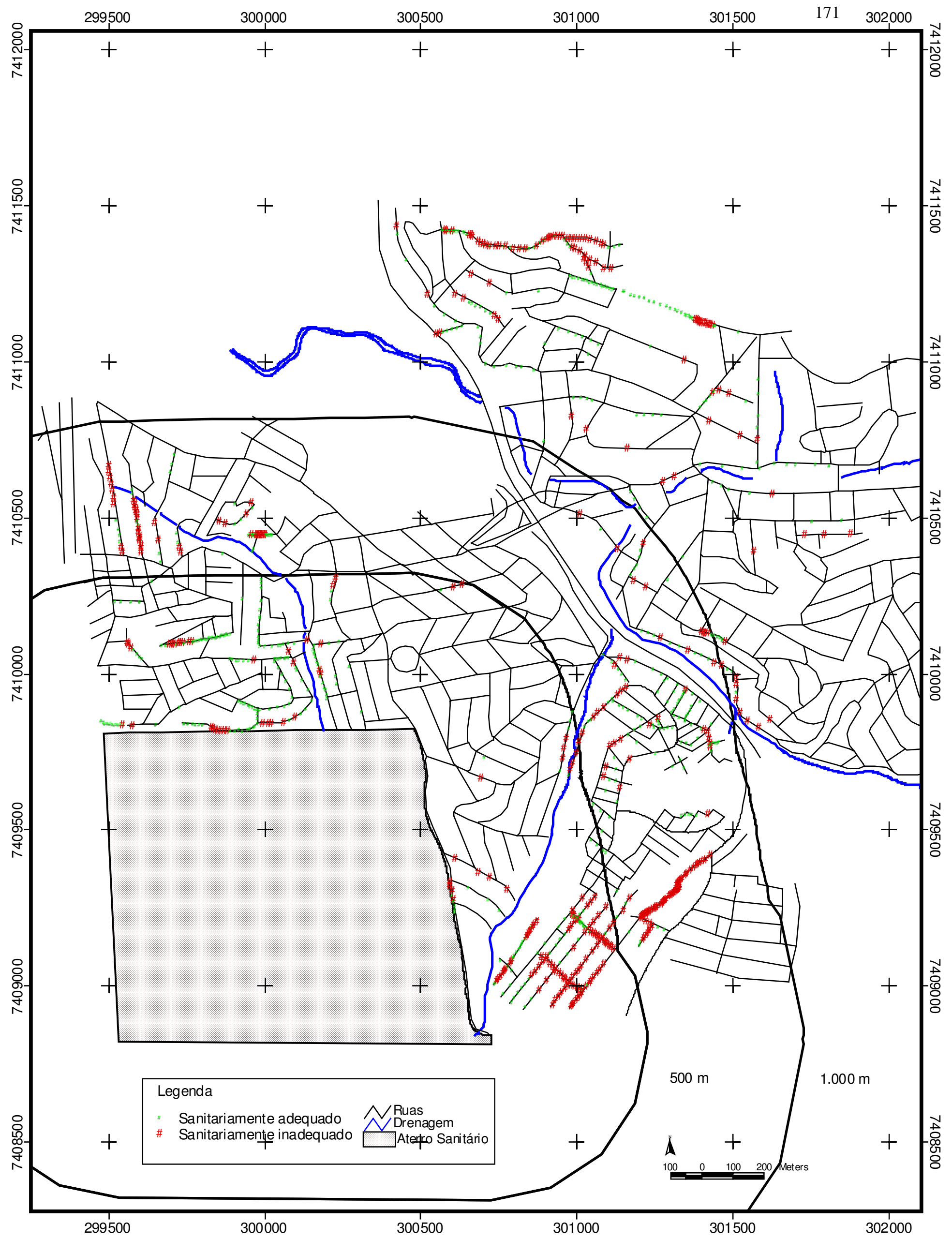

FIGURA 32 - Destino dado aos esgotos sanitários na área de estudo. 


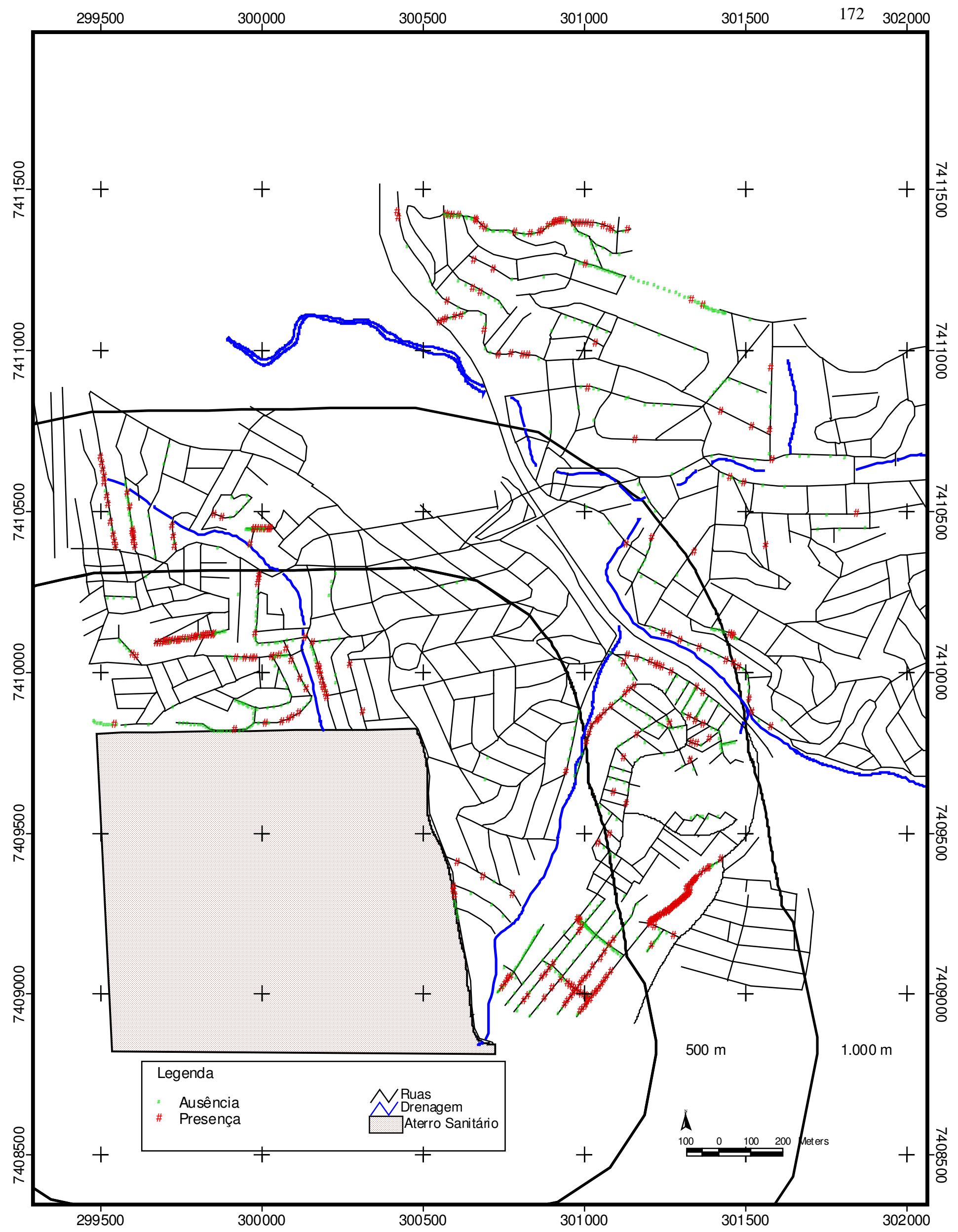

FIGURA 33 - Presença de esgoto à céu aberto na área de estudo. 


\subsection{Análise Multivariada}

Um modelo de regressão logística foi utilizado para estudar a variável resposta diarréia em relação as três áreas pesquisadas. As diferenças encontradas entre as três áreas na freqüência de ocorrência de diarréia foram estudadas por meio deste modelo com a finalidade de ajustar essas diferenças a um conjunto de variáveis explicativas, levantadas pela aplicação dos Protocolos de Pesquisa 1 e 2. As diferenças foram estudadas em termos de razão de probabilidades (RP) ou razão de chances ou Odds Ratio (OR) (SOARES \& SIQUEIRA, 2001).

No ajuste do modelo, as respostas de algumas variáveis explicativas foram agrupadas em categorias a fim de dicotomizar a saída dos resultados, devido a existência de dados esparsos. Inicialmente, foram selecionadas as variáveis explicativas que tiveram valor-p menor que 0,25 na análise univariada. Essas variáveis foram consideradas como candidatas a entrarem no modelo multivariado final de regressão logística.

Para a construção do modelo final, foi utilizado o procedimento forward, que consiste na inclusão de uma variável explicativa por vez. As variáveis incluídas no modelo de regressão foram selecionadas entre as que apresentaram teste de significância estatística associado ao valor-p inferior a 0,05 .

O resultado final do modelo de regressão logística é apresentado na Tabela 37. Pelo teste de Hosmer-Lemeshow, o valor-p obtido, para o ajuste do modelo de regressão logística, foi de 0,991 (HOSMER \& LEMESHOW, 2000).

As variáveis que permaneceram no modelo final da análise multivariada foram: hábito da criança lavar a mão após defecar, a separação domiciliar do lixo, 
problemas de falta d'água na habitação, o tipo de abastecimento de água da residência e a frequiência de limpeza da caixa d'água.

TABELA 37 - Resultado final do modelo de regressão logística

\begin{tabular}{l|c|c|c|c}
\hline \multicolumn{1}{c|}{$\begin{array}{c}\text { Variável significativa no } \\
\text { modelo }\end{array}$} & \multirow{2}{*}{ Coeficiente } & \multirow{2}{*}{ Valor-p } & \multicolumn{2}{c}{ Razão de chances (OR)* } \\
\cline { 4 - 5 } & & & Estimativa & IC(95 \%)** \\
\hline Lavagem de mão após defecar & 1,433 & 0,022 & 4,190 & $(1,226 ; 14,322)$ \\
\hline Separação do lixo em casa & $-1,057$ & 0,010 & 0,347 & $(0,155 ; 0,780)$ \\
\hline $\begin{array}{l}\text { Problemas de falta d'água na } \\
\text { habitação }\end{array}$ & 1,212 & 0,001 & 3,360 & $(1,633 ; 6,915)$ \\
\hline $\begin{array}{l}\text { Abastecimento de água } \\
\text { indireto }\end{array}$ & 1,540 & 0,047 & 4,498 & $(1,020 ; 19,829)$ \\
\hline Freqüûncia de limpeza da & & & & \\
caixa d'água & 0,986 & 0,011 & 2,680 & $(1,248 ; 5,754)$ \\
\hline Constante & & & & \\
\hline
\end{tabular}

* Odds Ratio

** IC - intervalo de confiança a $95 \%$ 


\section{CAPÍTULO V}

\section{DISCUSSÃO}

\subsection{Definição da Área de Exposição}

A definição da área de exposição, considerando como o grupo exposto as crianças residentes até a distância de mil metros do limite do aterro sanitário, mostrou-se adequada, por ter sido possível identificar as diferenças entre as áreas "exposto" (SPA e SPB) e "não-exposto" (SPC) e o grupo de variáveis utilizados como indicadores ambientais da área de estudo. Contudo, em relação ao indicador de saúde considerado na análise multivariada, doenças diarréicas, não houve uma correlação estatística entre o indicador e a maior ou menor proximidade de residência do aterro sanitário.

A distância de mil metros do aterro foi definida na metodologia de pesquisa, baseada em estudos epidemiológicos realizados por BERRY \& BOVE (1997). Contudo, estudos sobre o levantamento de impactos ambientais ocasionados em áreas próximas a aterros sanitários comprovam a adequação da faixa de exposição adotada por esta pesquisa. HONG et al. (1996), estudando a dispersão de poluentes 
em áreas próximas ao aterro sanitário da cidade de Fu Shan, China, concluíram que a dispersão dos poluentes via atmosfera, medida na área no entorno do aterro, não ultrapassava os padrões de qualidade do ar vigentes na China, após a distância de 600m do limite do aterro. Assim sendo, a distância de $600 \mathrm{~m}$ foi proposta pelos autores para a definição de uma zona de proteção no entorno do referido aterro.

Um estudo de avaliação das emissões do aterro sanitário e os impactos ambientais relacionados (CHRISTENSEN \& KJELDSEN, 1995), concluíram que a poluição da água superficial e subterrânea fica retida em uma zona próxima a $1 \mathrm{~km}$ do aterro sanitário. Os autores estimaram também a zona de influência de cada tipo de impacto ambiental ocasionado pelo aterro sanitário. Os impactos: emissão de compostos tóxicos - carbono orgânico voláteis; odor; barulho; presença de pássaros, roedores e insetos foram estimados até uma distância de $1 \mathrm{~km}$ do aterro, enquanto a poluição do solo; danos à vegetação e poeira até a distância de $100 \mathrm{~m}$ do aterro sanitário.

Os resultados obtidos pelo presente estudo, por meio do relato de problemas ambientais associados ao aterro sanitário, estão de acordo com o estudo anterior. A análise das Figuras 26 a 31, nas quais são apresentadas as distribuições na área de estudo dos problemas ambientais relacionados ao Aterro Bandeirantes, demonstram, nitidamente, um gradiente decrescente da freqüência de relatos. Os problemas foram identificados com maior freqüência na área de exposição SPA e decresceram para as áreas SPB e SPC (Figura 26).

O relato de problemas de odor (Figura 27) foi mais intenso nas Vilas Jardim do Russo, Recanto Paraíso e Nova Perus, distantes até 500m do Aterro Bandeirantes. Os problemas associados à poeira foram mais intensos na Vila Jardim do Russo e 
Nova Perus, onde as residências fazem divisas com o aterro sanitário. Apesar da frente atual de operação do aterro situar-se a uma distância aproximada de 500 a 1000m da Vila Jardim do Russo, o tráfego interno de veículos próximo a essa área é ainda intenso. As residências amostradas na Vila Nova Perus situam-se próximas à frente atual de operação e à avenida principal de acesso ao aterro sanitário, pelo Bairro de Perus.

O relato referente à presença de insetos na área de estudo demonstra uma maior freqüência nas Vilas Jardim do Russo, Recanto Paraíso e Nova Perus, situadas na área SPA, como também, uma redução crescente em relação às áreas de exposição SPB e SPC.

A presença de roedores na área de estudo, também apresentou um número maior de relatos nas Vilas Jardim do Russo, Recanto Paraíso e Nova Perus, situadas na área de exposição SPA. Exceção se faz à Vila Caiúba, área de exposição SPC, para as residências situadas à Rua Antônio Cândido de Alvarenga. Nessa região, houve uma freqüência grande de relatos referentes à presença de roedores. Contudo, pela análise das Figuras 32 e 33 referentes, respectivamente, ao destino dado aos esgotos sanitários na área de estudo e à presença de esgoto a céu aberto próxima às habitações, observa-se uma correlação entre essas variáveis e o relato da presença de roedores.

Em relação ao relato de problemas associados ao chorume, verifica-se uma coerência para as respostas dadas ao questionário. Pois, a única área identificada, durante todo o período de realização do estudo e em várias inspeções feitas na área, como, possivelmente, afetada pelo percolado do aterro, seria a área situada na divisa entre as Vilas Jardim do Russo e Manacá, próxima à drenagem local. Nessa área 
dada a topografia local e a proximidade das células do aterro AS-1 e AS-2, as quais não receberam impermeabilização de fundo, há grandes evidências de escoamento de líquidos percolados do aterro junto ao sistema de drenagem natural local. Nessa área foi coletada para análise, uma amostra da água subterrânea (amostra 8 - Tabela 33), onde foi constatada uma possível contaminação do lençol freático devido ao aterro sanitário. Os outros pontos de ocorrência de chorume, na extremidade noroeste do aterro, relatados na Vila Jardim do Russo, são devido à proximidade desses locais às lagoas de recebimento e acumulação de chorume.

A freqüência de citação de problemas relacionados ao chorume, nos outros pontos da área de estudo, pode-se explicar pela orientação de treinamento dada às entrevistadoras. Recomendou-se às entrevistadoras que fosse explicada à pessoa entrevistada o conceito de chorume, porém as entrevistadoras foram instruídas para deixar que a resposta fosse a mais espontânea possível, a fim de não induzir as respostas dadas, mesmo, quando na observação das condições ambientais do peridomicílo, não fosse constatada a presença de chorume.

Observa-se pela comparação das Figuras 29 e 33, que há uma coincidência nos locais onde foram citados os problemas relativos ao chorume e a presença de esgoto a céu aberto, indicando uma provável confusão entre esses conceitos.

Apesar de não ter sido objeto específico do presente estudo, a avaliação da qualidade da água subterrânea com a verificação da possível ocorrência da contaminação da água pelo aterro, a análise de uma amostra de água, coletada a uma distância inferior a 500m do limite do Aterro Sanitário Bandeirantes, na área SPA Vila Manacá (amostra 08 - Tabela 33), demonstrou a alteração de alguns parâmetros referentes à qualidade da água avaliados. A concentração de arsênio foi de $0,04 \mu \mathrm{g} / \mathrm{l}$, 
superior ao limite $0,01 \mu \mathrm{g} / \mathrm{l}$, preconizado pela Portaria $\mathrm{n}^{\mathrm{o}} 1.469$ do Ministério da Saúde. As concentrações de chumbo e cádmio, embora inferiores aos limites estipulados pelos padrões de potabilidade brasileiros, apresentavam valores bem próximos a esses, respectivamente de 0,009mg/l e 0,004mg/l. Esses valores se mantiveram superiores aos demais valores obtidos nos outros pontos amostrados também em outro ponto de amostragem, situado na Vila Manacá (amostra 09 Tabela 33). Ambos os pontos de amostragem situam-se a uma distância inferior a $500 \mathrm{~m}$ do aterro sanitário. As concentrações de bário foram bastante elevadas em ambos os pontos. Apresentaram valores de $96,9 \mu \mathrm{g} / \mathrm{l}$ e $48,8 \mu \mathrm{g} / \mathrm{l}$, respectivamente para as amostras 8 e 9, enquanto que o limite preconizado pela Portaria $\mathrm{n}^{\circ} 1.469$ é de $0,7 \mu \mathrm{g} / \mathrm{l}$. A concentração de mercúrio detectada no ponto 9 de amostragem foi de $0,085 \mu \mathrm{g} / \mathrm{l}$, a portaria estipula o valor de $0,001 \mu \mathrm{g} / \mathrm{l}$ para este parâmetro. A amostra 9 foi a única que apresentou contaminação bacteriológica, quando comparada aos padrões de potabilidade e aos outros pontos amostrados.

$\mathrm{Na}$ amostra 08, ponto de amostragem da água subterrânea, foi verificada uma concentração de nitrogênio amoniacal de $2,43 \mathrm{mg} / \mathrm{l}$ e de nitrogênio nitrato de 12,8mg/l, ambas superiores aos padrões de potabilidade. Embora, os valores referentes ao $\mathrm{pH}$ e à concentração de sulfatos, sólidos dissolvidos totais e cloretos estivessem abaixo dos limites especificados pela Portaria ${ }^{\circ} 1.469$, apresentavam-se elevados em relação aos demais pontos amostrados.

Os pontos amostrados nas áreas SPA e SPB compreendendo as Vilas Recanto Paraíso, Jardim do Russo e Jardim Manacá, todos situados a uma distância inferior a 500m do Aterro Sanitário Bandeirantes, apresentaram uma concentração de cádmio mais elevada em relação aos outros pontos de amostragem. Nesses pontos a 
concentração de mercúrio foi bastante elevada, quando comparada ao padrão de potabilidade especificado pela referida Portaria. Esses resultados obtidos indicam uma alteração da qualidade da água até uma distância de 500m do aterro.

\subsection{Plano de Amostragem}

A população de estudo, composta por crianças na faixa etária de 1 a 5 anos de idade incompletos, mostrou-se adequada aos métodos de avaliação e aos indicadores de saúde empregados nesta pesquisa, pelos seguintes fatores:

- Ter sido a faixa etária que apresentou maior prevalência de enfermidades diarréicas, segundo levantamento realizado na área de estudo (item 3.5);

- Apresentar maior susceptibilidade às condições ambientais investigadas pela pesquisa, por excluírem os possíveis lactantes;

- Ter sido adequada ao instrumento de aferição do peso adquirido pela pesquisa, com precisão de $200 \mathrm{~g}$. Este valor não poderia ser desconsiderado na mensuração do peso das crianças com idade inferior a um ano.

AZEVEDO (2003) investigando a exclusão sanitária em áreas destituídas de serviços de abastecimento de água e esgotamento sanitário em Belo Horizonte, MG, utilizou em seu estudo a mesma faixa etária. MORAES (1996) avaliou o impacto sobre a saúde das condições de saneamento em nove assentamentos humanos localizados na periferia de Salvador, Bahia. O autor considerou em seu estudo crianças menores de 5 anos de idade, para a avaliação da incidência de diarréia e do estado nutricional, e crianças de 5 a 14 anos de idade, para a avaliação da infecção por nematóides intestinais. 
O plano de amostragem desenvolvido, primeiramente, pelo estudo foi uma amostragem estratificada com alocação proporcional ao tamanho dos estratos. Isto é, ao número de residências contidas em cada área de exposição considerada. Com este plano, foi determinado para cada área de exposição o número de crianças a ser amostrado para que o valor da amostra de estudo (900 crianças) fosse alcançado (Tabela 24). Por esta metodologia, ter-se-ia um valor de amostra diferente para cada uma das três áreas de exposição.

Como, os mapas cadastrais, utilizados para a definição da metodologia de amostragem, não faziam distinção entre os imóveis residenciais e comerciais. Quadras consideradas como de ocupação residencial, dependendo da localização na área, eram de atividade exclusivamente comercial. Desta forma, houve a necessidade de adequação do plano amostral desenvolvida à realidade encontrada na área de estudo, como também, à viabilidade operacional da amostragem em campo.

A princípio, foram selecionadas seis entrevistadoras para o cumprimento do protocolo de pesquisa. Decidiu-se que duas entrevistadoras ficariam responsáveis por uma área de exposição, a fm de possibilitar a realização dos levantamentos dos dados de campo em dupla, devido à falta de segurança e à violência, características da área de estudo. As áreas de exposição consideradas foram distribuídas entre os membros da equipe, considerando a proximidade de residência de cada entrevistadora à área. As justificativas para a adoção deste critério foram: diminuição do deslocamento da entrevistadora com os equipamentos de aferição das medidas antropométricas (balança digital e régua antropométrica) e com blocos referentes aos protocolos de pesquisa; e a facilitação da adesão e da participação na pesquisa, pelo envolvimento de um membro conhecido da comunidade local. 
Dada às considerações expressas anteriores e a fim de haver uma distribuição equânime de atividades entre cada entrevistadora, decidiu-se distribuir de forma igualitária a amostra de estudo entre as três áreas de exposição pesquisada. Assim sendo, em cada área de estudo seriam amostradas 300 crianças e cada entrevistadora ficaria responsável pela execução do protocolo de pesquisa em 150 crianças.

A amostragem, nas áreas SPA e SPC, foi realizada por conglomerados (quadras), baseada no sorteio proporcional ao número de residências existentes em cada quadra. Um mapa com as quadras sorteadas e o número de residências a serem amostrados em cada quadra foi passado a cada entrevistadora para o cumprimento da metodologia de amostragem. Para a área de pesquisa SPB, a amostragem foi do tipo sistêmica, uma vez que, pelos dados obtidos da área, não foi possível conhecer a divisão da área em quadras residenciais. As entrevistadoras foram orientadas para amostrar uma residência a cada 14 casas. A Figura 34 apresenta as quadras sorteadas para efeito de amostragem. Na Figura 35 são apresentadas as quadras na área de estudo que tiveram pelo menos uma criança participando no estudo.

Pela análise das figuras, observa-se uma coerência relativamente grande entre a metodologia de amostragem proposta e a amostragem efetivamente realizada em campo. Havendo, portanto, o cumprimento por parte das entrevistadoras do plano amostral definido para a coleta de dados. Ressalta-se que as áreas referentes às Vilas Recanto dos Humildes e Recanto Paraíso, características da área de exposição SPB, por constituírem em áreas de ocupação irregular e não apresentarem, junto à Administração Regional de Perus, uma planta cadastral, não foram registradas na Figura 32. A amostragem nessas vilas foi do tipo sistêmica. 


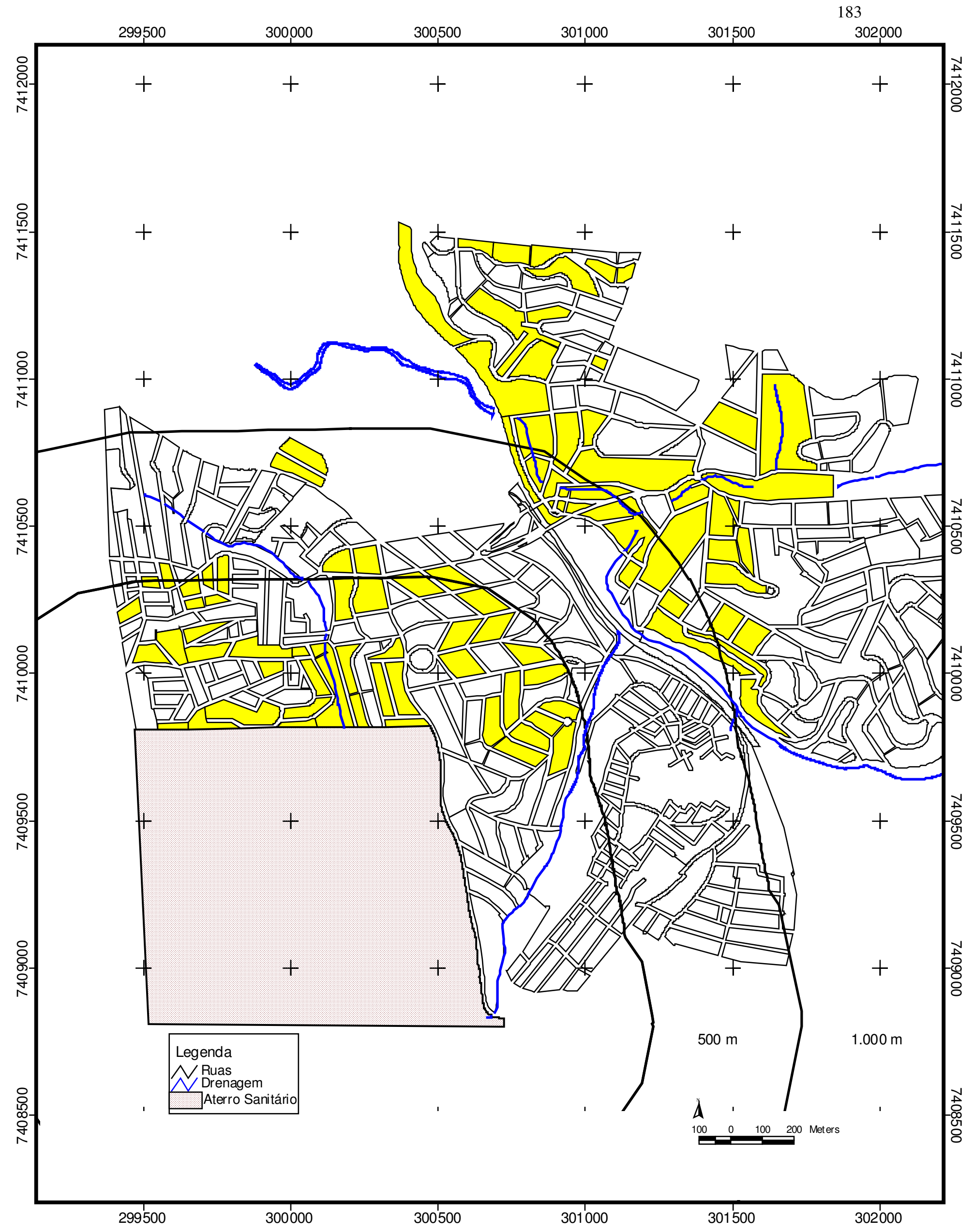

FIGURA 34 - Quadras sortea das para amostragem na área de estudo. 


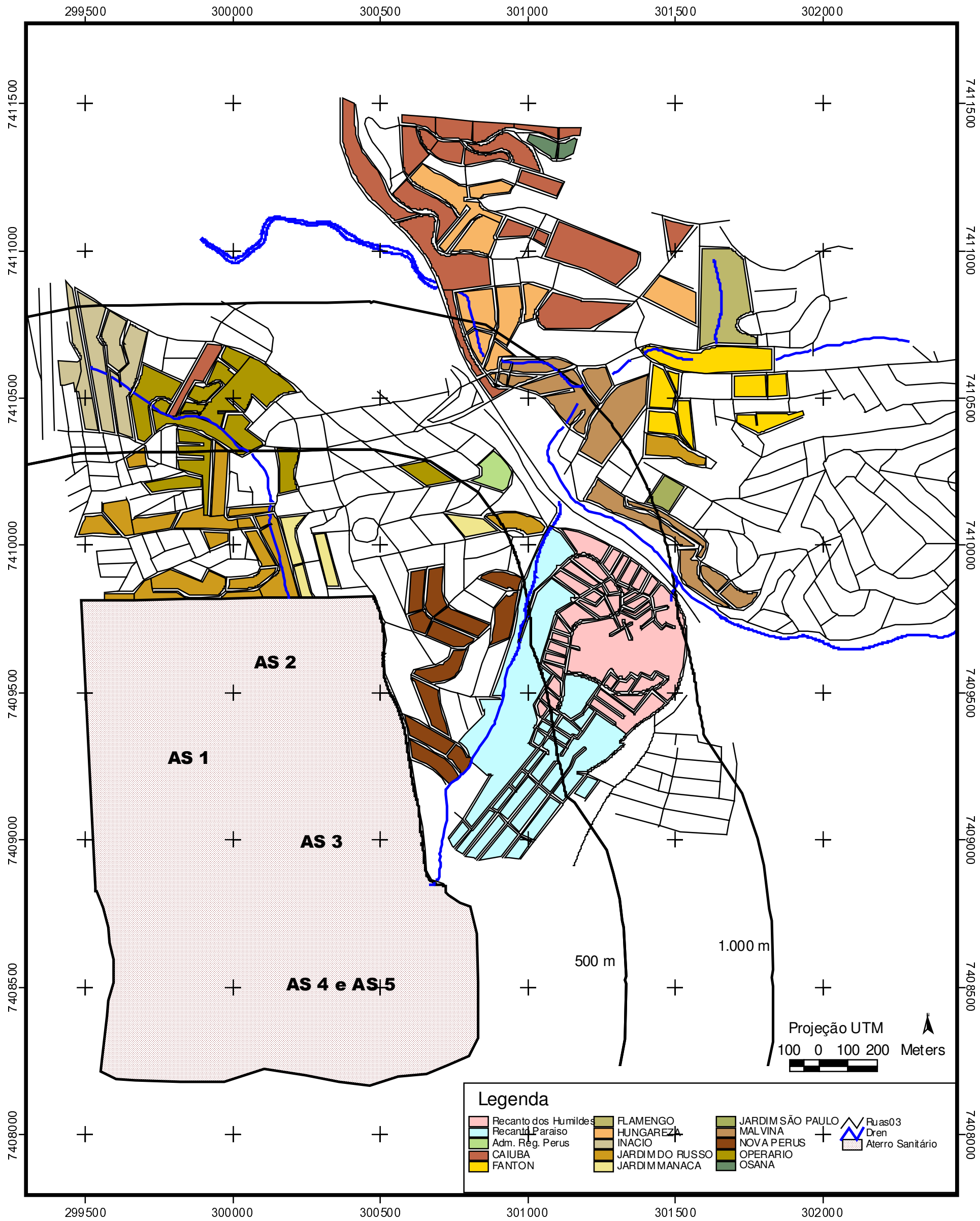

FIGURA 35 - Quadras amostradas na área de estudo. 
Para o cumprimento das faixas de exposição e do plano de amostragem em campo pelas entrevistadoras, foram definidos pontos e referências bastante conhecidos pela comunidade local, a fim de delimitar as três áreas de exposição. Contudo, pela observação da Figura 17, constata-se que pontos (crianças) considerados como pertencentes à área de exposição SPA, localizavam-se a uma distância superior a $500 \mathrm{~m}$ do aterro sanitário estando, portanto na faixa de exposição SPB. Da mesma forma, crianças pertencentes à área SPB residiam a uma distância inferior a $500 \mathrm{~m}$ do aterro sanitário. Estas constatações só foram possíveis pelos resultados obtidos pelo georreferenciamento, dado a amostra de estudo. Bem como, apontaram a necessidade do redirecionamento da análise estatística dos dados. $\mathrm{Na}$ Tabela 38 são apresentados os valores de amostras praticados em cada área de exposição, em função das metodologias de amostragem.

TABELA 38 - Valor da amostra obtido em função da metodologia de amostragem praticada

\begin{tabular}{c|c|c|c}
\hline \multirow{2}{*}{ Área } & \multicolumn{3}{|c}{ Metodologia de amostragem } \\
\cline { 2 - 4 } & Desenvolvida & Realizada & Verificada \\
\hline SPA & 393 & 302 & 389 \\
\hline SPB & 96 & 378 & 318 \\
\hline SPC & 411 & 292 & 265 \\
\hline Total & 900 & 972 & 972 \\
\hline
\end{tabular}


Na Tabela 38, os valores amostrais apresentados para a metodologia desenvolvida, referem-se aos valores determinados, inicialmente, pelo plano e metodologia de amostragem. $\mathrm{Na}$ amostragem realizada, são apresentados os valores referentes ao número total de crianças amostrado pelas entrevistadoras, responsáveis por cada área de exposição considerada. A amostragem verificada relaciona-se aos valores reais obtidos para a amostra em cada área de exposição considerada, após o georreferenciamento dos dados, indicando a importância da inclusão desse tipo de análise em estudos nos quais as condições de exposição são definidas por critérios geográficos.

\subsection{Indicadores Ambientais}

Ao se analisar os indicadores da qualidade ambiental das áreas de estudo, adotados pelo presente estudo - a ocorrência de vetores mecânicos e biológicos, observar - se pela análise das Figuras 18, 19 e 20, uma maior freqüência de ocorrência dos vetores quanto mais próxima a residência se situa do aterro sanitário.

As freqüências de ocorrência de moscas e baratas foram maiores na Vila Recanto Paraíso, cuja localização se encontra mais próxima da atual frente de operação do aterro sanitário, na área do sub-aterro AS-5. Contudo, quando comparadas as distribuições de ocorrência dos vetores na área de estudo, observa-se um gradiente decrescente das frequiências, a medida que se distancia a área do aterro sanitário. Estas observações feitas são comprovadas pelos resultados obtidos e apresentados na Tabela 30. Mesmo não tendo sido ajustadas as condições de exposição para os pontos (crianças) pertencentes às Vilas Recanto Paraíso, Inácio e 
Operário, a frequiência de ocorrência dos vetores na comparação das três áreas de estudo foi estatisticamente diferente, para os três vetores considerados.

Contudo, quando as áreas foram comparadas em relação ao período de aparecimento dos vetores, em relação às estações do ano, não houve diferenças estatísticas entre as áreas.

As amostras de monitorização da qualidade da água, coletadas na área de estudo, apresentaram em todos os pontos amostrados uma concentração de alumínio e bário bem acima dos limites estipulados pela Portaria ${ }^{\circ} 1.469$ do Ministério da Saúde.

Os pontos de amostragem da água situados nas áreas de exposição SPB e SPC (amostras: 1, 2, 3, 4, 5, 6 e 7 - Tabela 33), portanto, a uma distância mínima de 500m do aterro sanitário, não apresentaram alteração da qualidade da água, quando comparados aos limites preconizados pela referida Portaria. Os demais pontos situados a uma distância inferior a 500m do aterro sanitário, apresentaram, como discutido no item 5.1, alterações em relação a vários parâmetros de potabilidade da água, avaliados pelo presente estudo.

Pelos dados levantados no Protocolo de Pesquisa 1, 97,8\% das residências na área de estudo consumiam água proveniente da rede pública de abastecimento, apenas 2,2\% consumiam água de outras fontes. As alterações verificadas na qualidade da água consumida em residências situadas próximas ao aterro sanitário, podem estar ocorrendo devido às possíveis alterações da qualidade da água, verificada nos reservatórios domiciliares. Foi constatada a existência de reservatórios domiciliares em 73,0\% das casas na área de estudo. Desses, 96,2\% permaneciam cobertos. 


\subsection{Indicadores de saúde}

O indicador de saúde, eleito dentre os demais avaliados pelo presente trabalho, para fins da análise estatística multivariada e para a construção do modelo de regressão logística, foi a prevalência por enfermidades diarréicas, ocorridas na população de estudo, nas últimas 48h, quando da realização do inquérito domiciliar.

O indicador de saúde eleito tem sido o mais empregado nos estudos de avaliação do impacto das intervenções em saneamento sobre a saúde, devido à grande repercussão das doenças diarréicas na mortalidade infantil, principalmente, nos países em desenvolvimento (BRISCOE et al., 1986). Em 238 estudos, avaliados por HELLER (1995), sobre a associação entre as condições de saneamento e de saúde, verificou-se que em 105 estudos a morbidade por enfermidades diarréicas foi o indicador de saúde empregado.

AZEVEDO (2003) realizou uma análise comparativa entre vários indicadores de saúde mais comumente relatados na literatura em estudos de avaliação de impactos das medidas de saneamento, com o objetivo de avaliar os indicadores mais adequados para refletirem o efeito das intervenções em saneamento sobre a saúde. A autora investigou os seguintes indicadores: morbidade por diarréia, infecção por helmintos, desnutrição crônica, desnutrição aguda, déficit ponderal isolado, protozoose, helmintíases, infecção por enteropatógeneos de transmissão feco-oral e a presença de enteropatógenos associada a piócitos fecais. A autora comparou os indicadores analisados segundo cinco critérios:

1. -Intervenções em saneamento; 
2. Características epidemiológicas;

3. Inferências epidemiológicas;

4. Características de determinação;

5. Viabilidade operacional.

Segundo AZEVEDO (2003), o indicador morbidade por diarréia demonstrou ser sensível ao refletir as condições de saneamento avaliadas, ser de baixo custo e exequível na realidade de campo. Contudo, a autora ressalta que a morbidade por diarréia não é um indicador específico e de determinação objetiva.

A ocorrência de diarréia na população de estudo foi estatisticamente diferente nas três áreas de estudo avaliadas. Contudo, na análise de regressão logística, esse indicador não permaneceu no modelo final, indicando, portanto, que esse indicador não foi sensível para refletir as condições de exposição ambiental pesquisadas - a proximidade de residência ao aterro sanitário.

Pelos resultados obtidos do modelo de regressão logística, pode-se verificar que o indicador morbidade por diarréia foi mais eficiente para refletir as variáveis relacionadas às intervenções em abastecimento de água e as práticas de higiene doméstica e pessoal.

A análise dos resultados, apresentados na Tabela 37, demonstra que as variáveis explicativas para a morbidade de diarréia na população de estudo foram:

- Hábito de a criança lavar a mão após defecar $(0$ = não, $1=\operatorname{sim})$; valor da OR de 4,190 (1,226; 14,322);

- Separação do lixo em casa $(0=$ não, $1=\operatorname{sim})$; valor da OR de 0,347 $(0,155 ; 0,780)$ 
- Ocorrência de problemas de falta d'água na habitação $(0=$ não, $1=\operatorname{sim})$; valor da OR de $3,360(1,633 ; 6,915)$;

- Abastecimento de água indireto $(0=$ não, $1=\operatorname{sim})$; valor da OR de 4,498 $(1,020 ; 19,829)$

- Freqüência de limpeza da caixa d'água $(0=$ a cada seis meses, $1=$ uma vez por ano ou nunca foi lavada); valor da OR de $2,680(1,248 ; 5,754)$.

Os resultados obtidos demonstram que as crianças de uma habitação em que a caixa d'água é lavada uma vez por ano ou nunca é lavada têm o risco 2,68 vezes maior de terem diarréia do que o risco de uma criança em que a caixa d'água é lavada a cada seis meses. Com $95 \%$ de confiança, pode-se afirmar que este risco varia de 1,248 a 5,754 .

A interpretação dos resultados obtidos para todas as outras variáveis é feita da mesma forma. Os resultados obtidos apresentam coerência com as situações de exposição, com exceção para o hábito de a criança lavar as mãos após defecar. Os resultados obtidos indicam que a criança que tem o hábito de lavar as mãos após defecar, apresenta o risco de ter diarréia 4,190 vezes maior que a criança que não lava a mão após defecar, o que contraria o esperado. Contudo, tal resultado pode ser explicado pela faixa etária utilizada para a população de estudo, crianças entre 1 a 5 anos de idade incompletos. As crianças menores usam fraldas ou o hábito do asseio corporal após defecação é feito, geralmente, pelas mães ou pela pessoa responsável, e não pela própria criança.A resposta ao questionário da criança não lavar as mãos poderia ser explicada por esta colocação, o que representaria um fator de proteção à criança em relação às enfermidades diarréicas e não um fator de risco. 
Na análise da Figura 23, observa-se que não houve uma distribuição desigual dos episódios de diarréia ocorridos na população de estudo em relação às três áreas de estudo.

Em relação aos outros indicadores de saúde, avaliados por este estudo, observa-se na Figura 21 uma maior ocorrência de doenças respiratórias na população em geral, residente na área considerada como exposta, distante até $1000 \mathrm{~m}$ do aterro sanitário, quando comparada à área não - exposta, SPC. Observa-se, também, uma coerência entre a distribuição dos casos de doenças respiratórias nas áreas de estudo, com os relatos dos problemas ambientais associados ao aterro sanitário - odor e poeira.

A freqüência de distribuição das infecções parasitárias intestinais ocasionadas por protozoários nas áreas SPA e SPB foi maior que na área SPC (Figura 24). A prevalência por parasitoses ocasionadas por helmintos foi menor que a por protozoários em toda área de estudo, contudo ainda se observa um número maior de casos nas áreas SPA e SPB em relação à área SPC (Figura 25).

Da mesma forma, a ocorrência de casos de câncer e dengue foram maiores nas áreas distantes até $1000 \mathrm{~m}$ do aterro (SPA e SPB). Contudo, o desenho epidemiológico adotado no presente estudo, não se mostra adequado na avaliação desse tipo de exposição com a utilização desses indicadores de saúde.

\subsection{Aterro Sanitário Bandeirantes}

$\mathrm{Na}$ análise dos dados referentes à monitorização ambiental realizada no Aterro Sanitário Bandeirantes, CEPOLLINA (2003) afirma que o aqüífero freático, 
situado sob o Aterro Bandeirantes, trata-se de um reservatório de baixa vulnerabilidade relativa, devido a baixa dispersão dos contaminantes verificada na monitorização, e de baixa condutividade hidráulica, com alta inércia.

Os resultados da monitorização realizada indicam uma grande correlação entre os dados de condutividade e conteúdo de cloretos. Os contornos de condutividade (Apêndice 4) apontam uma grande célula de maior vulnerabilidade na área em torno do poço de monitorização PM3. Em relação à concentração de manganês solúvel, os índices mais elevados encontram-se na região entre os poços P6A e P5, com uma pequena queda em torno de P5 e uma expansão no sentido de PM6. A contagem total de bactérias mantém-se mais elevada em torno do poço P4, apresentando-se, também no poço PM2. A distribuição desse parâmetro não demonstra uma correlação consistente com a distribuição do Carbono Orgânico total e com outros parâmetros monitorizados. O mapa do $\mathrm{pH}$ indica a estabilidade dos fluxos.

Em uma Auditoria Ambiental realizada por técnicos do Tribunal de Contas do Município de São Paulo (MARTINELLI \& OLIVEIRA, 2003), no Aterro Sanitário Bandeirantes, foram identificadas as seguintes melhorias necessárias a serem implementadas no aterro:

- Recobrimento adequado das frentes de descarga;

- Isolamento do perímetro com cerca, nas áreas dos sub-aterros AS-1 e AS2

- Padronização dos procedimentos de carregamento e transporte de chorume; 
- Acompanhamento por parte da fiscalização do LIMPURB da monitorização ambiental do aterro;

- Melhoria no controle de pesagem e identificação dos resíduos sólidos.

Os auditores relatam que todos os itens levantados na auditoria foram cumpridos e melhorados, quanto à operação do Aterro bandeirantes, destacando-se apenas a necessidade de melhorar os procedimentos de identificação dos resíduos dispostos no aterro.

Esse trabalho comprova o cuidado operacional, praticado na operação do Aterro Sanitário Bandeirantes, observado durante todo o período de realização do presente estudo. 


\section{CAPÍTULO VI}

\section{CONCLUSÃO}

Por meio do estudo epidemiológico desenvolvido e pelos resultados obtidos da análise estatística utilizando a técnica de regressão logística, na qual se considerou como indicador de saúde a morbidade por enfermidades diarréicas, ocorridas em crianças na faixa etária de 1 a 5 anos de idade incompletos, pôde-se concluir que a disposição dos resíduos sólidos segundo a técnica do aterro sanitário, conforme as condições de operação praticadas no Aterro Bandeirantes da cidade de São Paulo, não representa risco para a saúde da população de estudo. A maior ou menor proximidade de residência ao aterro sanitário não afeta à saúde da população infantil, em idade de 1 a 5 anos, em relação às enfermidades diarréicas.

Contudo, em relação aos outros indicadores de saúde avaliados pelo presente estudo, há a necessidade de mensuração dos riscos envolvidos, para que sejam feitas as conclusões devidas a cada indicador de saúde pesquisado. A distribuição geográfica dos indicadores de saúde avaliados mostra uma diferença espacial das frequiências obtidas, indicando uma possível associação entre esses indicadores e as 
três áreas de exposição pesquisadas, definidas em função de faixas eqüidistantes do aterro sanitário a distâncias de 500m.

Pela análise dos indicadores da qualidade ambiental da área no entorno do aterro sanitário, avaliados pelo presente estudo, constatou-se uma alteração da qualidade ambiental maior na área de exposição situada até a distância de 500m do aterro e um gradiente decrescente para as áreas situadas às distâncias de 500 a 1000m e acima de $1000 \mathrm{~m}$ do aterro sanitário. Esses resultados demonstram ser adequada a adoção de critérios para o uso e ocupação do solo em áreas situadas no entorno de locais utilizados para a disposição final de resíduos sólidos, segundo a prática do aterro sanitário.

Pelos resultados obtidos, pode-se sugerir a importância da elaboração de leis municipais definindo envoltórias de proteção ambiental no entorno de áreas utilizadas pelas municipalidades para a disposição final dos resíduos sólidos urbanos. A ocupação humana até a distância de 500m do aterro, deveria ser evitada, por meio da proibição do parcelamento do solo em áreas no entorno do aterro até essa distância. Deveria ser criada uma segunda faixa de proteção, entre as distâncias de 500 e $1000 \mathrm{~m}$ do aterro, permitindo o uso do solo apenas para atividades industriais. A ocupação humana no entorno do aterro, deveria iniciar-se a partir da distância de 1000m do limite da área. Obviamente, que a criação de barreiras naturais de proteção, no limite das áreas de disposição final de resíduos sólidos, com uso de vegetação adequada, deveria ser estimulada.

Em relação à metodologia empregada no desenvolvimento do presente estudo, pôde-se concluir que ela se mostrou adequada para avaliar as associações pesquisadas, podendo ser empregada em estudos similares de avaliação de impactos 
sobre a saúde da disposição ambiental de resíduos sólidos. $\mathrm{O}$ uso do georeferenciamento dos dados obtidas nas pesquisas com este tipo de associação pesquisada no presente estudo, onde a localização geográfica significa um fator de risco a saúde, deve ser sempre que possível adotado.

O indicador morbidade por enfermidades diarréicas, demonstrou não ser específico para as associações pesquisadas. Desta forma, sugere-se que a pesquisa de indicadores mais específicos, que reflitam melhor a relação resíduos sólidos e saúde, deva ser estimulada, a fim de que estudos de avaliação de impactos da disposição ambiental de resíduos sólidos, possam englobar as vias e os domínios onde ocorrem as transmissões das doenças.

Da mesma forma, deve-se considerar o desenvolvimento de estudos epidemiológicos com outros tipos de desenhos, distintos do empregado no presente estudo, como os estudos longitudinal ou caso-controle, para a avaliação em longo prazo do efeito da exposição a outros fatores ambientais, como a emanação de gases, poeiras e contaminação da água superficial e subterrânea, sobre a saúde da população vizinha a áreas de disposição de resíduos.

Contudo, com o desenvolvimento do presente estudo, com os resultados obtidos e com o desenvolvimento da metodologia de pesquisa empregada, espera-se ter contribuído para um maior entendimento da relação resíduos sólidos, saúde pública e impactos ambientais. É esperado, também, que os resultados obtidos possam nortear a gestão de resíduos sólidos nas municipalidades brasileiras para a adoção da prática do aterro sanitário para a disposição de resíduos sólidos urbanos, com vistas à melhoria e à proteção da saúde pública. 
ANEXO A

Protocolo de Pesquisa 1 


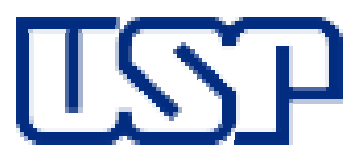

Universidade de Sã̃o Paulo

DEPARTAMENTO DE HIDRÁULICA E SANEAMENTO

DFAPESP FUNDAÇ̃̃O DE AMPARO À PESQUISA DO ESTADO DE SÃO PAULO

\section{AVALIAÇÃO DO RISCO PARA A SAÚDE DA \\ POPULAÇÃO VIZINHA ÀS ÁREAS DE DISPOSIÇÃO \\ FINAL DOS RESÍDUOS SÓLIDOS URBANOS}

\section{PROTOCOLO DE PESQUISA - 1}

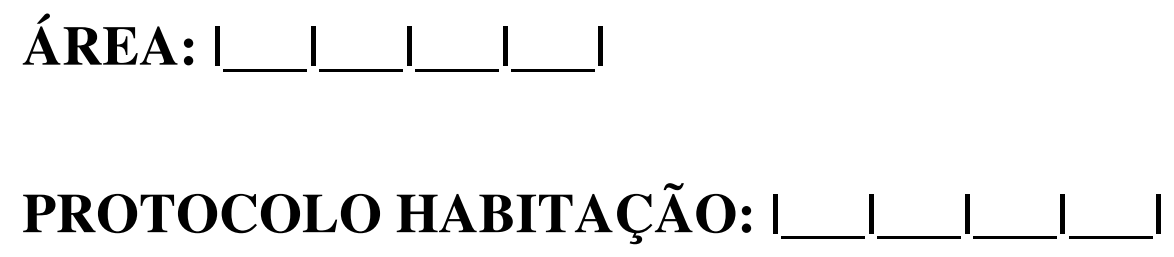

NÚMERO DE CRIANÇAS NO ESTUDO: ।__ I

ENTREVISTADOR: I___

Telefones para contato:

Pesquisadores: Mônica de Abreu Azevedo - (31) 38991738

Valdir Schalch - (16) 2739543 
Nome do entrevistador:

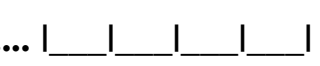

\section{PESQUISA EESC/USP/FAPESP}

\section{AVALIAÇÃO DAS CONDIÇÕES DE SAÚDE E SANEAMENTO \\ TERMO DE CONSENTIMENTO INFORMADO}

\section{ORIENTAÇÕES:}

Antes de preencher o termo de consentimento:

- Explique para o adulto, que o atender, que ele está sendo convidado para participar como sujeito da pesquisa que objetiva conhecer as condições de moradia, de saneamento e saúde da Vila onde ele reside.

- Explique que a participação na pesquisa consiste em responder a perguntas sobre a moradia, seus moradores e mostrar algumas instalações na casa e no lote e que as crianças, entre um e cinco anos incompletos, residentes na casa serão pesadas e medidas e terão suas fezes coletadas para exame parasitológico.

- Explique que a mãe ou a pessoa responsável pela criança entre um e cinco anos de idade será entrevistada semanalmente sobre os episódios de diarréia que a criança possa apresentar, durante o período de seis meses.

- Explique que as crianças, cujos exames parasitológicos forem positivos, serão encaminhadas ao posto de saúde do bairro para consulta médica e que o tratamento medicamentoso prescrito será fornecido com recursos da pesquisa.

- Explique que as informações fornecidas serão confidenciais e os dados referentes à identificação das pessoas não serão divulgadas com as informações obtidas com a pesquisa.

- Explique que a pessoa está livre para recusar em participar da pesquisa.

Depois de definida a pessoa a ser entrevistada, preencha os dados abaixo, leia em voz alta o TERMO DE CONSENTIMENTO, assine-o, date-o e colete a assinatura, em duas vias.

\section{DADOS SOBRE O ENTREVISTADO}

Nome:

Posição na família:

\section{ENDEREÇO DA HABITAÇÃO}

Rua:

Vila:

Telefone para contato: 


\section{TERMO DE CONSENTIMENTO INFORMADO}

Esta pesquisa da Universidade de São Paulo tem por objetivo analisar a situação de moradia, de saneamento e de saúde da população residente no bairro e, com isso, fornecer dados para a melhoria dessas condições.

Eu estou de acordo em participar da pesquisa, entendendo que essa participação significa responder a perguntas sobre a casa onde vivo e os seus moradores, e mostrar algumas instalações na casa e no lote. Estou ciente que as informações coletadas serão tratadas confidencialmente, sendo que eu nem a casa seremos identificadas durante a análise das informações e a divulgação dos resultados da pesquisa. O trabalho envolve a entrevista de cerca 1800 pessoas e minhas respostas serão combinadas com as dos outros participantes, para a análise dos totais.

Data: 1

Assinatura do participante

Assinatura do entrevistador

Telefones para contato:

Pesquisadores: Mônica de Abreu Azevedo (31) 38991738

Valdir Schalch (16) 2739543

\section{TERMO DE CONSENTIMENTO INFORMADO}

Esta pesquisa da Universidade de São Paulo tem por objetivo analisar a situação de moradia, de saneamento e de saúde da população residente no bairro e com isso fornecer dados para a melhoria dessas condições.

Eu estou de acordo em participar da pesquisa, entendendo que essa participação significa responder a perguntas sobre a casa onde vivo e os seus moradores, e mostrar algumas instalações na casa e no lote. Estou ciente que as informações coletadas serão tratadas confidencialmente, sendo que eu nem a casa seremos identificadas durante a análise das informações e a divulgação dos resultados da pesquisa. O trabalho envolve a entrevista de cerca 1800 pessoas e minhas respostas serão combinadas com as dos outros participantes, para a análise dos totais.

Data: 1

Assinatura do participante

Assinatura do entrevistador

Telefones para contato:

Pesquisadores: Mônica de Abreu Azevedo (31) 38991738

Valdir Schalch (16) 2739543 


\section{PESOUISA EESC/USP/FAPESP}

\section{AVALIAÇÃO DAS CONDIÇÕES DE SAÚDE E SANEAMENTO}

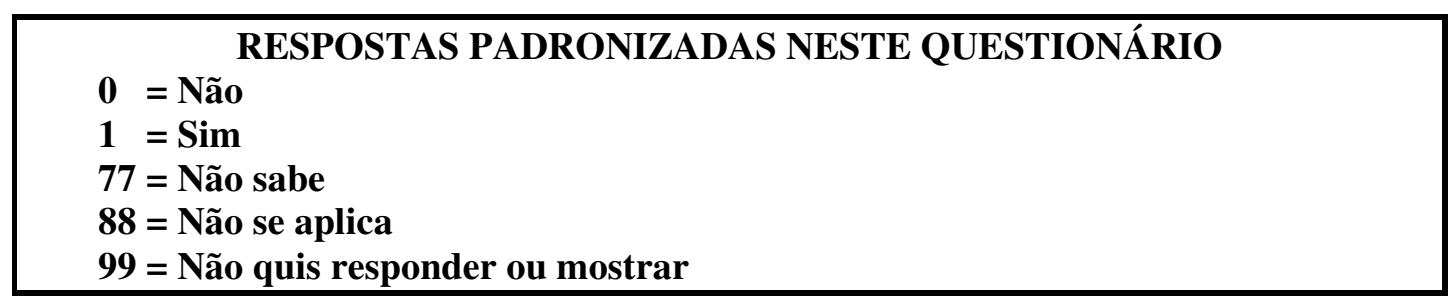

1. Nome do entrevistador:

2. Data da entrevista:

A - IDENTIFICAC̃̃̃O DA HABITAC̄̃̃O:

3. Número da Área: I

4. Endereço:

Vila:

Telefone para contato:

Nome pessoa para contato:

5. Código da vila:

6. Código da habitação: (não preencher)

7. Número de crianças de $\mathbf{1}$ a $\mathbf{4}$ anos (5 anos incompletos) que farão parte do estudo:

\section{B - INFORMACÕES SOBRE A PESSOA ENTREVISTADA:}

(preferência para a mãe biológica ou pessoa responsável pela criança de 1 a 4 anos de idade)

8. Nome:

9. Data de nascimento: $(\mathrm{dd} / \mathrm{mm} / \mathrm{aa})$

10. Idade: (anos)

$\begin{array}{lll}\text { 11. Sexo: } & \text { 1. Feminino } \quad \text { 2. Masculino } \quad 99 \text {. Não quis responder }\end{array}$

12. Estado Civil:

1. Solteira

2. Casada

3. União livre

4. Separada/divorciada

13. Local de nascimento (cidade):
CEP:

1.

2.

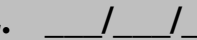

3.

4.

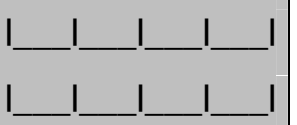

5.

6.

7. [

8.

9.

10. [

11. [

12. [

5. Viúva

77. Não sabe

99. Não quis responder

13. 
14. Estado onde nasceu: (nome ou sigla)

14. $\left[\begin{array}{ll}\text { 15. }[ & ]\end{array}\right.$

15. Há quanto tempo reside nesta habitação?

1. Menos de 1 ano

77. Não sabe

2. Mais de 1 ano

99. Não quis responder

16. Tempo de residência na habitação:
a. Anos ou
b. Meses ou
c. Dias

17. $O$ (a) senhor(a) sempre morou nesta casa?
$0 . \quad$ Não
77. Não sabe
1. $\operatorname{Sim}$
99. Não quis responder

SE A RESPOSTA À PERGUNTA ANTERIOR FOR NÃO, PERGUNTE:

18. Onde o(a) senhor(a) morava antes?

1. Mesma vila

3. Outro bairro

2. Outra vila do bairro

4. Outra cidade

5. Outro estado

77. Não sabe

88. Não se aplica (quando a resposta à pergunta anterior for $\underline{\mathbf{1}}$ ou $\underline{\mathbf{9 9}}$ )

99. Não quis responder

19. Até que série o(a) senhor(a) estudou?

0 . Não sabe ler nem escrever

1. Primário incompleto ou não completou a $4^{\mathrm{a}}$ série do primeiro grau

2. Primário completo ou completou a $4^{\mathrm{a}}$ série do primeiro grau

3. Ginásio incompleto ou estudou entre a $5^{\mathrm{a}}$ e $8^{\mathrm{a}}$ série do primeiro grau

4. Ginásio completo ou completou a $8^{\mathrm{a}}$ serie do primeiro grau

5. $2^{\circ}$ grau incompleto

6. $2^{\circ}$ grau completo

7. Superior incompleto

8. Superior completo

99. Não quis responder

20. Número de anos de estudo completos, sem considerar repetência:

\section{C - COMPOSIĊÃO FAMILIAR:}

21. Quantas crianças menores de 1 ano que vivem na casa?

22. Quantas crianças de 1 a 4 anos de idade vivem na casa?

23. Quantas crianças entre 5 e 14 anos vivem na casa?

24. Qual o número de adultos (maior de 14 anos completos) que vivem na casa?

18. [ ]

16. a. [
b. [ ]
c. [ ]
17. [ ]

19. $[\quad]$

20. [ ]

21. $[\quad]$

22. [ ]

23. [ ]

24. $[\quad]$ 
25. Número de crianças de 1 a 4 anos de idade (5 anos incompletos) que farão parte do estudo:

26. Composição familiar:

\begin{tabular}{|c|c|c|c|c|c|c|c|}
\hline No. & Primeiro Nome & $\begin{array}{c}\text { Data } \\
\text { Nascimento } \\
\text { (dd/mm/aa) }\end{array}$ & Idade & \begin{tabular}{|c|} 
Sexo \\
1-Fem \\
2-Masc
\end{tabular} & $\begin{array}{c}\text { Grau de } \\
\text { parentesco } \\
\text { (com a pessoa } \\
\text { entrevistada) }\end{array}$ & \begin{tabular}{|c|} 
Tipo de \\
permanên- \\
cia \\
$(\mathrm{C}, \mathrm{D}, \mathrm{CD})$
\end{tabular} & $\begin{array}{c}\text { Tempo de } \\
\text { permanên- } \\
\text { cia } \\
(1,2)\end{array}$ \\
\hline \multicolumn{8}{|l|}{1.} \\
\hline \multicolumn{8}{|l|}{2.} \\
\hline \multicolumn{8}{|l|}{3.} \\
\hline \multicolumn{8}{|l|}{4.} \\
\hline \multicolumn{8}{|l|}{5.} \\
\hline \multicolumn{8}{|l|}{6.} \\
\hline \multicolumn{8}{|l|}{7.} \\
\hline \multicolumn{8}{|l|}{8.} \\
\hline \multicolumn{8}{|l|}{9.} \\
\hline \multicolumn{8}{|l|}{10.} \\
\hline \multicolumn{8}{|l|}{11.} \\
\hline \multicolumn{8}{|l|}{12.} \\
\hline \multicolumn{8}{|l|}{13.} \\
\hline \multicolumn{8}{|l|}{14.} \\
\hline \multicolumn{8}{|l|}{15.} \\
\hline \multicolumn{8}{|l|}{16.} \\
\hline \multicolumn{8}{|l|}{17.} \\
\hline \multicolumn{8}{|l|}{18.} \\
\hline \multicolumn{8}{|l|}{19.} \\
\hline 20. & & & & & & & \\
\hline
\end{tabular}

Grau de parentesco ou relação com a pessoa entrevistada: 1: marido/companheiro; 2: filho/a; 3: mãe/pai; 4: irmão/a; 5: sogro/a; 6: genro/nora; 7: cunhado/a; 8: neto/a; 9: enteado/a; 11: tio/a; 12: empregada doméstica; 13: filho/a empregada.

Tipo de permanência: $C$ : come; D: dorme; CD: come e dorme na casa.

Tempo de permanência: 1: mora no domicílio há menos de 6 meses; 2: mora no domicílio há mais de 6 meses.

\section{D - DADOS SOCIOECONÔMICOS:}

\section{Qual é a renda familiar mensal?}

1. Menos de 1 salário mínimo

2. Maior ou igual a 1 e menor que 2 salários mínimos

3. Maior ou igual a 2 e menor que 3 salários mínimos

4. Maior ou igual a 3 e menor que 5 salários mínimos

5. Maior ou igual a 5 e menor que 10 salários mínimos

6. Maior ou igual a 10 salários mínimos

77. Não sabe

99. Não quis responder

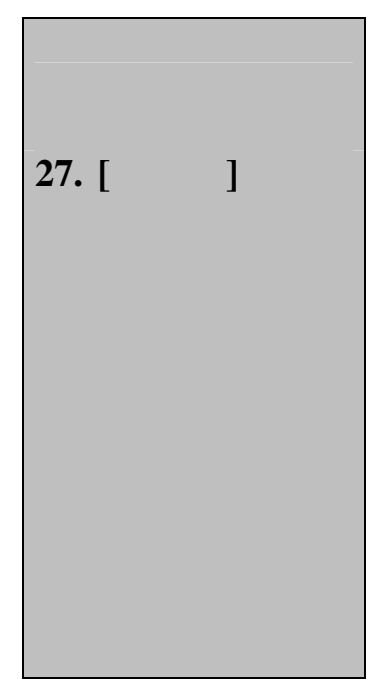


28. A residência é:

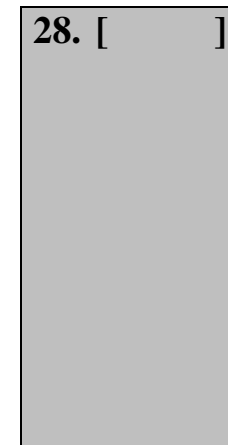

0. Própria (quitada, sem ônus)

1. Alugada

2. Sublocada

3. Cedida

4. Hipotecada (própria, com ônus)

77. Não sabe

99. Não quis responder

29. A família possui geladeira?

29. [ ]
0. Não
77. Não sabe
1. Sim
99. Não quis responder

30. A família possui televisão?
0. Não
77. Não sabe
1. Sim
99. Não quis responder

31. Entre os membros da família, quem é o responsável principal pelo sustento familiar? (Especificar)

31. $[\quad]$

(não preencher)

32. Entre os membros da família, quem é o segundo responsável pelo sustento familiar? (Especificar)

32. [ (não preencher)

33. Qual é a relação com o trabalho do responsável principal pelo sustento familiar?

1. Patrão/patroa (empregador(a))

2. Trabalho assalariado com carteira assinada

3. Trabalho assalariado sem carteira assinada

4. Trabalha por conta própria

5. Funcionário(a) público(a)

6. Aposentado(a)

7. Em licença temporária

8. Trabalho eventual

9. Desempregado(a)

77. Não sabe 99. Não quis responder

\section{E - CONDIĈ̃̃ES DA HABITAÇÃO E ESGOTAMENTO SANITÁRIO:}

34. Há quanto tempo a família reside na casa?
a. Anos ou
b. Meses ou
c. Dias

34.

a.[ ]

b. [ ]

c. [ ] 
35. A família sempre residiu nesta casa?
0. Não
77. Não sabe
1. Sim
99. Não quis responder

36. Onde a família residia antes?

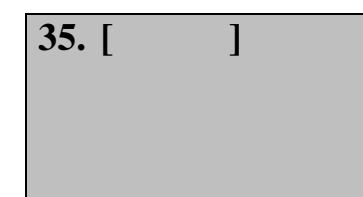

36. $[\quad]$

1. Mesma vila

2. Outra vila do mesmo bairro

3. Outro bairro

4. Outra cidade

5. Outro estado

77. Não sabe

88. Não se aplica

99. Não quis responder

37. A casa se localiza em:

1. Em loteamento regular

2. Em área de ocupação

3. Em área de ocupação em processo de legalização

99. 77. Não sabe $\quad$ 88. Não se aplica $\quad 99$. Não quis responder

38. Qual é o tipo de habitação?

38. $[\quad]$
1. Casa
3. Barraco
2. Apartamento
4. Quarto
77. Não sabe
99. Não quis responder

39. Quantos cômodos possui a casa? (excluir banheiro e varanda)

40. A casa possui:

0. Não possui nenhum tipo de banheiro (vá para a pergunta 47)

1. Um banheiro dentro da casa

2. Mais de um banheiro dentro da casa

3. Um banheiro fora da casa

4. Latrina (casinha) fora da casa (vá para a pergunta 42)

77. Não sabe 99. Não quis responder

41. O banheiro possui as seguintes características:

1. Vaso sanitário com descarga de água (0. Não; 1. Sim; 77. Não sabe; 99. Não quis responder ou mostrar)

2. Vaso sanitário sem descarga de água (0. Não; 1. Sim; 77. Não sabe; 99. Não quis responder ou mostrar)

3. Pia (0. Não; 1. Sim; 77. Não sabe; 99. Não quis responder ou mostrar)

4. Chuveiro (0. Não; 1. Sim; 77. Não sabe; 99. Não quis responder ou mostrar)

PERGUNTAR SOMENTE SE A RESPOSTA DA PERGUNTA $\underline{40}$ FOR A OPÇÃO $\underline{4}$

42. A latrina é do tipo?

42. [

39. $\left[\begin{array}{ll}\text { 40. }[ & ]\end{array}\right.$

41.

41.1. [

]

41.2. [

]

41.3. $[$ ]

41.4. $[$ ]

1. Casinha com vaso sanitário sem descarga de água com tampa 
2. Casinha com vaso sanitário sem descarga de água sem tampa

3. Casinha com buraco para defecar com tampa

4. Casinha com buraco para defecar sem tampa

77. Não sabe

99. Não quis responder ou mostrar

43. Existe separação entre o esgoto do vaso sanitário e do restante da casa (água de pia, chuveiro)?
0. Não (vá para a pergunta 46)
77. Não sabe
1. $\operatorname{Sim}$
99. Não quis responder

\section{Qual o destino dado aos dejetos (fezes e urina) de sua habitação?}

1. Rede pública coletora de esgoto

2. Rede de drenagem de água pluvial (boca de lobo/bueiro da rua)

3. Vala a céu aberto na rua

4. Escoa a céu aberto no terreno

5. Fossa séptica seguida de poço de infiltração ou sumidouro

6. Fossa séptica com lançamento na rede de drenagem pluvial

7. Fossa séptica com lançamento na rua ou no terreno

8. Lançado direto no córrego ou riacho próximo

9. Buraco escavado no solo

77. Não sabe

99. Não quis responder ou mostrar

45. Qual é o destino dado as águas servidas (pia e chuveiro) de sua habitação?

1. Rede pública coletora de esgoto

2. Rede de drenagem de água pluvial (boca de lobo/bueiro da rua)

3. Vala a céu aberto na rua

4. Escoa a céu aberto no terreno

5. Fossa séptica seguida de poço de infiltração ou sumidouro

6. Fossa séptica com lançamento na rede de drenagem pluvial

7. Fossa séptica com lançamento na rua ou no terreno

8. Lançado direto no córrego ou riacho próximo

9. Buraco escavado no solo

77. Não sabe

99. Não quis responder ou mostrar

46. Onde o esgoto da casa é lançado?

46. $[\quad]$

1. Rede pública coletora de esgoto

2. Rede de drenagem de água pluvial (boca de lobo/bueiro da rua)

3. Vala a céu aberto na rua

4. Escoa a céu aberto no terreno

5. Fossa séptica seguida de poço de infiltração ou sumidouro

45. $[\quad]$
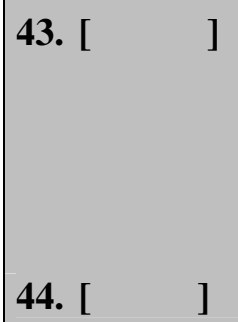
6. Fossa séptica com lançamento na rede de drenagem pluvial

7. Fossa séptica com lançamento na rua ou no terreno

8. Lançado direto no córrego ou riacho próximo

9. Buraco escavado no solo

77. Não sabe

99. Não quis responder ou mostrar

\section{PERGUNTAR SOMENTE SE A RESPOSTA DA QUESTÃO $\underline{40}$ TIVER SIDO NÃO}

47. Onde as pessoas que residem na casa fazem as suas necessidades?

1. No próprio terreno da casa

2. Usam um recipiente e jogam fora no terreno da casa

3. Usam um recipiente e jogam fora em terreno baldio próximo da casa

4. Usam um recipiente e dispõem para a coleta de lixo

5. Usam banheiro público

77. Não sabe

99. Não quis responder

48. É comum a ocorrência de entupimento na rede de esgoto da rua?
0. Não
77. Não sabe
1. Sim
99. Não quis responder

49. A casa possui cozinha independente?
0. Não
77. Não sabe
1. Sim
99. Não quis responder

50. A cozinha possui instalação de água (pia)?

47. $[\quad]$
0. Não
77. Não sabe
1. Sim
88. Não se aplica
99. Não quis responder

51. Quantas torneiras têm na habitação?

52. Há torneiras externas à habitação que são usadas pela família?
0. Não
77. Não sabe
1. Sim
99. Não quis responder

53. Qual o tipo de material e revestimento das paredes da habitação?

53. $[\quad]$

(observar, em caso de dúvida, perguntar)

1. Tijolo ou bloco com reboco

2. Tijolo ou bloco sem reboco

2. Pré-moldado em concreto

3. Taipa

4. Reaproveitamento de madeira, lata ou papelão

5. Madeira

99. Não quis responder ou mostrar 
54. Qual o tipo de piso da habitação? (observar, em caso de dúvida, perguntar)

1. Terra batida

2. Cimentado

3. Madeira sobre palafitas

4. Cerâmica

5. Madeira (taco ou tabuado)

6. Carpete

7. Pedra mármore ou similar

8. Outro. Especificar:

77. Não sabe

99. Não quis responder ou mostrar

\section{Qual o tipo de piso do banheiro?}

1. Terra batida

2. Cimentado

3. Madeira

4. Cerâmica

5. Pedra mármore ou similar

6. Outro. Especificar:

77. Não sabe

99. Não quis responder ou mostrar

56. Qual é a cobertura da habitação? (observar, em caso de dúvida, perguntar)

1. Laje de concreto ou pré-moldada e telhado em telha de cerâmica, amianto ou zinco

2. Laje de concreto ou pré-moldada sem telhado

3. Telhado de cerâmica sem laje

4. Telhado de amianto sem laje

5. Telhado de zinco sem laje

6. Telhado em madeirite ou compensado

7. Taipa ou palha

8. Lona ou plástico

99. Não quis responder ou mostrar

\section{O abastecimento de água da casa é do tipo:}

57. [ ]

0. A casa não é ligada a rede pública de abastecimento de água

1. Direto (sem reservatório superior ou caixa d'água)

2. Indireto (com reservatório superior ou caixa d'água)

3. Misto (direto e indireto)

77. Não sabe

99. Não quis responder ou mostrar 
58. Na habitação, existe caixa d'água (reservatório de água superior)?

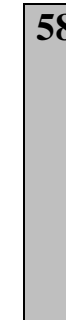

59. Como é a caixa d'água de sua habitação?

59. $[$ ]

1. Cimento amianto ou concreto

2. Fibra de vidro

3. Tonel

4. Outro material

77. Não sabe

99. Não quis responder ou mostrar

60. A caixa d'água é coberta?

60. $[\quad]$
0. Não
77. Não sabe
1. Sim
99. Não quis responder

61. De quanto em quanto tempo a caixa d'água costuma ser esvaziada e lavada?

0. Nunca foi lavada

1. Pelo menos uma vez a cada três meses

2. Pelo menos uma vez a cada seis meses

3. Pelo menos uma vez por ano

4. Demora mais que um ano para ser lavada

77. Não sabe

99. Não quis responder

RESPONDER AS PERGUNTAS 62 A 65 SOMENTE SE A RESPOSTA DA QUESTÃO 58 TIVER SIDO $\underline{\text { NÃO }}$

62. Como é reservada a água em sua habitação?

62. $[\quad]$

0. Não reserva ou guarda água

1. Em caixa de cimento amianto, fibra de vidro ou concreto

2. Em tonel

3. Panela ou balde

77. Não sabe 99. Não quis responder

63. O recipiente onde é armazenada a água é tampado?

63. $[\quad]$
0. Não
88. Não se aplica
1. Sim
99. Não quis responder

77. Não sabe

64. De quanto em quanto tempo o recipiente de armazenamento de água costuma ser esvaziado e lavado? 
0. Nunca foi lavado

1. Pelo menos uma vez a cada três meses

2. Pelo menos uma vez a cada seis meses

3. Pelo menos uma vez por ano

4. Demora mais que um ano para ser lavado

77. Não sabe 88. Não se aplica 99. Não quis responder

65. Como a água é retirada do recipiente de armazenamento?

1. Por torneira

2. Por mangueira

3. Por balde, lata ou vasilha

4. Outro. Especificar:

77. Não sabe $\quad$ 88. Não se aplica

99. Não quis responder

\section{F - ABASTECIMENTO DE ÁGUA:}

66. De onde vem a água consumida na habitação?

1. Rede pública de abastecimento de água

2. Poço ou cisterna (vá para a pergunta 70)

3. Caminhão pipa (vá para a pergunta 74)

4. Torneira pública ou chafariz

5. Caixa d'água comunitária

6. Mais de uma das opções anteriores. Quais? $\left(n^{\circ}\right.$.)

7. Outro. Especificar:

77. Não sabe 99. Não quis responder

67. Na sua casa há problemas de falta d'água?
0. Não
77. Não sabe
1. Sim
99. Não quis responder

\section{A água chega em sua casa com qual freqüência?}

0 . Nunca chega

1. O abastecimento é constante

2. Todos os dias da semana

3. Em mais de três dias da semana

4. No máximo em três dias da semana

5. Somente em um dia da semana

6. De 15 em 15 dias

7. Pelo menos uma vez por mês

77. Não sabe

88. Não se aplica

99. Não quis responder

65.

65. $[\quad]$

66. $[\quad]$

66.6.

66.7.

67. [

]

68. [

] 
69. A água consumida em sua casa apresenta algum aspecto desagradável (cor barrenta, cheiro, gosto)? - Se o cheiro elou gosto forem de cloro, preencha 0
0. Não
77. Não sabe
1. Sim
99. Não quis responder

\section{RESPONDER AS PERGUNTAS $\underline{70}$ A $\underline{73}$ SOMENTE SE EXISTIR POCO NA HABITACÃO}

70. Como é a parte superior do poço?

1. Coberta com laje e tampa de concreto

3. Coberta com madeira

2. Coberta com laje e tampa metálica

4. Descoberta

77. Não sabe

99. Não quis responder ou mostrar

71. Como a água é retirada do poço?

71. $[\quad]$

1. Com bomba elétrica

2. Com bomba manual

3. Com balde e corda

4. Por outro meio. Especificar

a.

77. Não sabe

99. Não quis responder ou mostrar

72. É utilizado algum tipo de clorador dentro do poço?
0. Não
77. Não sabe
1. Sim
99. Não quis responder

73. A água do poço apresenta algum aspecto desagradável (cor barrenta, cheiro, gosto)? - Se o cheiro elou gosto forem de cloro, preencha $O$
0. Não
77. Não sabe
1. Sim
99. Não quis responder

RESPONDER AS PERGUNTAS $\underline{74}$ A $\underline{76}$ SOMENTE SE HOUVER ABASTECIMENTO DE ÁGUA NA HABITAÇÃO POR CAMINHÃO PIPA

74. Você conhece a procedência da água distribuída pelo caminhão pipa?
0. Não
1. Sim
99. Não quis responder

75. Qual é a freqüência com a qual o caminhão pipa passa em sua casa?

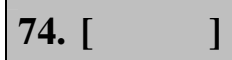

72. $[\quad]$

1. Todos os dias da semana (seg. ter. qua. quin. sex. sab.dom)

2. Todos os dias úteis (seg. ter. qua. quin. sex)

3. Três vezes por semana

4. Duas vezes por semana

5. Uma vez por semana

6. Demora mais de 1 semana para passar

77. Não sabe

99. Não quis responder

75. $[\quad]$ 
76. A água do caminhão pipa apresenta algum aspecto desagradável (cor barrenta, cheiro, gosto)? - Se o cheiro elou gosto forem de cloro, preencha $\underline{\boldsymbol{0}}$
0. Não
77. Não sabe
1. Sim
99. Não quis responder

77. Que cuidados vocês têm com a água de beber?

77. $[\quad]$

0. É consumida sem nenhum cuidado adicional (direto da torneira ou poço)

1. Filtrada

2. Fervida

3. Misturada com cloro ou água sanitária

4. Misturada com cloro ou água sanitária e depois filtrada

5. Só é consumida água mineral engarrafada

77. Não sabe

99. Não quis responder

\section{G - RESÍDUOS SÓLIDOS DOMICILIARES:}

78. Em sua casa, há o costume de acondicionar, em separado, o lixo gerado na cozinha (resto do preparo de alimentos e de comida), do lixo do banheiro e dos materiais recicláveis (plástico, papel, papelão, lata, vidro, etc)?
0. Não
77. Não sabe
1. Sim
99. Não quis responder

79. Como o lixo de cozinha (resto de preparo de alimentos e de comida) é acondicionado?

0. Não é acondicionado

1. Em saco ou sacola de plástico

2. Em recipiente rígido de plástico ou metal

3. Em saco de papel ou caixa de papelão

4. Outro. Especificar:

77. Não sabe

99. Não quis responder

80. Qual é o destino dado ao lixo de cozinha?

a

1. Colocado acondicionado na rua para a coleta pela Prefeitura

2. Colocado em caçamba estacionária para a coleta da Prefeitura

3. Jogado no quintal da casa

4. Jogado em terreno baldio

5. Despejado diretamente na rua/viela

6. Utilizado na alimentação de animais

7. Enterrado

8. Queimado

77. Não sabe

99. Não quis responder

80. $[\quad]$ 
81. Como é acondicionado o lixo do banheiro (papel higiênico usado)

0. Jogado direto no vaso sanitário ou latrina (saltar a questão82)

1. Em saco ou sacola de plástico que fica dentro do banheiro

2. Em recipiente rígido de plástico ou metal com tampa

3. Em recipiente rígido de plástico ou metal sem tampa

4. Em saco de papel ou caixa de papelão

5. Outro. Especificar:

77. Não sabe

99. Não quis responder

\section{Qual o destino dado ao lixo do banheiro?}

1. Colocado acondicionado na rua para a coleta da Prefeitura

2. Colocado em caçamba estacionária para a coleta da Prefeitura

3. Jogado no quintal da casa

4. Jogado em terreno baldio

5. Despejado diretamente na rua/viela

6. Enterrado

7. Queimado

8. Outro. Especificar:

77. Não sabe 99. Não quis responder

83. O lixo da casa, em geral, é acondicionado em:

0 . Não é acondicionado

1. Em saco ou sacola de plástico

2. Em recipiente rígido de plástico ou metal

3. Em saco de papel ou caixa de papelão

4. Outro. Especificar:

77. Não sabe

99. Não quis responder

84. O recipiente (saco, sacola, caixa ou lata) utilizado para colocar o lixo, quando permanece dentro da casa, fica constantemente:

1. Tampado ou fechado

2. Aberto com o lixo exposto

77. Não sabe

99. Não quis responder

85. Qual o destino dado ao lixo produzido na casa?

0. Não é acondicionado

1. Colocado acondicionado na rua para a coleta da Prefeitura

2. Colocado em caçamba estacionária para coleta da Prefeitura

3. Jogado no quintal da casa

4. Jogado em terreno baldio

85. [ ]

82. [ ]

a.

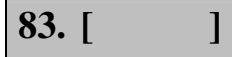

a.

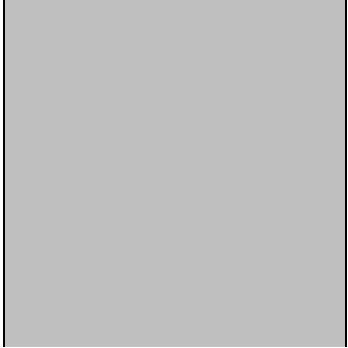


5. Despejado diretamente na rua/viela

6. Enterrado

7. Queimado

77. Não sabe

99. Não quis responder

86. Qual o destino dado às fezes das fraldas da criança?

1. Jogado no vaso sanitário ou latrina

2. Disposta junto com o lixo da casa

3. Jogada no tanque ou pia (esgoto)

4. Jogada no terreno

5. Outro. Especificar:

77. Não sabe

99. Não quis responder

87. As fraldas descartáveis usadas pela criança são dispostas junto com o lixo da casa?
0. Não
77. Não sabe
1. Sim
88. Não se aplica

99. Não quis responder

88. Com que freqüência ocorre a coleta de lixo?

88.

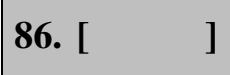

a.

0. Não há coleta de lixo

1. Diária

2. Três vezes por semana

3. Duas vezes por semana

4. Uma vez por semana

5. A cada quinze dias

6. De vez em quanto. Especificar:

77. Não sabe

99. Não quis responder

89. Em sua opinião, a coleta de lixo em sua rua é satisfatória?
0. Não
77. Não sabe
1. Sim
88. Não se aplica
99. Não quis responder

90. Sem considerar o Aterro Sanitário de Lixo da Prefeitura, existe perto de sua habitação algum depósito particular de material reciclado (ferro velho) ou lixo amontoado em terrenos baldios, encostas ou córrego?
0. Não
77. Não sabe
1. Sim
99. Não quis responder

91. Em sua opinião, como a senhora acha que se encontra a limpeza desta parte do bairro?
1. Ótima
2. Boa
3. Regular
4. Péssima
77. Não sabe
99. Não quis responder

90. [ ] 
92. Em sua opinião, sua residência é afetada por problemas relacionados ao Aterro Sanitário de Lixo da Prefeitura?
0. Não
77. Não sabe
1. Sim
99. Não quis responder

SE A RESPOSTA ANTERIOR FOR SIM, PERGUNTAR:

93. Qual o tipo de problema que afeta sua habitação? (marcar todas as opções)

1. Mau cheiro (0. Não ou 1. Sim)

93.

2. Poeira (0. Não ou 1. Sim)

93.1. [

3. Fumaça pela queima de lixo (0. Não ou 1. Sim)

4. Chorume escorrendo perto da habitação (0. Não ou 1. Sim)

93.3. [ ]

5. Aumento da população de insetos (mosca, mosquito e barata) (0. Não ou 1. Sim)

6. Aumento da população de ratos (0. Não ou 1. Sim).

93.4. [ ]

7. Barulho pelo tráfego de caminhões de lixo (0. Não ou 1. Sim)

8. Doenças na família (0. Não ou 1. Sim). Quais?

94. Em sua opinião, quais são os piores problemas associados a seu bairro? (citar no máximo cinco opções)

1. Abastecimento de água inadequado

2. Falta de rede de esgoto

3. Transporte urbano inadequado

4. Urbanização inadequada

5. Escolas e creches insuficientes

6. Segurança pública

7. Coleta de lixo e limpeza urbana inadequadas

8. Postos de saúde insuficientes

9. Atendimento médico inadequado

10. Proximidade do aterro sanitário

11. Iluminação pública inadequada

77. Não sabe

99. Não quis responder

\section{H - DRENAGEM URBANA:}

95. Quando chove, a água que escoa pela rua ou pelo lote vizinho costuma invadir em grande quantidade o lote desta habitação?

1. Nunca

2. Mais de cinco vezes por ano

3. Menos de cinco vezes por ano
77. Não sabe

99. Não quis responder

93.8. [ ]
(codificar)

94. [ ]

$\begin{array}{ll}{[} & ] \\ {[} & ] \\ {[} & ] \\ {[} & ]\end{array}$

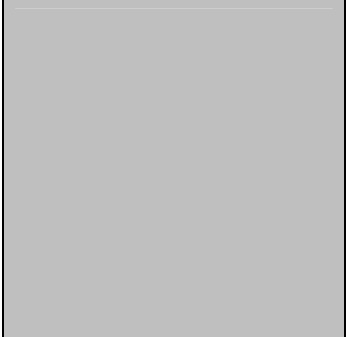


96. Existem partes baixas no lote, onde é comum o empoçamento de água?
0. Não
77. Não sabe
1. Sim
99. Não quis responder

97. Quando chove muito, o que acontece com sua habitação?

0. Não acontece nada

1. Alaga toda a casa

2. Alaga uma parte da casa

3. Há risco de desabamento

4. Há contaminação da água de consumo

5. Outro. Especificar:

77. Não sabe

99. Não quis responder

98. Há problemas de infiltração de água na habitação? (paredes ou teto úmidos; existência de mofo ou bolor no teto ou paredes)
0. Não
77. Não sabe
1. Sim
99. Não quis responder

\section{I - VETORES:}

99. Qual a freqüência que é observada mosca em sua casa?

0 . Nunca aparece

1. Todo dia

2. Pelo menos 1 vez por semana

3. Pelo menos 1 vez por mês

4. Pelo menos 1 vez a cada 3 meses

5. Pelo menos 1 vez a cada 6 meses

6. Pelo menos 1 vez por ano

7. Menos de 1 vez por ano (demora mais de 1 ano para aparecer)

77. Não sabe

99. Não quis responder

100. Em quais meses do ano são observadas moscas em sua casa?

(Marcar quantas opções forem necessárias)
0. Nunca aparece
7. Julho
1. Janeiro
8. Agosto
2. Fevereiro
9. Setembro
3. Março
10. Outubro
4. Abril
11. Novembro
5. Maio
12. Dezembro
6. Junho
13. Todos os meses do ano

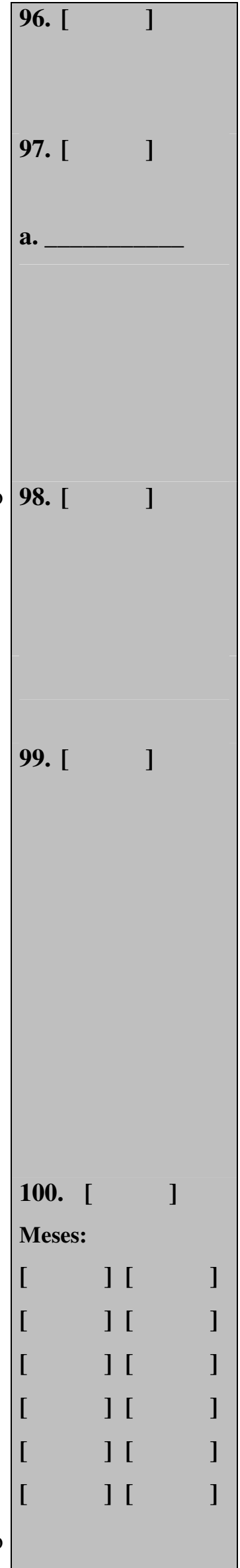


77. Não sabe

99. Não quis responder

101. Qual a freqüência que é observada barata em sua casa?

101. $[\quad]$

0 . Nunca aparece

1. Todo dia

2. Pelo menos 1 vez por semana

3. Pelo menos 1 vez por mês

4. Pelo menos 1 vez a cada 3 meses

5. Pelo menos 1 vez a cada 6 meses

6. Pelo menos $1 \mathrm{vez}$ por ano

7. Menos de 1 vez por ano (demora mais de 1 ano para aparecer)

77. Não sabe

99. Não quis responder

102. Em quais meses do ano são observadas baratas em sua casa?

102. $[\quad]$

(Marcar quantas opções forem necessárias)
0 . Nunca aparece
7. Julho
1. Janeiro
8. Agosto
2. Fevereiro
9. Setembro
3. Março
10. Outubro
4. Abril
11. Novembro
5. Maio
12. Dezembro
6. Junho
13. Todos os meses do ano
77. Não sabe
99. Não quis responder

103. Qual a frequiência que aparece rato na casa, no lote ou no lote vizinho?

103. [

Meses:

$\left[\begin{array}{lll}{[} & ][ & ] \\ {[} & ][ & ] \\ {[} & ][ & ] \\ {[} & ][ & ] \\ {[} & ][ & ] \\ {[} & ][ & ]\end{array}\right.$

0. Nunca aparece

1. Todo dia

2. Pelo menos 1 vez por semana

3. Pelo menos 1 vez por mês

4. Pelo menos 1 vez a cada 3 meses

5. Pelo menos 1 vez a cada 6 meses

6. Pelo menos 1 vez por ano

7. Menos de 1 vez por ano (demora mais de 1 ano para aparecer)

77. Não sabe

99. Não quis responder

104. Em quais meses do ano são observados ratos em sua casa?

$\begin{array}{lllll}\text { 104. [ } & & ] & \\ \text { Meses: } & & & \\ {[} & ][ & & ] \\ {[} & ][ & & ]\end{array}$

(Marcar quantas opções forem necessárias)
0. Nunca aparece
7. Julho
1. Janeiro
8. Agosto
2. Fevereiro
9. Setembro

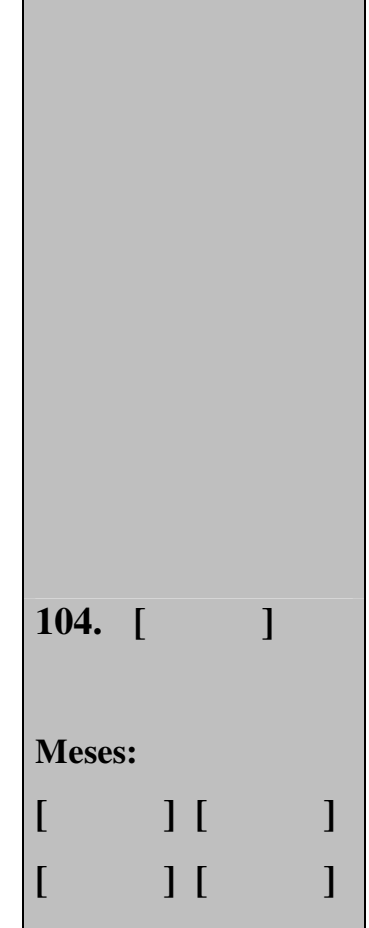



3. Março
4. Abril
5. Maio
6. Junho
77. Não sabe

10. Outubro

11. Novembro

12. Dezembro

13. Todos os meses do ano

99. Não quis responder

\section{J - CONDIČ̃̃ES DE SAÚDE DA FAMÍLIA:}

105. Entre as pessoas residentes na habitação, houve durante o último ano algum caso de dengue confirmado por exame?
0. Não
77. Não sabe
1. Sim
99. Não quis responder

106. Entre as pessoas residentes há pelo menos um ano na habitação, há alguém que sofre de alguma doença respiratória, confirmada por diagnóstico médico? (Excluir as crianças de 1 a 4 anos de idade que participarão do estudo)
0. Não
77. Não sabe
99. Não quis responder

1. Sim

88. Não se aplica

SE A RESPOSTA A QUESTÃO ANTERIOR FOR SIM, RESPONDER A QUESTÃO SEGUINTE E PREENCHER O QUADRO 108

107. Qual doença? (marcar as opções citadas e o número de pessoas que sofrem da doença)

1. Asma. Número:

107.1. [ ]

2. Bronquite. Número:

107.2. [

107.3. [

107.4. [

107.5. [

107.6. [

3. Pneumonia. Número:

4. Renite. Número:

5. Sinusite. Número: Qual?

a.

99. Não quis responder

108. Doenças respiratórias na família:

108. 
Quadro 108

\begin{tabular}{|c|c|c|c|c|c|c|c|}
\hline No. & Primeiro Nome & $\begin{array}{c}\text { Sexo } \\
(1-\mathrm{F} / 2-\mathrm{M})\end{array}$ & $\begin{array}{c}\text { Idade } \\
\text { (anos) }\end{array}$ & $\begin{array}{c}\text { Data Nasc. } \\
(\mathrm{dd} / \mathrm{mm} / \mathrm{aa})\end{array}$ & $\begin{array}{c}\text { Fumante } \\
\text { (0-Não / 1-Sim) }\end{array}$ & $\begin{array}{l}\text { Tempo de } \\
\text { residência }\end{array}$ & $\begin{array}{l}\text { Ocupação } \\
\text { Principal }\end{array}$ \\
\hline 1 & & & & & & & \\
\hline 2 & & & & & & & \\
\hline 3 & & & & & & & \\
\hline 4 & & & & & & & \\
\hline 5 & & & & & & & \\
\hline 6 & & & & & & & \\
\hline 7 & & & & & & & \\
\hline 8 & & & & & & & \\
\hline 9 & & & & & & & \\
\hline 10 & & & & & & & \\
\hline 11 & & & & & & & \\
\hline
\end{tabular}

Tempo de residência $=$ tempo em anos que a pessoa reside na habitação. Caso a pessoa resida a menos de 1 ano na habitação. Preencher: menos de 1 ano.

Ocupação principal $=$ preencher com a atividade principal (tipo de emprego) da pessoa.

109. Entre as pessoas residentes há pelo menos 5 anos na habitação, há algum caso de câncer ou alguém que já teve algum tipo de câncer, confirmado por diagnóstico médico?
0. Não
77. Não sabe
99. Não quis responder
1. Sim
88. Não se aplica

\section{SE A RESPOSTA A QUESTÃO ANTERIOR FOR SIM, RESPONDER A QUESTÃO SEGUINTE:}

110. Qual tipo de câncer?

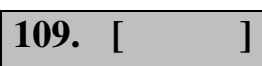

1. Câncer de colo de útero

2. Câncer de mama

3. Câncer de estômago

4. Câncer de intestino

5. Câncer de pulmão

6. Câncer de traquéia

110. $[\quad]$

7. Câncer de fígado

8. Outro. Especificar:

77. Não sabe

99. Não quis responder

a.

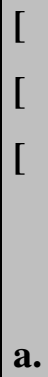

[ ] ]

[ ] [

[ ] [ ] 


\section{L - CONDICÕES DO PERIDOMICÍLIO: (Verificar)}

111. Qual é o tipo de via de acesso da habitação?

111. [

1. Rua

2. Escada

3. Caminho

4. Viela

112. A via de acesso é pavimentada?
0. Não
1. $\operatorname{Sim}$

113. Há calçada na frente da habitação?
0. Não
1. Sim

114. A calçada é pavimentada?

112. $[\quad]$
0. Não
1. Sim
88. Não se aplica

115. Há a presença de alguma vala de esgoto a céu aberto perto da habitação? (Verificar)
0. Não
1. Sim

116. Existe algum córrego, brejo, lago ou açude próximo a casa?
0. Não
77. Não sabe
1. Sim
99. Não quis responder

117. Verifique se existe lixo acumulado na casa ou no lote:
0. Não
77. Não sabe
1. Sim
99. Não quis responder ou mostrar

118. Verifique se existem lugares mais altos, vizinhos ao lote da habitação, por onde a água de chuva possa invadi-lo:
0. Não
77. Não sabe
1. Sim
99. Não quis responder ou mostrar

119. Verifique se existem pontos mais baixos no lote, onde possam ocorrer empoçamentos de água:
0. Não
77. Não sabe
1. Sim
99. Não quis responder ou mostrar

PARA CADA CRIANÇA RESIDENTE NA HABITAÇÃO QUE FIZER PARTE DO ESTUDO APLICAR, SEPARADAMENTE, O PROTOCOLO DE PESOUISA - 2. 
ANEXO B

Protocolo de Pesquisa 2 


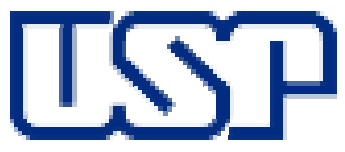

Universidade de Sẫo Paulo
DEPARTAMENTO DE HIDRÁULICA E SANEAMENTO

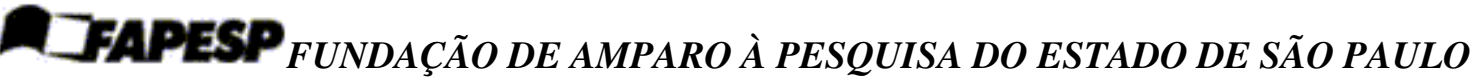

\section{AVALIAÇÃO DO RISCO PARA A SAÚDE DA POPULAÇÃO VIZINHA ÀS ÁREAS DE DISPOSIÇÃO FINAL DOS RESÍDUOS SÓLIDOS URBANOS}

\section{PROTOCOLO DE PESQUISA - 2}

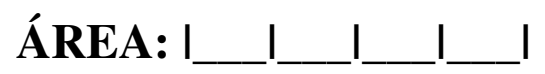

PROTOCOLO HABITAÇÃO:

PROTOCOLO CRIANÇA: I $|-|$

NÚMERO DE CRIANÇAS NA CASA QUE PARTICIPAM DO ESTUDO: I

ENTREVISTADOR:

Telefones para contato:

Pesquisadores: Mônica de Abreu Azevedo - (31) 38991738

Valdir Schalch - (16) 2739543 
Nome do entrevistador:

. I

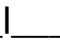

\section{PESQUISA EESC/USP/FAPESP}

\section{AVALIAÇÃO DAS CONDIÇÕES DE SAÚDE E SANEAMENTO}

\section{TERMO DE CONSENTIMENTO INFORMADO PARA A PARTICIPACÃO DA CRIANCA}

\section{ORIENTAÇÕES:}

Antes de preencher o termo de consentimento:

- Caso os pais da criança ou o representante legal não seja o adulto que responderá ao questionário, explique os objetivos e os métodos da pesquisa, seguindo os procedimentos anteriores utilizados para informar sobre a participação do adulto.

- Informe que a participação da criança consiste em ser pesada e medida e ter as fezes coletadas para a realização de exames de laboratório no início da pesquisa e após seis meses.

- Informe que a mãe ou a pessoa responsável pela criança será entrevistada semanalmente sobre os episódios de diarréia que criança possa apresentar.

- Informe que o resultado do exame será repassado aos pais ou ao representante legal e que o material coletado será desprezado após a realização do exame laboratorial.

- Informe que a criança, cujo exame parasitológico for positivo, será encaminhada ao posto de saúde do bairro para consulta médica e que o tratamento medicamentoso prescrito será fornecido com recursos da pesquisa.

- Respeite a recusa da criança em não participar.

- Leia em voz alta o TERMO DE AUTORIZAÇÃO PARA A PARTICIPAÇÃO DA CRIANÇA, assine-o, date-o e colete a assinatura em duas vias.

- Os dados devem ser preenchidos e o Termo de Consentimento assinado para cada criança que irá participar do estudo.

\section{DADOS SOBRE O ENTREVISTADO}

Nome:

Posição na família:

Nome da criança:

\section{ENDEREÇO DA HABITAÇÃO}

Rua:

Vila:

Telefone para contato: 
Nome do entrevistador:

\section{TERMO DE AUTORIZAÇÃO PARA A PARTICIPAÇ̃̃O DA CRIANÇA}

Na qualidade de responsável legal, autorizo a participação do menor.

na pesquisa que objetiva obter dados sobre as condições de moradia, de saneamento e de saúde da população residente no meu bairro, entendendo que a criança que participar desse estudo terá seu peso e altura aferidos e suas fezes coletadas para exame de laboratório.

Data: 1

Assinatura do responsável legal pela criança

Assinatura do entrevistador

Telefones para contato:

Pesquisadores: Mônica de Abreu Azevedo (31) 38991738

Valdir Schalch (16) 2739543

\section{TERMO DE AUTORIZAÇÃO PARA A PARTICIPAÇ̃̃O DA CRIANÇA}

Na qualidade de responsável legal, autorizo a participação do menor. na pesquisa que objetiva obter dados sobre as condições de moradia, de saneamento e de saúde da população residente no meu bairro, entendendo que a criança que participar desse estudo terá seu peso e altura aferidos e suas fezes coletadas para exame de laboratório.

Data: I

Assinatura do responsável legal pela criança

Assinatura do entrevistador

Telefones para contato:

Pesquisadores: Mônica de Abreu Azevedo (31) 38991738

Valdir Schalch (16) 2739543 


\section{PESQUISA EESC/USP/FAPESP}

\section{AVALIAÇÃO DAS CONDIÇÕES DE SAÚDE E SANEAMENTO}

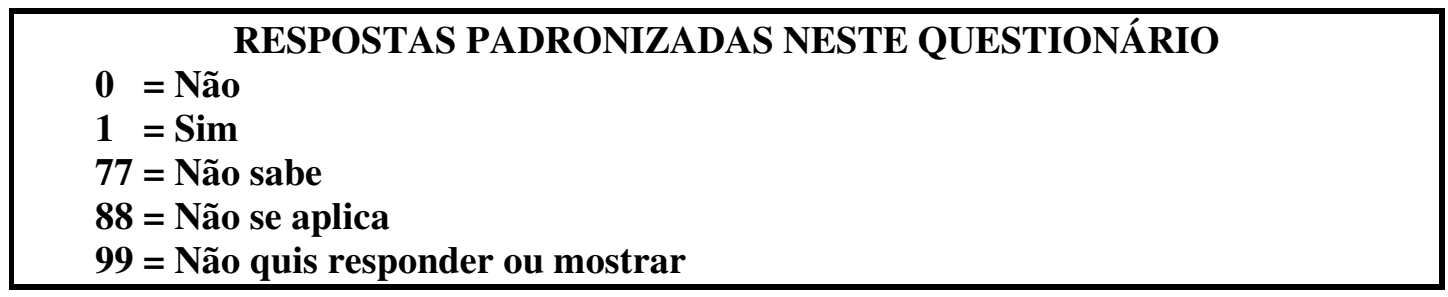

\section{AS QUESTÕES SEGUINTES DEVEM SER PREENCHIDAS PARA CADA CRIANÇA RESIDENTE NA CASA QUE IRÁ PARTICIPAR DO ESTUDO}

120. Nome do entrevistador:

121. Data da entrevista:

122. Número da área:

123. Número do protocolo da habitação:

124. Nome da criança:

125. A mãe da criança vive na casa?
0. Não
77. Não sabe
1. Sim
99. Não quis responder

AS PERGUNTAS SEGUINTES DEVEM SER RESPONDIDAS PELA MÃE BIOLÓGICA DA CRIANÇA OU PESSOA RESPONSÁVEL PELA CRIANÇA

\section{M. - INFORMACÕES SOBRE A ENTREVISTADA:}

(mãe biológica ou pessoa responsável pela criança de 1 a 4 anos de idade)

126. Nome:

127. Data de nascimento: $(\mathrm{dd} / \mathrm{mm} / \mathrm{aa})$

128. Idade: (anos)

129. Estado Civil:
1. Solteira
5. Viúva
2. Casada
77. Não sabe
3. União livre
99. Não quis responder
4. Separada/divorciada

130. Local de nascimento: (cidade)

131. Estado onde nasceu: (nome ou sigla)

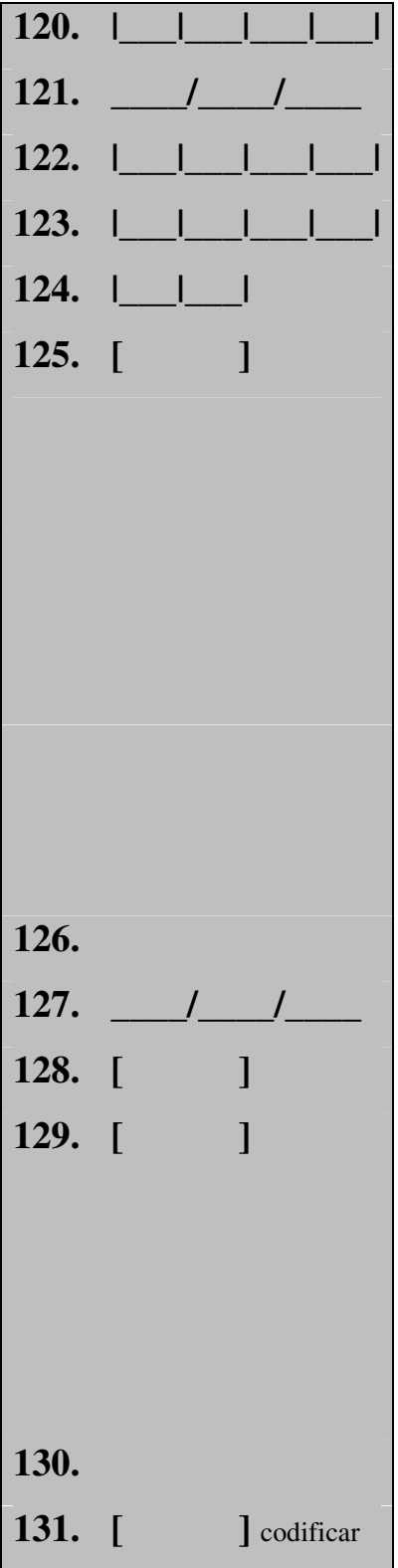


132. Há quanto tempo a senhora reside na habitação?

1. Menos de 6 meses

2. De 6 meses a 1 ano

3. Mais de 1 ano

4. De 1 a 5 anos
133. Tempo de residência na habitação:

134. A senhora sempre morou nesta casa?
0. Não
77. Não sabe
1. $\operatorname{Sim}$
99. Não quis responder

5. De 5 a 10 anos

6. Mais de 10 anos

77. Não sabe

99. Não quis responder

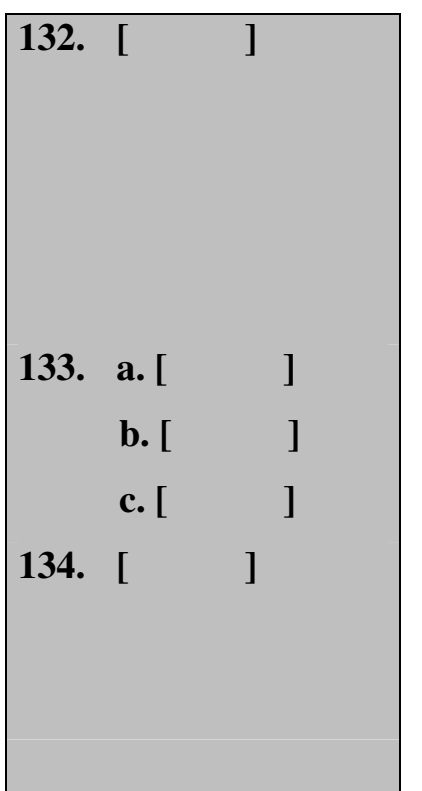

135. [ ]
4. Outra cidade
5. Outro estado
77. Não sabe

136. Até que série a senhora estudou?

0 . Não sabe ler nem escrever

1. Primário incompleto ou não completou a $4^{\mathrm{a}}$ série do primeiro grau

2. Primário completo ou completou a $4^{\mathrm{a}}$ série do primeiro grau

3. Ginásio incompleto ou estudou entre a $5^{\mathrm{a}}$ e $8^{\mathrm{a}}$ série do primeiro grau

4. Ginásio completo ou completou a $8^{\mathrm{a}}$ serie do primeiro grau

5. $2^{\circ}$ grau incompleto

6. $2^{\circ}$ grau completo

7. Superior incompleto

8. Superior completo

99. Não quis responder

137. Qual a relação da senhora com o trabalho?

137. [ ]

1. Exerce trabalho familiar não assalariado (dona de casa) (ir para questão 140)

2. Exerce trabalho remunerado com carteira assinada

3. Exerce trabalho remunerado sem carteira assinada

4. Trabalha por conta própria

5. É funcionária pública

136. [ ]

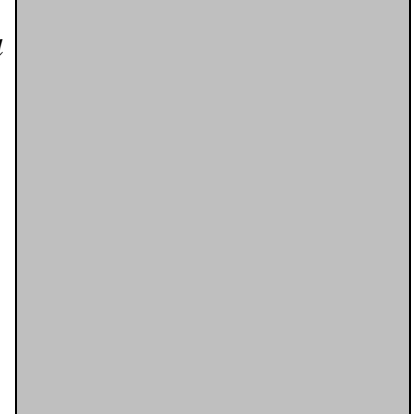


6. É aposentada

7. Está desempregada

8. Está em licença temporária

9. Não possui trabalho fixo, trabalha eventualmente
77. Não sabe
99. Não quis responder

138. Quantas horas a senhora trabalha por dia?

139. Quantos dias a senhora trabalha por semana?
140. A senhora é a mãe natural da criança?
0. Não 1. Sim

141. Se a resposta à pergunta anterior for $\underline{\mathrm{Sim}}$, escrever 88 e passar a 138. $[$ ]

139. [ ]

\section{questão $\underline{144}$}

\section{O que aconteceu com a mãe natural da criança?}

1. Não mora mais na casa

2. Morreu

3. Está viajando por um período superior a 1 mês

4. Outro. Especificar:
77. Não sabe
88. Não se aplica
99. Não quis responder

142. Que idade tinha a criança quando a senhora começou a se ocupar
dele/dela?
a. Anos ou
b. Meses ou
c. Dias

143. Quantas gestações a mãe da criança teve?

144. História reprodutiva da mãe da criança:

\begin{tabular}{|c|c|c|c|c|c|c|c|c|}
\hline $\begin{array}{c}\text { No. de } \\
\text { ordem }\end{array}$ & $\begin{array}{c}\text { Idade no } \\
\text { início da } \\
\text { gestação } \\
\text { (anos) }\end{array}$ & $\begin{array}{c}\text { Resultado da } \\
\text { gestação } \\
\text { (se 2, encerre na } \\
\text { coluna 4) }\end{array}$ & $\begin{array}{c}\text { Duração } \\
\text { da } \\
\text { gestação } \\
\text { (meses) }\end{array}$ & $\begin{array}{c}\text { Data de } \\
\text { nascimento } \\
\text { do filho } \\
\text { (dd/mm/aa) }\end{array}$ & $\begin{array}{c}\text { Sexo } \\
1-\mathrm{F} \\
2-\mathrm{M}\end{array}$ & $\begin{array}{c}\text { Condição } \\
\text { atual do } \\
\text { filho } \\
1 \text {-vivo } \\
\text { 2-morto }\end{array}$ & $\begin{array}{c}\text { Data do } \\
\text { óbito do } \\
\text { filho(a) } \\
\text { (dd/mm/aa) }\end{array}$ & $\begin{array}{c}\text { Toma(ou) } \\
\text { leite } \\
\text { materno } \\
\text { 1-sim } \\
\text { 2-não }\end{array}$ \\
\hline $\mathbf{1}$ & & & & & & & & \\
\hline $\mathbf{3}$ & & & & & & & & \\
\hline $\mathbf{4}$ & & & & & & & & \\
\hline $\mathbf{5}$ & & & & & & & & \\
\hline $\mathbf{6}$ & & & & & & & & \\
\hline $\mathbf{7}$ & & & & & & & & \\
\hline $\mathbf{8}$ & & & & & & & & \\
\hline $\mathbf{9}$ & & & & & & & & \\
\hline
\end{tabular}

Resultado da gestação: 1- nascido vivo; 2- nascido morto ou aborto

Duração da gestação: 0 se ignorada; 1 se menor ou igual a 1 mês 
AS QUESTÕES SEGUINTES REFEREM-SE APENAS A UMA CRIANÇA E DEVEM SER RESPONDIDAS PARA CADA CRIANCGA

\section{N - INFORMACÕES SOBRE A CRIANCA:}

145. Sexo: 1 - Feminino 2 -Masculino

146. Data de nascimento: $(\mathrm{dd} / \mathrm{mm} / \mathrm{aa})$

147. A data de nascimento foi obtida através de documento? (0. Não; 1 . Sim)

148. A criança nasceu de:

1. Parto natural

2. Parto por cesariana

3. Parto com aplicação de fórceps

77. Não sabe

99. Não quis responder

149. Durante a gravidez da criança, a mãe necessitou de ser internada devido alguma doença?
0. Não
77. Não sabe
1. Sim
99. Não quis responder

Especificar:

150. A gravidez dessa criança foi de número:
1. Primeira
4. Quarta
2. Segunda
5. Quinta
3. Terceira
6. Sexta ou mais
77. Não sabe
99. Não quis responder

151. Após quantos meses de gravidez a criança nasceu?

1. Com nove meses completos

2. Entre oito e noves meses

3. Com oito meses completos

4. Entre sete e oito meses

77. Não sabe

99. Não quis responder

152. Quanto a criança pesava ao nascer? Peso: g

77. Não sabe

99. Não quis responder

153. No primeiro mês de vida a criança apresentou alguma doença que necessitasse de internação?
0. Não
77. Não sabe
1. Sim
99. Não quis responder

Qual?

149.

145. [

146.

147. [

148. [

1

a.

a.

150. [ ]

151. [ ]

152. g

153. [ ] ]

a.

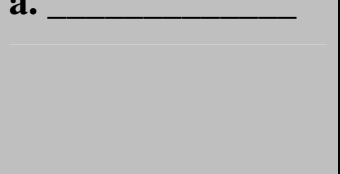


154. A criança recebeu todas as vacinas que estão indicadas para a sua idade?
0. Não
77. Não sabe
1. Sim
99. Não quis responder

155. A criança ainda mama no peito?
0. Não
77. Não sabe
1. Sim
99. Não quis responder

156. Até que idade a criança tomou o leite materno?

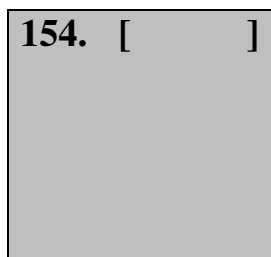

155. $[\quad]$

0 . Nunca tomou leite materno

1. Até 15 dias

2. Entre 15 dias e 3 meses

3. Entre 3 e 6 meses

4. Mais de 6 meses

77. Não sabe

99. Não quis responder

157. Até que idade criança recebeu o leite materno sem outro alimento?

157. [ ]
0 . Nunca tomou leite materno
1. Até 15 dias
2. Entre15 dias e 3 meses
3. Entre 3 e 6 meses
77. Não sabe

99. Não quis responder

158. A criança faz uso de mamadeira?

158. $[\quad]$
0. Não
77. Não sabe
1. Sim
99. Não quis responder

159. Quantas vezes por dia a criança usa a mamadeira?

160. A criança recebe algum suplemento nutricional?
0. Não
77. Não sabe
1. Sim
99. Não quis responder

Qual. Especificar:

161. A criança participa do programa de reforço alimentar da Pastoral da Criança?
0. Não
77. Não sabe
1. $\mathrm{Sim}$
99. Não quis responder

162. A criança faz uso constante de alguma medicação?

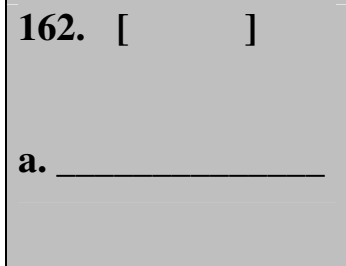


163. No momento, a criança tem alguma doença?
0. Não
77. Não sabe
1. Sim
99. Não quis responder

Qual? Especificar:

164. Quantas horas por dia a criança passa em casa?

165. A criança freqüienta a creche ou escola?

163. [ ]

a.

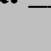

164. [

165. [

]

0. Não (salte a pergunta seguinte)

1. Sim, de manhã

2. Sim de tarde

3. Sim, o dia todo

77. Não sabe

99. Não quis responder

166. A creche ou escola da criança se situa no mesmo bairro?
0. Não
1. Sim
77. Não sabe
88. Não se aplica
99. Não quis responder

167. Onde a criança passa a maior parte do dia?

167. [

]

1. Em casa

2. Creche ou escola

3. Casa de vizinhos

4. Casa de parentes em outro bairro

5. Na rua

77. Não sabe

99. Não quis responder

168. Durante o último ano, quem ficou tomando conta da criança, em casa?

1. Mãe 2. Pai

3. Outra pessoa. (responder as questões 171 e 172)

77. Não sabe

99. Não quis responder

169. O pai da criança vive em casa?

169. $[\quad]$
1. Não
77. Não sabe
2. Sim
99. Não quis responder

170. Qual o grau de instrução do pai da criança?

170. $[$ ]
0 . Não sabe ler nem escrever
1. Primário incompleto ou não completou a $4^{\mathrm{a}}$.série do primeiro grau
2. Primário completo ou completou a $4^{\mathrm{a}}$. série do primeiro grau
3. Ginásio incompleto ou estudou entre a $5^{\mathrm{a}}$. e $8^{\mathrm{a}}$. série do primeiro grau
4. Ginásio completo ou completou a $8^{\mathrm{a}}$. série do primeiro grau
5. $2^{\circ}$. grau incompleto
6. $2^{\circ}$. grau completo

168. [

]

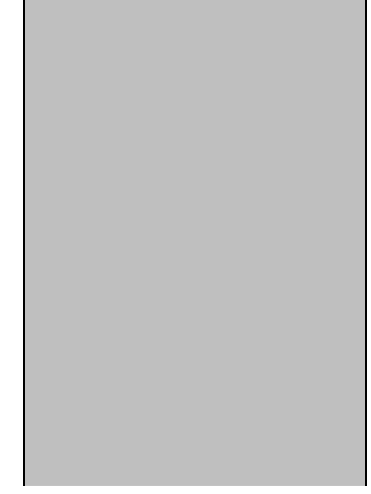


7. Superior incompleto

8. Superior completo

77. Não sabe

99. Não quis responder

SE A RESPOSTA À QUESTÃO 168 FOR OUTRA PESSOA, RESPONDER AS QUESTÕES 171 E $172:$

171. Qual a relação dessa pessoa com a criança?
1. Irmão/irmã
5. Madrasta/padrasto
2. Avô/avó
6. Empregada
3. Tio/tia
7. Vizinha sem relação de parentesco
4. Primo/prima
77. Não sabe
99. Não quis responder

172. Qual o grau de instrução da pessoa que toma conta da criança?

0 . Não sabe ler nem escrever

1. Primário incompleto ou não completou a $4^{\mathrm{a}}$.série do primeiro grau

2. Primário completo ou completou a 4 a série do primeiro grau

3. Ginásio incompleto ou estudou entre a $5^{\mathrm{a}}$. e $8^{\mathrm{a}}$. série do primeiro grau

4. Ginásio completo ou completou a $8^{\mathrm{a}}$. série do primeiro grau

5. $2^{\circ}$. grau incompleto

6. $2^{\circ}$. grau completo

7. Superior incompleto

8. Superior completo

99. Não quis responder

173. Há alguma pessoa residente na casa que exerça alguma atividade relacionada com o lixo, com a reciclagem de resíduos ou que trabalhe no aterro sanitário?

0. Não (ir para questão $\underline{\mathbf{1 7 6}}$ )

77. Não sabe

1. Sim

99. Não quis responder

CASO A RESPOSTA DA PERGUNTA ANTERIOR TIVER SIDO SIM, RESPONDER AS PERGUNTAS $\underline{174}$ E 175

174. Esta pessoa tem algum contato com a criança (cuida, brinca, prepara o alimento)?
0. Não
77. Não sabe
1. Sim
99. Não quis responder 
175. Qual o grau de parentesco dessa pessoa com a criança?

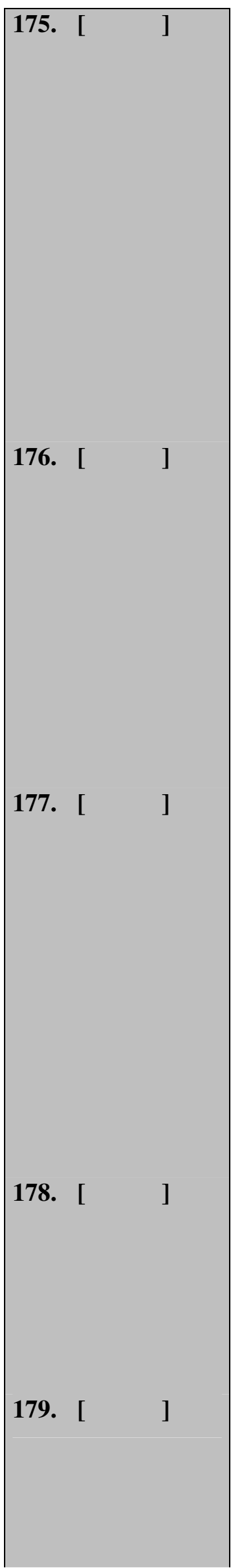

1. Mãe

2. Pai

3. Irmão/irmã

4. Avô/avó

5. Tio/tia

6. Primo/prima

7. Madrasta/padrasto

8. Outro. Especificar:

77. Não sabe

99. Não quis responder

176. A água consumida pela criança para bebida é proveniente:

1. Da rede pública de abastecimento de água

2. De poço ou cisterna

3. De caminhão pipa

4. Da torneira pública ou chafariz

5. Da caixa d'água comunitária

6. De água mineral engarrafada

77. Não sabe

99. Não quis responder

177. A água que a criança bebe tem algum preparo?

0. Não

1. Sim, é filtrada em filtro de vela

2. Sim, é filtrada em outro tipo de filtro. Especificar:

3. Sim, é misturada com cloro (água sanitária)

4. Sim, é misturada com cloro e filtrada

5. Sim, é fervida

6. Só bebe água mineral
77. Não sabe
99. Não quis responder

178. As frutas e verduras que a criança come têm antes algum preparo?

0. Não

1. Sim, são lavadas

2. Sim, são postas em água sanitária, vinagre ou iodo
77. Não sabe
88. Não se aplica
99. Não quis responder

179. A criança tem o hábito de lavar as mãos antes de se alimentar?

0. Não

1. Sim, com água e sabão

2. Sim, apenas com água 
3. Com pequena freqüência

77. Não sabe

99. Não quis responder

180. A criança tem o hábito de lavar as mãos depois de defecar?

180. $[\quad]$

0. Não

1. Sim, com água e sabão

2. Sim, apenas com água

3. Com pequena freqüência

77. Não sabe

99. Não quis responder

181. Existe, próximo a sua casa, algum córrego, brejo, lago ou açude que a criança costuma brincar e ter contato com a água?

0. Não

1. Sim, costuma brincar na água

2. Sim, costuma atravessar a água descalça

77. Não sabe

99. Não quis responder

182. Existe esgoto correndo na rua ou em outro local freqüentado pela criança?
0. Não
77. Não sabe
1. Sim
99. Não quis responder

183. A criança costuma brincar em algum local ou terreno que haja lixo jogado no chão (ponto de lançamento de lixo)?
0. Não
77. Não sabe
1. Sim
99. Não quis responder

184. A criança sofre de alguma doença respiratória confirmada por diagnóstico médico?
0. Não
77. Não sabe
1. Sim
99. Não quis responder

185. Qual doença?

184. $[\quad]$

182. $[\quad]$

183. [

]

1. Asma.

2. Bronquite

3. Pneumonia

4. Renite

5. Sinusite

6. Outra. Qual?

77. Não sabe

99. Não quis responder

186. A criança apresentou alguma diarréia nas últimas 48 horas?

a.
0. Não
77. Não sabe
1. Sim
99. Não quis responder

186. [ ] ] 


\section{Quando iniciou o episódio atual de diarréia?}

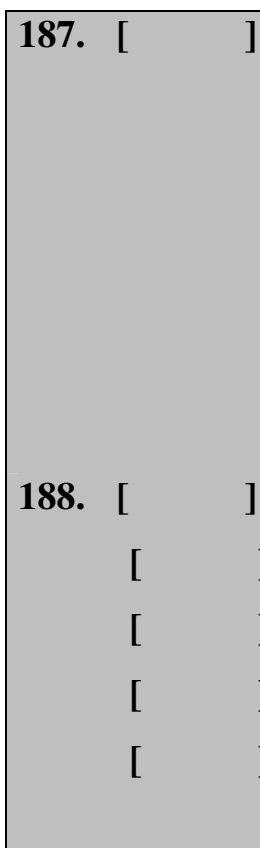

1. Há menos de 24 horas

2. Entre 1 a 3 dias

3. Entre 3 a 7 dias

4. Entre 7 e 15 dias

5. Há mais de 15 dias

77. Não sabe

99. Não quis responder

188. A criança apresentou junto com a diarréia? (Marcar as opções citadas)

1. Febre

2. Vômito

3. Sangue nas fezes

4. Muco nas fezes

77. Não sabe

99. Não quis responder

189. Foi necessário levar a criança a um serviço de saúde para tratar da 189. [ ] diarréia?
0. Não
77. Não sabe
1. Sim
99. Não quis responder

190. Foi necessário internação?
0. Não
77. Não sabe
1. Sim
99. Não quis responder

191. A criança fez uso de antibiótico nos últimos sete dias?
0. Não
77. Não sabe
1. Sim
99. Não quis responder

AGORA, VOCÊ DEVE PESAR E MEDIR A CRIANCAA:

192. Peso: $\mathrm{Kg}$ g

191. [ ]

190. $[\quad]$

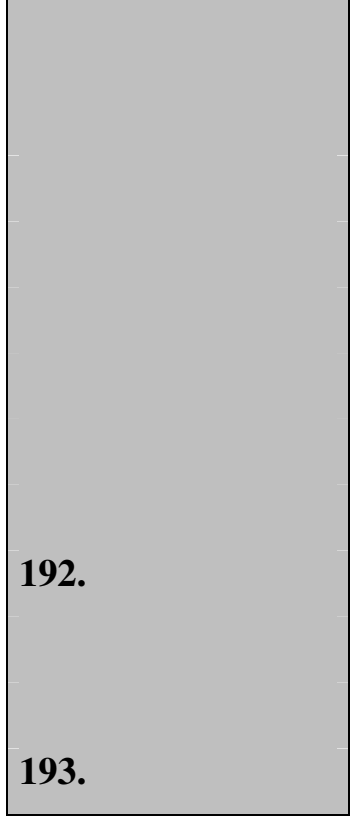

193. Altura: m cm

193. 
ANEXO C

Protocolo de Pesquisa 3 


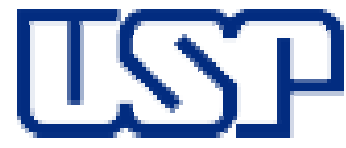

Universidade de Sã̃o Paulo

\section{AVALIAÇÃO DO RISCO PARA A SAÚDE DA POPULAÇÃO VIZINHA ÀS ÁREAS DE DISPOSIÇÃO FINAL DOS RESÍDUOS SÓLIDOS URBANOS}

\section{PROTOCOLO DE PESQUISA - 3}

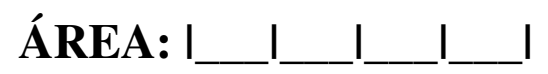

PROTOCOLO HABITAÇÃO: ।_________ |

PROTOCOLO CRIANÇA: I________ I - I___

ENTREVISTADOR: I_______ I

Última Semana:

Data:

Peso:

Altura:

Telefones para contato: 


\section{TSPE E C \\ Universidade de São Paulo de São Carlos \\ DEPARTAMENTO DE HIDRÁULICA E SANEAMENTO \\ DFAPESP FUNDAÇÃO DE AMPARO À PESQUISA DO ESTADO DE SÃO PAULO}

Pesquisa: Avaliação do Risco para a Saúde da População da População Vizinha às Áreas de Disposição Final de Resíduos Sólidos Urbanos

1. Nome do entrevistador:

2. Nome da criança:

3. Semana no.

- Período:

4. Dias da Semana

5. Data: $(\mathrm{dd} / \mathrm{mm} / \mathrm{aa})$

6. Dia de visita semanal? $(0,1)$

7. Data de obtenção da informação?

8. A criança teve diarréia? $(0,1,77,99)$

9. Quantas vezes evacuou

10. Quantas vezes fezes amolecidas?

11. Quantas vezes fezes líquidas?

12. Presença de sangue nas fezes? $(0,1,77,99)$

13. Presença de muco nas fezes? $(0,1,77,99)$

14. Teve febre? $(0,1,77,99)$

15. Teve vômito? $(0,1,77,99)$

16. Foi necessário ir a um serviço de saúde? $(0,1,77,99)$

16. Foi necessário internação?

$(0,1,77,99)$

17. Fez uso de antibiótico? $(0,1,77,99)$

18. Grau de parentesco da pessoa entrevistada em relação à criança

Respostas padronizadas:

I

I

\begin{tabular}{|c|c|c|}
\hline $\mathbf{2}^{\text {a. }}$ feira & $\mathbf{3}^{\text {a }}$. feira \\
\hline
\end{tabular}

(7, 99)

\begin{tabular}{ll|ll|ll}
\hline & $l$ & $l$ & $l$ & $l$ & $l$ \\
\hline
\end{tabular}

?

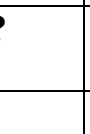

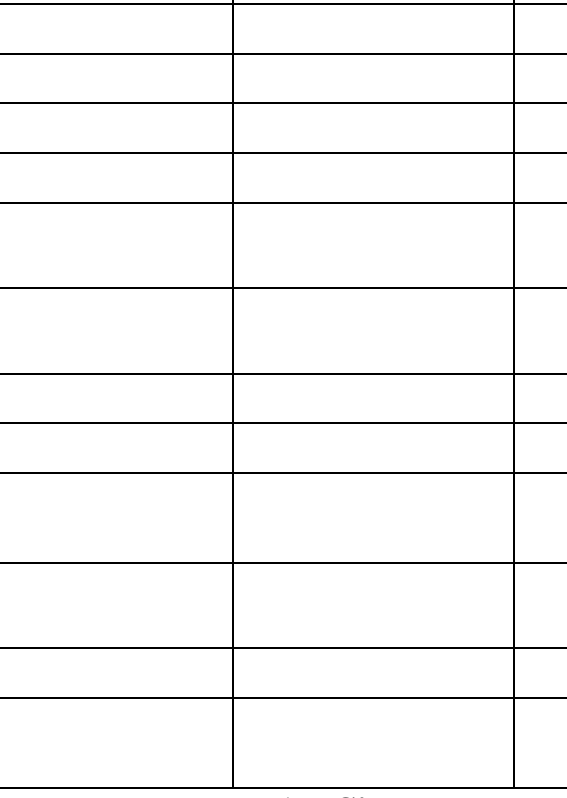

0 = Não

$$
1=\operatorname{Sim}
$$

77 = Não sabe

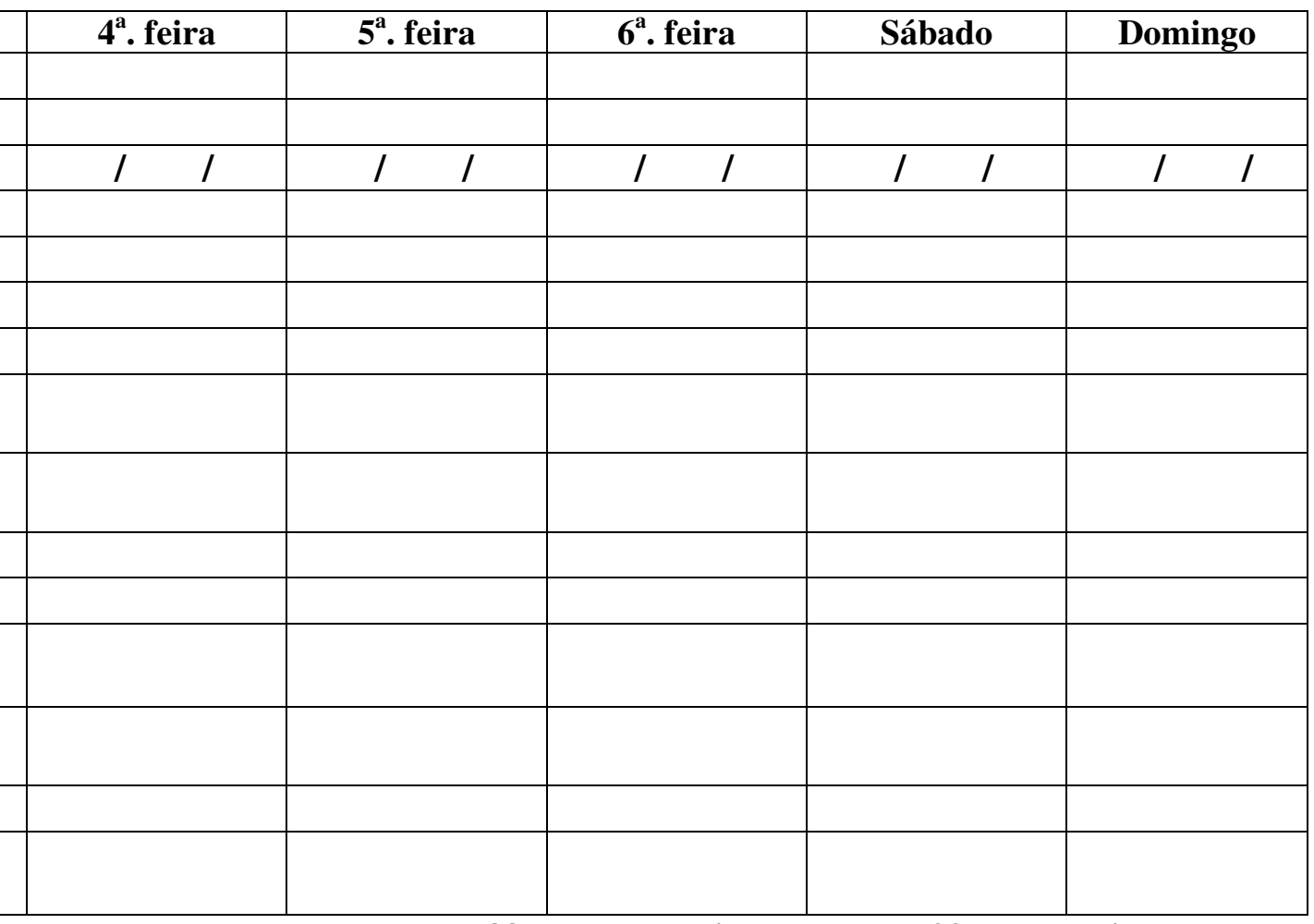

I________ I

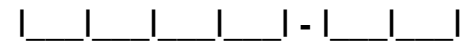
(utilizar o mesmo número do Protocolo 2) 


\section{TSPE E C \\ Universidade de São Paulo de São Carlos \\ DEPARTAMENTO DE HIDRÁULICA E SANEAMENTO \\ DFAPESP FUNDAÇÃO DE AMPARO À PESQUISA DO ESTADO DE SÃO PAULO}

Pesquisa: Avaliação do Risco para a Saúde da População da População Vizinha às Áreas de Disposição Final de Resíduos Sólidos Urbanos

1. Nome do entrevistador:

2. Nome da criança:

3. Semana no.

- Período:

4. Dias da Semana

5. Data: $(\mathrm{dd} / \mathrm{mm} / \mathrm{aa})$

6. Dia de visita semanal? $(0,1)$

7. Data de obtenção da informação?

8. A criança teve diarréia? $(0,1,77,99)$

9. Quantas vezes evacuou?

10. Quantas vezes fezes amolecidas?

11. Quantas vezes fezes líquidas?

12. Presença de sangue nas fezes? $(0,1,77,99)$

13. Presença de muco nas fezes? $(0,1,77,99)$

14. Teve febre? $(0,1,77,99)$

15. Teve vômito? $(0,1,77,99)$

16. Foi necessário ir a um serviço de saúde? $(0,1,77,99)$

16. Foi necessário internação?

$(0,1,77,99)$

17. Fez uso de antibiótico? $(0,1,77,99)$

18. Grau de parentesco da pessoa entrevistada em relação à criança

Respostas padronizadas:

I

I

\begin{tabular}{|l|l|l}
$\mathbf{4}^{\mathrm{a}}$. feira & $\mathbf{5}^{\mathrm{a}}$. feira & $\mathbf{6}^{\mathrm{a}}$. feira
\end{tabular}

\begin{tabular}{|c|c|}
\hline $\mathbf{2}^{\text {a. }}$ feira & $\mathbf{3}^{\text {a }}$. feira \\
\hline
\end{tabular}

99)

$\begin{array}{lll}0=\text { Não } & 1=\text { Sim } & 77=\text { Não sabe }\end{array}$

88 = Não se aplica

\begin{tabular}{|c|c|c|c|c|c|c|}
\hline $2^{\text {a. }}$ feira & $3^{a}$. feira & $4^{a}$ feira & $5^{a}$ feira & $6^{a}$. feira & Sábado & Domingo \\
\hline 1 & l & l & l & l & l & I \\
\hline
\end{tabular}

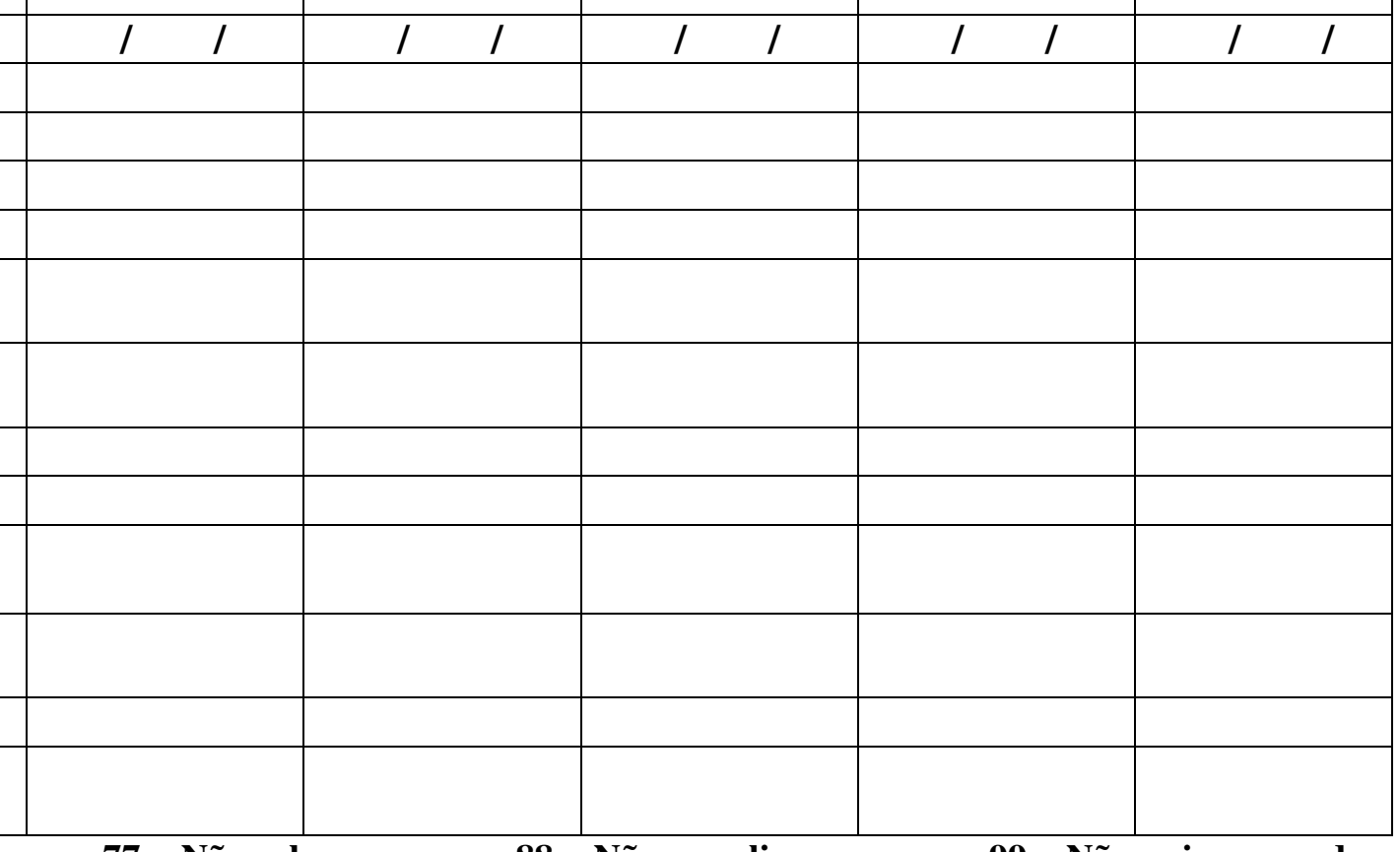

99 = Não quis responder

$$
\text { I_I______ I }
$$$$
\text { I I I I I- I I I }
$$
(utilizar o mesmo número do Protocolo 2) 


\section{TSPE E C \\ Universidade de São Paulo de São Carlos \\ DEPARTAMENTO DE HIDRÁULICA E SANEAMENTO \\ DFAPESP FUNDAÇÃO DE AMPARO À PESQUISA DO ESTADO DE SÃO PAULO}

Pesquisa: Avaliação do Risco para a Saúde da População da População Vizinha às Áreas de Disposição Final de Resíduos Sólidos Urbanos

1. Nome do entrevistador:

2. Nome da criança:

3. Semana no.

- Período:

4. Dias da Semana

5. Data: $(\mathrm{dd} / \mathrm{mm} / \mathrm{aa})$

6. Dia de visita semanal? $(0,1)$

7. Data de obtenção da informação?

8. A criança teve diarréia? $(0,1,77,99)$

9. Quantas vezes evacuou?

10. Quantas vezes fezes amolecidas?

11. Quantas vezes fezes líquidas?

12. Presença de sangue nas fezes? $(0,1,77,99)$

13. Presença de muco nas fezes? $(0,1,77,99)$

14. Teve febre? $(0,1,77,99)$

15. Teve vômito? $(0,1,77,99)$

16. Foi necessário ir a um serviço de saúde? $(0,1,77,99)$

16. Foi necessário internação?

$(0,1,77,99)$

17. Fez uso de antibiótico? $(0,1,77,99)$

18. Grau de parentesco da pessoa entrevistada em relação à criança

Respostas padronizadas:

I

I

\begin{tabular}{|l|l|l}
$\mathbf{4}^{\mathrm{a}}$. feira & $\mathbf{5}^{\mathrm{a}}$. feira & $\mathbf{6}^{\mathrm{a}}$. feira
\end{tabular}

\begin{tabular}{|c|c|}
\hline $\mathbf{2}^{\text {a. }}$ feira & $\mathbf{3}^{\text {a }}$. feira \\
\hline
\end{tabular}

99)

$\begin{array}{lll}0=\text { Não } & 1=\text { Sim } & 77=\text { Não sabe }\end{array}$

88 = Não se aplica

\begin{tabular}{|c|c|c|c|c|c|c|}
\hline $2^{\text {a. }}$ feira & $3^{a}$. feira & $4^{a}$ feira & $5^{a}$ feira & $6^{a}$. feira & Sábado & Domingo \\
\hline 1 & l & l & l & l & l & I \\
\hline
\end{tabular}

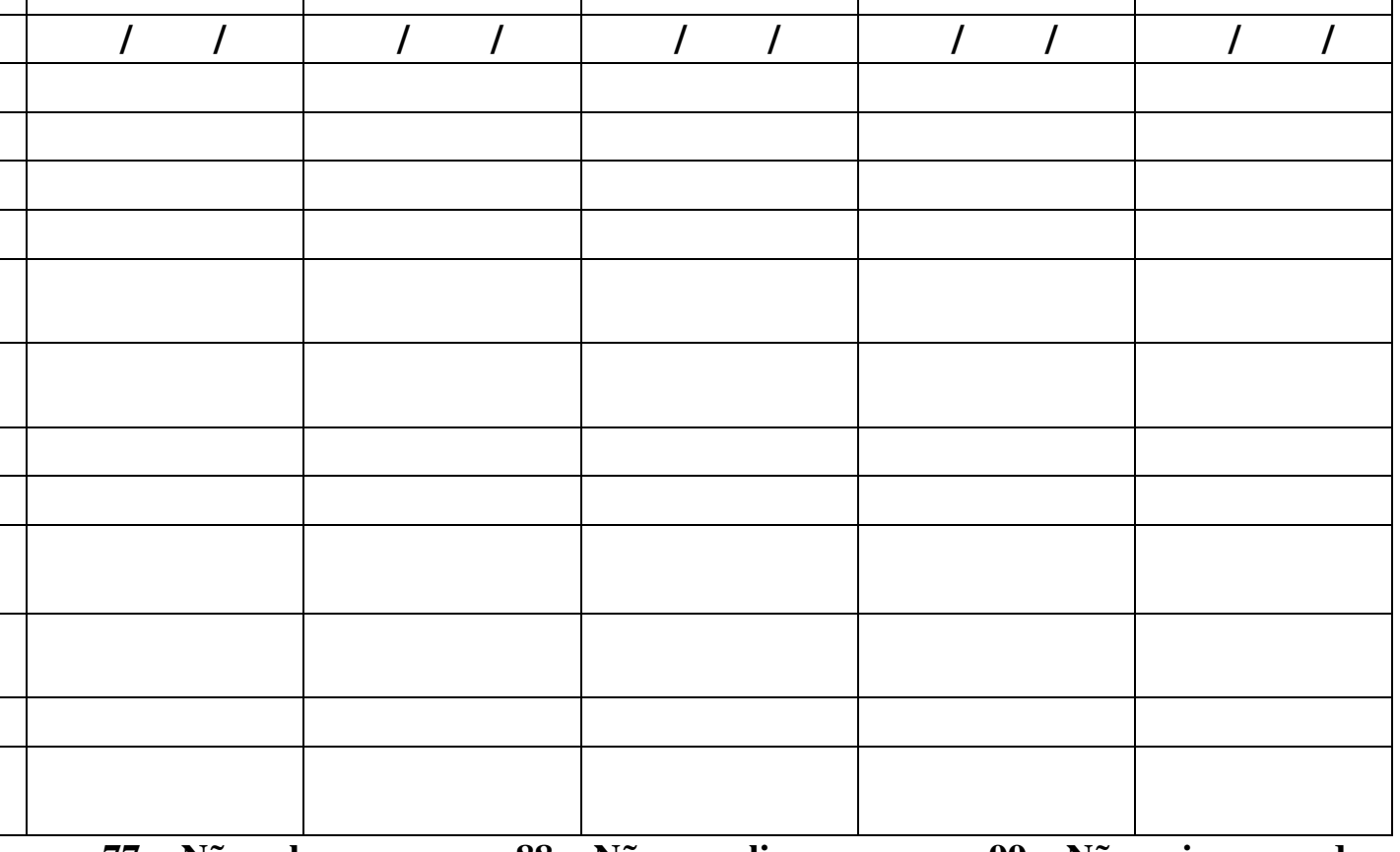

99 = Não quis responder

$$
\text { I_I______ I }
$$$$
\text { I I I I I- I I I }
$$
(utilizar o mesmo número do Protocolo 2) 


\section{TSPE E C \\ Universidade de São Paulo de São Carlos \\ DEPARTAMENTO DE HIDRÁULICA E SANEAMENTO \\ DFAPESP FUNDAÇÃO DE AMPARO À PESQUISA DO ESTADO DE SÃO PAULO}

Pesquisa: Avaliação do Risco para a Saúde da População da População Vizinha às Áreas de Disposição Final de Resíduos Sólidos Urbanos

1. Nome do entrevistador:

2. Nome da criança:

3. Semana no.

- Período:

4. Dias da Semana

5. Data: $(\mathrm{dd} / \mathrm{mm} / \mathrm{aa})$

6. Dia de visita semanal? $(0,1)$

7. Data de obtenção da informação?

8. A criança teve diarréia? $(0,1,77,99)$

9. Quantas vezes evacuou?

10. Quantas vezes fezes amolecidas?

11. Quantas vezes fezes líquidas?

12. Presença de sangue nas fezes? $(0,1,77,99)$

13. Presença de muco nas fezes? $(0,1,77,99)$

14. Teve febre? $(0,1,77,99)$

15. Teve vômito? $(0,1,77,99)$

16. Foi necessário ir a um serviço de saúde? $(0,1,77,99)$

16. Foi necessário internação?

$(0,1,77,99)$

17. Fez uso de antibiótico? $(0,1,77,99)$

18. Grau de parentesco da pessoa entrevistada em relação à criança

Respostas padronizadas:

I

I

\begin{tabular}{|l|l|l}
$\mathbf{4}^{\mathrm{a}}$. feira & $\mathbf{5}^{\mathrm{a}}$. feira & $\mathbf{6}^{\mathrm{a}}$. feira
\end{tabular}

\begin{tabular}{|c|c|}
\hline $\mathbf{2}^{\text {a. }}$ feira & $\mathbf{3}^{\text {a }}$. feira \\
\hline
\end{tabular}

99)

$\begin{array}{lll}0=\text { Não } & 1=\text { Sim } & 77=\text { Não sabe }\end{array}$

88 = Não se aplica

\begin{tabular}{|c|c|c|c|c|c|c|}
\hline $2^{\text {a. }}$ feira & $3^{a}$. feira & $4^{a}$ feira & $5^{a}$ feira & $6^{a}$. feira & Sábado & Domingo \\
\hline 1 & l & l & l & l & l & I \\
\hline
\end{tabular}

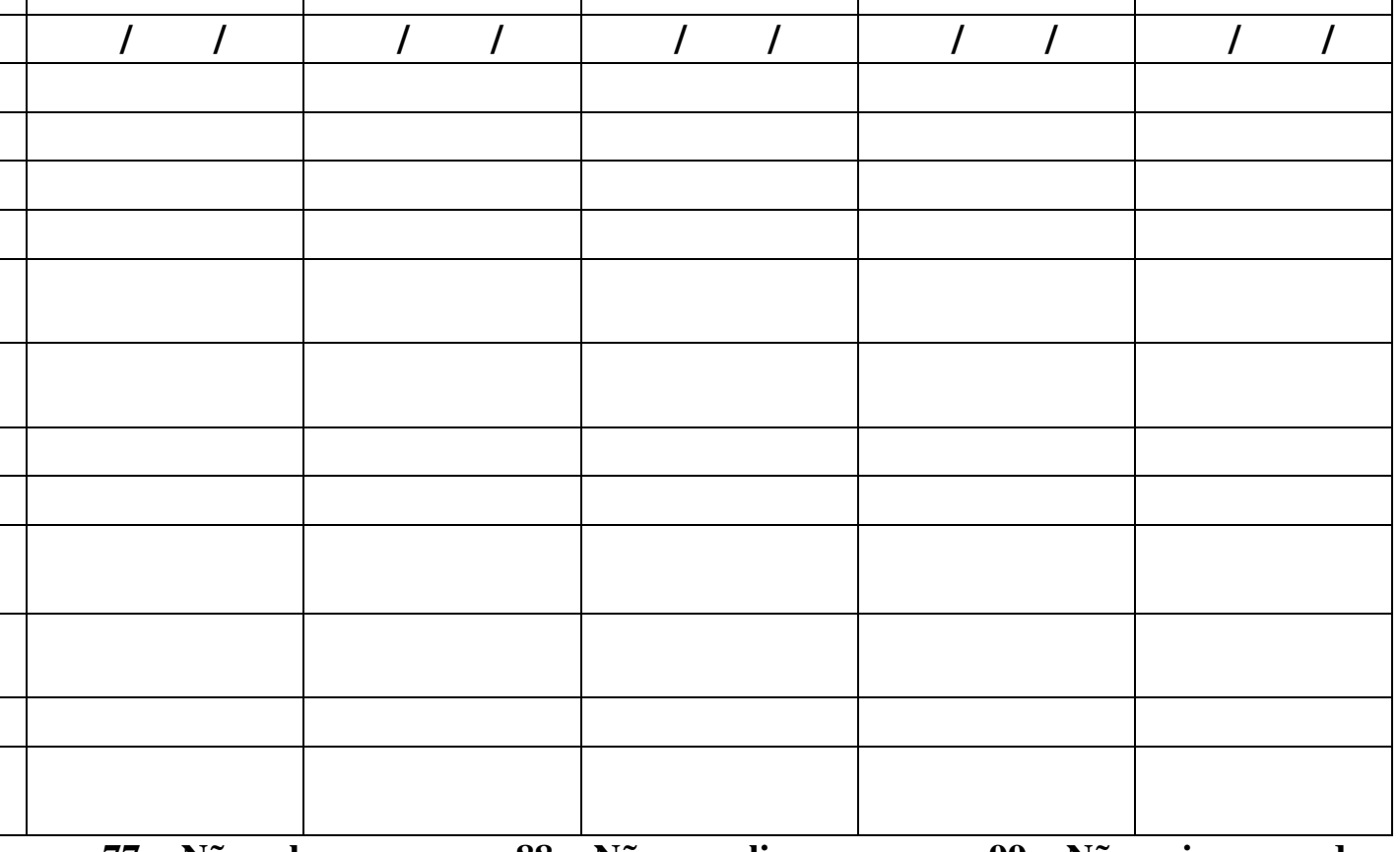

99 = Não quis responder

$$
\text { I_I______ I }
$$$$
\text { I I I I I- I I I }
$$
(utilizar o mesmo número do Protocolo 2) 


\section{TSPE E C \\ Universidade de São Paulo de São Carlos \\ DEPARTAMENTO DE HIDRÁULICA E SANEAMENTO \\ DFAPESP FUNDAÇÃO DE AMPARO À PESQUISA DO ESTADO DE SÃO PAULO}

Pesquisa: Avaliação do Risco para a Saúde da População da População Vizinha às Áreas de Disposição Final de Resíduos Sólidos Urbanos

1. Nome do entrevistador:

2. Nome da criança:

3. Semana no.

- Período:

4. Dias da Semana

5. Data: $(\mathrm{dd} / \mathrm{mm} / \mathrm{aa})$

6. Dia de visita semanal? $(0,1)$

7. Data de obtenção da informação?

8. A criança teve diarréia? $(0,1,77,99)$

9. Quantas vezes evacuou?

10. Quantas vezes fezes amolecidas?

11. Quantas vezes fezes líquidas?

12. Presença de sangue nas fezes? $(0,1,77,99)$

13. Presença de muco nas fezes? $(0,1,77,99)$

14. Teve febre? $(0,1,77,99)$

15. Teve vômito? $(0,1,77,99)$

16. Foi necessário ir a um serviço de saúde? $(0,1,77,99)$

16. Foi necessário internação?

$(0,1,77,99)$

17. Fez uso de antibiótico? $(0,1,77,99)$

18. Grau de parentesco da pessoa entrevistada em relação à criança

Respostas padronizadas:

I

I

\begin{tabular}{|l|l|l}
$\mathbf{4}^{\mathrm{a}}$. feira & $\mathbf{5}^{\mathrm{a}}$. feira & $\mathbf{6}^{\mathrm{a}}$. feira
\end{tabular}

\begin{tabular}{|c|c|}
\hline $\mathbf{2}^{\text {a. }}$ feira & $\mathbf{3}^{\text {a }}$. feira \\
\hline
\end{tabular}

99)

$\begin{array}{lll}0=\text { Não } & 1=\text { Sim } & 77=\text { Não sabe }\end{array}$

88 = Não se aplica

\begin{tabular}{|c|c|c|c|c|c|c|}
\hline $2^{\text {a. }}$ feira & $3^{a}$. feira & $4^{a}$ feira & $5^{a}$ feira & $6^{a}$. feira & Sábado & Domingo \\
\hline 1 & l & l & l & l & l & I \\
\hline
\end{tabular}

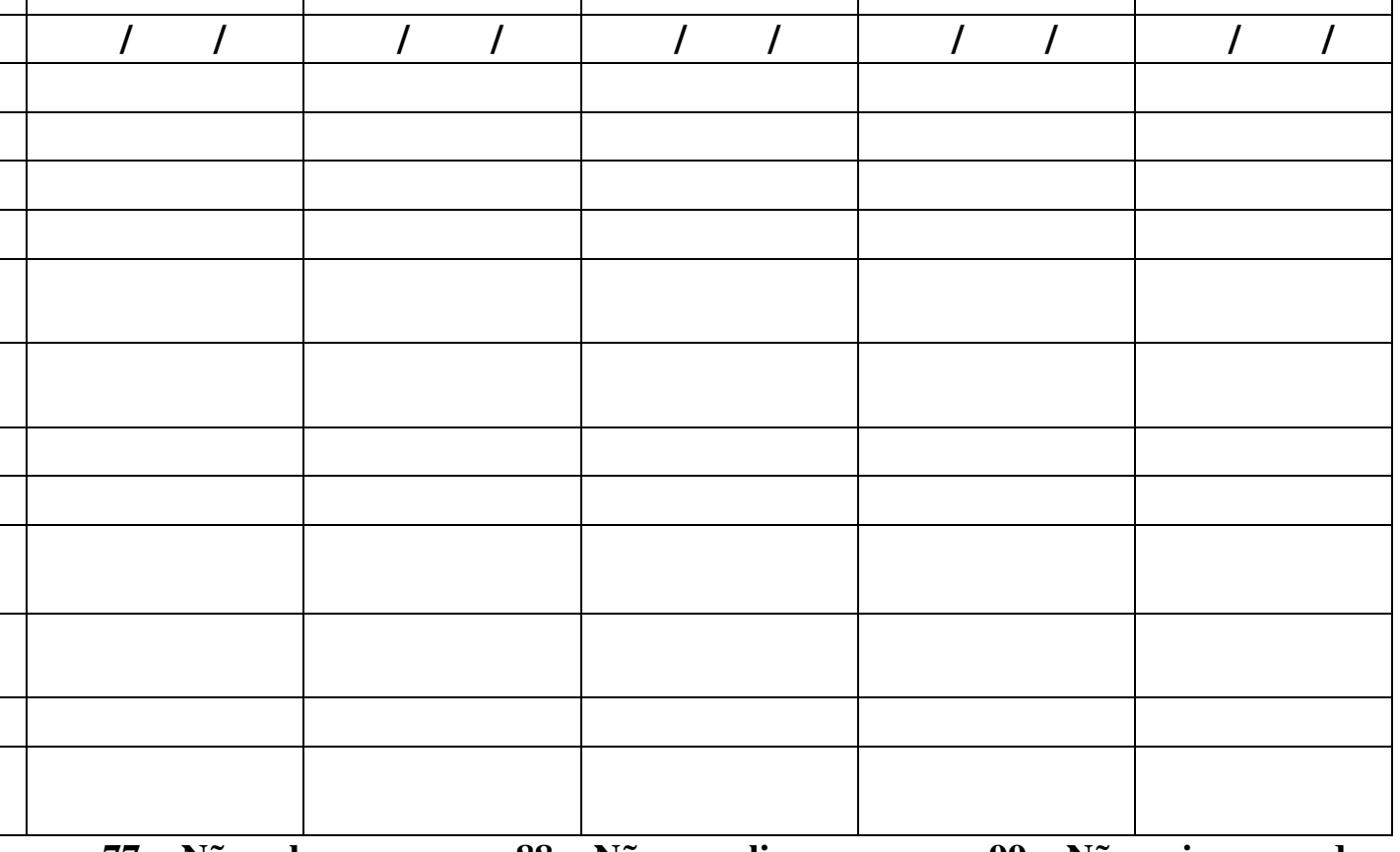

99 = Não quis responder

$$
\text { I_I______ I }
$$$$
\text { I I I I I- I I I }
$$
(utilizar o mesmo número do Protocolo 2) 


\section{TSPE E C \\ Universidade de São Paulo de São Carlos \\ DEPARTAMENTO DE HIDRÁULICA E SANEAMENTO \\ DFAPESP FUNDAÇÃO DE AMPARO À PESQUISA DO ESTADO DE SÃO PAULO}

Pesquisa: Avaliação do Risco para a Saúde da População da População Vizinha às Áreas de Disposição Final de Resíduos Sólidos Urbanos

1. Nome do entrevistador:

2. Nome da criança:

3. Semana no.

- Período:

4. Dias da Semana

5. Data: $(\mathrm{dd} / \mathrm{mm} / \mathrm{aa})$

6. Dia de visita semanal? $(0,1)$

7. Data de obtenção da informação?

8. A criança teve diarréia? $(0,1,77,99)$

9. Quantas vezes evacuou?

10. Quantas vezes fezes amolecidas?

11. Quantas vezes fezes líquidas?

12. Presença de sangue nas fezes? $(0,1,77,99)$

13. Presença de muco nas fezes? $(0,1,77,99)$

14. Teve febre? $(0,1,77,99)$

15. Teve vômito? $(0,1,77,99)$

16. Foi necessário ir a um serviço de saúde? $(0,1,77,99)$

16. Foi necessário internação?

$(0,1,77,99)$

17. Fez uso de antibiótico? $(0,1,77,99)$

18. Grau de parentesco da pessoa entrevistada em relação à criança

Respostas padronizadas:

I

I

\begin{tabular}{|l|l|l}
$\mathbf{4}^{\mathrm{a}}$. feira & $\mathbf{5}^{\mathrm{a}}$. feira & $\mathbf{6}^{\mathrm{a}}$. feira
\end{tabular}

\begin{tabular}{|c|c|}
\hline $\mathbf{2}^{\text {a. }}$ feira & $\mathbf{3}^{\text {a }}$. feira \\
\hline
\end{tabular}

99)

$\begin{array}{lll}0=\text { Não } & 1=\text { Sim } & 77=\text { Não sabe }\end{array}$

88 = Não se aplica

\begin{tabular}{|c|c|c|c|c|c|c|}
\hline $2^{\text {a. }}$ feira & $3^{a}$. feira & $4^{a}$ feira & $5^{a}$ feira & $6^{a}$. feira & Sábado & Domingo \\
\hline 1 & l & l & l & l & l & I \\
\hline
\end{tabular}

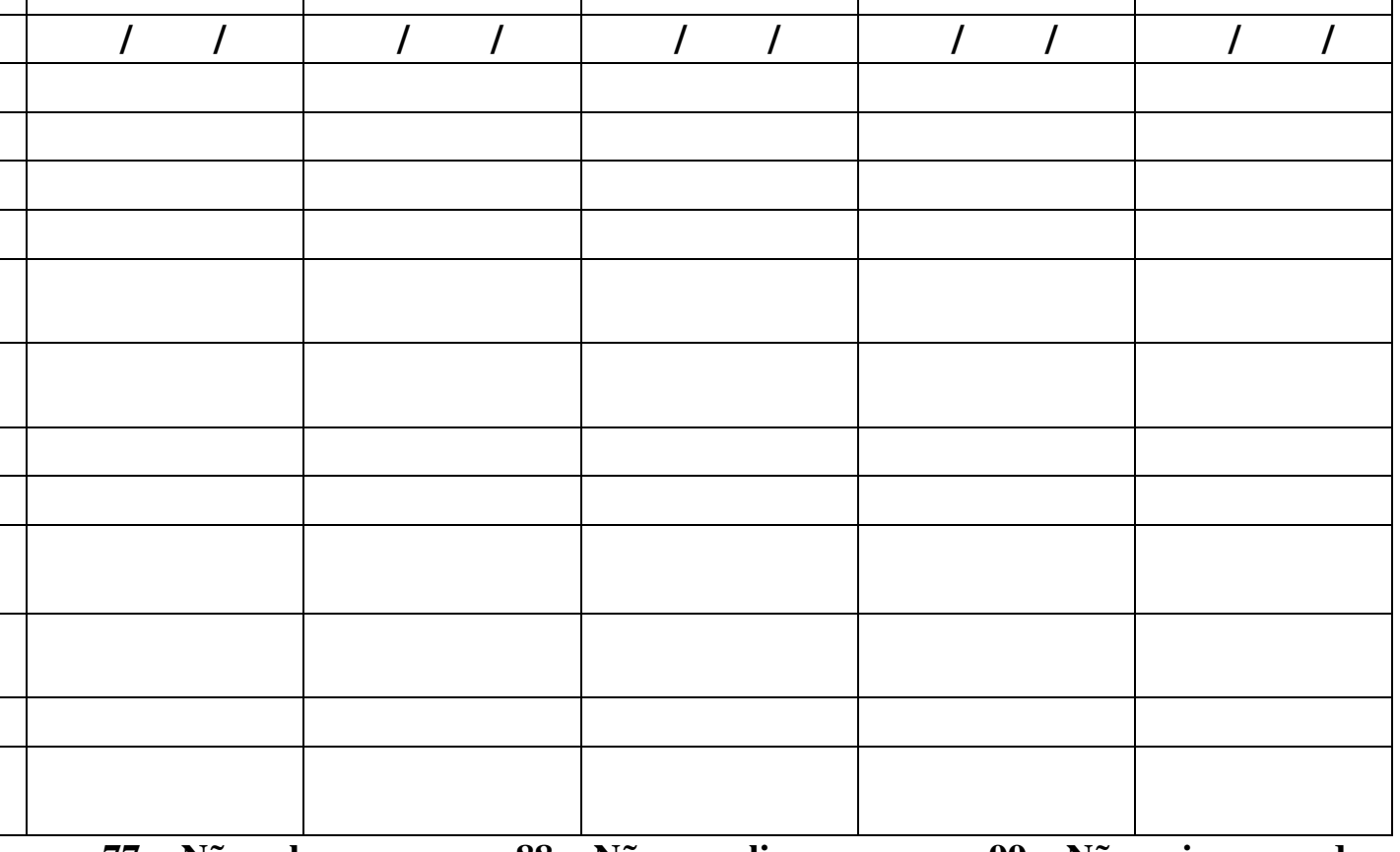

99 = Não quis responder

$$
\text { I_I______ I }
$$$$
\text { I I I I I- I I I }
$$
(utilizar o mesmo número do Protocolo 2) 


\section{TSPE E C \\ Universidade de São Paulo de São Carlos \\ DEPARTAMENTO DE HIDRÁULICA E SANEAMENTO \\ DFAPESP FUNDAÇÃO DE AMPARO À PESQUISA DO ESTADO DE SÃO PAULO}

Pesquisa: Avaliação do Risco para a Saúde da População da População Vizinha às Áreas de Disposição Final de Resíduos Sólidos Urbanos

1. Nome do entrevistador:

2. Nome da criança:

3. Semana no.

- Período:

4. Dias da Semana

5. Data: $(\mathrm{dd} / \mathrm{mm} / \mathrm{aa})$

6. Dia de visita semanal? $(0,1)$

7. Data de obtenção da informação?

8. A criança teve diarréia? $(0,1,77,99)$

9. Quantas vezes evacuou?

10. Quantas vezes fezes amolecidas?

11. Quantas vezes fezes líquidas?

12. Presença de sangue nas fezes? $(0,1,77,99)$

13. Presença de muco nas fezes? $(0,1,77,99)$

14. Teve febre? $(0,1,77,99)$

15. Teve vômito? $(0,1,77,99)$

16. Foi necessário ir a um serviço de saúde? $(0,1,77,99)$

16. Foi necessário internação?

$(0,1,77,99)$

17. Fez uso de antibiótico? $(0,1,77,99)$

18. Grau de parentesco da pessoa entrevistada em relação à criança

Respostas padronizadas:

I

I

\begin{tabular}{|l|l|l}
$\mathbf{4}^{\mathrm{a}}$. feira & $\mathbf{5}^{\mathrm{a}}$. feira & $\mathbf{6}^{\mathrm{a}}$. feira
\end{tabular}

\begin{tabular}{|c|c|}
\hline $\mathbf{2}^{\text {a. }}$ feira & $\mathbf{3}^{\text {a }}$. feira \\
\hline
\end{tabular}

99)

$\begin{array}{lll}0=\text { Não } & 1=\text { Sim } & 77=\text { Não sabe }\end{array}$

88 = Não se aplica

\begin{tabular}{|c|c|c|c|c|c|c|}
\hline $2^{\text {a. }}$ feira & $3^{a}$. feira & $4^{a}$ feira & $5^{a}$ feira & $6^{a}$. feira & Sábado & Domingo \\
\hline 1 & l & l & l & l & l & I \\
\hline
\end{tabular}

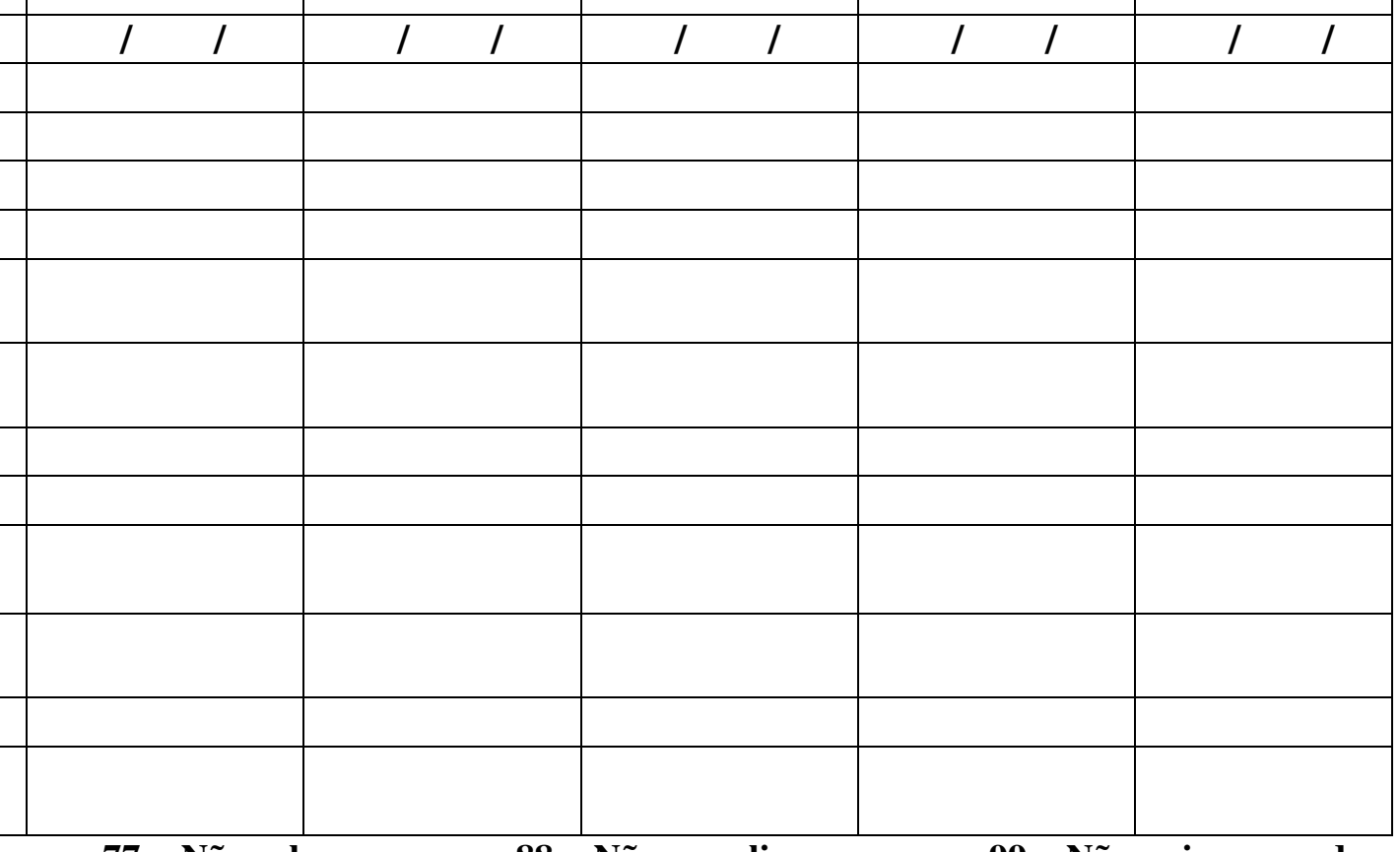

99 = Não quis responder

$$
\text { I_I______ I }
$$$$
\text { I I I I I- I I I }
$$
(utilizar o mesmo número do Protocolo 2) 


\section{TSPE E C \\ Universidade de São Paulo de São Carlos \\ DEPARTAMENTO DE HIDRÁULICA E SANEAMENTO \\ DFAPESP FUNDAÇÃO DE AMPARO À PESQUISA DO ESTADO DE SÃO PAULO}

Pesquisa: Avaliação do Risco para a Saúde da População da População Vizinha às Áreas de Disposição Final de Resíduos Sólidos Urbanos

1. Nome do entrevistador:

2. Nome da criança:

3. Semana no.

- Período:

4. Dias da Semana

5. Data: $(\mathrm{dd} / \mathrm{mm} / \mathrm{aa})$

6. Dia de visita semanal? $(0,1)$

7. Data de obtenção da informação?

8. A criança teve diarréia? $(0,1,77,99)$

9. Quantas vezes evacuou?

10. Quantas vezes fezes amolecidas?

11. Quantas vezes fezes líquidas?

12. Presença de sangue nas fezes? $(0,1,77,99)$

13. Presença de muco nas fezes? $(0,1,77,99)$

14. Teve febre? $(0,1,77,99)$

15. Teve vômito? $(0,1,77,99)$

16. Foi necessário ir a um serviço de saúde? $(0,1,77,99)$

16. Foi necessário internação?

$(0,1,77,99)$

17. Fez uso de antibiótico? $(0,1,77,99)$

18. Grau de parentesco da pessoa entrevistada em relação à criança

Respostas padronizadas:

I

I

\begin{tabular}{|l|l|l}
$\mathbf{4}^{\mathrm{a}}$. feira & $\mathbf{5}^{\mathrm{a}}$. feira & $\mathbf{6}^{\mathrm{a}}$. feira
\end{tabular}

\begin{tabular}{|c|c|}
\hline $\mathbf{2}^{\text {a. }}$ feira & $\mathbf{3}^{\text {a }}$. feira \\
\hline
\end{tabular}

99)

$\begin{array}{lll}0=\text { Não } & 1=\text { Sim } & 77=\text { Não sabe }\end{array}$

88 = Não se aplica

\begin{tabular}{|c|c|c|c|c|c|c|}
\hline $2^{\text {a. }}$ feira & $3^{a}$. feira & $4^{a}$ feira & $5^{a}$ feira & $6^{a}$. feira & Sábado & Domingo \\
\hline 1 & l & l & l & l & l & I \\
\hline
\end{tabular}

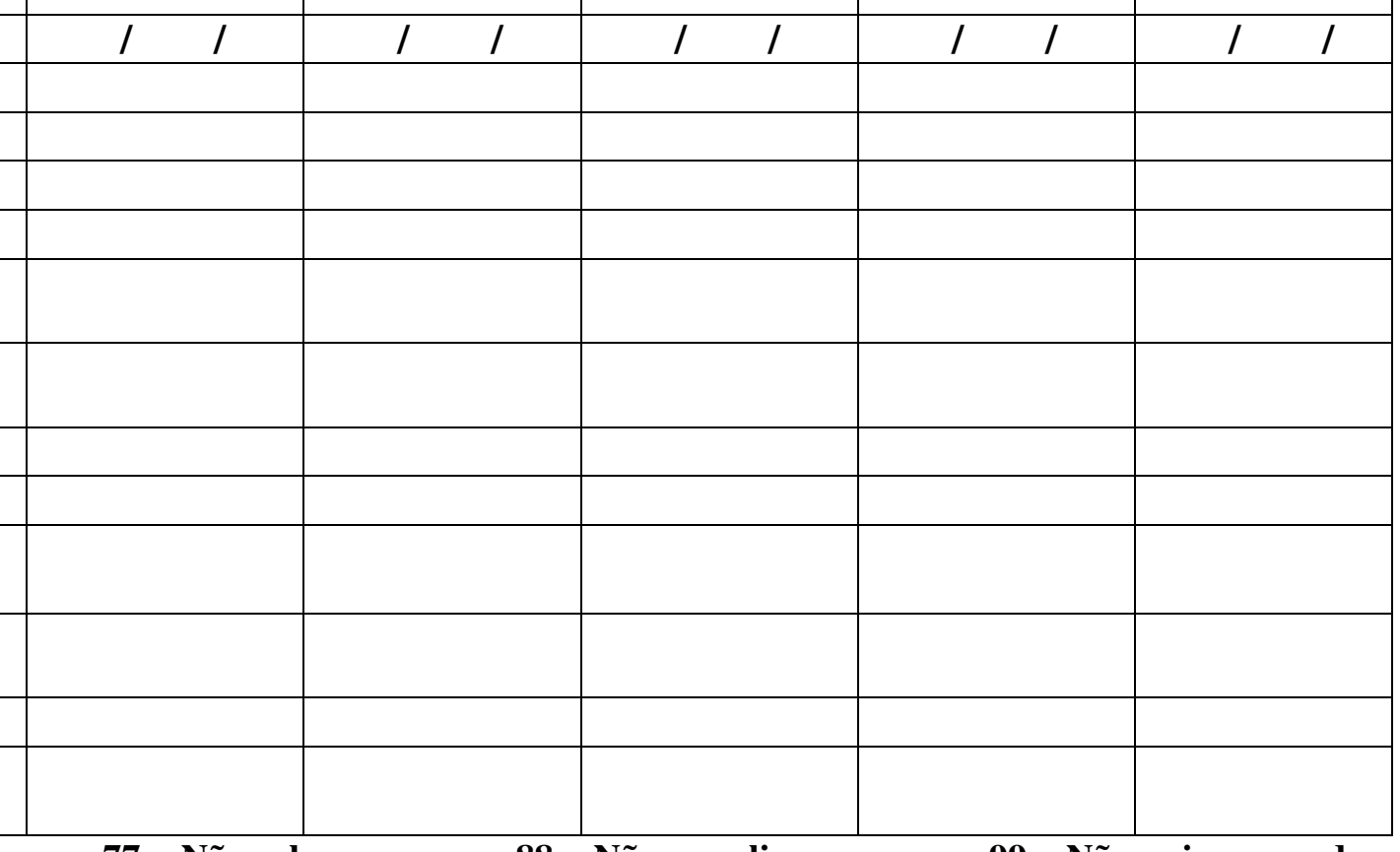

99 = Não quis responder

$$
\text { I_I______ I }
$$$$
\text { I I I I I- I I I }
$$
(utilizar o mesmo número do Protocolo 2) 


\section{TSPE E C \\ Universidade de São Paulo de São Carlos \\ DEPARTAMENTO DE HIDRÁULICA E SANEAMENTO \\ DFAPESP FUNDAÇÃO DE AMPARO À PESQUISA DO ESTADO DE SÃO PAULO}

Pesquisa: Avaliação do Risco para a Saúde da População da População Vizinha às Áreas de Disposição Final de Resíduos Sólidos Urbanos

1. Nome do entrevistador:

2. Nome da criança:

3. Semana no.

- Período:

4. Dias da Semana

5. Data: $(\mathrm{dd} / \mathrm{mm} / \mathrm{aa})$

6. Dia de visita semanal? $(0,1)$

7. Data de obtenção da informação?

8. A criança teve diarréia? $(0,1,77,99)$

9. Quantas vezes evacuou?

10. Quantas vezes fezes amolecidas?

11. Quantas vezes fezes líquidas?

12. Presença de sangue nas fezes? $(0,1,77,99)$

13. Presença de muco nas fezes? $(0,1,77,99)$

14. Teve febre? $(0,1,77,99)$

15. Teve vômito? $(0,1,77,99)$

16. Foi necessário ir a um serviço de saúde? $(0,1,77,99)$

16. Foi necessário internação?

$(0,1,77,99)$

17. Fez uso de antibiótico? $(0,1,77,99)$

18. Grau de parentesco da pessoa entrevistada em relação à criança

Respostas padronizadas:

I

I

\begin{tabular}{|l|l|l}
$\mathbf{4}^{\mathrm{a}}$. feira & $\mathbf{5}^{\mathrm{a}}$. feira & $\mathbf{6}^{\mathrm{a}}$. feira
\end{tabular}

\begin{tabular}{|c|c|}
\hline $\mathbf{2}^{\text {a. }}$ feira & $\mathbf{3}^{\text {a }}$. feira \\
\hline
\end{tabular}

99)

$\begin{array}{lll}0=\text { Não } & 1=\text { Sim } & 77=\text { Não sabe }\end{array}$

88 = Não se aplica

\begin{tabular}{|c|c|c|c|c|c|c|}
\hline $2^{\text {a. }}$ feira & $3^{a}$. feira & $4^{a}$ feira & $5^{a}$ feira & $6^{a}$. feira & Sábado & Domingo \\
\hline 1 & l & l & l & l & l & I \\
\hline
\end{tabular}

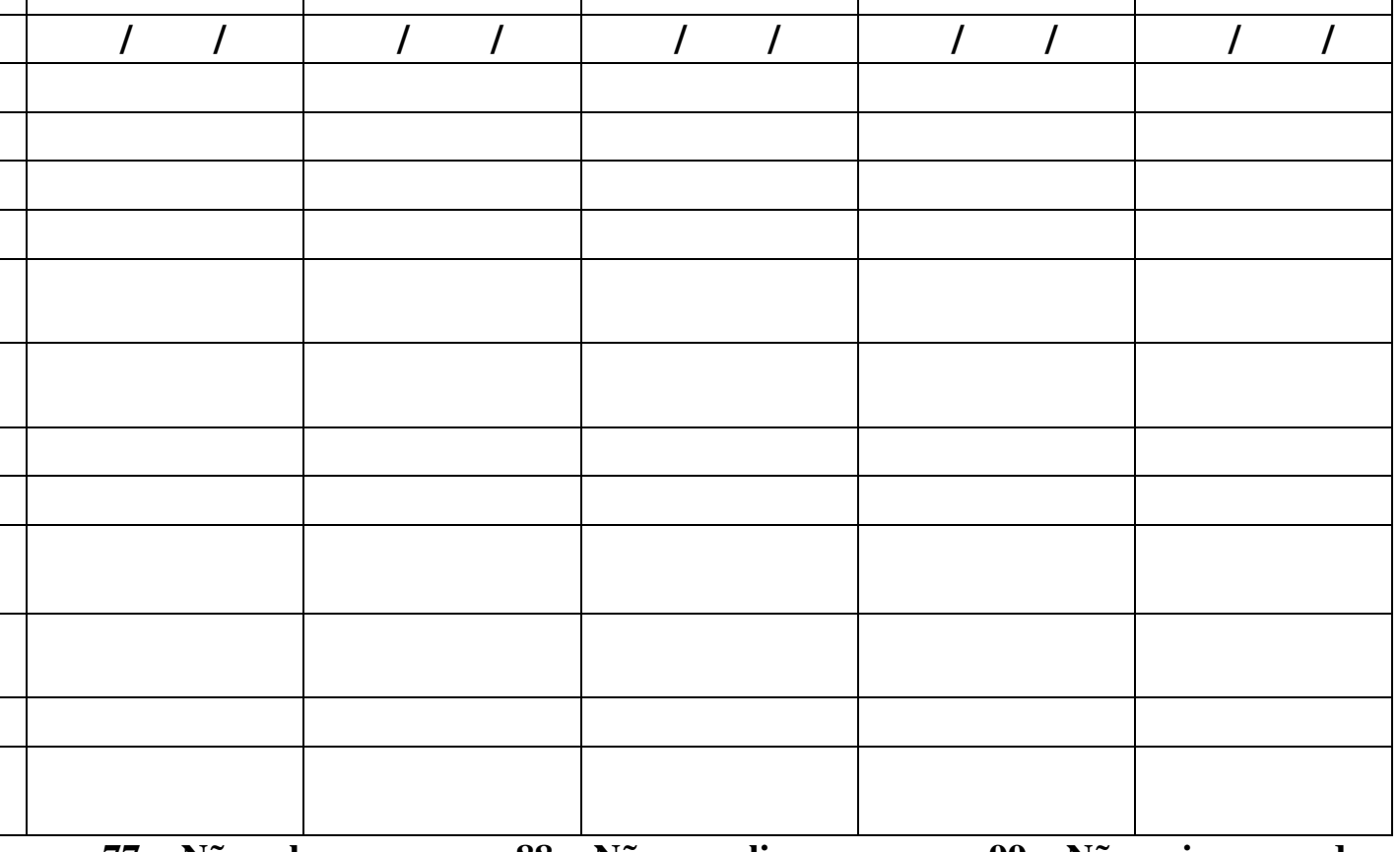

99 = Não quis responder

$$
\text { I_I______ I }
$$$$
\text { I I I I I- I I I }
$$
(utilizar o mesmo número do Protocolo 2) 


\section{TSPE E C \\ Universidade de São Paulo de São Carlos \\ DEPARTAMENTO DE HIDRÁULICA E SANEAMENTO \\ DFAPESP FUNDAÇÃO DE AMPARO À PESQUISA DO ESTADO DE SÃO PAULO}

Pesquisa: Avaliação do Risco para a Saúde da População da População Vizinha às Áreas de Disposição Final de Resíduos Sólidos Urbanos

1. Nome do entrevistador:

2. Nome da criança:

3. Semana no.

- Período:

4. Dias da Semana

5. Data: $(\mathrm{dd} / \mathrm{mm} / \mathrm{aa})$

6. Dia de visita semanal? $(0,1)$

7. Data de obtenção da informação?

8. A criança teve diarréia? $(0,1,77,99)$

9. Quantas vezes evacuou?

10. Quantas vezes fezes amolecidas?

11. Quantas vezes fezes líquidas?

12. Presença de sangue nas fezes? $(0,1,77,99)$

13. Presença de muco nas fezes? $(0,1,77,99)$

14. Teve febre? $(0,1,77,99)$

15. Teve vômito? $(0,1,77,99)$

16. Foi necessário ir a um serviço de saúde? $(0,1,77,99)$

16. Foi necessário internação?

$(0,1,77,99)$

17. Fez uso de antibiótico? $(0,1,77,99)$

18. Grau de parentesco da pessoa entrevistada em relação à criança

Respostas padronizadas:

I

I

\begin{tabular}{|l|l|l}
$\mathbf{4}^{\mathrm{a}}$. feira & $\mathbf{5}^{\mathrm{a}}$. feira & $\mathbf{6}^{\mathrm{a}}$. feira
\end{tabular}

\begin{tabular}{|c|c|}
\hline $\mathbf{2}^{\text {a. }}$ feira & $\mathbf{3}^{\text {a }}$. feira \\
\hline
\end{tabular}

99)

$\begin{array}{lll}0=\text { Não } & 1=\text { Sim } & 77=\text { Não sabe }\end{array}$

88 = Não se aplica

\begin{tabular}{|c|c|c|c|c|c|c|}
\hline $2^{\text {a. }}$ feira & $3^{a}$. feira & $4^{a}$ feira & $5^{a}$ feira & $6^{a}$. feira & Sábado & Domingo \\
\hline 1 & l & l & l & l & l & I \\
\hline
\end{tabular}

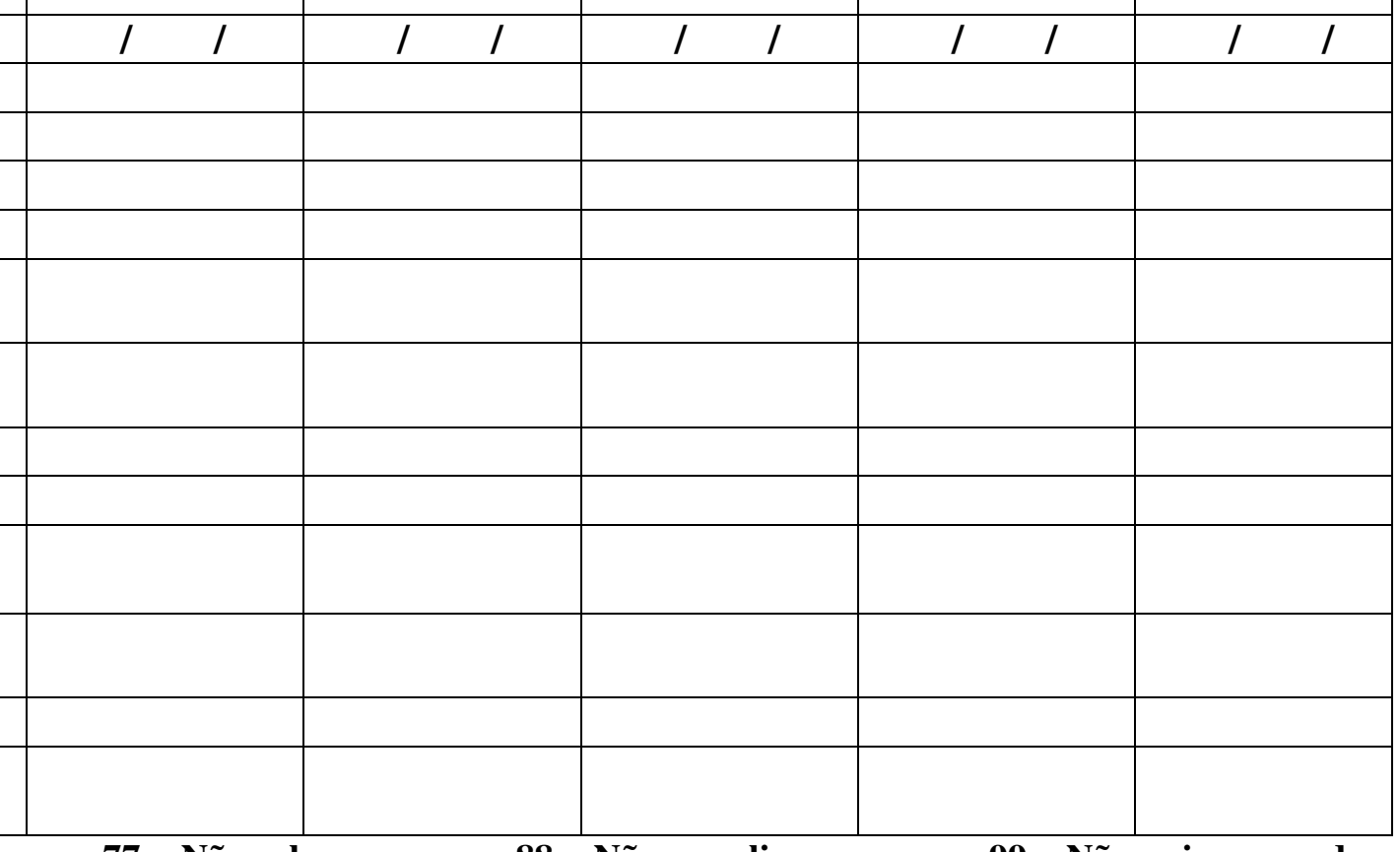

99 = Não quis responder

$$
\text { I_I______ I }
$$$$
\text { I I I I I- I I I }
$$
(utilizar o mesmo número do Protocolo 2) 


\section{TSPE E C \\ Universidade de São Paulo de São Carlos \\ DEPARTAMENTO DE HIDRÁULICA E SANEAMENTO \\ DFAPESP FUNDAÇÃO DE AMPARO À PESQUISA DO ESTADO DE SÃO PAULO}

Pesquisa: Avaliação do Risco para a Saúde da População da População Vizinha às Áreas de Disposição Final de Resíduos Sólidos Urbanos

1. Nome do entrevistador:

2. Nome da criança:

3. Semana no.

- Período:

4. Dias da Semana

5. Data: $(\mathrm{dd} / \mathrm{mm} / \mathrm{aa})$

6. Dia de visita semanal? $(0,1)$

7. Data de obtenção da informação?

8. A criança teve diarréia? $(0,1,77,99)$

9. Quantas vezes evacuou?

10. Quantas vezes fezes amolecidas?

11. Quantas vezes fezes líquidas?

12. Presença de sangue nas fezes? $(0,1,77,99)$

13. Presença de muco nas fezes? $(0,1,77,99)$

14. Teve febre? $(0,1,77,99)$

15. Teve vômito? $(0,1,77,99)$

16. Foi necessário ir a um serviço de saúde? $(0,1,77,99)$

16. Foi necessário internação?

$(0,1,77,99)$

17. Fez uso de antibiótico? $(0,1,77,99)$

18. Grau de parentesco da pessoa entrevistada em relação à criança

Respostas padronizadas:

I

I

\begin{tabular}{|l|l|l}
$\mathbf{4}^{\mathrm{a}}$. feira & $\mathbf{5}^{\mathrm{a}}$. feira & $\mathbf{6}^{\mathrm{a}}$. feira
\end{tabular}

\begin{tabular}{|c|c|}
\hline $\mathbf{2}^{\text {a. }}$ feira & $\mathbf{3}^{\text {a }}$. feira \\
\hline
\end{tabular}

99)

$\begin{array}{lll}0=\text { Não } & 1=\text { Sim } & 77=\text { Não sabe }\end{array}$

88 = Não se aplica

\begin{tabular}{|c|c|c|c|c|c|c|}
\hline $2^{\text {a. }}$ feira & $3^{a}$. feira & $4^{a}$ feira & $5^{a}$ feira & $6^{a}$. feira & Sábado & Domingo \\
\hline 1 & l & l & l & l & l & I \\
\hline
\end{tabular}

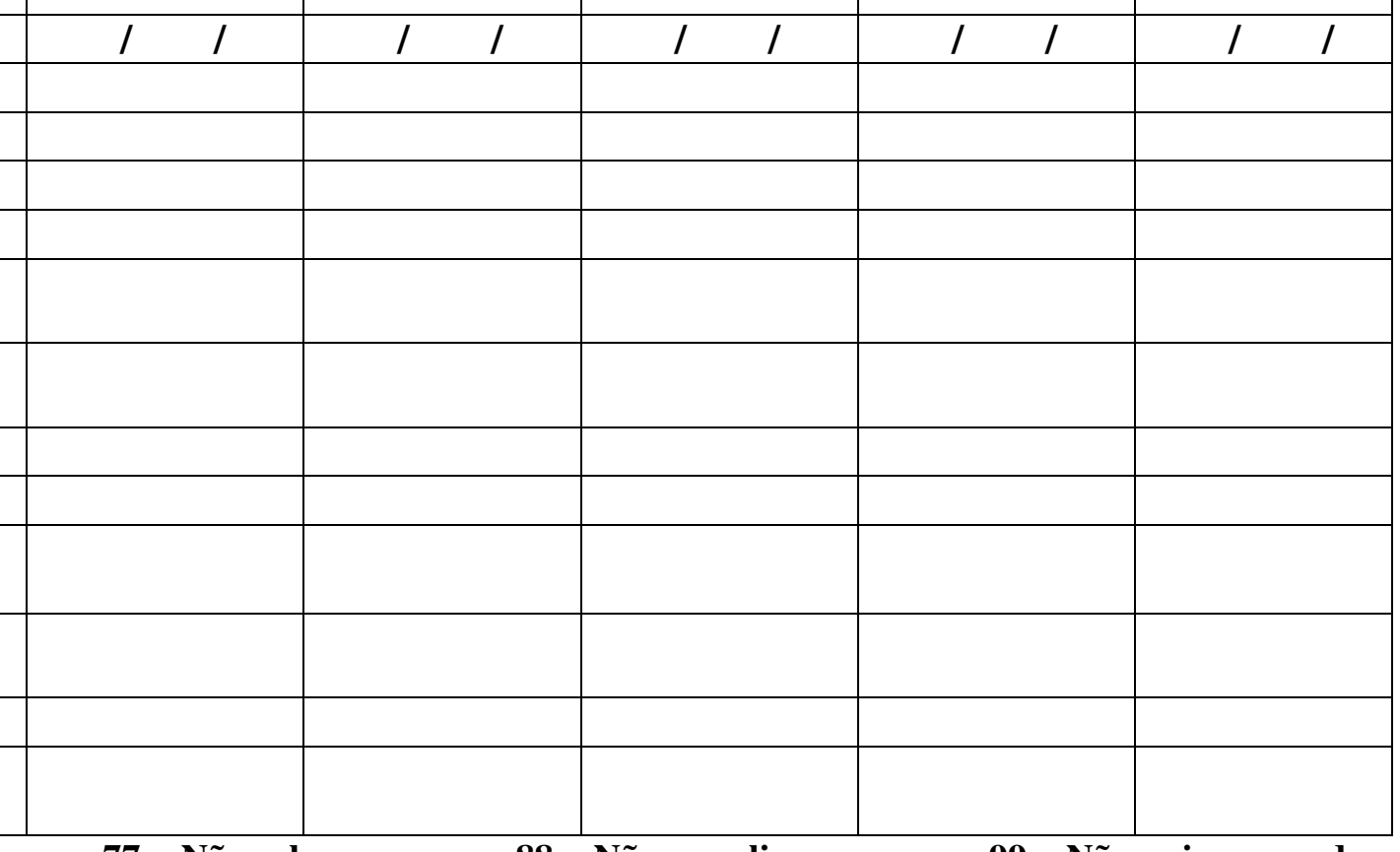

99 = Não quis responder

$$
\text { I_I______ I }
$$$$
\text { I I I I I- I I I }
$$
(utilizar o mesmo número do Protocolo 2) 


\section{TSPE E C \\ Universidade de São Paulo de São Carlos \\ DEPARTAMENTO DE HIDRÁULICA E SANEAMENTO \\ DFAPESP FUNDAÇÃO DE AMPARO À PESQUISA DO ESTADO DE SÃO PAULO}

Pesquisa: Avaliação do Risco para a Saúde da População da População Vizinha às Áreas de Disposição Final de Resíduos Sólidos Urbanos

1. Nome do entrevistador:

2. Nome da criança:

3. Semana no.

- Período:

4. Dias da Semana

5. Data: $(\mathrm{dd} / \mathrm{mm} / \mathrm{aa})$

6. Dia de visita semanal? $(0,1)$

7. Data de obtenção da informação?

8. A criança teve diarréia? $(0,1,77,99)$

9. Quantas vezes evacuou?

10. Quantas vezes fezes amolecidas?

11. Quantas vezes fezes líquidas?

12. Presença de sangue nas fezes? $(0,1,77,99)$

13. Presença de muco nas fezes? $(0,1,77,99)$

14. Teve febre? $(0,1,77,99)$

15. Teve vômito? $(0,1,77,99)$

16. Foi necessário ir a um serviço de saúde? $(0,1,77,99)$

16. Foi necessário internação?

$(0,1,77,99)$

17. Fez uso de antibiótico? $(0,1,77,99)$

18. Grau de parentesco da pessoa entrevistada em relação à criança

Respostas padronizadas:

I

I

\begin{tabular}{|l|l|l}
$\mathbf{4}^{\mathrm{a}}$. feira & $\mathbf{5}^{\mathrm{a}}$. feira & $\mathbf{6}^{\mathrm{a}}$. feira
\end{tabular}

\begin{tabular}{|c|c|}
\hline $\mathbf{2}^{\text {a. }}$ feira & $\mathbf{3}^{\text {a }}$. feira \\
\hline
\end{tabular}

99)

$\begin{array}{lll}0=\text { Não } & 1=\text { Sim } & 77=\text { Não sabe }\end{array}$

88 = Não se aplica

\begin{tabular}{|c|c|c|c|c|c|c|}
\hline $2^{\text {a. }}$ feira & $3^{a}$. feira & $4^{a}$ feira & $5^{a}$ feira & $6^{a}$. feira & Sábado & Domingo \\
\hline 1 & l & l & l & l & l & I \\
\hline
\end{tabular}

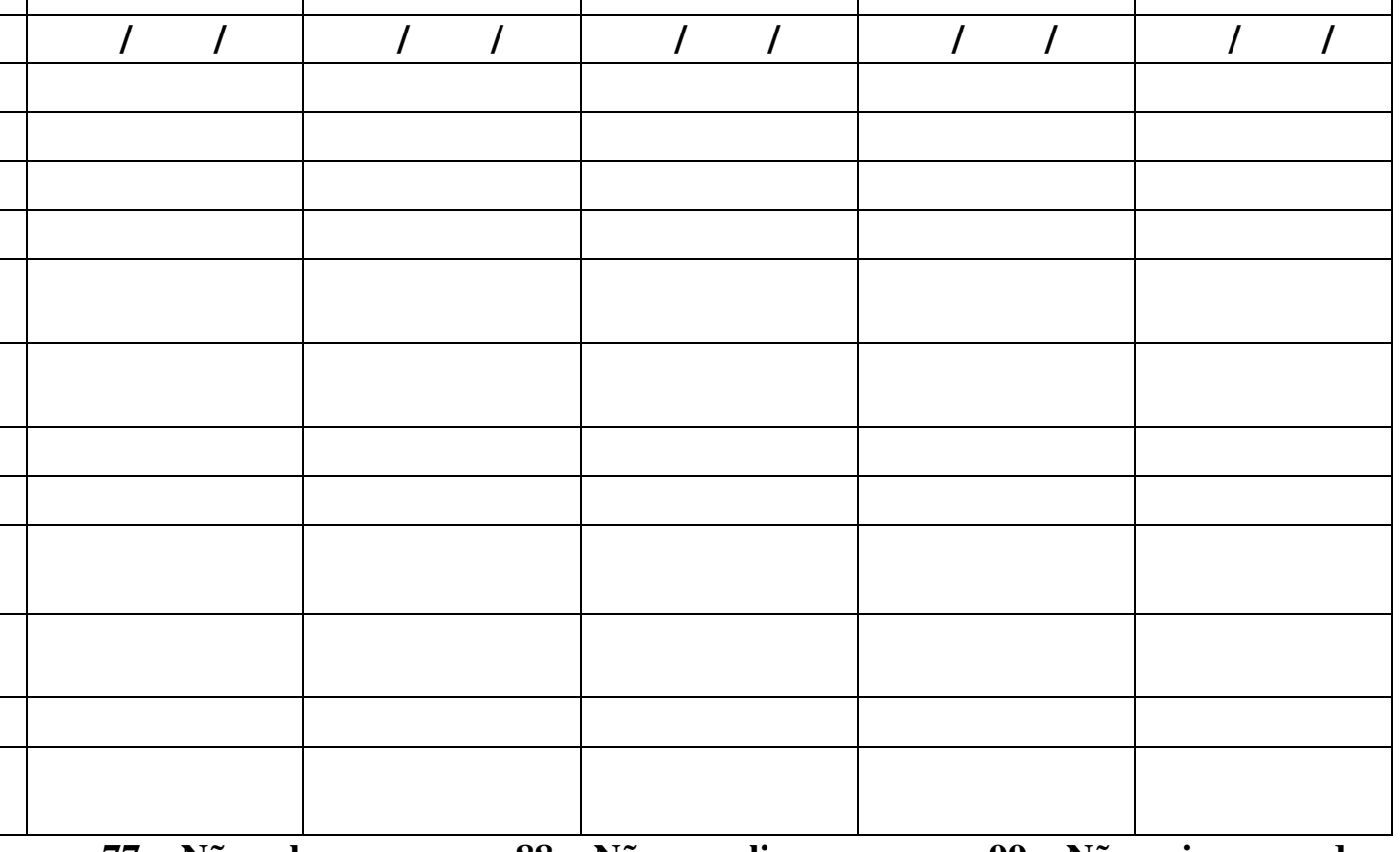

99 = Não quis responder

$$
\text { I_I______ I }
$$$$
\text { I I I I I- I I I }
$$
(utilizar o mesmo número do Protocolo 2) 


\section{TSPE E C \\ Universidade de São Paulo de São Carlos \\ DEPARTAMENTO DE HIDRÁULICA E SANEAMENTO \\ DFAPESP FUNDAÇÃO DE AMPARO À PESQUISA DO ESTADO DE SÃO PAULO}

Pesquisa: Avaliação do Risco para a Saúde da População da População Vizinha às Áreas de Disposição Final de Resíduos Sólidos Urbanos

1. Nome do entrevistador:

2. Nome da criança:

3. Semana no.

- Período:

4. Dias da Semana

5. Data: $(\mathrm{dd} / \mathrm{mm} / \mathrm{aa})$

6. Dia de visita semanal? $(0,1)$

7. Data de obtenção da informação?

8. A criança teve diarréia? $(0,1,77,99)$

9. Quantas vezes evacuou?

10. Quantas vezes fezes amolecidas?

11. Quantas vezes fezes líquidas?

12. Presença de sangue nas fezes? $(0,1,77,99)$

13. Presença de muco nas fezes? $(0,1,77,99)$

14. Teve febre? $(0,1,77,99)$

15. Teve vômito? $(0,1,77,99)$

16. Foi necessário ir a um serviço de saúde? $(0,1,77,99)$

16. Foi necessário internação?

$(0,1,77,99)$

17. Fez uso de antibiótico? $(0,1,77,99)$

18. Grau de parentesco da pessoa entrevistada em relação à criança

Respostas padronizadas:

I

I

\begin{tabular}{|l|l|l}
$\mathbf{4}^{\mathrm{a}}$. feira & $\mathbf{5}^{\mathrm{a}}$. feira & $\mathbf{6}^{\mathrm{a}}$. feira
\end{tabular}

\begin{tabular}{|c|c|}
\hline $\mathbf{2}^{\text {a. }}$ feira & $\mathbf{3}^{\text {a }}$. feira \\
\hline
\end{tabular}

99)

$\begin{array}{lll}0=\text { Não } & 1=\text { Sim } & 77=\text { Não sabe }\end{array}$

88 = Não se aplica

\begin{tabular}{|c|c|c|c|c|c|c|}
\hline $2^{\text {a. }}$ feira & $3^{a}$. feira & $4^{a}$ feira & $5^{a}$ feira & $6^{a}$. feira & Sábado & Domingo \\
\hline 1 & l & l & l & l & l & I \\
\hline
\end{tabular}

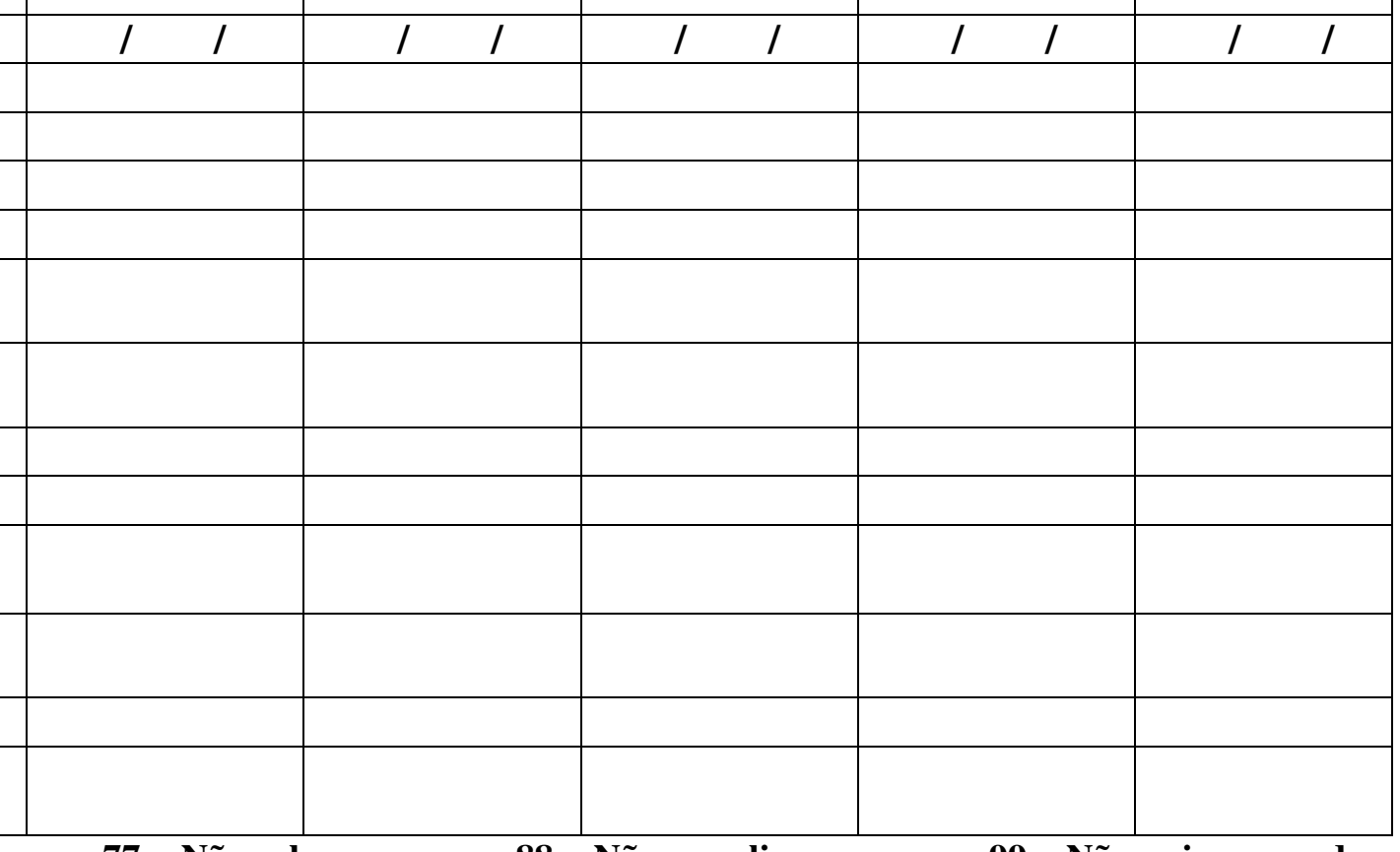

99 = Não quis responder

$$
\text { I_I______ I }
$$$$
\text { I I I I I- I I I }
$$
(utilizar o mesmo número do Protocolo 2) 


\section{TSPE E C \\ Universidade de São Paulo de São Carlos \\ DEPARTAMENTO DE HIDRÁULICA E SANEAMENTO \\ DFAPESP FUNDAÇÃO DE AMPARO À PESQUISA DO ESTADO DE SÃO PAULO}

Pesquisa: Avaliação do Risco para a Saúde da População da População Vizinha às Áreas de Disposição Final de Resíduos Sólidos Urbanos

1. Nome do entrevistador:

2. Nome da criança:

3. Semana no.

- Período:

4. Dias da Semana

5. Data: $(\mathrm{dd} / \mathrm{mm} / \mathrm{aa})$

6. Dia de visita semanal? $(0,1)$

7. Data de obtenção da informação?

8. A criança teve diarréia? $(0,1,77,99)$

9. Quantas vezes evacuou?

10. Quantas vezes fezes amolecidas?

11. Quantas vezes fezes líquidas?

12. Presença de sangue nas fezes? $(0,1,77,99)$

13. Presença de muco nas fezes? $(0,1,77,99)$

14. Teve febre? $(0,1,77,99)$

15. Teve vômito? $(0,1,77,99)$

16. Foi necessário ir a um serviço de saúde? $(0,1,77,99)$

16. Foi necessário internação?

$(0,1,77,99)$

17. Fez uso de antibiótico? $(0,1,77,99)$

18. Grau de parentesco da pessoa entrevistada em relação à criança

Respostas padronizadas:

I

I

\begin{tabular}{|l|l|l}
$\mathbf{4}^{\mathrm{a}}$. feira & $\mathbf{5}^{\mathrm{a}}$. feira & $\mathbf{6}^{\mathrm{a}}$. feira
\end{tabular}

\begin{tabular}{|c|c|}
\hline $\mathbf{2}^{\text {a. }}$ feira & $\mathbf{3}^{\text {a }}$. feira \\
\hline
\end{tabular}

99)

$\begin{array}{lll}0=\text { Não } & 1=\text { Sim } & 77=\text { Não sabe }\end{array}$

88 = Não se aplica

\begin{tabular}{|c|c|c|c|c|c|c|}
\hline $2^{\text {a. }}$ feira & $3^{a}$. feira & $4^{a}$ feira & $5^{a}$ feira & $6^{a}$. feira & Sábado & Domingo \\
\hline 1 & l & l & l & l & l & I \\
\hline
\end{tabular}

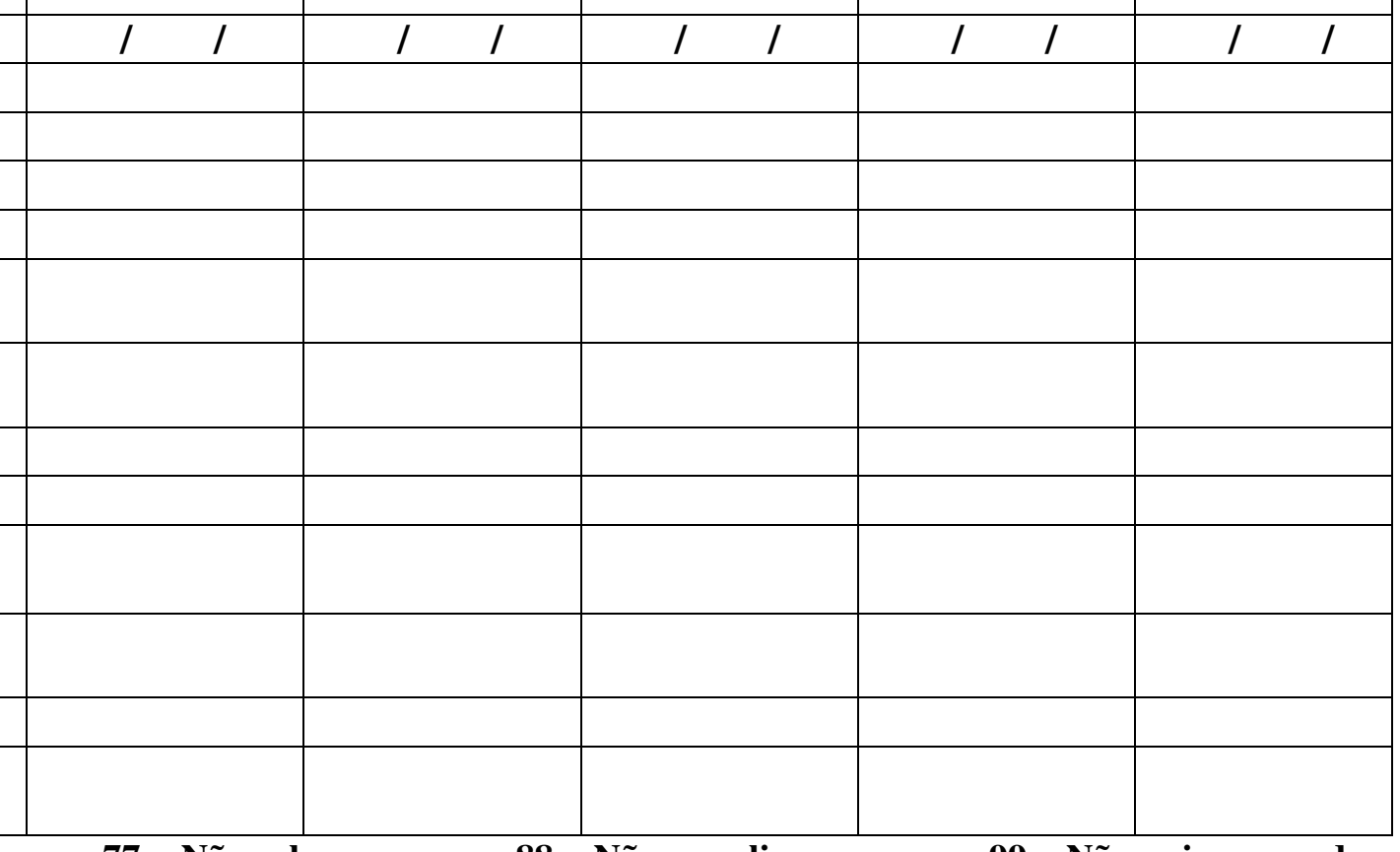

99 = Não quis responder

$$
\text { I_I______ I }
$$$$
\text { I I I I I- I I I }
$$
(utilizar o mesmo número do Protocolo 2) 


\section{TSPE E C \\ Universidade de São Paulo de São Carlos \\ DEPARTAMENTO DE HIDRÁULICA E SANEAMENTO \\ DFAPESP FUNDAÇÃO DE AMPARO À PESQUISA DO ESTADO DE SÃO PAULO}

Pesquisa: Avaliação do Risco para a Saúde da População da População Vizinha às Áreas de Disposição Final de Resíduos Sólidos Urbanos

1. Nome do entrevistador:

2. Nome da criança:

3. Semana no.

- Período:

4. Dias da Semana

5. Data: $(\mathrm{dd} / \mathrm{mm} / \mathrm{aa})$

6. Dia de visita semanal? $(0,1)$

7. Data de obtenção da informação?

8. A criança teve diarréia? $(0,1,77,99)$

9. Quantas vezes evacuou?

10. Quantas vezes fezes amolecidas?

11. Quantas vezes fezes líquidas?

12. Presença de sangue nas fezes? $(0,1,77,99)$

13. Presença de muco nas fezes? $(0,1,77,99)$

14. Teve febre? $(0,1,77,99)$

15. Teve vômito? $(0,1,77,99)$

16. Foi necessário ir a um serviço de saúde? $(0,1,77,99)$

16. Foi necessário internação?

$(0,1,77,99)$

17. Fez uso de antibiótico? $(0,1,77,99)$

18. Grau de parentesco da pessoa entrevistada em relação à criança

Respostas padronizadas:

I

I

\begin{tabular}{|l|l|l}
$\mathbf{4}^{\mathrm{a}}$. feira & $\mathbf{5}^{\mathrm{a}}$. feira & $\mathbf{6}^{\mathrm{a}}$. feira
\end{tabular}

\begin{tabular}{|c|c|}
\hline $\mathbf{2}^{\text {a. }}$ feira & $\mathbf{3}^{\text {a }}$. feira \\
\hline
\end{tabular}

99)

$\begin{array}{lll}0=\text { Não } & 1=\text { Sim } & 77=\text { Não sabe }\end{array}$

88 = Não se aplica

\begin{tabular}{|c|c|c|c|c|c|c|}
\hline $2^{\text {a. }}$ feira & $3^{a}$. feira & $4^{a}$ feira & $5^{a}$ feira & $6^{a}$. feira & Sábado & Domingo \\
\hline 1 & l & l & l & l & l & I \\
\hline
\end{tabular}

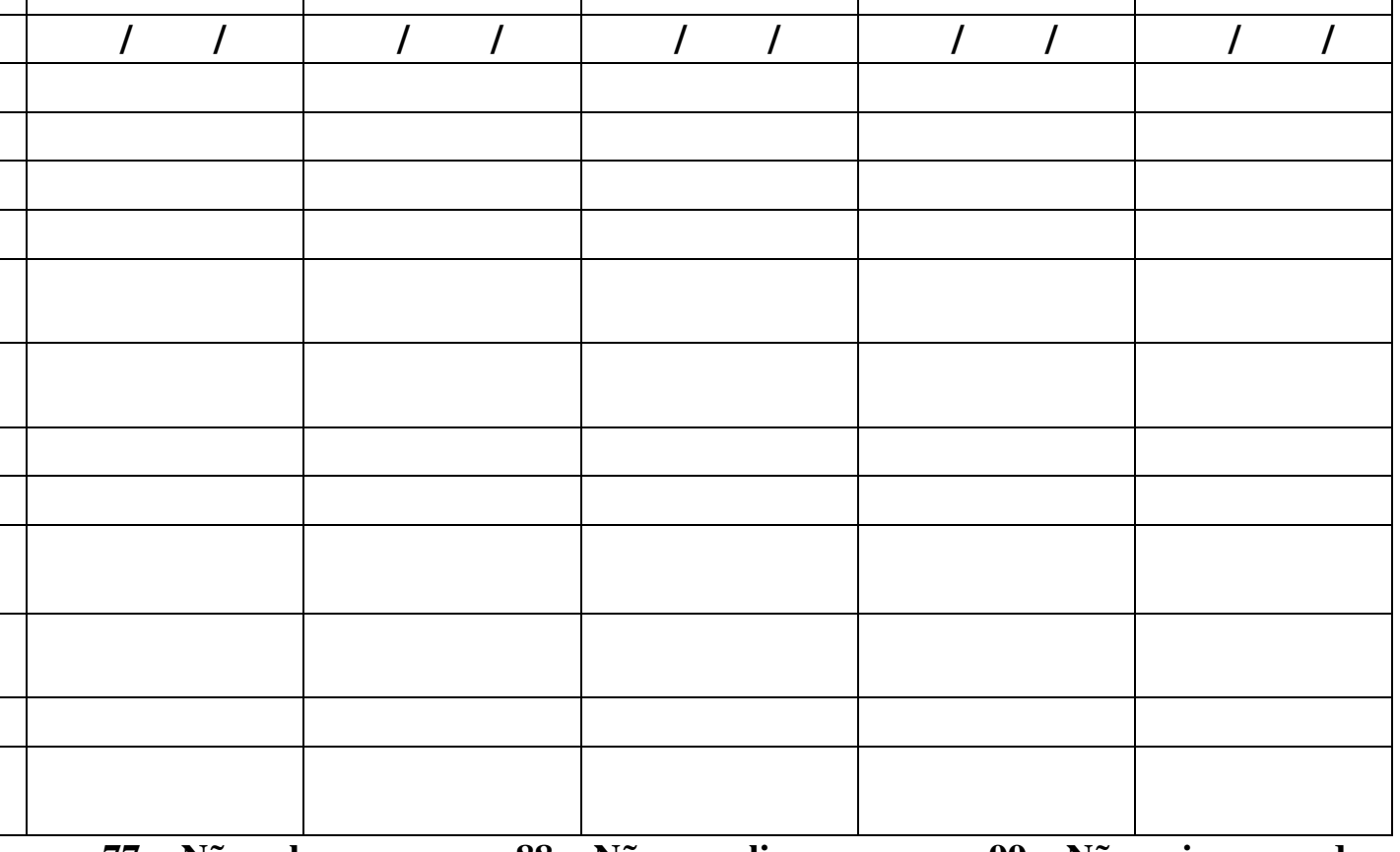

99 = Não quis responder

$$
\text { I_I______ I }
$$$$
\text { I I I I I- I I I }
$$
(utilizar o mesmo número do Protocolo 2) 


\section{TSPE E C \\ Universidade de São Paulo de São Carlos \\ DEPARTAMENTO DE HIDRÁULICA E SANEAMENTO \\ DFAPESP FUNDAÇÃO DE AMPARO À PESQUISA DO ESTADO DE SÃO PAULO}

Pesquisa: Avaliação do Risco para a Saúde da População da População Vizinha às Áreas de Disposição Final de Resíduos Sólidos Urbanos

1. Nome do entrevistador:

2. Nome da criança:

3. Semana no.

- Período:

4. Dias da Semana

5. Data: $(\mathrm{dd} / \mathrm{mm} / \mathrm{aa})$

6. Dia de visita semanal? $(0,1)$

7. Data de obtenção da informação?

8. A criança teve diarréia? $(0,1,77,99)$

9. Quantas vezes evacuou?

10. Quantas vezes fezes amolecidas?

11. Quantas vezes fezes líquidas?

12. Presença de sangue nas fezes? $(0,1,77,99)$

13. Presença de muco nas fezes? $(0,1,77,99)$

14. Teve febre? $(0,1,77,99)$

15. Teve vômito? $(0,1,77,99)$

16. Foi necessário ir a um serviço de saúde? $(0,1,77,99)$

16. Foi necessário internação?

$(0,1,77,99)$

17. Fez uso de antibiótico? $(0,1,77,99)$

18. Grau de parentesco da pessoa entrevistada em relação à criança

Respostas padronizadas:

I

I

\begin{tabular}{|l|l|l}
$\mathbf{4}^{\mathrm{a}}$. feira & $\mathbf{5}^{\mathrm{a}}$. feira & $\mathbf{6}^{\mathrm{a}}$. feira
\end{tabular}

\begin{tabular}{|c|c|}
\hline $\mathbf{2}^{\text {a. }}$ feira & $\mathbf{3}^{\text {a }}$. feira \\
\hline
\end{tabular}

99)

$\begin{array}{lll}0=\text { Não } & 1=\text { Sim } & 77=\text { Não sabe }\end{array}$

88 = Não se aplica

\begin{tabular}{|c|c|c|c|c|c|c|}
\hline $2^{\text {a. }}$ feira & $3^{a}$. feira & $4^{a}$ feira & $5^{a}$ feira & $6^{a}$. feira & Sábado & Domingo \\
\hline 1 & l & l & l & l & l & I \\
\hline
\end{tabular}

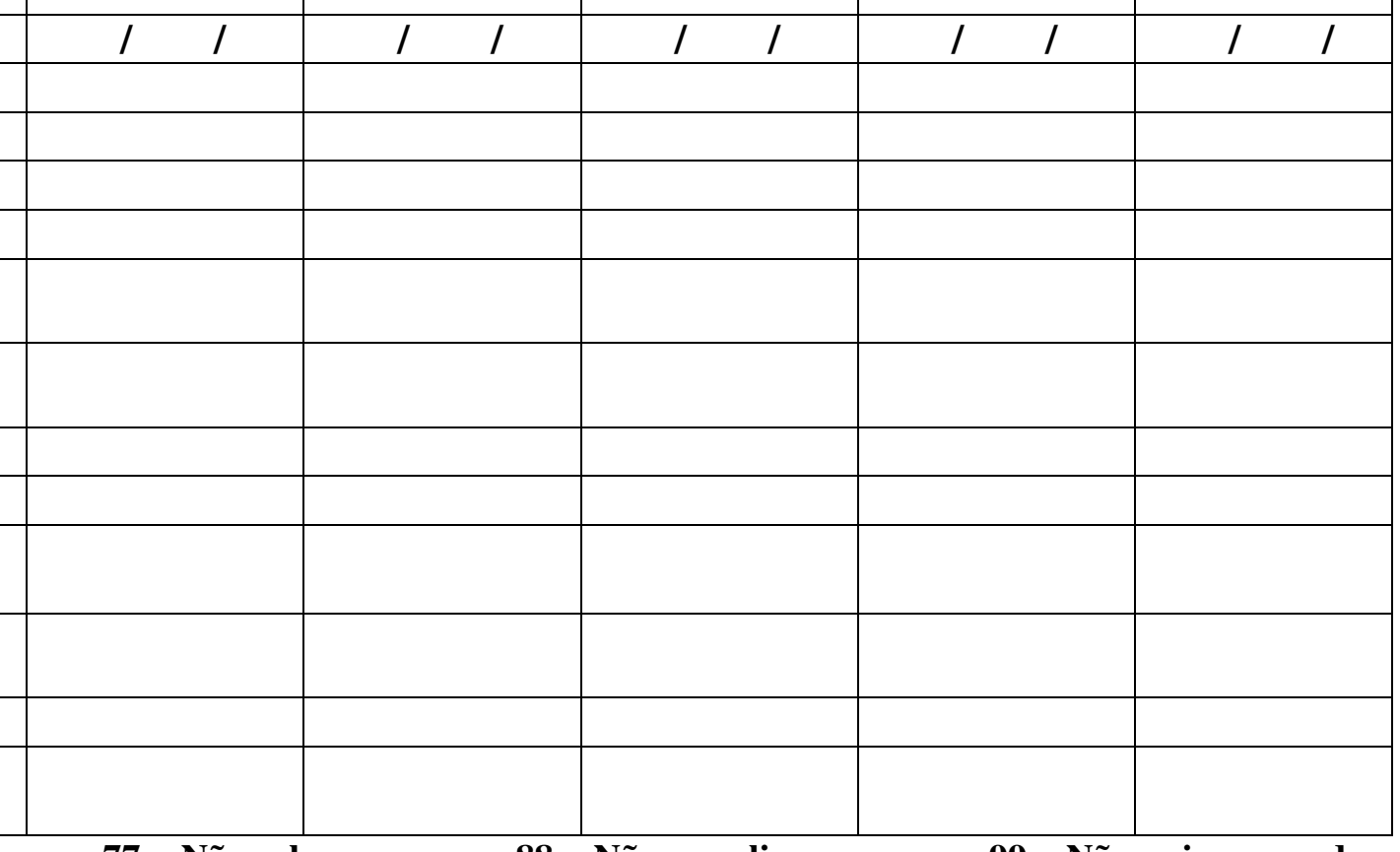

99 = Não quis responder

$$
\text { I_I______ I }
$$$$
\text { I I I I I- I I I }
$$
(utilizar o mesmo número do Protocolo 2) 


\section{TSPE E C \\ Universidade de São Paulo de São Carlos \\ DEPARTAMENTO DE HIDRÁULICA E SANEAMENTO \\ DFAPESP FUNDAÇÃO DE AMPARO À PESQUISA DO ESTADO DE SÃO PAULO}

Pesquisa: Avaliação do Risco para a Saúde da População da População Vizinha às Áreas de Disposição Final de Resíduos Sólidos Urbanos

1. Nome do entrevistador:

2. Nome da criança:

3. Semana no.

- Período:

4. Dias da Semana

5. Data: $(\mathrm{dd} / \mathrm{mm} / \mathrm{aa})$

6. Dia de visita semanal? $(0,1)$

7. Data de obtenção da informação?

8. A criança teve diarréia? $(0,1,77,99)$

9. Quantas vezes evacuou?

10. Quantas vezes fezes amolecidas?

11. Quantas vezes fezes líquidas?

12. Presença de sangue nas fezes? $(0,1,77,99)$

13. Presença de muco nas fezes? $(0,1,77,99)$

14. Teve febre? $(0,1,77,99)$

15. Teve vômito? $(0,1,77,99)$

16. Foi necessário ir a um serviço de saúde? $(0,1,77,99)$

16. Foi necessário internação?

$(0,1,77,99)$

17. Fez uso de antibiótico? $(0,1,77,99)$

18. Grau de parentesco da pessoa entrevistada em relação à criança

Respostas padronizadas:

I

I

\begin{tabular}{|l|l|l}
$\mathbf{4}^{\mathrm{a}}$. feira & $\mathbf{5}^{\mathrm{a}}$. feira & $\mathbf{6}^{\mathrm{a}}$. feira
\end{tabular}

\begin{tabular}{|c|c|}
\hline $\mathbf{2}^{\text {a. }}$ feira & $\mathbf{3}^{\text {a }}$. feira \\
\hline
\end{tabular}

99)

$\begin{array}{lll}0=\text { Não } & 1=\text { Sim } & 77=\text { Não sabe }\end{array}$

88 = Não se aplica

\begin{tabular}{|c|c|c|c|c|c|c|}
\hline $2^{\text {a. }}$ feira & $3^{a}$. feira & $4^{a}$ feira & $5^{a}$ feira & $6^{a}$. feira & Sábado & Domingo \\
\hline 1 & l & l & l & l & l & I \\
\hline
\end{tabular}

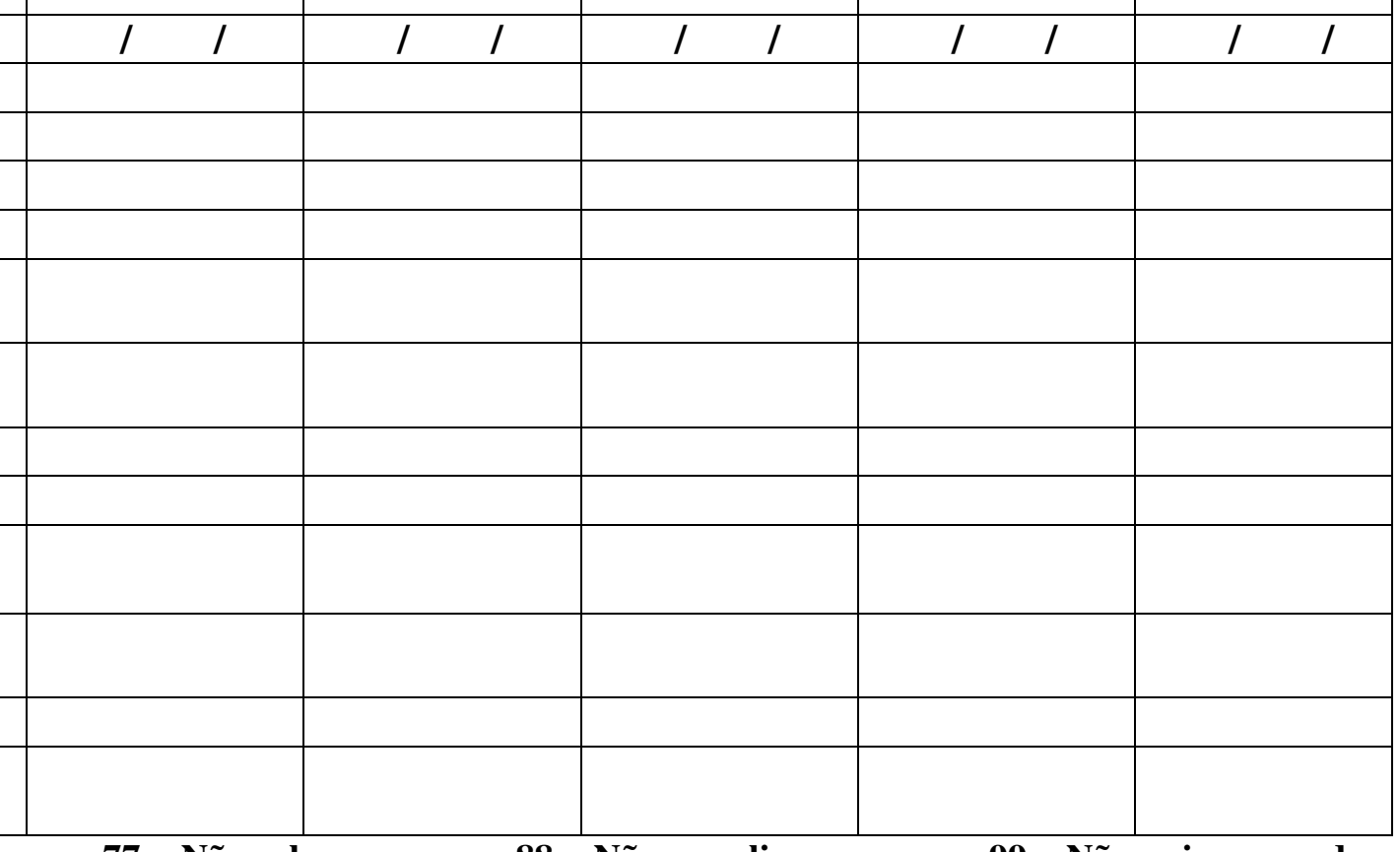

99 = Não quis responder

$$
\text { I_I______ I }
$$$$
\text { I I I I I- I I I }
$$
(utilizar o mesmo número do Protocolo 2) 
ANEXO D

Carta de Encerramento da Pesquisa 


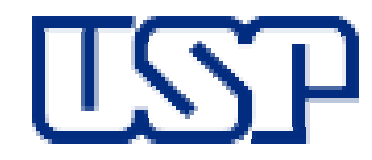

Universidade de 5ão Paulo

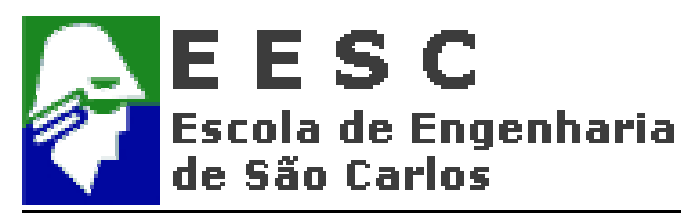

de Sấo Carlos

DEPARTAMENTO DE HIDRÁULICA E SANEAMENTO

DFAPESP

FUndAÇão dE AMPARO À PESQUISA do ESTADO DE SÃo PaUlo

Pesquisa: AVALIAÇÃO DO RISCO PARA A SAÚDE DA POPULAÇÃO VIZINHA ÀS ÁREAS DE DISPOSIÇÃO FINAL DOS RESÍDUOS SÓLIDOS URBANOS

São Paulo, 31 de março de 2003.

Prezada Senhora,

Comunicamos que estamos encerrando a etapa de coleta de dados, levantados junto à população do Bairro de Perus, da pesquisa intitulada: “AVALIAÇÃO DO RISCO PARA A SAÚdE da POPULAÇÃo VIZINHA ÀS ÁREAS dE DISPOSIÇÃo FINAL dOS RESÍDUOS SÓLIDOS URBANOS”, na qual contamos com sua participação e colaboração.

Encaminhamos, em anexo, o resultado do exame parasitológico realizado em seu filho. Comunicamos que, caso o resultado do exame seja positivo, que estaremos informando o resultado à Unidade Básica de Saúde de Perus/Secretaria Municipal de Saúde, a qual entrará em contato com a senhora, agendando um dia e local para o atendimento da criança. Pedimos o seu comparecimento, dada a importância para a saúde de seu filho.

Gostaríamos de agradecer a sua participação na referida pesquisa, sem a qual não teríamos obtido os resultados esperados. Obrigado.

Atenciosamente,

Mônica de Abreu Azevedo e Valdir Schalch

Pesquisadores Responsáveis 


\section{REFERÊNCIAS BIBLIOGRÁFICAS}

ACURIO, G. \& et al. Diagnóstico de la situación del manejo de residuos sólidos municipales en América Latina y el Caribe.2 ed. Washington: OPS, 1998, 153 p.

AHUMADA, H. T. Condiciones de salud de la población vencina a una planta recicladora de residuos en México. Rev. Panam. Salud Publica, 3 (1): 15-20, 1998.

ALMEIDA FILHO, N. \& ROUQUAYROL, M. Z. Introdução à epidemiologia moderna. 2. ed. Belo Horizonte: COOPMED, 1992. 186 p.

AZEVEDO, M. A. Estudo e avaliação de quatro modos de aeração para sistemas de compostagem em leiras. Belo Horizonte. Escola de Engenharia da UFMG, 1993. 194 p. (Dissertação, Mestrado em Saneamento, Meio Ambiente e Recursos Hídricos).

AZEVEDO, M. A. Gerenciamento de resíduos sólidos. Departamento de Engenharia Civil, UFV, 1995. 79 p. (Apostila).

AZEVEDO, M. A. Realização de diagnóstico sócio-ambiental participativo - uma ferramenta para a implantação de sistemas de saneamento básico em comunidades carentes. In: Reunião Anual da SBPC, 50, Natal, 1998, Anais. São Paulo: SBPC, 1998.

AZEVEDO, M. A. Ações desenvolvidas por estudantes de engenharia para a melhoria das condições ambientais de uma comunidade carente. In: Congresso Brasileiro de Ensino de Engenharia, 27, Natal, 1999, Anais eletrônico ... ABENGE, 1999, 16p.

AZEVEDO, M. A., AZEVEDO, E. A. \& HELLER, L. Bases metodológicas para o desenvolvimento de uma classificação ambiental para as doenças relacionadas aos resíduos sólidos. In: Congreso Interamericano de Ingeniería Sanitaria y 
Ambiental, 27, Porto Alegre, 2000, Anais eletrônico... Rio de Janeiro: ABES, 2000. 6p.

AZEVEDO, E. A. Exclusão sanitária em Belo Horizonte, MG: caracterização e associação com indicadores de saúde. Belo Horizonte: Escola de Engenharia, UFMG, 2003. 187 p. (Dissertação, Mestrado em Saneamento, Meio Ambiente e Recursos Hídricos).

AZEVEDO, M. A. \& AZEVEDO E. A. Proposição de uma classificação ambiental para as doenças relacionadas aos resíduos sólidos. In: Congresso Brasileiro de Engenharia Sanitária e Ambiental, 22, Joinville, 2003, Anais eletrônico... Rio de Janeiro: ABES, 2003. 29p.

BARREIRA, L. P. \& PHILIPPI JR., A. Panorama da situação do tratamento e disposição de resíduos sólidos urbanos na cidade de São Paulo: Aterros Bandeirantes e Sítio São João. In: Congresso Brasileiro de Engenharia Sanitária e Ambiental, 21, João Pessoa, 2001, Anais eletrônico ... Rio de Janeiro: ABES, 2001, 5p.

BARROS, R. T. V. Resíduos sólidos. Belo Horizonte. Departamento de Engenharia Sanitária e Ambiental, Escola de Engenharia da UFMG, 1998, 62 p. (Apostila).

BERRY, M. \& BOVE, F. Birth weight redution associated with residence near a hazardous waste landifill. Environmental Health Perspectives, 105 (8): 856 861.

BORJA, P. C. \& MORAES, L. R. S. Indicadores de saúde ambiental - saneamento em políticas públicas: análise crítica e proposta. In: Congreso Interamericano de Ingeniería Sanitaria y Ambiental, 27, Porto Alegre, 2000, Anais eletrônico... Rio de Janeiro: ABES, 2000. 17 p.

BRILHANTE, O. M. \& CALDAS, L. Q. A. Gestão e avaliação de risco em saúde ambiental. Rio de Janeiro: FIOCRUZ, 1999, 155 p.

BRISCOE, J., FEACHEM, R. G. \& RAHAMAN, M. M. Evaluating health impact: water supply. sanitation and higiene education. Ottawa: Internacional Development Research Centre, 1866. 80 p.

BUDNICK, L. D.; SOKAL, D. C.; FALK, H.; LOGUE, J. N. \& FOX, J. Cancer and birth defects near the Drake Superfund Site, Pennsylvania. Archives of Environmental Health, 39 (6): 409 - 413, 1984. 
CAIRNCROSS, S.; FEACHEM, R. G. Environmental health engineering in the tropics an introductory text. 2 ed. Chichester/New York/Brisbane/Toronto/ Singapore: John Wiley \& Sons, 1990. 283 p.

CATAPRETA, C. A. A. Associação entre coleta de resíduos sólidos domiciliares e indicadores de saúde em vilas e favelas de Belo Horizonte. Belo Horizonte: Escola de Engenharia da UFMG, 1997. 158 p. (Dissertação, Mestrado em Saneamento, Meio Ambiente e Recursos Hídricos).

CEPIS. Guía para el manejo de residuos sólidos en ciudades pequeñas y zonas rurales. OPS/CEPIS, 1997, $70 \mathrm{p}$.

CEPOLLINA ENGENHEIROS CONSULTORES S/C. Aterro Sanitário Bandeirantes - relatório ambiental HFCT 300503. São Paulo, 2003.

CHRISTENSEN, T. H. \& KJELDSEN, P. Landfill emissions and environmental impact: an introduction. In: International Landifill Symposium, 5, Italy, 1995. Anais ... Cagliari: CIA, Environmental Sanitary Engineering Centre, 1995, p.3 12.

COAD, A. Manejo de desechos médicos en países en desarrollo. Genebra: OMS, 1992, 43 p.

CROEN, L. A.; SHAW, G. M.; SANBONMATSU, L.; SELVIN, S. \& BUFFLER, P. A. Maternal residential proximity to hazardous waste site and risk for selected congenital malformations. Epidemiology, 8 (4): 347 - 354, 1997, 1997.

DANIEL, M.; SIXL, W. \& KOCK, M. Problems of housing and health of people utilizing the garbage in Cairo from the viewpoint of medical entomology. Journal of Hygiene, Epidemiology, Microbiology and Immunology, 33 (4): 568 $-576,1989$.

DIAZ, L. F. Solid Waste Management for Economically Developing Countries. ISWA, 1996, $415 \mathrm{p}$.

DE CARLI, G. A. Diagnóstico laboratorial das parasitoses humanas - métodos e técnicas. Rio de Janeiro: Editora Médica e Científica, 1994. 315 p.

EPA. Design, Operation and Closure of Municipal Solid Waste Landfills. Cincinnati: EPA, 1994, 86 p.

ESRI. ENVIRONMENTAL SYSTEM RESEARCH INSTITUTE. PC ARC/INFO, Command references. New York, 1994. 
FEACHEM, R.G. Water supplies for low-income communities in developing coutries. J. Envir. Engrg Div, ASCE, v. 101, p. 687-703, 1975.

FEACHEM, R.G.; BRADLEY, D. J.; GARELICK, H. \& MARA, D. D. Sanitation and disease - health aspects of excreta and wastewater management. Chichester: John Wiley, 1983. 501 p.

FEDORAK, P. M. \& ROGERS, R. E. Assessment of the potencil health risks associated with the dissemination of microorganisms from landifill site. In: Waste Management \& Research. ISWA, 1991. p. 537 - 563.

FORATTINI, O. P. Aspectos epidemiológicos ligados ao lixo. In: Lixo e Limpeza Pública. USP-FSP/OMS-OPAS. São Paulo. 1969. p. 3.1-3.19.

GERBA, C. P. Microbial pathogens in municipal solid waste. In: Microbiology of Solid Waste. New York, CRC Press, 1996, p. 155 - 173.

GESCHWIND, S. A.; STOLWIJK, J. A J.; BRACKEN, M.; FITZGERALD, E.; STARK, A; OLSEN, C. \& MELIUS, J. Risk of congenital malformation associated with proximity to hazardous waste sites. American Journal of Epidemiology, 135 (11): 1197 - 1207, 1992.

GIROUT, E. \& BROWN, J. C. A. Public health aspects of municipal solid waste management. In: Internacional source book on environmentally sound technologies for municipal solid waste management / UNEP - Internacional Environmental Technology Centre. Osaka/Shiga, 1996. 12 p.

GOLUEKE, C.G. "Biological processing: composting and hydrolisis". Handbook of Solid Waste Management. New York, Van Nostrand Reinholds Company, 1977. p. 197-225.

GOMES, L. P. Estudo da caracterização física e da biodegradabilidade dos resíduos sólidos urbanos em aterros sanitários. São Carlos, 1989, 166 p. Dissertação (Mestrado) - Departamento de Hidráulica e Saneamento - Escola de Engenharia de São Carlos, Universidade de São Pulo, 1989.

GOLDBERG, M. S.; GOULET L.; RIBERDY, H. \& BONVALOT, Y. Low birth weight and preterm births among infants born to women living near a municipal solid waste landfill site in Montreal, Quebec. Environmental Research, 69 (1): $37-50,1995 \mathrm{a}$. 
GOLDBERG, M. S.; AL-HOMSI, N.; GOULET L. \& RIBERDY, H. Incidence of cancer among persons living near a municipal solid waste landfill site in Montreal, Quebec. Archives of Environmental Health, 50 (6): 416 - 424, 1995b.

GREISER, E.; LOTZ, I.; BRAND, H. \& WEBER, H. Increased incidence of leukemias in the vicinity of a previous industrial waste dump in North RhineWestfalia, West Germany. American Journal of Epidemiology, 134 (7): 755, 1991.

GRIFFITH, J.; DUNCAN, R. C.; RIGGAN, W. B. \& PELlOM, A C. Cancer mortality in U. S. counties with hazardous waste sites and ground water pollution. Archives of Environmental Health, 44 (2): 69 - 74, 1989.

HELLER, L. Associação entre cenários de saneamento e diarréia em Betim - MG: o emprego do delineamento epidemiológico caso - controle na definição de prioridades de intervenção. Belo Horizonte: Escola de Veterinária, UFMG, 1995. 294 p. (Tese, Doutorado em Ciência Animal).

HELLER, L. \& MÖLlER, L. M. Saneamento e Saúde Pública. In: Manual de Saneamento e Proteção Ambiental para os Municípios. v.2. Belo Horizonte: Escola de Engenharia da UFMG, 1995. p. $51-61$.

HELLER, L. Saneamento e Saúde. Brasília: OPAS/OMS, 1997, 97 p.

HOSMER, D. W. \& LEMESHOW, S. Applied logistic regression. 2 ed. New York: John Wiley, 2000.

HONG, Y.; PAN, S.; SHOA, Q.; LIU, F. \& DUO, Y. A study to define a standard health protection zone for sanitary landfill in Fu Shan city. Waste management \& Research, 14 (5): 505-510, 1996.

JARAMILLO, J. Residuos Solidos Municipales - Guia para el diseño, construccion y operacion de rellenos sanitarios manuales. Washington: OPS, 1997, 213 p.

KHARRAZI, M.; VON BEHREN, J.; SMITH, M. LOMAS, T.; ARMSTRONG, M.; BROADWIN, R.; BLAKE, E.; MCLAUGHLIN, B.; WORSTELL, G. \& GOLDMAN, L. A community-based study of adverse pregnancy outcomes near a large hazardous waste landifill in California. Toxicology and Industrila Health, $13(2 / 3): 299-310,1997$.

KNOLL, K.H. "Public heath and refuse disposal". Compost Science, p. 35-40, 1961. 
MALLIN, K. Investigation of a bladder cancer custer in Northwestern Illinois. American Journal of Epidemiology, 132 (1): s96 - s106, 1990.

MARA, D. D. \& ALABASTER, G. P. An environmental classification of housingrelated diseases in develping countries. Journal of Tropical Medicine and Hygiene, v.98, p.41-51, 1995.

MARA, D. D.; FEACHEM, R. G. A. Water and excreta-related diseases: unitary environmental classification. Journal of Environmental Engineering, v. 125, n. 4, p. 334-339, 1999.

MARTINELLI, C. A. \& OLIVEIRA, M. T. B. Auditoria ambiental - aterro sanitário Bandeirantes, caso prático. In: Encontro Técnico Nacional de Auditoria de Obras Públicas, 2, Rio de Janeiro, 2003

MERBACH JR, P.S. Estudo de avaliação de metais pesados em percolado de aterro sanitário em função do tempo de disposição. São Carlos, 1989, 83 p. Dissertação (Mestrado) - Departamento de Hidráulica e Saneamento - Escola de Engenharia de São Carlos, Universidade de São Paulo, 1989. Anais ... Rio de Janeiro; IBRAOP, 2003. 13 p.

MERCEDES, S. S. P., PEREIRA NETO, J. T. \& AZEVEDO, M.A. Avaliação da eficiência de dois sistemas de aeração forçada na eliminação de patógenos durante a compostagem do lixo urbano. In: VI Encontro Nacional de Saneamento Básico, 6, Setúbal 1993, Anais ... Setúbal, APRH, 1993.

MORAES, L. R. S. Health impact of sewerage and drainage in poor urban areas in Salvador, Brazil. London, 1996, 243 p. Thesis (Doctor of Philosophy in Faculty of Medicine) - Department of Epidemiology and Population Sciences, London School of Hygiene and Tropical Medicine, University of London, 1996.

MORAES, L. R. S. Aspectos epidemiológicos relacionados aos resíduos sólidos domiciliares urbanos: um estudo de caso. In: Congresso Brasileiro de Engenharia Sanitária e Ambiental, 19, Foz do Iguaçu, 1997, Anais eletrônico ... Foz do Iguaçu: ABES, 1997. p.1643 - 1649.

MORAES, L. R. S. Impacto na saúde do acondicionamento e coleta dos resíduos sólidos domiciliares. In: Congreso Interamericano de Ingeniería Sanitaria y Ambiental, 26, Lima 1998, Anais eletrônico ... Lima: AIDIS, 1998. 10 p. 
MORRIS, S. S., COUSENS, S. N., KIRKWOOD, B. R., ARTUR, P. \& ROSS, D. A. Is prevalence of diarrhoea a better indicator of subsequent mortality and weight gain than diarrhoea incidence? American Journal of Epidemiology, 144 (6): 582588, 1996.

NEVES, D. P. Parasitologia Humana. 4 ed. Rio de Janeiro: Guanabara Koogan, 1979, 368p.

OBENG, L. \& WRIGHT,F. W. The co-composting of domestic solid and human wastes. World Bank, Technical Paper, Number 57, 101 p., 1987.

OLIVEIRA, W. E. Sócio economic, environmental and health implications of solid wastes. In: Regional Simposium of Solid Wastes. Santo Domingo. Anais ... Santo Domingo, 1978, $10 \mathrm{p}$.

OREA, D. G. Evaluacion de impacto ambiental. 2 ed. Madri: Editora Agrícola Española, 1994, 259 p.

PAHREN, R.H. Microorganisms in municipal solid waste and public health implications. In: CRC Critical Reviews of Environmental Control, 1987. p.187 228. v.17.

PAIGEN, B.; GOLDMAN, L. R.; MAGNANT, M.M.; HIGHLAND, J. H. \& STEEGMANN JR., A. T. Human Biology, 59 (3): 489 - 508, 1987.

PALMISANO, A. \& BARLAZ, M. A. Microbiology of Solid Waste. New York, CRC Press, 1996, 224 p.

PEAVY, H. S; ROWE, D. R. \& TCHOBANOGLOUS, G. Environmental Engineering. 2 ed. New York, 1987, 699 p.

PREFEITURA MUNICIPAL DE SÃO PAULO. SECRETARIA DE OBRAS E SERVIÇOS. Estado da arte das destinações - caracterização das unidades existentes. Parte 1. Departamento de Limpeza Urbana, São Paulo, 1995.

PREFEITURA MUNICIPAL DE SÃO PAULO. DISTRITO DE SAÚDE DE PERUS. Plano Distrital de Saúde, São Paulo, 2002.

PREFEITURA MUNICIPAL DE SÃO PAULO. SECRETARIA DE OBRAS E SERVIÇOS. DEPARTAMENTO DE LIMPEZA URBANA. Divisão técnica de aterros sanitários, ofício n. 621/LIMPURB/2003, São Paulo, 2003.

ROCHA, A. A. \& LINDENBERGER, R.C. Impacto dos resíduos sólidos urbanos. In: resíduos sólidos e limpeza pública. CETESB: São Paulo. 1990. P. 1-13. 
ROUQUAYROL, M. Z. \& ALMEIDA FILHO, N. Epidemiologia e Saúde. 5 ed. Rio de Janeiro: MEDSI, 1999. 570 p.

SCHALCH, V. Produção e caracterização do chorume em processos de decomposição de lixo urbano. São Carlos, 1984, 103 p. Dissertação (Mestrado) Departamento de Hidráulica e Saneamento - Escola de Engenharia de São Carlos, Universidade de São Pulo, 1984.

SCHALCH, V. Análise comparativa do comportamento de dois aterros sanitários semelhantes e correlações dos parâmetros do processo de digestão anaeróbia. São Carlos, 1992, 220 p. Tese (Doutorado) - Departamento de Hidráulica e Saneamento - Escola de Engenharia de São Carlos, Universidade de São Paulo, 1992.

SÉNGES, G. H. Limpeza urbana - métodos e sistemas. Rio de Janeiro: Instituto Brasileiro de Administração Municipal, 1969.

SOARES, J. F. \& SIQUEIRA, A. L. Introdução à estatística médica. 2 ed. Belo Horizonte: Departamento de Estatística, UFMG, 201. 300 p.

STENTIFORD, E. I. Composting of Sewage Sludges and Solid Wastes. Leeds. University of Leeds, 1991. 60 p.

SUBERKROPP, K. F. \& KLUG, M. J. Microbial ecology, 196-123, 1974.

TCHOBANOGLOUS, G., THEISEN, H. \& ELIASSEN, R. Solid wastes: engineering principles and management issues. New York: MacGraw-Hill, 1977. $621 \mathrm{p}$.

VIANNA, N. J. \& POLAN, A. K. Incidence of low birth weight among Love Canal residents. Science, 226 (4679): 1217 - 1219, 1984.

WILLSON, G. B; PARR, J. F; EPSTEIN, E; MARSH, P.B; CHANEY, R.L; COLACICCO, D; BURGE, W.D; SIKORA, L.J; TESTER, C.F. \& HORNICK, S. Manual For Composting Sewage Sludge By The Beltsville Aerated Pile Method. Municipal Environmental Research Laboratory, U.S. Enviromental Protection Agency, Cincinnati, 1980, 65p. 


\section{APÊNDICE 1}

Quadras do setor 187 pertencentes à faixa de exposição SPA e às vilas Jardim do Russo, Inácio Manacá e Operário 


\begin{tabular}{|c|c|c|c|c|c|}
\hline $\begin{array}{c}\text { No. } \\
\text { quadra }\end{array}$ & No. residências & $\begin{array}{c}\text { No. } \\
\text { quadra }\end{array}$ & No. residências & $\begin{array}{c}\text { No. } \\
\text { quadra }\end{array}$ & No. residências \\
\hline 80. & (NQNPS) & 105. & (NQNPS) & 130. & (NQNPS) \\
\hline 81. & SD & 106. & 12 & 131. & (NQNPS) \\
\hline 82. & SD & 107. & 23 & 132. & (NQNPS) \\
\hline 83. & 13 & 108. & (NQNPS) & 133. & (NQNPS) \\
\hline 84. & SD & 109. & (NQNPS) & 134. & (NQNPS) \\
\hline 85. & SD & 110. & (NQNPS) & 135. & 21 \\
\hline 86. & 13 & 111. & (NQNPS) & 136. & 16 \\
\hline 87. & 17 & 112. & 23 & 137. & 69 \\
\hline 88. & 9 & 113. & (NQNPS) & 138. & 22 \\
\hline 89. & 19 & 114. & (NQNPS) & 139. & 18 \\
\hline 90. & 15 & 115. & (NQNPS) & 140. & 68 \\
\hline 91. & 30 & 116. & (NQNPS) & 141. & 33 \\
\hline 92. & (NQNPS) & 117. & (NQNPS) & 142. & 21 \\
\hline 93. & (NQNPS) & 118. & (NQNPS) & 143. & 18 \\
\hline 94. & (NQNPS) & 119. & (NQNPS) & 144. & 21 \\
\hline 95. & 30 & 120. & 21 & 145. & 17 \\
\hline 96. & 76 & 121. & 44 & 146. & 16 \\
\hline 97. & 22 & 122. & (NQNPS) & 147. & 15 \\
\hline 98. & (NQNPS) & 123. & (NQNPS) & 148. & 33 \\
\hline 99. & 99 & 124. & (NQNPS) & 149. & 16 \\
\hline 100. & 16 & 125. & (NQNPS) & 150. & 60 \\
\hline 101. & (NQNPS) & 126. & (NQNPS) & 151. & SD \\
\hline 102. & (NQNPS) & 127. & (NQNPS) & 152. & (NQNPS) \\
\hline 103. & (NQNPS) & 128. & (NQNPS) & 153. & 71 \\
\hline 104. & (NQNPS) & 129. & (NQNPS) & 154. & 27 \\
\hline 155. & 41 & 181. & (NQNPS) & 207. & (NQNPS) \\
\hline 156. & 52 & 182. & (NQNPS) & 208. & (NQNPS) \\
\hline 157. & (NQNPS) & 183. & (NQNPS) & 209. & (NQNPS) \\
\hline 158. & (NQNPS) & 184. & (NQNPS) & 210. & (NQNPS) \\
\hline
\end{tabular}




\begin{tabular}{c|l|l|l|l|l}
\hline $\mathbf{1 5 9}$. & (NQNPS) & $\mathbf{1 8 5}$. & (NQNPS) & $\mathbf{2 1 1 .}$ & (NQNPS) \\
\hline $\mathbf{1 6 0 .}$ & (NQNPS) & $\mathbf{1 8 6 .}$ & (NQNPS) & $\mathbf{2 1 2 .}$ & (NQNPS) \\
\hline $\mathbf{1 6 1 .}$ & (NQNPS) & $\mathbf{1 8 7 .}$ & (NQNPS) & $\mathbf{2 1 3 .}$ & (NQNPS) \\
\hline $\mathbf{1 6 2 .}$ & (NQNPS) & $\mathbf{1 8 8 .}$ & 19 & $\mathbf{2 1 4 .}$ & (NQNPS) \\
\hline $\mathbf{1 6 3 .}$ & (NQNPS) & $\mathbf{1 8 9 .}$ & 28 & $\mathbf{2 1 5 .}$ & (NQNPS) \\
\hline $\mathbf{1 6 4 .}$ & (NQNPS) & $\mathbf{1 9 0 .}$ & 34 & $\mathbf{2 1 6 .}$ & (NQNPS) \\
\hline $\mathbf{1 6 5 .}$ & (NQNPS) & $\mathbf{1 9 1 .}$ & 33 & $\mathbf{2 1 7 .}$ & (NQNPS) \\
\hline $\mathbf{1 6 6 .}$ & (NQNPS) & $\mathbf{1 9 2 .}$ & 17 & $\mathbf{2 1 8 .}$ & (NQNPS) \\
\hline $\mathbf{1 6 7 .}$ & (NQNPS) & $\mathbf{1 9 3 .}$ & 25 & $\mathbf{2 1 9 .}$ & (NQNPS) \\
\hline $\mathbf{1 6 8 .}$ & (NQNPS) & $\mathbf{1 9 4 .}$ & 5 & $\mathbf{2 2 0 .}$ & (NQNPS) \\
\hline $\mathbf{1 6 9 .}$ & (NQNPS) & $\mathbf{1 9 5 .}$ & 15 & $\mathbf{2 2 1 .}$ & (NQNPS) \\
\hline $\mathbf{1 7 0 .}$ & (NQNPS) & $\mathbf{1 9 6 .}$ & & $\mathbf{2 2 2 .}$ & (NQNPS) \\
\hline $\mathbf{1 7 1 .}$ & (NQNPS) & $\mathbf{1 9 7 .}$ & & $\mathbf{2 2 3 .}$ & (NQNPS) \\
\hline $\mathbf{1 7 2 .}$ & (NQNPS) & $\mathbf{1 9 8 .}$ & 12 & $\mathbf{2 2 4 .}$ & 47 \\
\hline $\mathbf{1 7 3 .}$ & (NQNPS) & $\mathbf{1 9 9 .}$ & (NQNPS) & $\mathbf{2 2 5 .}$ & 115 \\
\hline $\mathbf{1 7 4 .}$ & (NQNPS) & $\mathbf{2 0 0 .}$ & (NQNPS) & $\mathbf{2 2 6 .}$ & 12 \\
\hline $\mathbf{1 7 5 .}$ & (NQNPS) & $\mathbf{2 0 1 .}$ & (NQNPS) & $\mathbf{2 2 7 .}$ & 32 \\
\hline $\mathbf{1 7 6 .}$ & (NQNPS) & $\mathbf{2 0 2 .}$ & (NQNPS) & $\mathbf{2 2 8 .}$ & 46 \\
\hline $\mathbf{1 7 7 .}$ & (NQNPS) & $\mathbf{2 0 3 .}$ & (NQNPS) & $\mathbf{2 2 9 .}$ & (NQNPS) \\
\hline $\mathbf{1 7 8 .}$ & (NQNPS) & $\mathbf{2 0 4 .}$ & (NQNPS) & $\mathbf{2 3 0 .}$ & (NQNPS) \\
\hline $\mathbf{1 7 9 .}$ & (NQNPS) & $\mathbf{2 0 5 .}$ & (NQNPS) & $\mathbf{2 3 1 .}$ & (NQNPS) \\
\hline $\mathbf{1 8 0 .}$ & (NQNPS) & $\mathbf{2 0 6 .}$ & (NQNPS) & $\mathbf{2 3 2 .}$ & (NQNPS) \\
\hline & & & & & \\
\hline & & & & & \\
\hline
\end{tabular}

NQNPS - número de quadra não pertencente ao setor

SD - quadra sem dado ou planta cadastral 


\section{APÊNDICE 2}

Quadras do setor 187 pertencentes à faixa de exposição SPA e à vila Nova Perus 


\begin{tabular}{|c|c|c|c|c|c|}
\hline $\begin{array}{c}\text { No. } \\
\text { quadra }\end{array}$ & No. residências & $\begin{array}{c}\text { No. } \\
\text { quadra }\end{array}$ & No. residências & $\begin{array}{c}\text { No. } \\
\text { quadra }\end{array}$ & No. residências \\
\hline 108. & 12 & 132. & 26 & & \\
\hline 109. & 26 & 133. & 28 & 203. & 27 \\
\hline 110. & 28 & 134. & 27 & 204. & 23 \\
\hline 111. & 22 & 135. & & 205. & 26 \\
\hline 112. & & 136. & & 206. & 70 \\
\hline 113. & & 13. & & 207. & 25 \\
\hline 114. & & 138. & & 208. & 34 \\
\hline 115. & & 139. & & 209. & 29 \\
\hline 116. & 9 & 140. & & 210. & 59 \\
\hline 117. & 27 & $---/ /---$ & ---//--- & 211. & 77 \\
\hline 118. & 23 & & & 212. & 26 \\
\hline 119. & 11 & 157. & 29 & 213. & 12 \\
\hline 120. & & 158. & 27 & 214. & 26 \\
\hline 121. & & 159. & 24 & 215. & 19 \\
\hline 122. & & 160. & 30 & 216. & 36 \\
\hline 123. & & & & 217. & 42 \\
\hline 124. & 22 & & & 218. & 36 \\
\hline 125. & 33 & & & 219. & 47 \\
\hline 126. & 28 & & & 220. & 33 \\
\hline 127. & 21 & & & 221. & 51 \\
\hline 128. & 10 & & & 222. & 33 \\
\hline 129. & 28 & & & 223. & 7 \\
\hline 130. & 23 & & & & \\
\hline 131. & 16 & & & & \\
\hline
\end{tabular}

NQNPS - número de quadra não pertencente ao setor

SD - quadra sem dado ou planta cadastral 


\section{APÊNDICE 3}

Quadras do setor 187 pertencentes à faixa de exposição SPC e às vilas Caiúba, Osana, Hungareza, Fanton, Malvina, Flamengo e Jardim São Paulo 


\begin{tabular}{c|c|c|c|c|c}
\hline $\begin{array}{c}\text { No. } \\
\text { quadra }\end{array}$ & No. residências & $\begin{array}{c}\text { No. } \\
\text { quadra }\end{array}$ & No. residências & $\begin{array}{c}\text { No. } \\
\text { quadra }\end{array}$ & No. residências \\
\hline $\mathbf{1 .}$ & 43 & $\mathbf{2 5 .}$ & 20 & $\mathbf{4 9 .}$ & 100 \\
\hline $\mathbf{2 .}$ & 35 & $\mathbf{2 6 .}$ & SD & $\mathbf{5 0 .}$ & 20 \\
\hline $\mathbf{3 .}$ & 10 & $\mathbf{2 7 .}$ & 46 & $\mathbf{5 1 .}$ & 26 \\
\hline $\mathbf{4 .}$ & 14 & $\mathbf{2 8 .}$ & 16 & $\mathbf{5 2 .}$ & 106 \\
\hline $\mathbf{5 .}$ & 28 & $\mathbf{2 9 .}$ & 96 & $\mathbf{5 3 .}$ & 34 \\
\hline $\mathbf{6 .}$ & 48 & $\mathbf{3 0 .}$ & 79 & $\mathbf{5 4 .}$ & 4 \\
\hline $\mathbf{7 .}$ & 39 & $\mathbf{3 1 .}$ & 65 & $\mathbf{5 5 .}$ & 14 \\
\hline $\mathbf{8 .}$ & 37 & $\mathbf{3 2 .}$ & 17 & $\mathbf{5 6 .}$ & 38 \\
\hline $\mathbf{9 .}$ & 22 & $\mathbf{3 3 .}$ & 17 & $\mathbf{5 7 .}$ & 23 \\
\hline $\mathbf{1 0 .}$ & 29 & $\mathbf{3 4 .}$ & SD & $\mathbf{5 8 .}$ & 27 \\
\hline $\mathbf{1 1 .}$ & 21 & $\mathbf{3 5 .}$ & 47 & $\mathbf{5 9 .}$ & 195 \\
\hline $\mathbf{1 2 .}$ & 21 & $\mathbf{3 6 .}$ & SD & $\mathbf{6 0 .}$ & 29 \\
\hline $\mathbf{1 3 .}$ & SD & $\mathbf{3 7 .}$ & 51 & $\mathbf{6 1 .}$ & 52 \\
\hline $\mathbf{1 4 .}$ & 82 & $\mathbf{3 8 .}$ & 23 & $\mathbf{6 2 .}$ & 52 \\
\hline $\mathbf{1 5 .}$ & 10 & $\mathbf{3 9 .}$ & 38 & $\mathbf{6 3 .}$ & 163 \\
\hline $\mathbf{1 6 .}$ & 6 & $\mathbf{4 0 .}$ & 41 & $\mathbf{6 4 .}$ & 74 \\
\hline $\mathbf{1 7 .}$ & 22 & $\mathbf{4 1 .}$ & 34 & $\mathbf{6 5 .}$ & 38 \\
\hline $\mathbf{1 8 .}$ & 13 & $\mathbf{4 2 .}$ & 15 & $\mathbf{6 6 .}$ & 62 \\
\hline $\mathbf{1 9 .}$ & 20 & $\mathbf{4 3 .}$ & 16 & $\mathbf{6 7 .}$ & 80 \\
\hline $\mathbf{2 0 .}$ & 45 & $\mathbf{4 4 .}$ & SD & $\mathbf{6 8 .}$ & 22 \\
\hline $\mathbf{2 1 .}$ & 48 & $\mathbf{4 5 .}$ & 27 & $\mathbf{6 9 .}$ & 19 \\
\hline $\mathbf{2 2 .}$ & 38 & $\mathbf{4 6 .}$ & 30 & $\mathbf{7 0 .}$ & 19 \\
\hline $\mathbf{2 3 .}$ & 24 & $\mathbf{4 7 .}$ & 30 & $\mathbf{7 1 .}$ & 28 \\
\hline $\mathbf{2 4 .}$ & 57 & $\mathbf{4 8 .}$ & 22 & $\mathbf{7 2 .}$ & 21 \\
\hline $\mathbf{7 3 .}$ & SD & $\mathbf{1 8 6 .}$ & 21 & $\mathbf{2 2 9 .}$ & 30 \\
\hline $\mathbf{7 4 .}$ & 38 & $\mathbf{1 9 6 .}$ & 27 & $\mathbf{2 3 0 .}$ & 11 \\
\hline $\mathbf{7 5 .}$ & SD & $\mathbf{1 9 9 .}$ & 13 & $\mathbf{2 3 1 .}$ & 17 \\
\hline $\mathbf{7 6 .}$ & 53 & $\mathbf{2 0 1 .}$ & 22 & & \\
\hline $\mathbf{1 8 5 .}$ & 35 & $\mathbf{2 0 2 .}$ & 19 & & \\
\hline & & & & & \\
\hline
\end{tabular}

SD - quadra sem dado ou planta cadastral 


\section{APÊNDICE 4}

Figuras referentes à monitorização do lençol freático realizado durante o mês de março de 2003 no Aterro Sanitário Bandeirantes 
E E E E E

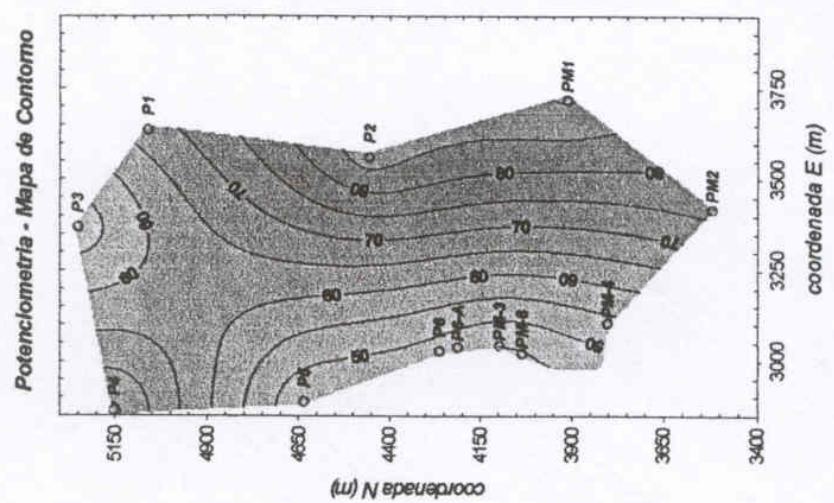

E

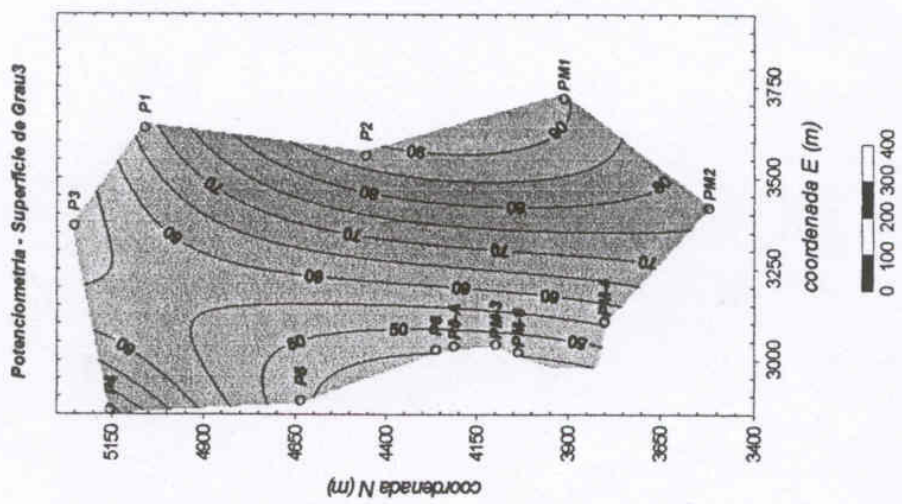

E E E E E E E E E E E E E

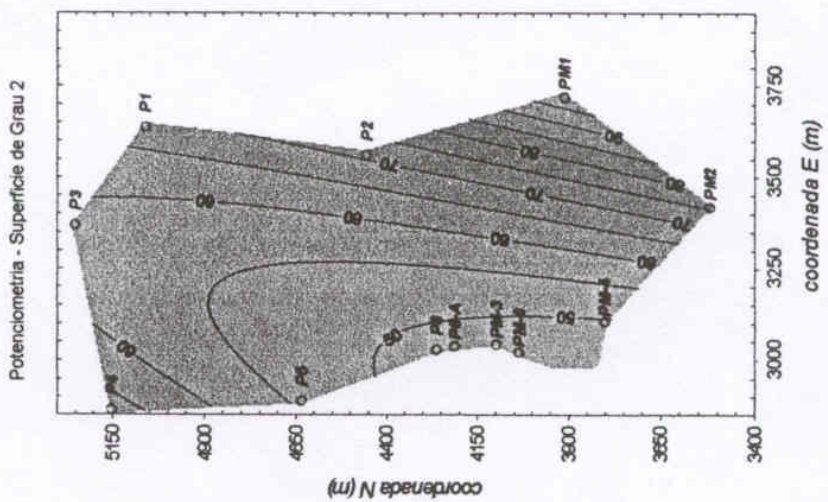

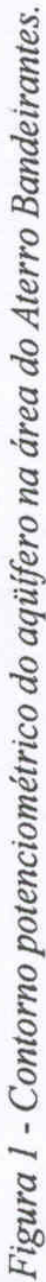




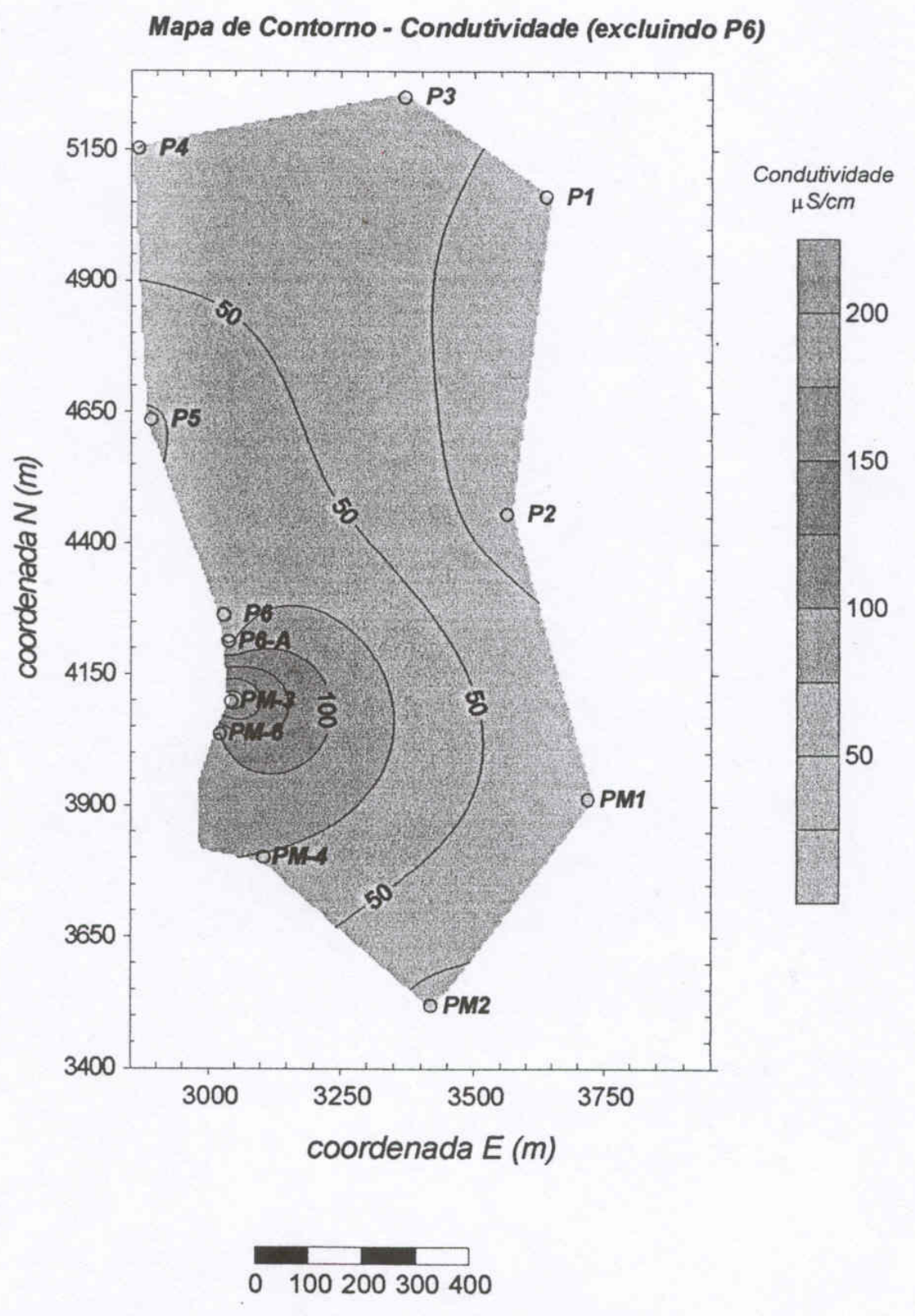

Figura 2 - Condutividade da água em março/2003. 


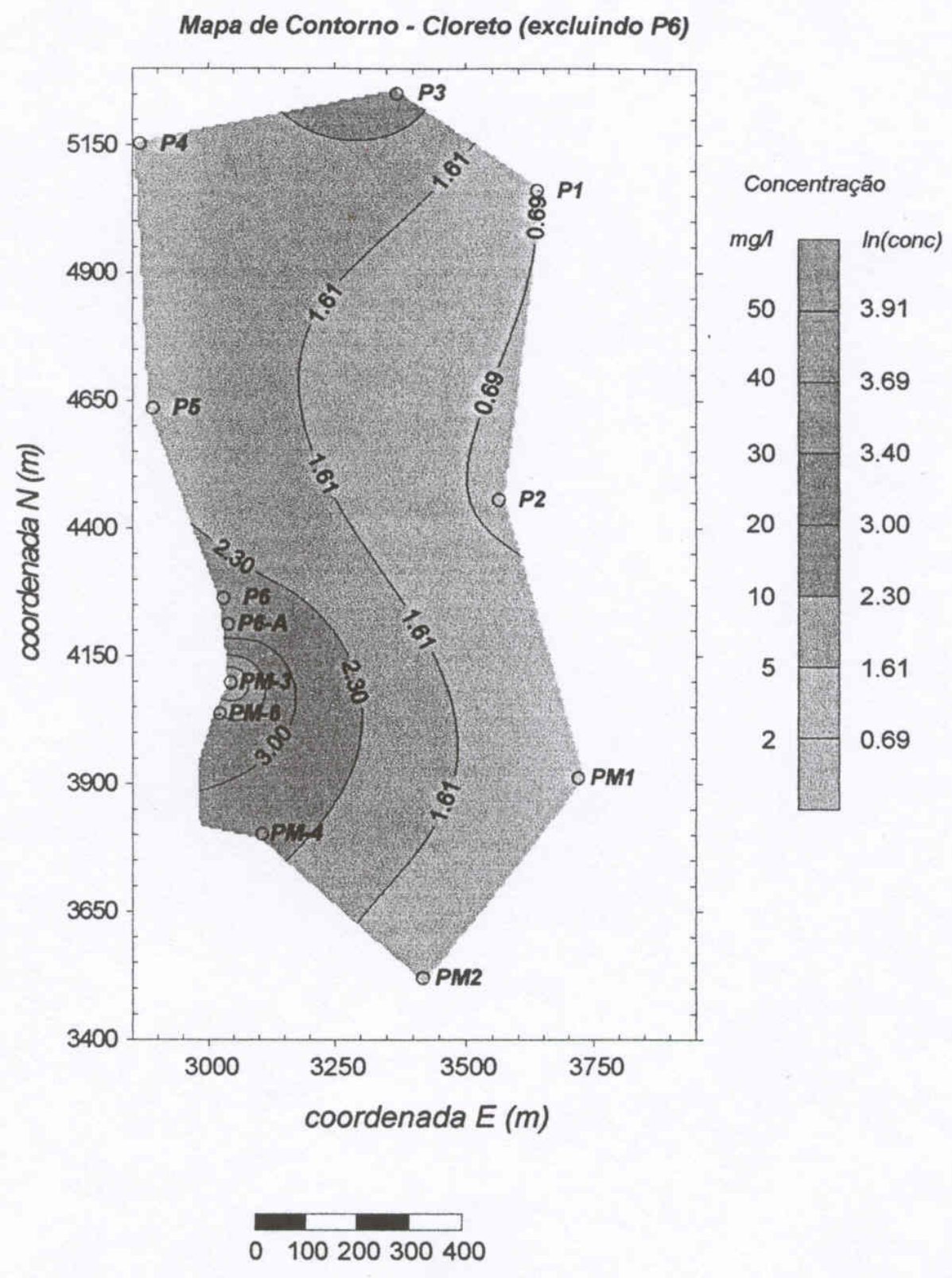

Figura 3 - Concentração de cloreto dissolvido em março/2003. 


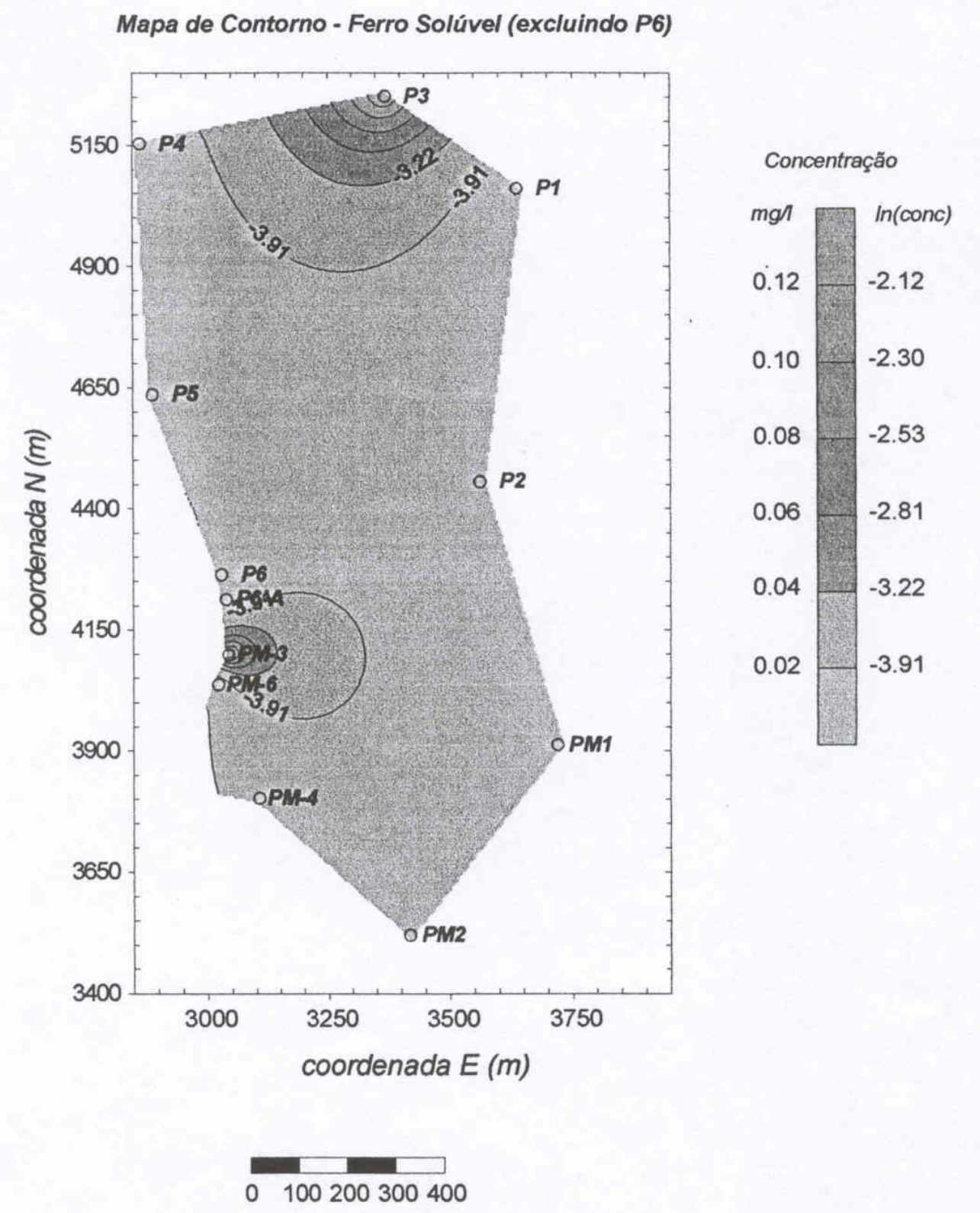

Figura 4 - Concentração de ferro dissolvido em março/2003. 


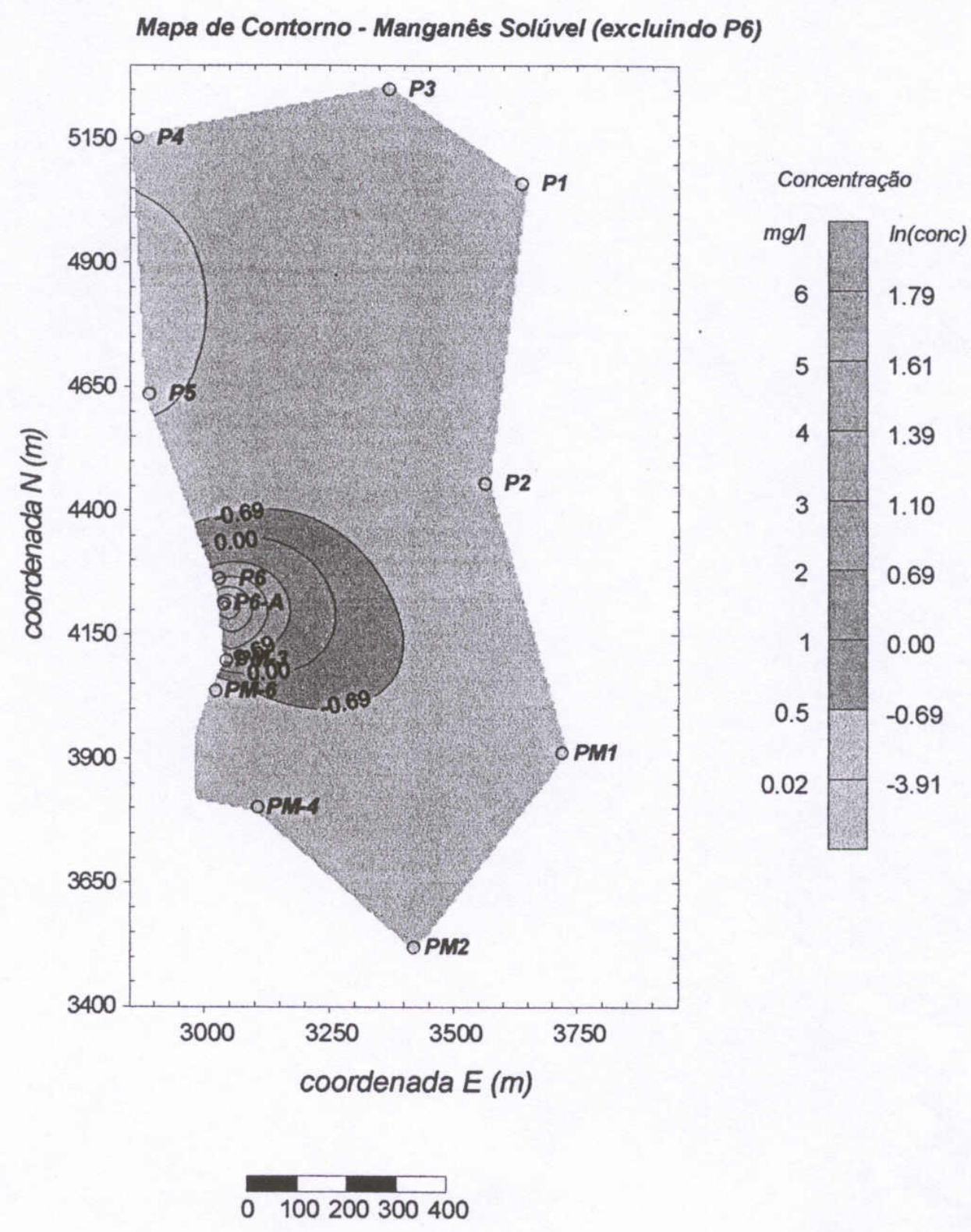

Figura 5 - Concentração de manganês dissolvido em março/2003. 


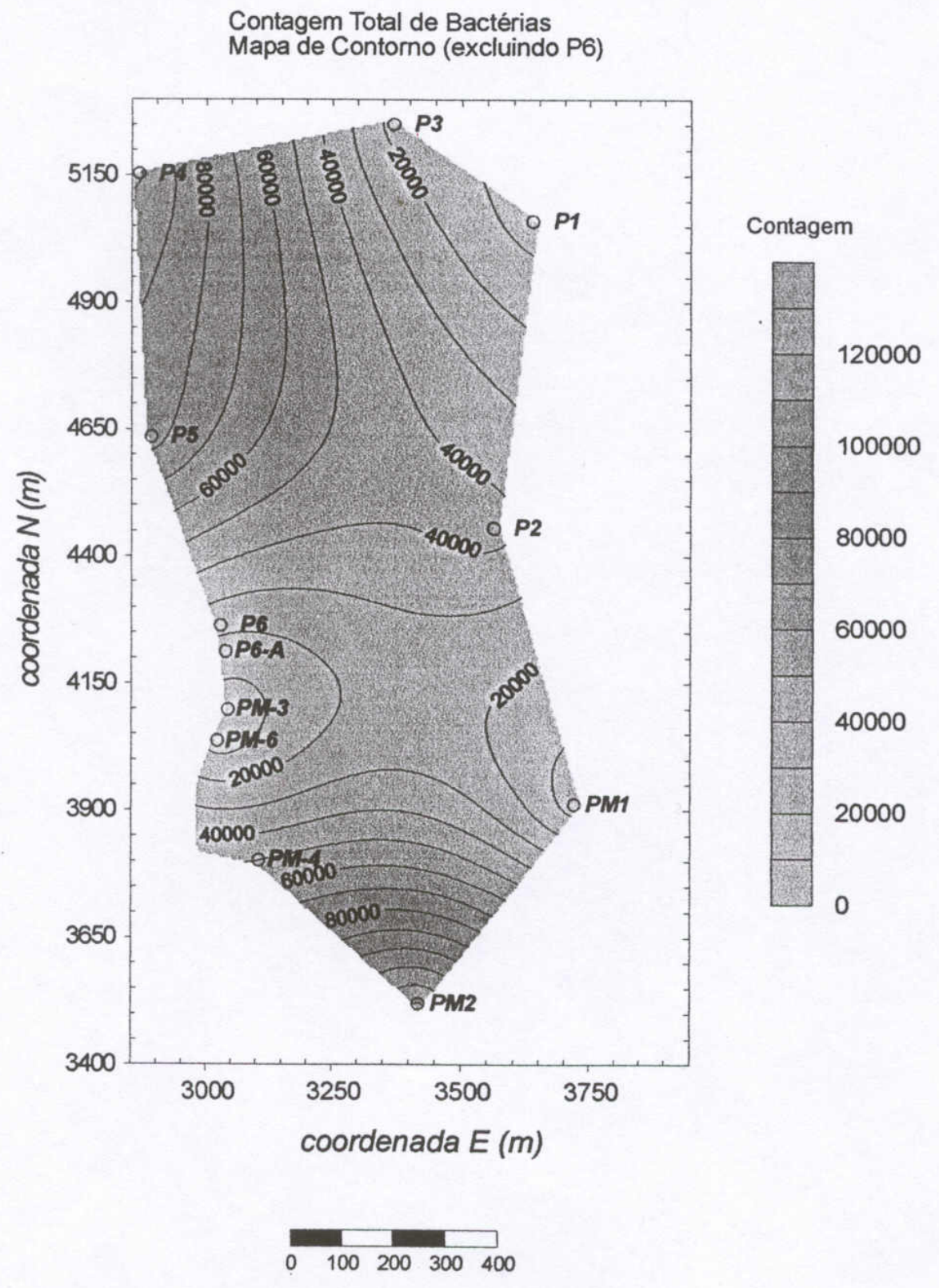

Figura 6 - Contagem total de bactérias em março/2003. 

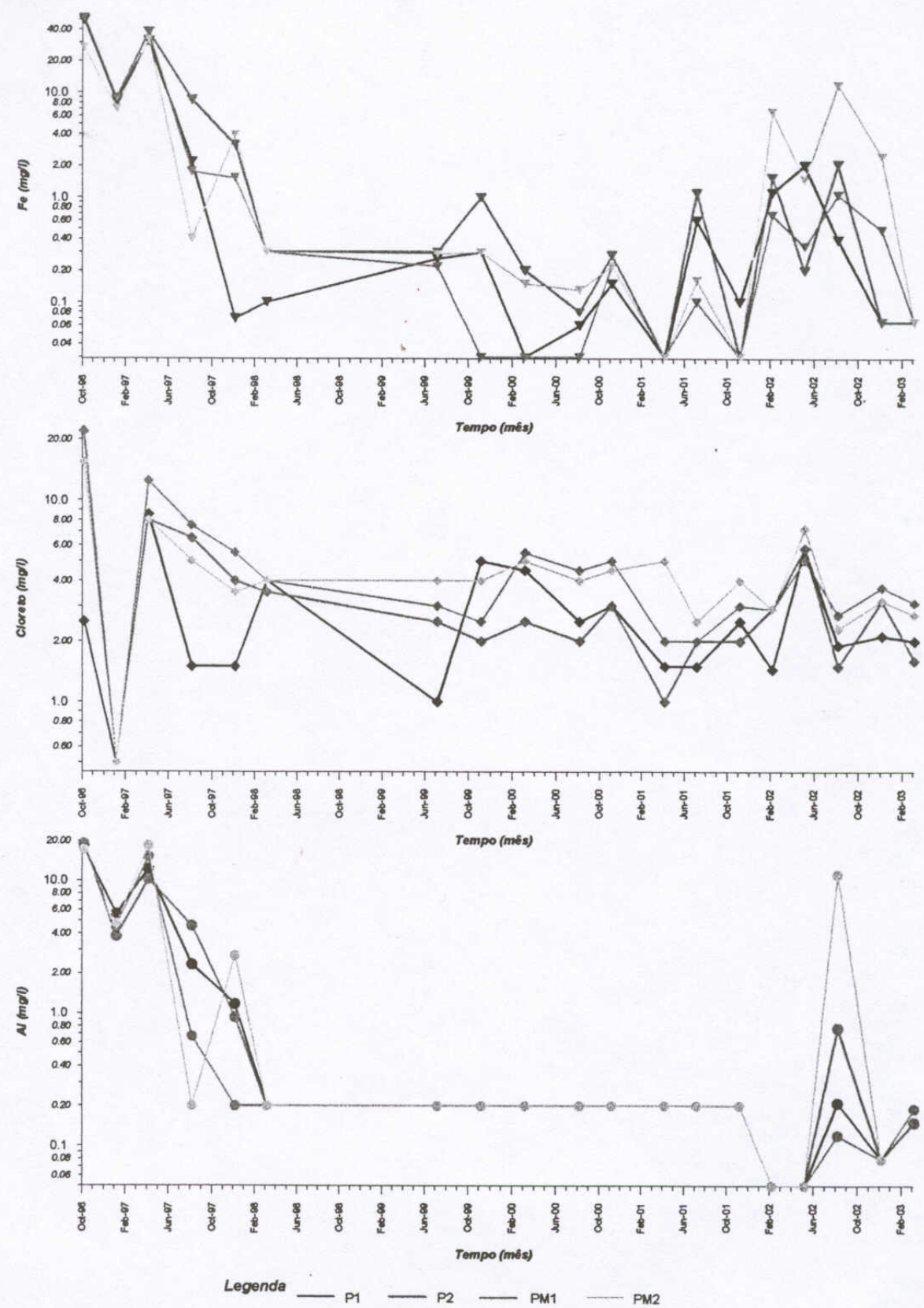

Figura 7 - Variação de concentração de alumínio, cloreto e ferro de setembro/96 a março/2003 nos poços da face leste do Aterro Bandeirantes. 

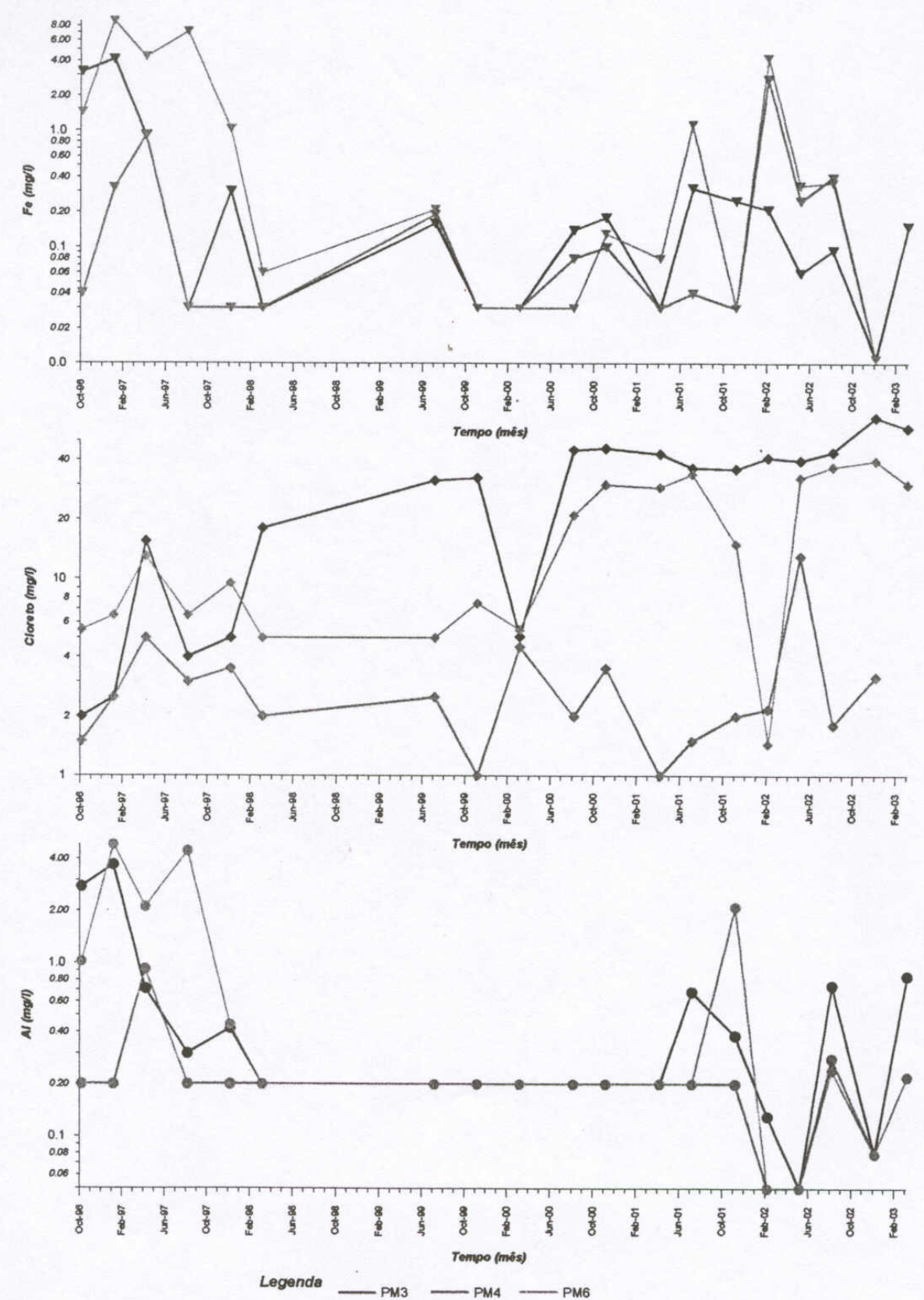

Figura 8 - Variação de concentração de alumínio, cloreto e ferro de setembro/96 a março/2003 nos poços a montante da face oeste do Aterro Bandeirantes. 

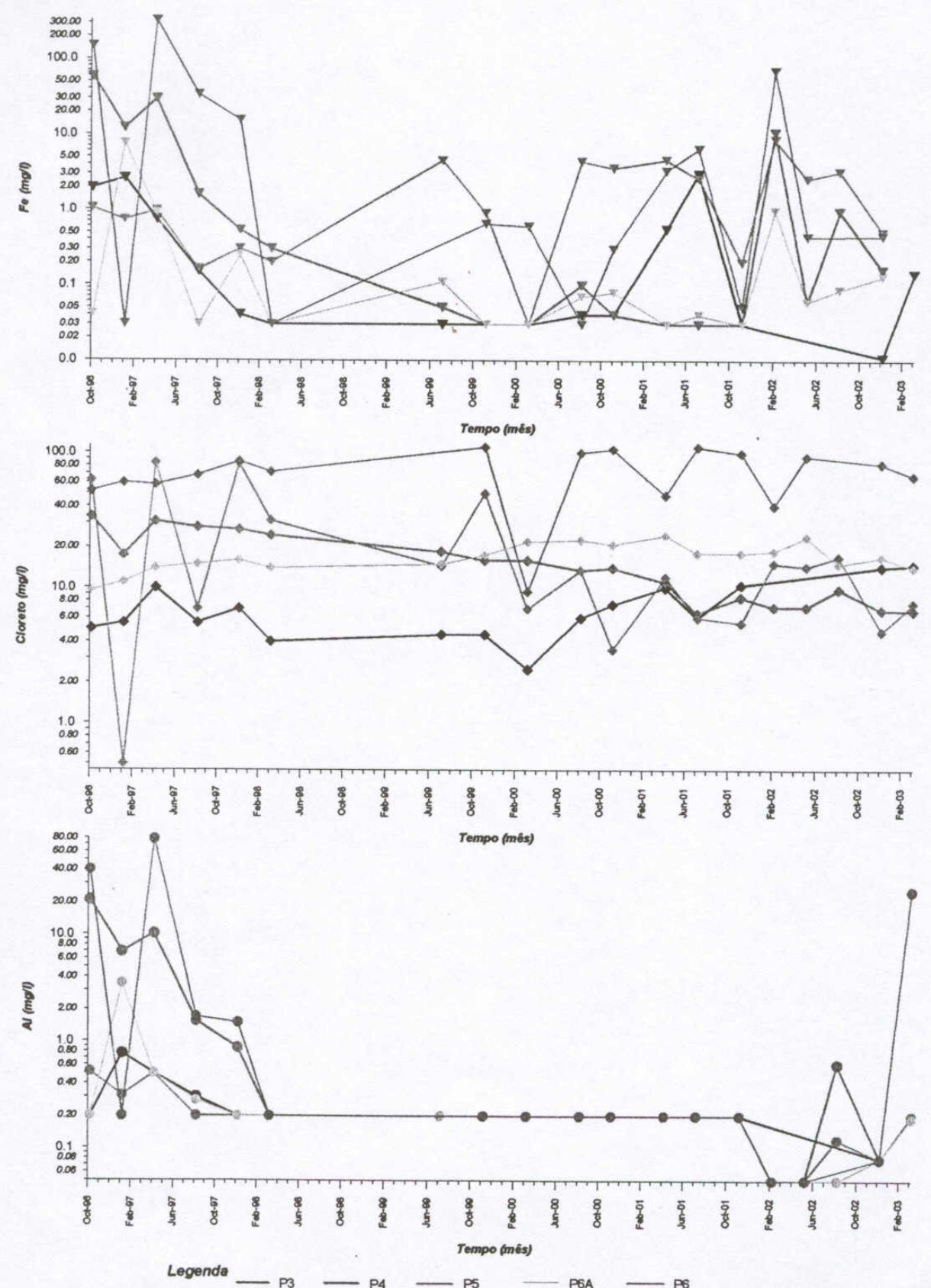

Figura 9 - Variação de concentração de alumínio, cloreto e ferro de setembro/96 a março/2003 nos poços a jusante da face oeste do Aterro Bandeirantes. 

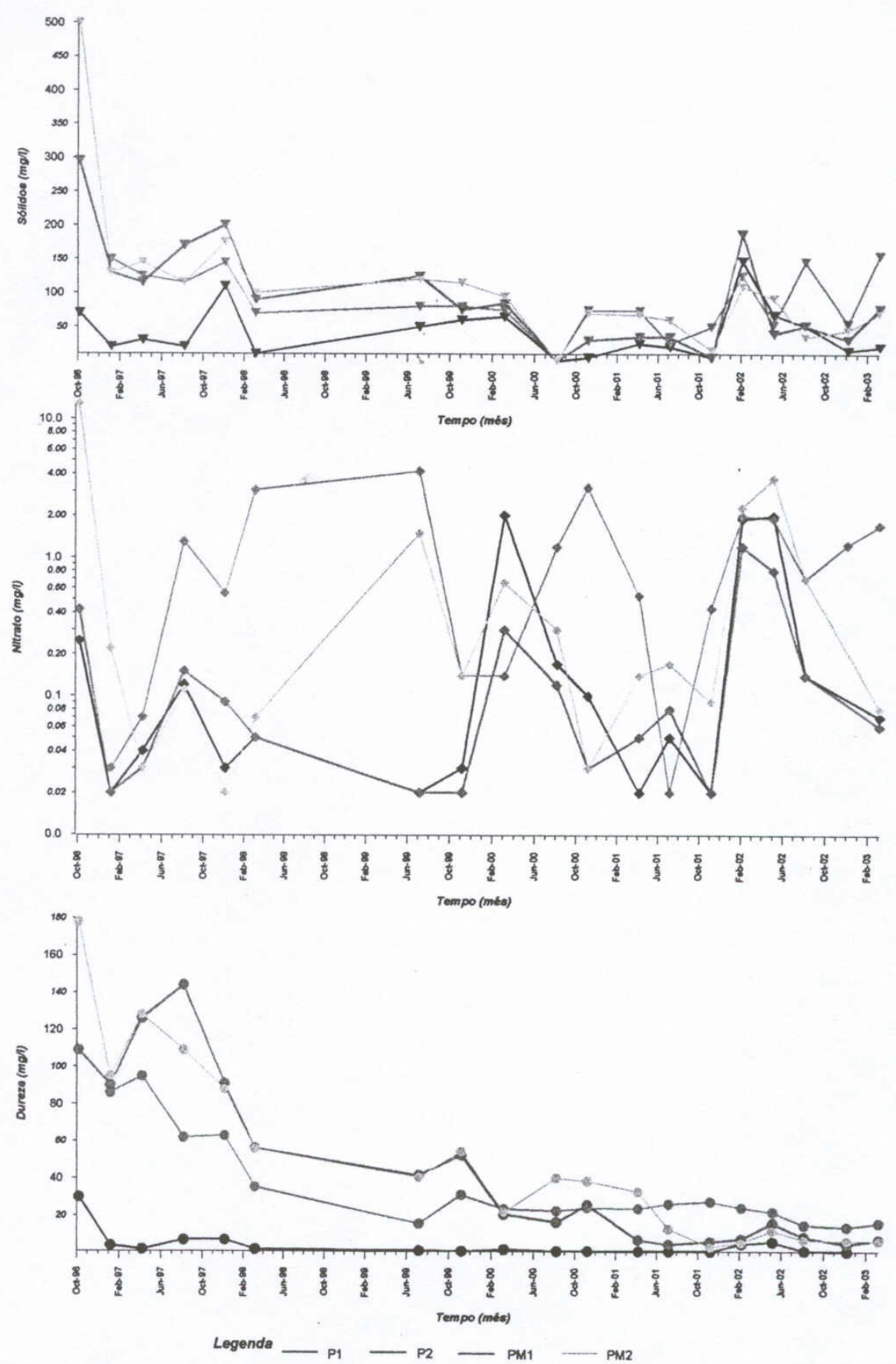

Figura 10 - Variação de concentração de sólidos, nitrato e de dureza da água de setembro/96 a março/2003 nos poços da face leste do Aterro Bandeirantes 

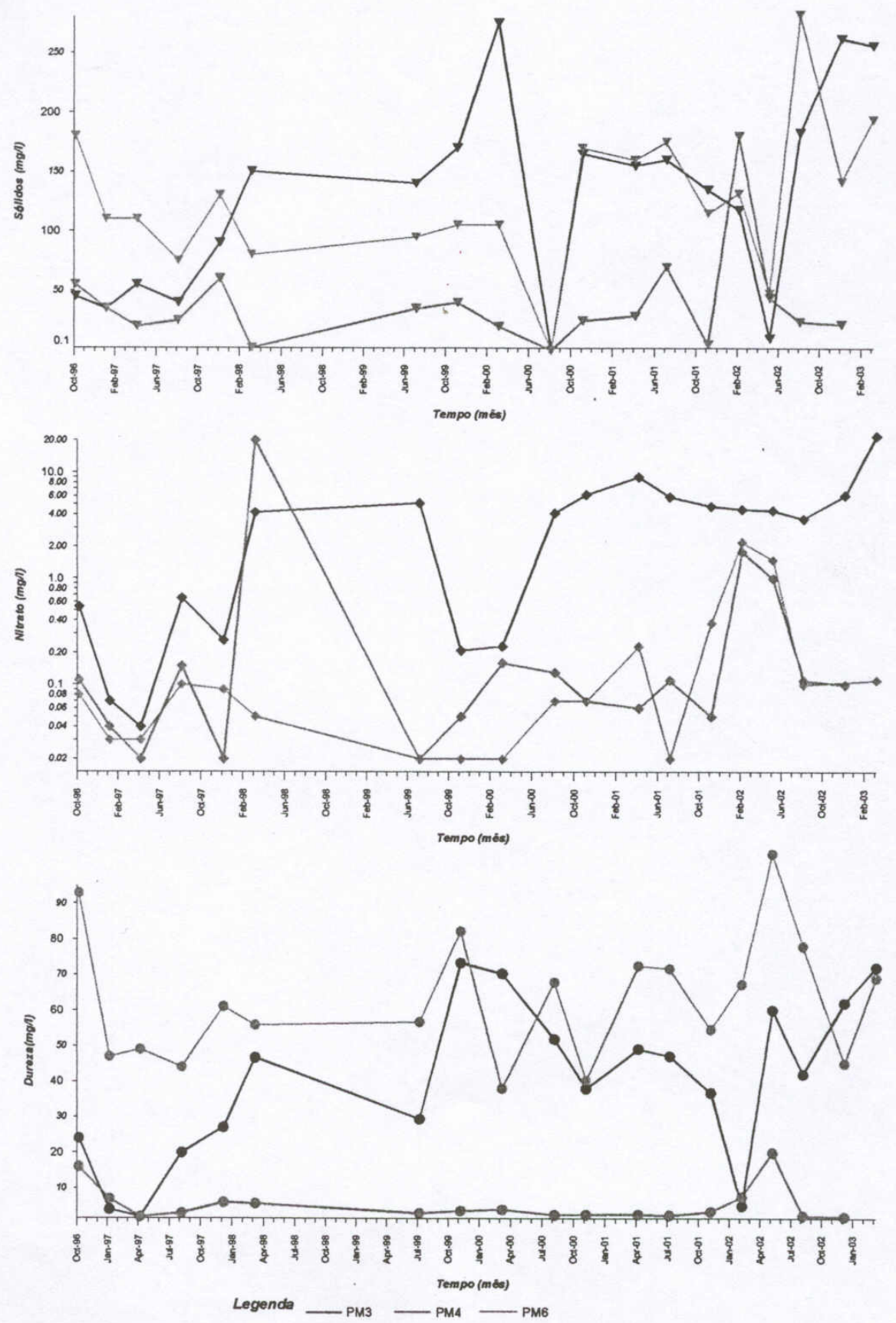

Figura 11 - Variação de concentração de sólidos, nitrato e de dureza da água de setembro/96 a março/2003 nos poços a montante da face oeste do Aterro Bandeirantes. 

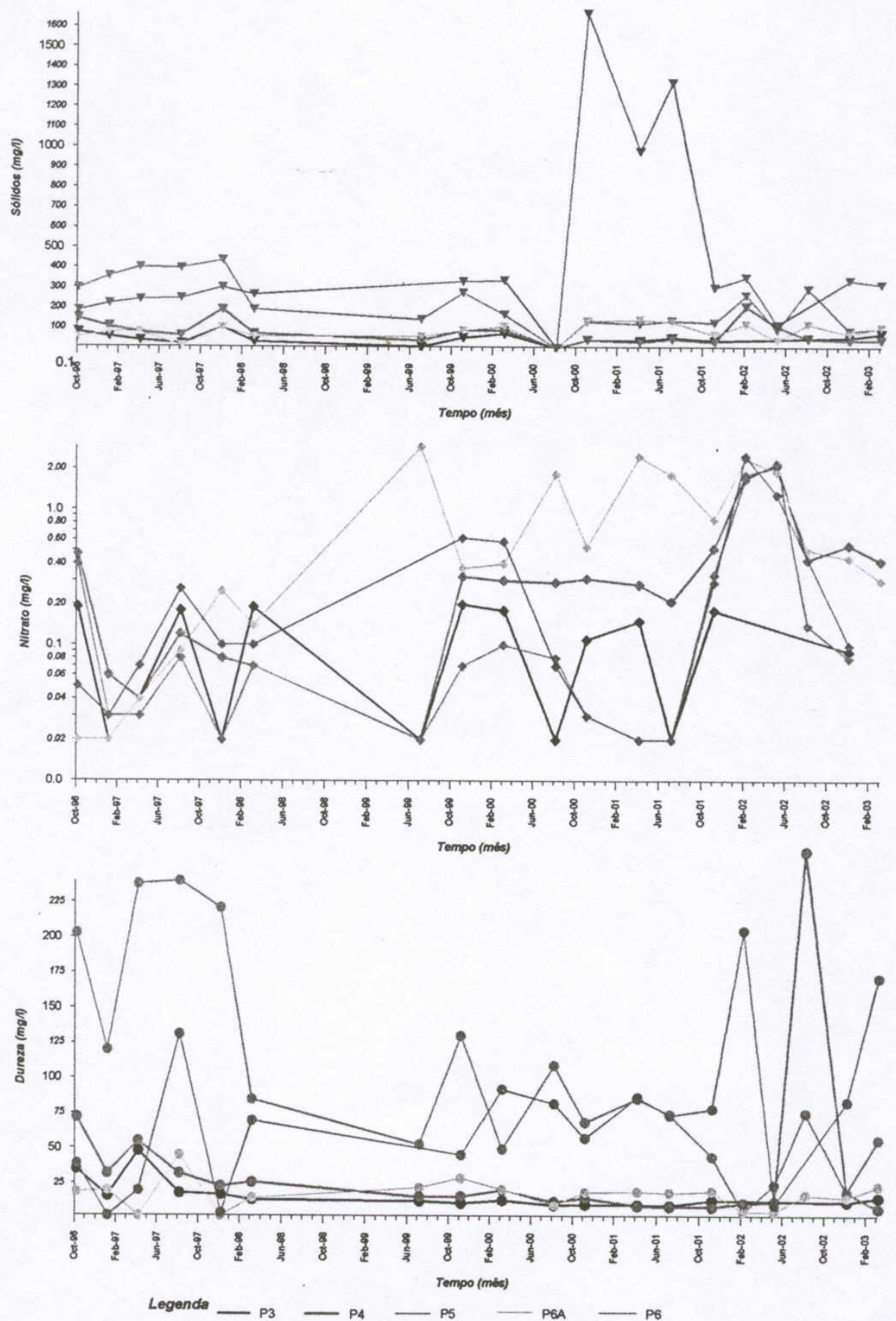

Figura 12 - Variação de concentração de sólidos, nitrato e de dureza da água de setembro/96 a março/2003 nos poços a jusante da face oeste do Aterro Bandeirantes. 


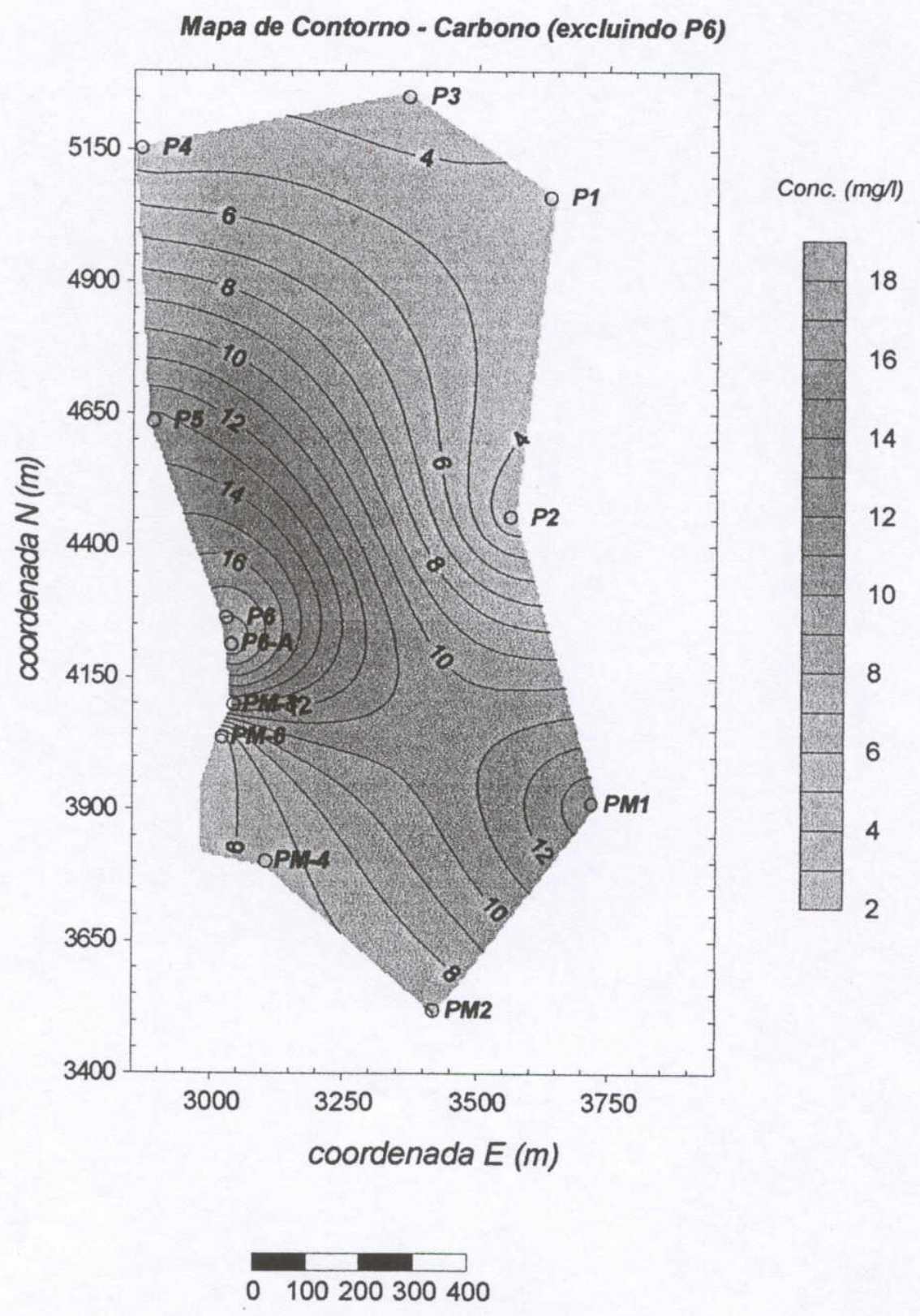

Figura 13 - Concentração de carbono orgânico total em março/2003. 


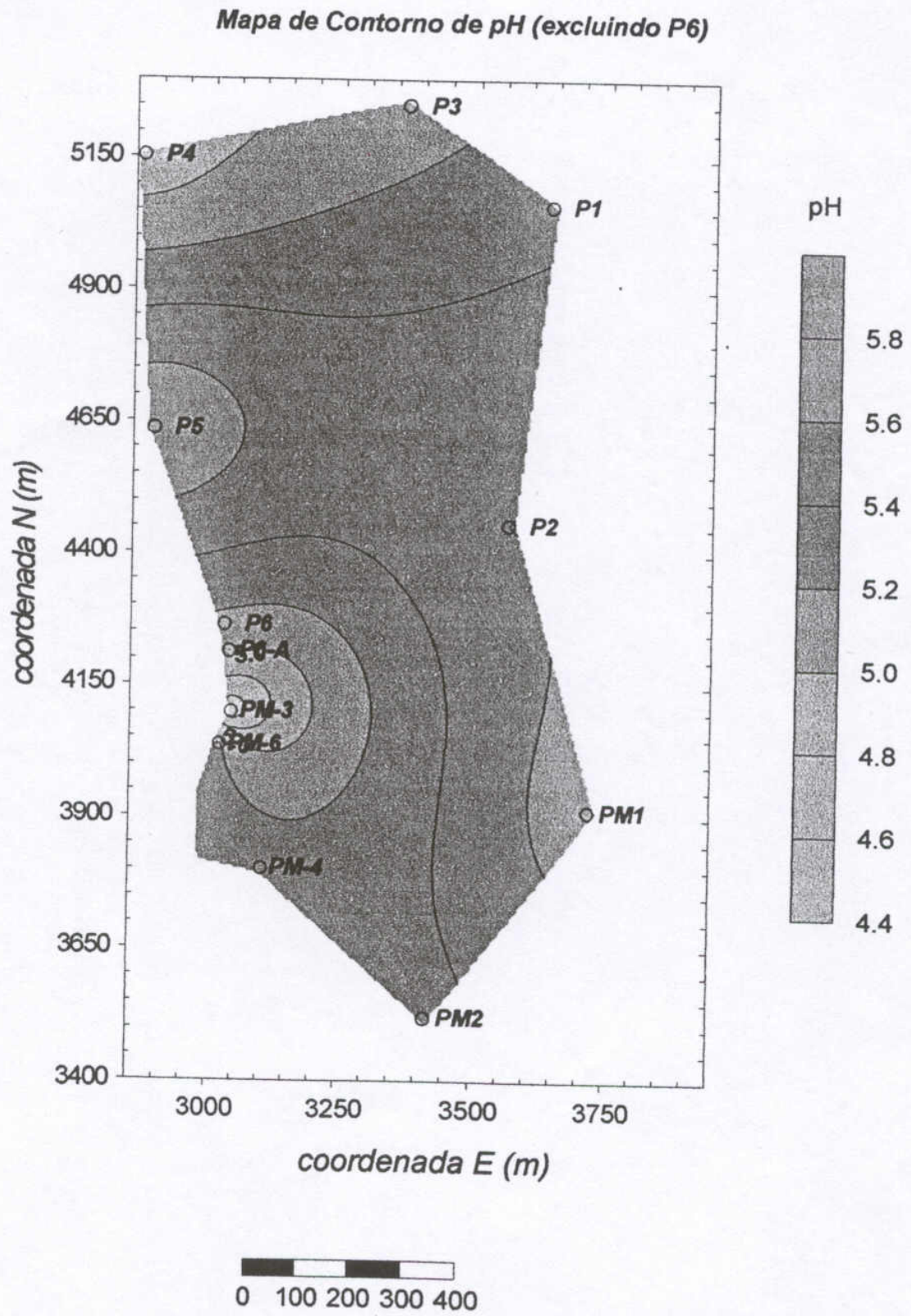

Figura 14 - Mapa de contorno do pH de campo em março/2003. 